\title{
Changing Governance of Public Research: Research-for-Development (R4D) Funders in the United Kingdom, Canada and Australia
}

\author{
by \\ Bruce Currie-Alder
}

A thesis submitted to the Faculty of Graduate and Postdoctoral Affairs in partial fulfillment of the requirements for the degree of

Doctor of Philosophy

in

Public Policy

Carleton University

Ottawa, Ontario

(C) 2014, Bruce Currie-Alder 


\begin{abstract}
Research-for-development (R4D) has been viewed as generating evidence on the effectiveness of foreign aid, inventing new technologies that serve poor people, and strengthening research capabilities in poor countries. What determines which of these policy goals are pursued? This thesis argues that public funders continually adjust their approach based on pressure to satisfy the expectations of their home governments.
\end{abstract}

The concepts of performance regime and program theory are used to examine how funders responded to changing expectations and maintained credibility with both their government sponsors and the research community. The United Kingdom, Canada, and Australia all experienced a shift towards market-inspired governance of public research, which favoured shorter time-horizons and encouraged funders' to alter their perspective regarding whom to target for funding (researchers at home and abroad) and what constituted the point of delivery (between field and lab-based science). Funders resisted to a limited extent by adapting selectively to these pressures, inserting their own ideas into the performance regime, and covertly pursuing their existing program theory.

Yet performance regimes matter. Changes in performance expectations clearly led to fundamental changes in program theory and grantmaking practice. In previous decades, funders had some degree of freedom, to interpret broad policy directions and mediate between public research and international development, drawing on the ideas championed by the individuals that founded and led each organization. Yet performance 
regimes became increasingly prescriptive over time, with governments determining on what, for whom, and where research funding was to flow. With an eroded autonomy, funders had less opportunity to set and pursue their own program theory, consequently moving closer to government and further from the research community.

This understanding illuminates future prospects for R4D, as funders face new pressures to foster international scientific collaboration and research on shared "global challenges". Given that funders are rooted in different national contexts, it is easier for them to contribute towards a common agenda using their individual grantmaking practice. The future of R4D requires funders to broker the ideas of international development with the ideas of publicly-funded science, a relationship that is at time symbiotic and at time conflictive. 


\section{Acknowledgements}

First, I gratefully acknowledge the wise counsel of my committee. Robert Shepherd, Lisa Mills, and Marc-Andre Gagnon were remarkably patient and encouraging as I struck out on this topic and refined my ideas. I am particularly thankful for Robert's sage advice of preparing a document guide: identifying what information I was looking for and how it linked to the theoretical framework. This step proved invaluable in staying focused:

avoiding intellectual distractions or otherwise getting lost in the archives. Luc Juillet and Michael Brklacich provided sage advice that sharpened the conclusions and understanding of performance regimes.

Second, this work was made possible thanks to the dedication and passion of many R4D grantmakers in three countries. I have been privileged to meet numerous men and women who have set aside their own research careers to help others address the needs of people living in developing countries. Lauchlan Munro deserves special praise for endorsing my request to pursue a doctorate while remaining engaged in the workforce, and for encouraging me to question corporate myths and received wisdom.

Finally, I am indebted to Nora, Miranda, and David, for tolerating far too many one-day weekends and time without their spouse and father. I look forward to making up for lost time. 


\section{Table of Contents}

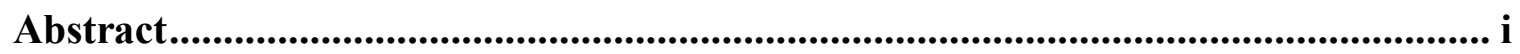

Acknowledgements ...................................................................................................... ii

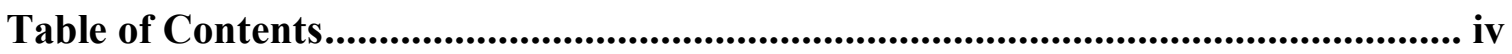

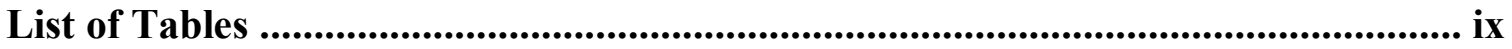

List of Figures ..........................................................................................................................

List of Appendices .........................................................................................................................

1 Chapter: Setting the Scene .........................................................................................1

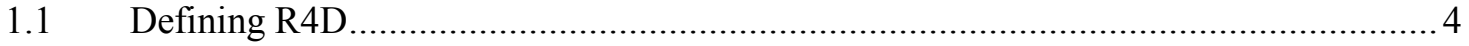

1.1.1 Problem statement and hypothesis ............................................................. 8

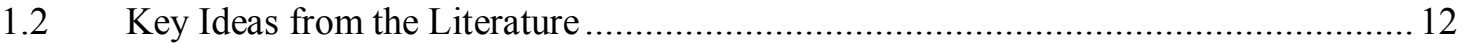

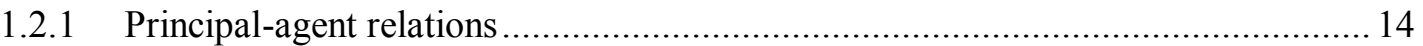

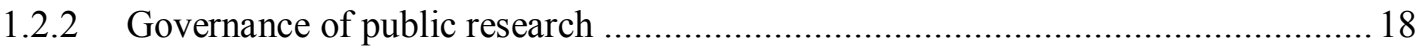

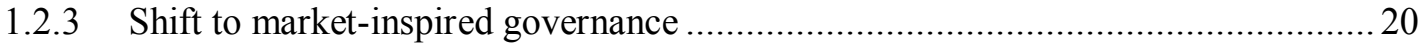

1.2.4 Trends among funders of public research.........................................................22

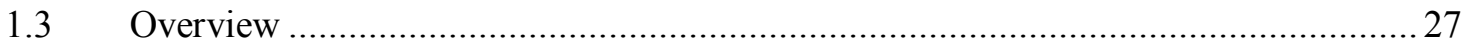

2 Chapter: Framework and Methods ...............................................................32

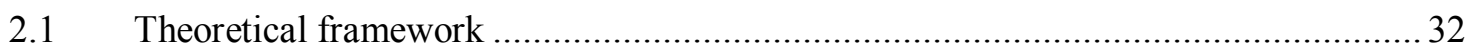

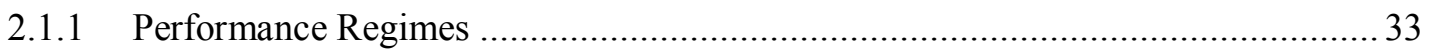

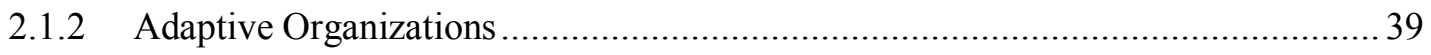

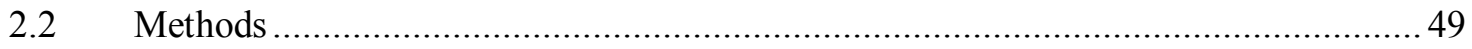

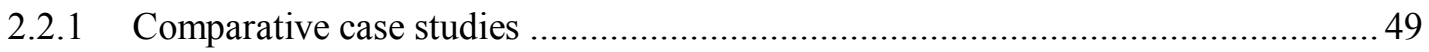

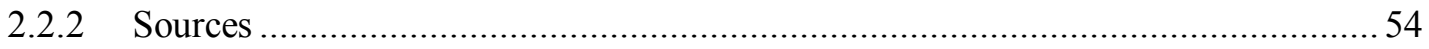




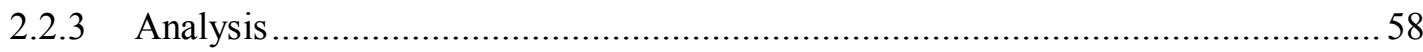

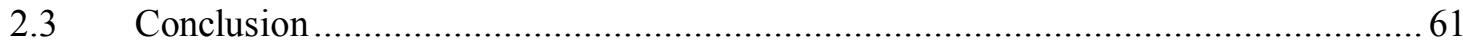

3 Chapter: United Kingdom.......................................................................62

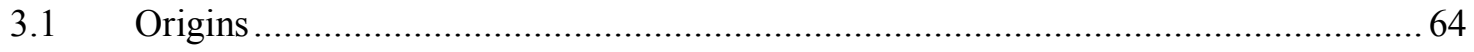

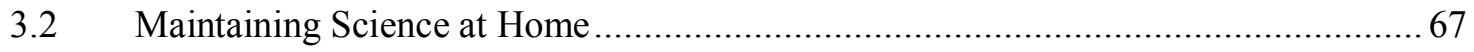

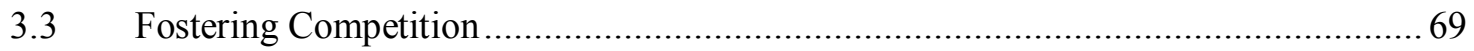

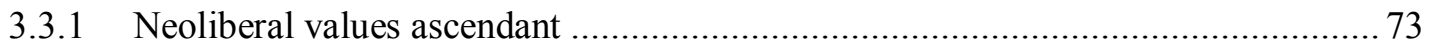

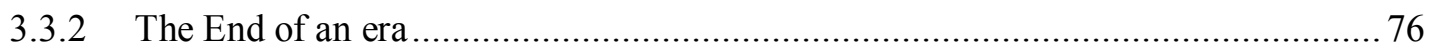

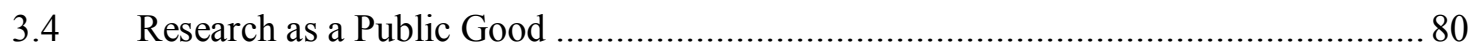

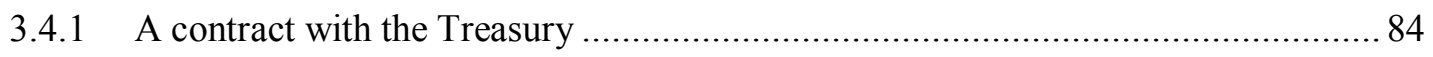

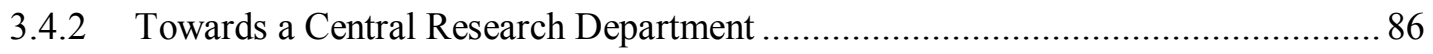

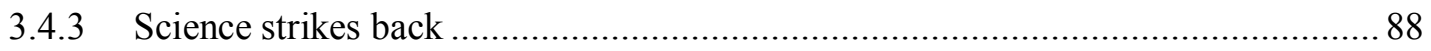

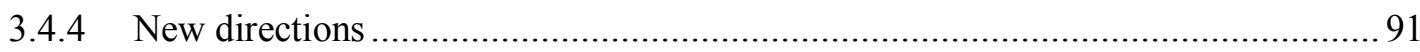

3.5 The Promise of Technology and Evidence ....................................................... 94

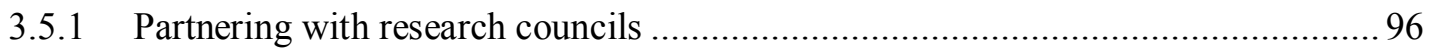

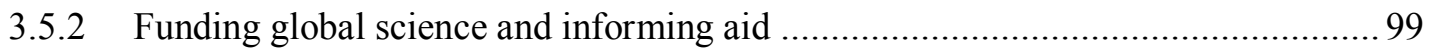

3.5.3 Setting a research strategy and seeing RED ............................................. 102

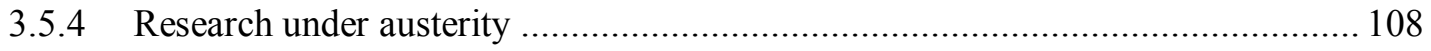

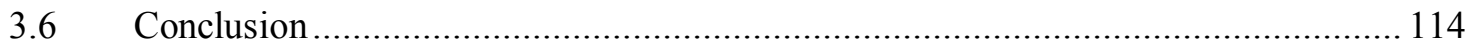

4 Chapter: Canada ................................................................................................121

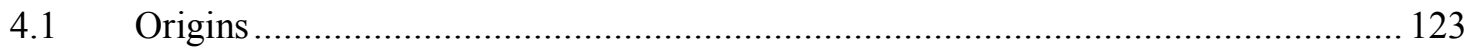

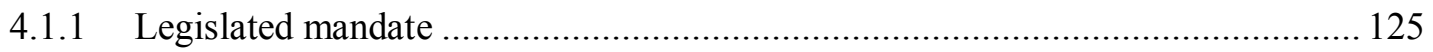

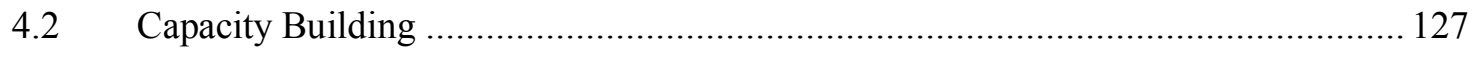

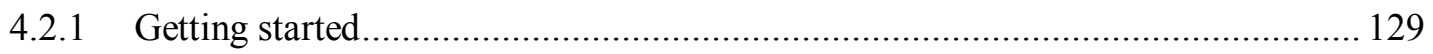

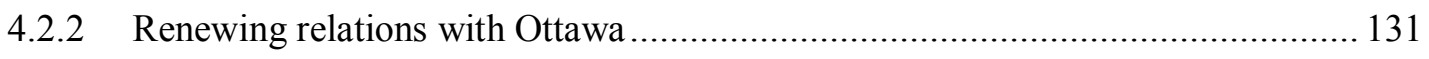




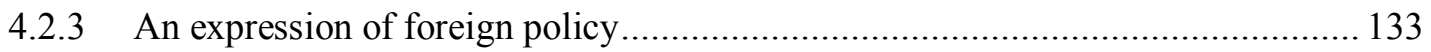

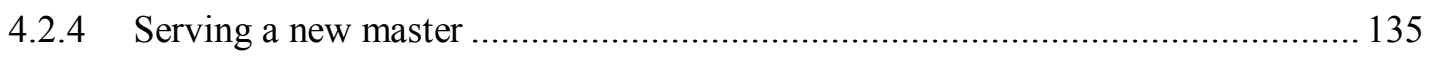

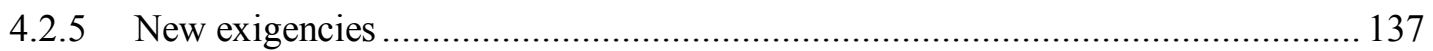

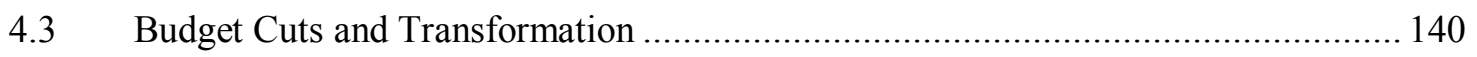

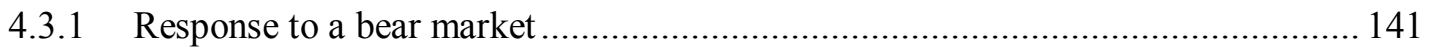

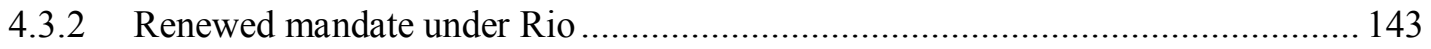

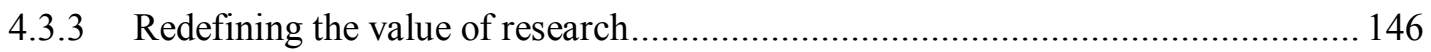

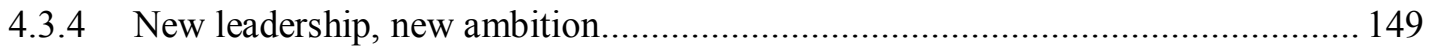

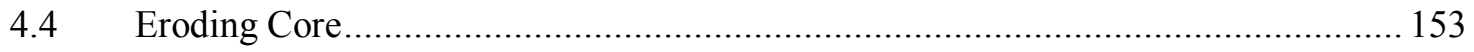

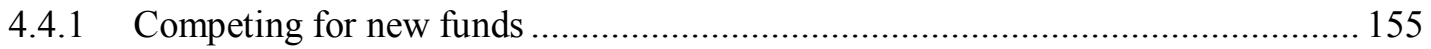

4.4.2 Donor partnerships and government agendas ................................................ 157

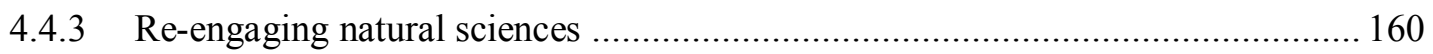

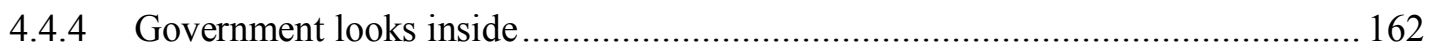

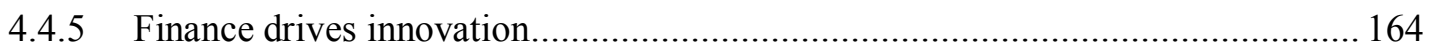

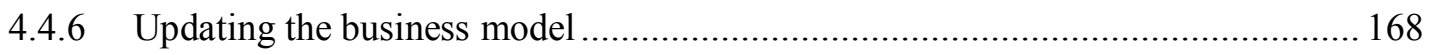

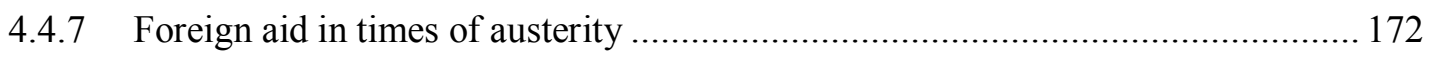

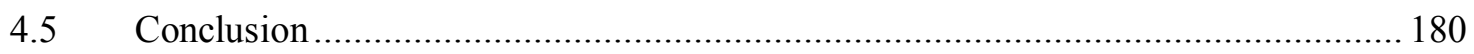

5 Chapter: Australia ...............................................................................185

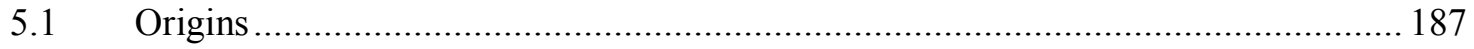

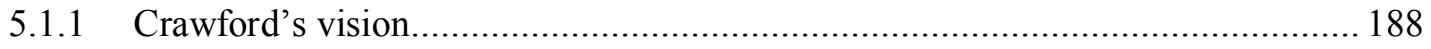

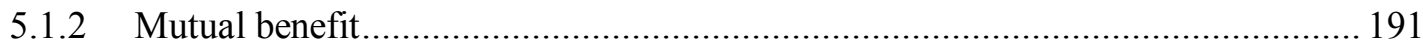

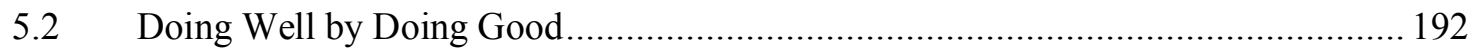

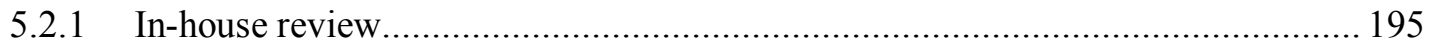

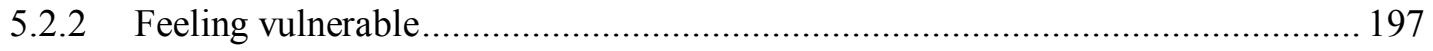

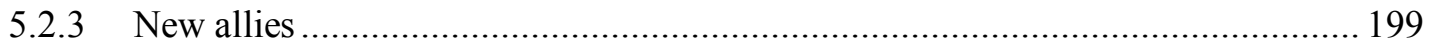




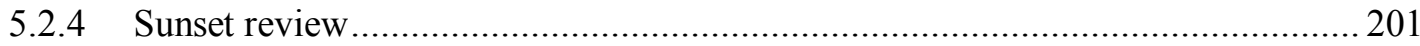

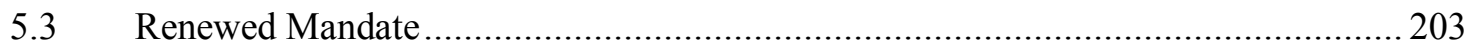

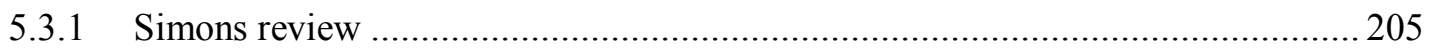

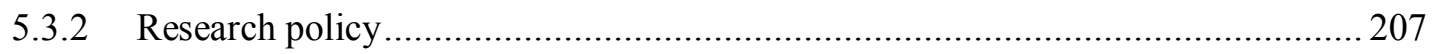

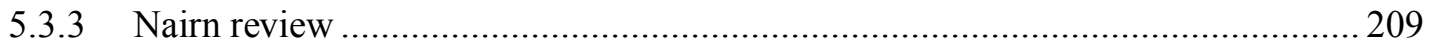

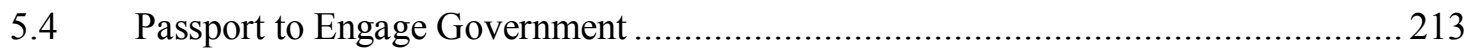

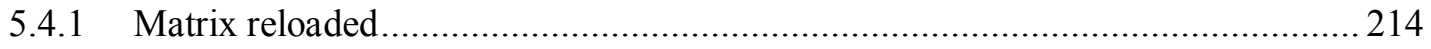

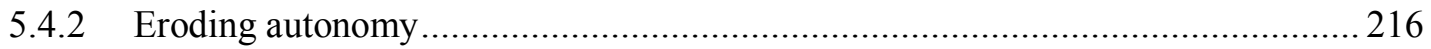

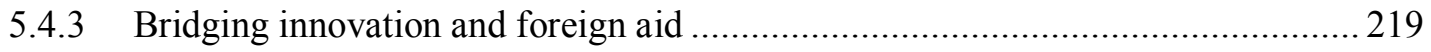

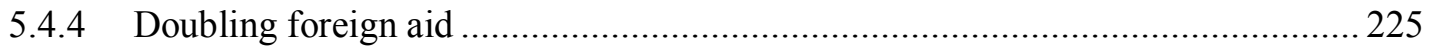

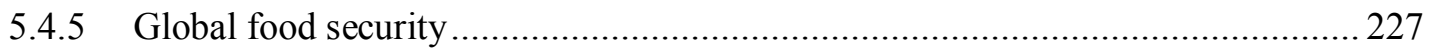

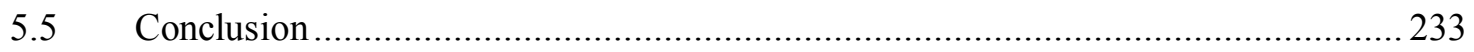

6 Chapter: Synthesis and Findings .............................................................241

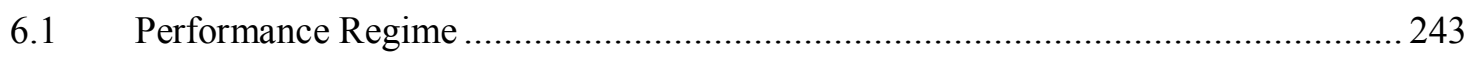

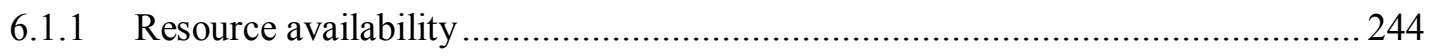

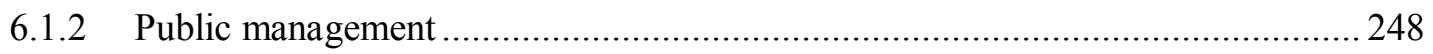

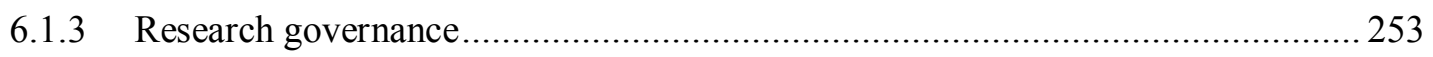

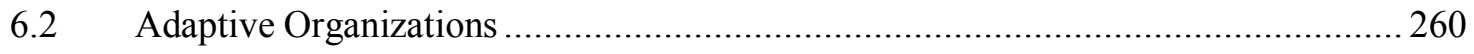

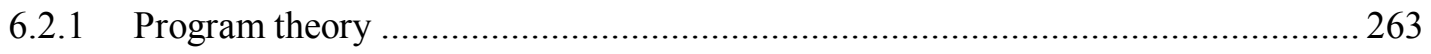

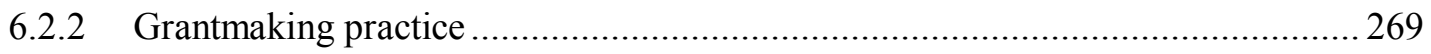

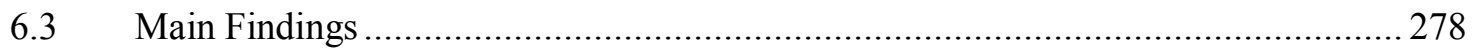

6.3.1 Shift towards market-inspired governance ............................................... 279

6.3.2 Changes in time-horizon, recipients, and point of delivery …...........................2283

6.3.3 Covert program implementation in adverse contexts .......................................28

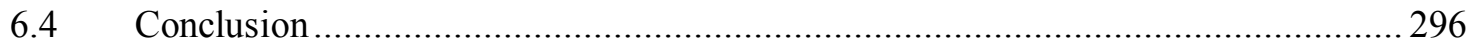


7 Chapter: Contribution and Implications ..................................................298

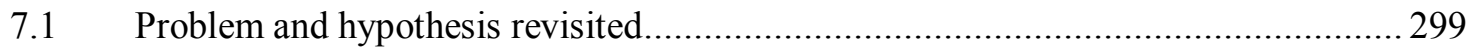

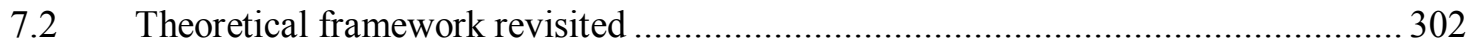

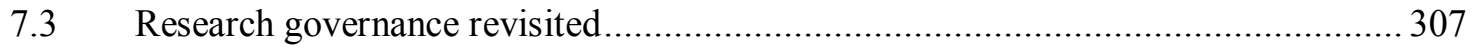

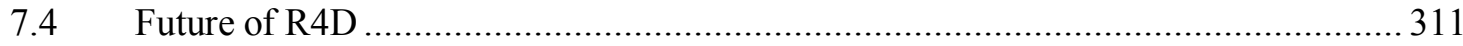

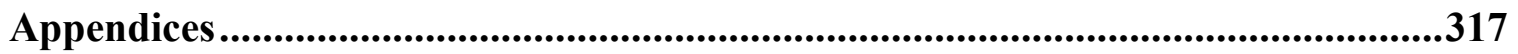

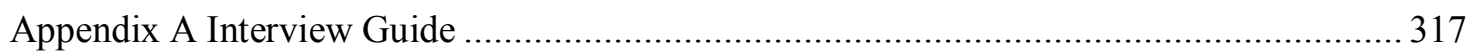

References ..........................................................................................................318 


\section{List of Tables}

Table 1: Variety in how R4D is defined and funded................................................

Table 2: Research question and hypothesis ..................................................... 11

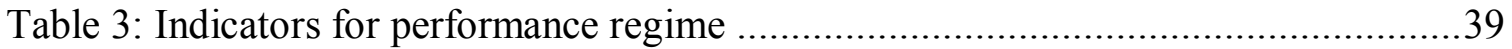

Table 4: Indicators for adaptive organization ............................................... 46

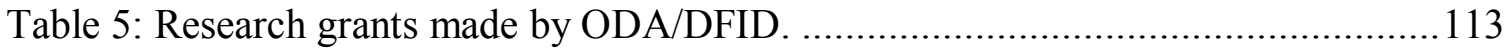

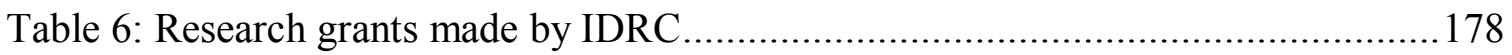

Table 7: Comparison of the case studies as performance regime ..............................243

Table 8: Comparison of the case studies as adaptive organization ............................263

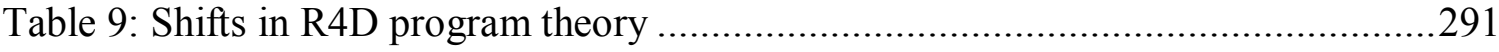




\section{List of Figures}

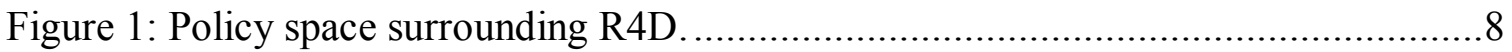

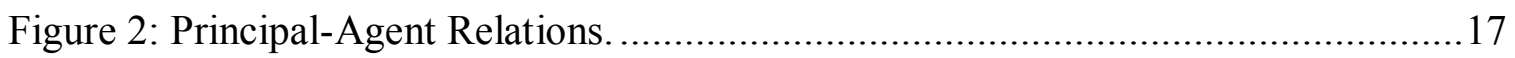

Figure 3: Recipients seek support from multiple funders .............................................17

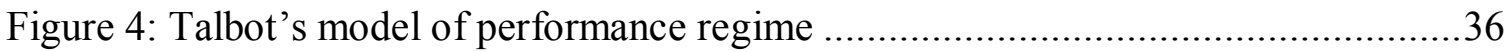

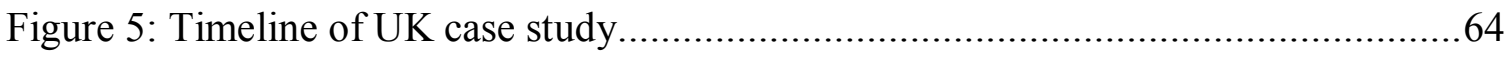

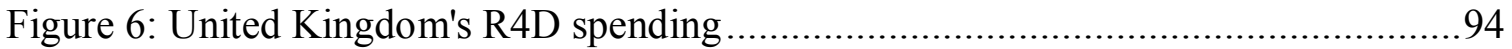

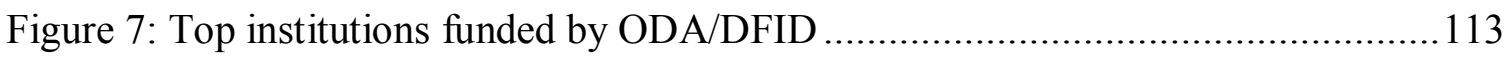

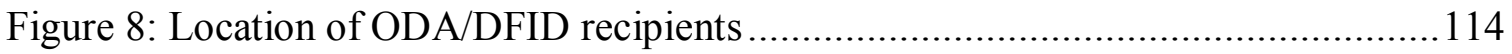

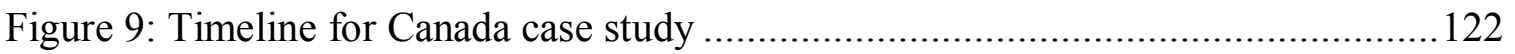

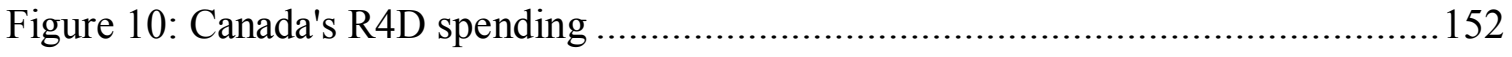

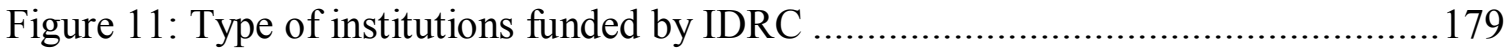

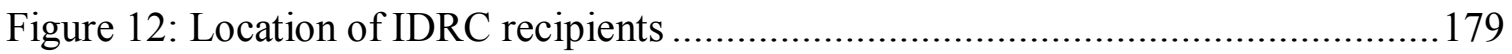

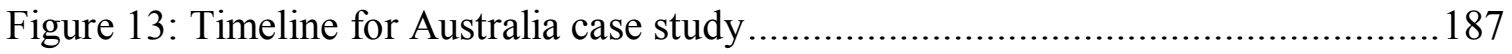

Figure 14: Bridging the innovation and foreign aid portfolios ....................................222

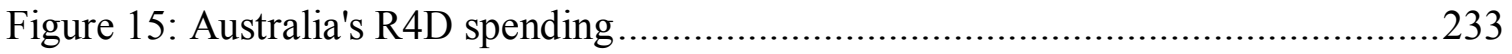

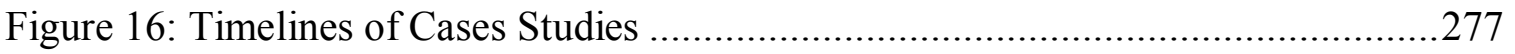

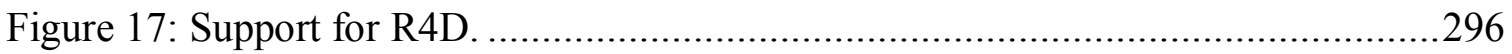

\section{List of Appendices}

Appendix A: Interview Guide............................................. 317 


\section{Chapter: Setting the Scene}

Research-for-development (R4D) concerns research directed towards the benefit of developing countries, including the strengthening of research capabilities within these countries. A number of organizations fund R4D including private foundations, bilateral donors and specialized agencies. ${ }^{1}$ The label of 'research funder' distinguishes these organizations from those that perform, regulate, and use research. They provide a bridge between the source of their funding, and the research communities and host societies that are the intended beneficiaries of their activities. A key challenge facing these organizations is how to allocate limited funding among competing priorities in a way that satisfies multiple stakeholders so as to maintain the support from their home government and credibility with researchers and host societies.

This challenge is further complicated as R4D funders bridge policies for international development and science: research can directly address the needs of poor women and men, yet the capability to absorb, adapt and develop knowledge also benefits society at large. The OECD's Development Assistance Committee fosters a model of aid effectiveness that encourages harmonization among donor agencies, alignment with the priorities of host countries, and focus on particular countries and sectors. Meanwhile, both advanced and developing countries adopt domestic science policies that identify thematic priorities perceived to benefit their societies. Over time, R4D funders must

\footnotetext{
${ }^{1}$ Examples include bilateral donors (e.g. Swedish International Development Agency and the Netherlands' Ministry of Foreign Affairs), specialized agencies (e.g. the World Bank and France's Institut de recherche pour le développement) and private philanthropies (e.g. Rockefeller Foundation and the Bill \& Melinda Gates Foundation).
} 
adapt as the accepted ideas about these policies evolve, and as their home governments redefine what they want to know about their activities.

The advent of market-inspired governance of public research is one such change. Governments increasingly seek to direct their investments to areas expected to generate higher returns: whether based on perceived scientific advantage compared to other nations, or on complementing the efforts of industry and civil society to grow the economy and solve social problems. Whereas the tasks of priority setting and performance management used to be delegated to the research community, governments have stepped up efforts to assess individuals and organizations, based on the assumption that these efforts optimize resource allocation and boost research performance. In turn, research funders face pressure to rationalize their expenditures by identifying goals that complement their government`s priorities, demonstrating their own performance in designing strategies and programs, and scrutinizing the value and cost-effectiveness of the work they support.

This thesis examines how three R4D funding organizations responded to the changing expectations within the policy environment ("performance regime") and a shift towards market-inspired governance of publicly-funded research. How R4D funders responded led to shifts in how R4D was defined and funded which carried implications for which topics and researchers received funding. 
The thesis consists of seven chapters. This first chapter introduces the research question, hypothesis, and identifies key ideas from the literature on policies governing publiclyfunded research. Chapter two provides the theoretical framework which draws on the concepts of context (or "performance regime") surrounding a research funding organization, and its agency ("program theory") in choosing among competing goals and responding to various expectations. Chapter two also describes the data sources used and methods of analysis employed in the case studies that follow. Chapters three, four, and five recount the historical experience of three R4D funding organizations: the United Kingdom's Department for International Development (DFID) ${ }^{2}$, Canada's International Development Research Centre (IDRC), and the Australian Centre for International Agricultural Research (ACIAR). Chapter six provides a synthesis which compares the three case studies to the theoretical framework. All three countries experienced a shift towards market-inspired governance, which favoured a shorter-term research agenda. R4D funders partially adapted to this context while trying to influence it and continued to pursue their program theory covertly. Chapter seven identifies some implications for the future of R4D and the research community, as well as the contribution this thesis makes to the literature.

This introductory chapter presents a brief overview of 'research-for-development' (R4D) and presents the problem statement and hypotheses. The key question is how do funders decide on their approach to $\mathrm{R} 4 \mathrm{D}$, and why do these approaches vary over time and

\footnotetext{
${ }^{2}$ Prior to 1997, this organization was the Overseas Development Administration (ODA)
} 
between funders? The hypothesis proposes that funders continually adjust to the changing expectations of their governments and the research community, as well as the experience gained from past programming. Three drivers shape the context for these choices: the availability of public resources, trends in public management, and research governance. The latter part of the chapter identifies some key ideas from the literature, namely the application of principal-agent relations to research funding organizations, the governance of public research, and a shift in recent decades to market-inspired governance. The chapter concludes by highlighting some trends among funders of public research, including greater use of competitions among prospective grantees, more time-limited project grants, more targeted programs that earmark funding to priority areas, expanded selection criteria, and expanding ex post evaluation of the results of public funding. These trends provide a yardstick against which to compare the experience of the case study organizations.

\subsection{Defining R4D}

Policies to support 'research-for-development' (R4D) are marked by multiple competing goals (figure 1). Over time, different authors and organizations have described the purpose of research in developing countries as: providing evidence to inform donors on the effects of different interventions to reduce poverty; mobilizing existing talent to invent new technologies that serve poor people; and building the capability of poorer countries to participate in global science for mutual benefit (table 1, Singer et al. 1970, King and McGrath 2004, UN Millennium Project 2005, Scoones and Leach 2006, 
Wagner 2008, Molenaar et al. 2009, Khagram et al. 2009; Conway and Waage 2010,

Edwards 2010, Ely and Leach 2010). Many funders seek to simultaneously advance knowledge and build research capabilities required for future advances. This requires a long-term perspective to assess the full benefits of funded activities intended to further the careers of young researchers or contribute to development outcomes for poor and disadvantaged members of society. At the same time, there is also rising demand for research on global challenges affecting both developing countries and advanced economies, such as infectious disease, food security and climate adaptation (cf Reid et al. 2010, Varmus et al 2003).

Table 1: Variety in how R4D is defined and funded. Over time, different authors and organizations have pursued various ways of supporting research intended to benefit developing countries. This table was crafted by the author based on a wide reading of the R4D literature. While the first three rows denote unique program logics, the last two column spread across them as there is limited number of grantmaking practice and there are multiple ways each can connect with development outcomes.

\begin{tabular}{|c|c|c|c|c|}
\hline WHY & ON WHAT & WITH WHOM & HOW & FOR WHAT \\
\hline Inform policy & $\begin{array}{l}\text { Economic policy } \\
\text { Governance }\end{array}$ & $\begin{array}{l}\text { Aid practitioners } \\
\text { and policy } \\
\text { researchers }\end{array}$ & $\begin{array}{l}\text { Core funding } \\
\text { Project grants }\end{array}$ & $\begin{array}{l}\text { Assess interventions } \\
\text { Reduce local poverty }\end{array}$ \\
\hline Build capacity & $\begin{array}{l}\text { Health systems } \\
\text { Think tanks }\end{array}$ & $\begin{array}{l}\text { Local intuitions in } \\
\text { developing } \\
\text { countries }\end{array}$ & Scholarships & Improve well-being \\
\hline $\begin{array}{l}\text { Design } \\
\text { technology }\end{array}$ & $\begin{array}{l}\text { Vaccines } \\
\text { Seeds }\end{array}$ & $\begin{array}{l}\text { Tap scientific talent } \\
\text { anywhere }\end{array}$ & $\begin{array}{l}\text { In-house research } \\
\text { Prizes }\end{array}$ & $\begin{array}{l}\text { Connect to global } \\
\text { Raise productivity }\end{array}$ \\
\hline
\end{tabular}


Habermann and Langthale (2010) distinguish among research "on development" as a social phenomenon done mainly by social sciences, humanities, and economics; "for development" supporting innovation in developing countries and oriented towards technical, agro-, and natural science; and "policy-related" work on strategy and practice of development co-operation. Rousseau (2006) and Nutley et al (2007) note a turn inspired by clinical medicine, which sees the utility of research as establishing and quantifying a cause-effect relation between donor interventions and outcomes. This turn can be seen as a reflection of the rise of empiricism and experimentation in the social sciences in the latter twentieth century. Meanwhile Khagram et al. (2009) suggest that 'successful' R4D outputs are accessible, credible, and actionable: in other words outputs can be easily communicated, accepted as valid, and inform decision-making.

In deciding how to support R4D, funders must decide what knowledge to advance, what types of support to offer, and how research might be used. Some funders act like think tanks and fund intramural research performed by staff or consultants, others act like granting councils and fund work performed by the research community. Collectively, R4D funders pursue multiple approaches including funding researchers at home, abroad in developing countries, or collaboration between these two groups. Ravallion and Gelb (2010) argue that researchers in developing countries better understand local reality, priorities of host societies, and "the underlying political economy that shapes policies." 
Research can vary with its intended purpose and audience. Its purpose can range from understanding the natural world or society, to trying out new approaches or technologies, to assessing the outcomes of particular interventions. Audience can range from research peers in the same disciplinary field, donor or partner governments promoting development, or local people, civil society, social movements or private enterprises that can contest such top-down efforts and engage in bottom-up ones. As research funders choose among their goals, purpose and audience, they set the cornerstones for the program theory which will inform their grantmaking. In practice there are a limited number of instruments available. The tool of choice is the project grant, although funders can and do offer a variety of awards, including scholarships or fellowships for talented individuals, block grants or core funding to particular research-performing organizations, or ex-post prizes for research in particular areas or that answers a priority problem (table 1). The choice among these options relies on assumptions regarding the importance of the research process being connected to local conditions (Wagner 2008): whether to study local phenomenon and reach local audiences (e.g. field-level agricultural production among farmers), or if the research can take place anywhere and reach global audiences (e.g. vaccine development, design of low-cost products). 


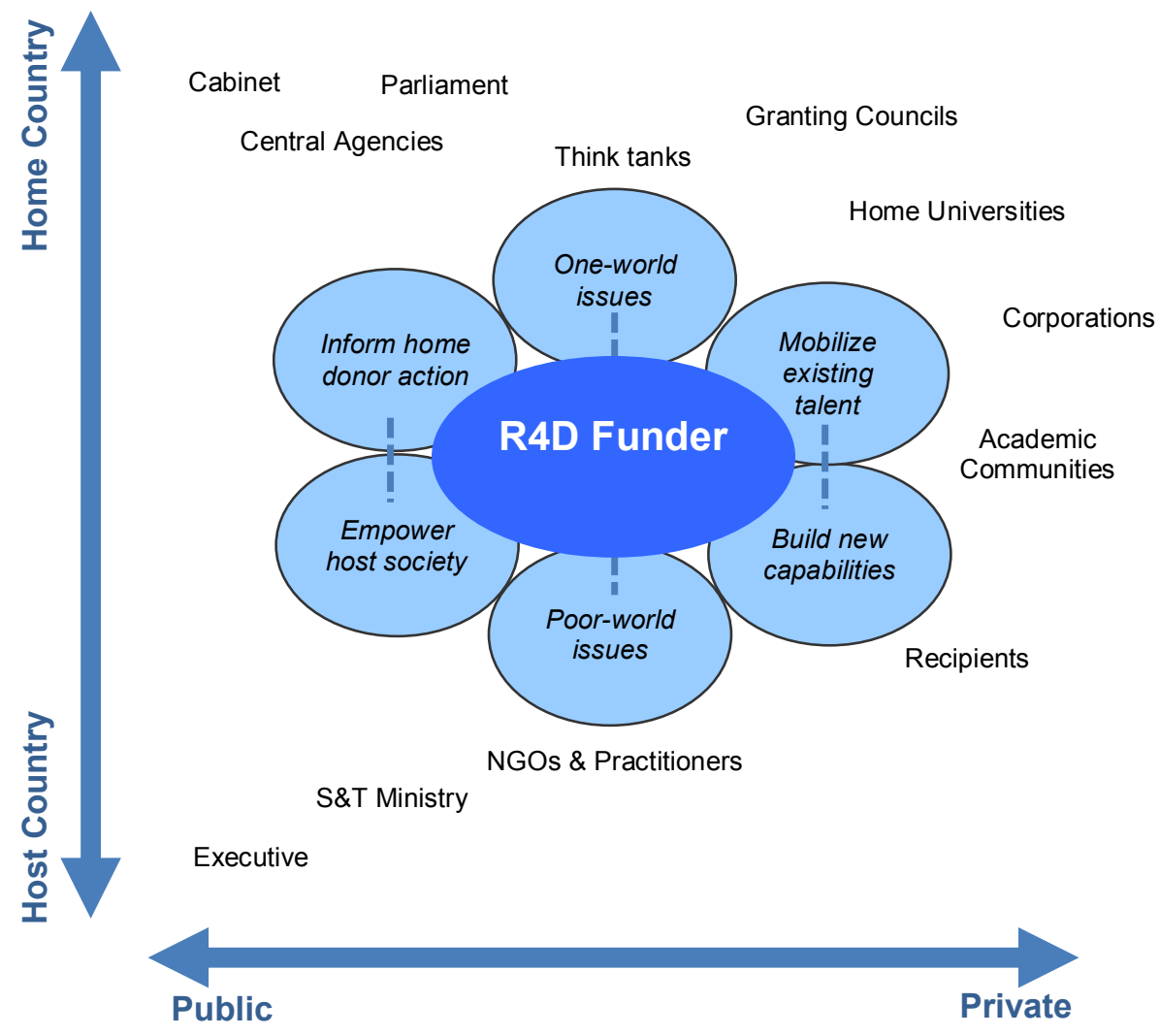

Figure 1: Policy space surrounding R4D Policy space surrounding R4D. Funders are subject to multiple expectations and must balance competing goals.

\subsubsection{Problem statement and hypothesis}

From the brief overview above, it is clear that R4D can be viewed as generating evidence on the effectiveness of foreign aid, inventing new technologies that serve poor people, and strengthening research capabilities in poor countries. Yet what determines which of these policy goals are pursued? How do funders decide on their approach to R4D, and why do these approaches vary over time and between funders? Answering these 
questions would provide insight on the implications for the research community at home or abroad.

The hypothesis is that funders continually adjust to the changing expectations of their governments and the research community, as well as the experience gained from past programming. Funders must respond to these stakeholders' views on priority and performance, in order to justify the resources they receive and maintain their credibility. At the same time, funders evolve over time to refine program theory on how research contributes to international development, incorporating this learning into their organizational routines, namely their grantmaking practice. Three contextual drivers are proposed to encourage change among R4D funders: the availability of public resources, trends in public management, and research governance. Each of these contribute to the context within which funders decide to adapt, or persist with, their program theory over time. The saliency of each driver varies over time, and together they form a historic braid that explains why funders change their approach to R4D.

The importance of resource availability is self-evident: R4D funders would cease to exist without money for their programs, and the rise and fall of budgets influences the scale of such programs. Waves of budget growth permit funders the opportunity to become more ambitious or expand their work, while waves of austerity require them to be more focused or scale back their work. Less evident are the conditions placed upon access to public funding, both the expectations placed on the funder when it receives additional funding and the scrutiny it receives during periods of austerity when funds for science 
and foreign aid become scarce. These conditions can cascade down to potential grantees and see the funder alter their selection criteria or performance expectations, for example limiting grants to a certain percentage of overall project costs or requiring the grantee to interact with particular types of actors (e.g. local communities, policymakers, private sector).

For the purposes of this thesis, public management is understood as the ideas on the purpose, role, and operation of government. Public organizations are embedded within government and respond to waves of ideas on how they should organize themselves, including the functions of planning, evaluation, and performance management. At times they may be left to simply pursue their own mandate, while at other times they may be expected to make a contribution within a 'whole-of-government' agenda. Such ideas shape the opportunities to support R4D and how the funder relates to other parts of government, including Cabinet, the foreign ministry, and central agencies.

Research governance encompasses the decision-making processes over priority setting, the allocation of funds, and the management of research institutes and the assessment of their performance (OECD 2003). It is concerned with how to encourage, support, and direct research in order to further some common or public good. Over time, the pressure to rationalize public expenditures prompted governments to become more proactive in directing their investments to areas expected to generate higher returns. Governments want to know more about the effectiveness and efficiency of the research they fund. The next section elaborates further on this shift. 
This thesis uses the concepts of performance regime and program theory, introduced in chapter two, to examine how three funders of public research - one in each of the United Kingdom, Canada, and Australia-responded to a changing context for supporting R4D. Table 2 describes the relationship between the research question, hypothesis, and theoretical framework, which is argued to contribute to the choice among multiple competing goals of R4D. How R4D is defined and funded has real implications for the research community in terms of which recipients and which topics receive scarce public funding.

Table 2: Research question and hypothesis The policy space shapes the opportunities for R4D funders to pursue their work, a context which is influenced by the availability of public resources, trends in public management, and research governance. Funders selectively adapt to this context: adjusting their program theory, renewing support and justification for their work, and persisting with some grantmaking practice. The combination of these forces contributes to how R4D is defined and funded.

\begin{tabular}{|c|c|c|}
\hline $\begin{array}{c}\text { Research } \\
\text { Question }\end{array}$ & \multicolumn{2}{|c|}{$\begin{array}{c}\text { Why do funders periodically change } \\
\text { how they define and fund research? }\end{array}$} \\
\hline Hypothesis & $\begin{array}{c}\text { They respond to a performance } \\
\text { regime }\end{array}$ & $\begin{array}{c}\text {...selectively as an adaptive } \\
\text { organization }\end{array}$ \\
\hline $\begin{array}{c}\text { Theoretical } \\
\text { Framework }\end{array}$ & $\begin{array}{c}\text { This regime shapes context: } \\
\text { Resource Availability } \\
\text { Public Management } \\
\text { Research Governance }\end{array}$ & $\begin{array}{c}\text { Organizations exercise agency: } \\
\text { Program Theory } \\
\text { Grantmaking Practice }\end{array}$ \\
\hline
\end{tabular}




\subsection{Key Ideas from the Literature}

This second half of the introductory chapter identifies key ideas from the research policy literature that frame the subject matter of this thesis: the application of principal-agent relations to research funding organizations, the governance of public research, and a shift in recent decade to market-inspired governance. This shift has given rise to a number of trends among funders of public research, including greater use of competitions among prospective grantees, more time-limited project grants, more targeted programs that earmark funding to priority areas, expanded selection criteria, and expanded use of $e x$ post evaluation and performance management frameworks.

R4D exists within a wider context that has seen changes in how publicly-funded research is governed. These changes are due to a greater rationalization of research effort based on the expected value of its potential output. Public research was once seen as a sine qua non for social progress: a vibrant research community was valued in its own right for generating fundamental discoveries and for contributing to the national missions of providing defense, public health, etc. Yet the advent of neoliberal values within government subjected publicly-funded research to market-inspired thinking, justifying investments in projects based on their expected return and how that return compares to other research opportunities. 
Before proceeding further into this context, it is useful to define science, research and innovation. Science can be defined as a set of procedures used to certify a claim to knowledge, or to skeptically subject ideas to argument, criticism and empirical evidence (Merton 1942). The methods of science include observing phenomenon, formulating potential explanations, and testing hypotheses. Science is also communal as scientists share their own findings, and test and extend the findings made by others. Approaches to conducting science vary from the experimental to the speculative depending on the use of evidence and causal explanation. Scientific works are expected to be plausible, valuable, original, and falsifiable: attributes that contribute to the notions of 'scientific excellence' and 'research quality'.

Research is often taken to be synonymous with 'doing science'. It is creative work undertaken on a systematic basis in order to increase the stock of knowledge, and the use of this stock of knowledge to devise new applications (OECD 2002). The Frascati manual describes surveys of research expenditures and outputs, and distinguishes activities for generating new knowledge ("research and development", or R\&D) from related-scientific activities for sharing knowledge, such as workshops and conferences (which together with R\&D sums "science and technology", or S\&T). Innovation, in contrast, is the implementation of a new or significantly improved product, process, or method (OECD-Eurostat 2005). The Oslo manual describes surveys of the activities intended to lead to innovations, including design, engineering, and management. While research is about of new knowledge, innovation is about converting knowledge into value 
by making or doing things in new ways. Innovations can be entirely original (new-toworld) or novel for given place or use (new-to-context).

The problem is how to define the value of publicly-funded research: value for whom, where, and to do what? Changes in the governance of publicly-funded research are rooted in how this value is interpreted over time in different countries. In Anglo-Saxon countries, recent decades witnessed a shift from broader public interest, towards a narrower agenda predicated on raising revenues and reducing costs for private firms. Researchers no longer have unquestioned authority to allocate public funds and govern their own affairs. The governance of publicly-funded research has moved from a selforganized "republic of science", to market-inspired goals negotiated among policymakers, stakeholders, and research 'consumers'. Researchers, and the funding organizations that support them, must demonstrate the value of their work, not only in terms of scientific excellence in the eyes of peers, but in terms of its cost-effectiveness, impact, and relevance to others.

\subsubsection{Principal-agent relations}

Guston (2000) argues that "[t]he asymmetry of information between those who would conduct research and those who would govern it presents the central problem of science policy". The classic solution to such asymmetry is the principal-agent model. Consider two rational actors: a contractor (principal) who provides an incentive to another party (agent) to conduct some work or services on their behalf. In this simple situation the principal does not have full information of what the agent is doing at all times. The agent 
is expected to also pursue his or her own goals and interests in addition to doing the principal's bidding. Thus the extent to which the agent acts on behalf of the principal is a function of the incentives provided (e.g. payments) and the efforts invested to monitor the agent's activities.

An expansion of the principal-agent model casts research funders as intermediaries between what government wants done and what researchers actually do (figure 2, Braun 1993, Rip 1994). In this model, the research funder is a boundary organization that both responds to direction from government and provides incentives to researchers who compete for the resources offered. The funder is simultaneously an agent of the government and a principal to the research community. As Rip (1994) argues, funders "must legitimate next year's budget in terms of an attractive portfolio of projects to be funded, while the money must be disbursed in a way that is acceptable to the scientists." Braun (2003) describes the problem of governance as how to attract the curiosity of researchers to problems of research users. This includes the means by which policymakers get researchers to respond to policy demand, ensure they recruit qualified recipients (avoid adverse selection), and that these recipients apply themselves to task (avoid moral hazard).

Yet qualified researchers also choose among different funders when seeking support for their work. Shove (2003) considers the point of view of the researcher (agent) who manages different opportunities through sequential participation with different funders. Over time, researchers string together separately funded projects to pursue their longer- 
term interests and professional career (figure 3). Projects pull individual researchers into temporary, for-purpose networks with specific objectives. Individual researchers are akin to free agents that move between projects. When one project ends, they enter into another and may be part of multiple projects at any given time. Researchers can be expected to ignore funding opportunities that stray too far from their interests or that do not further their careers. Funders thus compete for the limited time researchers have to prepare grant applications and project proposals: qualified researchers can be expected to prefer opportunities that offer greater return on the effort invested in applying for funding. In other words, publicly-funded research is not necessarily a 'buyer's market' in which researchers compete for scarce funding; it can also be a 'seller's market' in which funders compete for scarce talent and ideas.

As such, research funders can be interpreted as an example of what Meyer and Kearnes (2013) define as an intermediary organization, or entities that "structure expertise and policy imperatives...[and] selectively mobilise and reframe contemporary policy discourse and ideas of usability, applicability and impact so as to influence the conduct of researchers and research institutions". These authors identify three approaches to the study of such intermediaries: documentary (describing a shift towards distributed forms of governance), contractual (underpinned by principal-agent theory), and performance (behaviour of intermediaries "getting things done"). Meyer and Kearnes (2013) describe the contractual approach as drawing on the concept of rational choice, focused on "the delegation of political authority... and the particular mandates that enable intermediary 
organisations to operate simultaneously as principals and agents when acting as an interface between national governments and research communities".
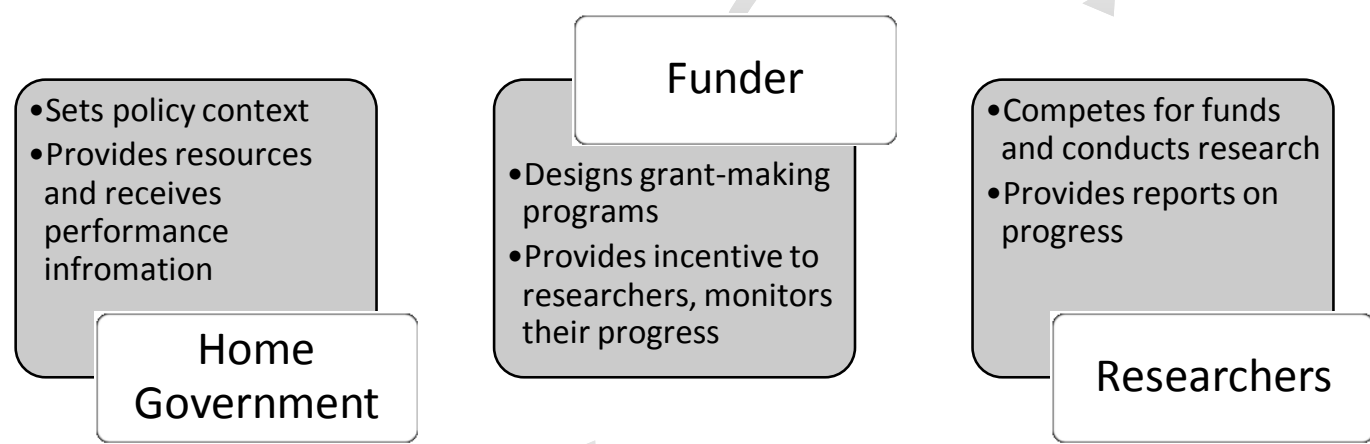

Figure 2: Principal-Agent Relations Organizations that support publicly-funded research are simultaneous an agent of home governments and principal to researchers.

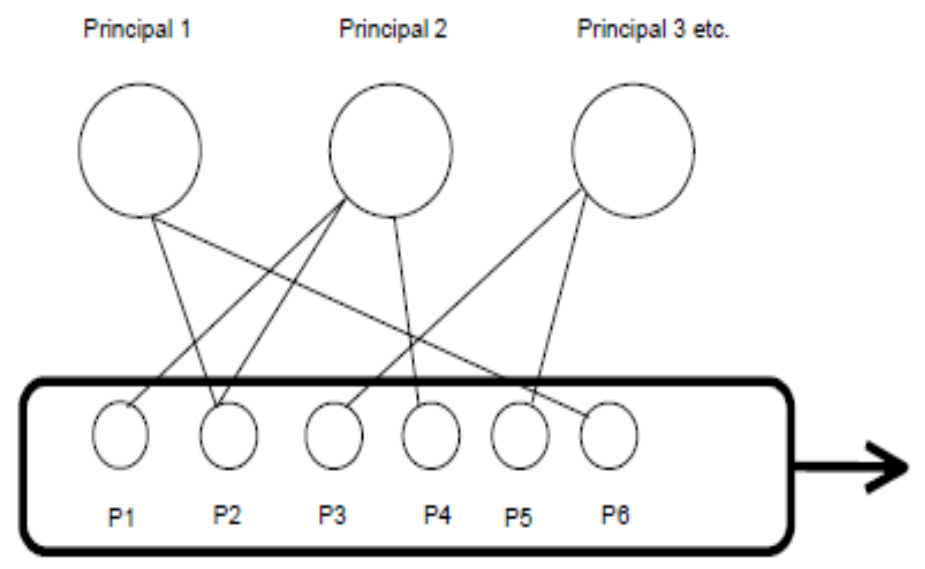

Figure 3: Recipients seek support from multiple funders Different researchers (or principals) piece together their longer-term career by linking together projects (P1, P2, etc.) (Source: Shove 2003). 


\subsubsection{Governance of public research}

Despite its elegance, the principal-agent model ignores the institutional arrangements that surround research funders as well as the organizational processes within them. The OECD (2003) defines the governance of public research as "decision-making processes that govern priority setting, the allocation of funds, and the management of research institutes and the assessment of their performance in terms of contribution to knowledge creation, economic growth and responses to societal needs." The OECD innovation strategy (2010) uses a similar definition, seeing governance as the "institutional arrangements, incentive structures, etc. that determine how ... actors ... interact in allocating and managing resources... to steer and give direction" to research and innovation. Similarly Polster (2003) asserts that policy and programs shape the social relations of research, or "the courses of action in and through which research is conceived, produced, and transmitted to society."

The governance of research is a nested set of relationships. One can describe research governance in the United Kingdom or Canada, yet there is also a distinct subset of relationships that enable or constrain the actions of a particular funding organization in either country. Benner (2011) identifies three levels: the macro goals for public research and the role of research policy in relation to the political and economic systems; the meso-level of selecting, monitoring, and evaluation of publicly-funded research; and the micro-level of negotiated practice within academic and research organizations. Edgerton (2009) similarly acknowledges the existence of multiple levels. In his words, there "is no stable entity called science which is governed, worried about, applauded, condemned, 
invested in, much less understood. Each small part of 'science' is governed by many institutions, and many policies."

Polanyi's (1962) 'republic of science' provides one vision of research governance: an ideal set of relationships among scientists working in isolation from markets and society. This vision sees science as a self-organizing community in which members optimize their time and effort based on the results published by others. Coordination relies on merit principles (plausibility, accuracy, importance, and originality) rather than the market principles (price, consumer surplus, and efficiency). The self-organizing 'republic of science' offers only an indirect promise of public benefit, focusing instead on how a given work is valued among peers within the research community based on its contribution to discovery and scientific progress.

Yet the practice of publicly-funded research has always been tied to the expectation of some outcome of interest to government. Stretching back to before the 18th century, royal patronage of scientists was part of the competition among nations for international prestige, and the UK government offered prizes for new military or navigational technologies. In the twentieth-century, Slaughter and Rhoades (1996) describe the United States as funding "Cold War science" under a Keynesian state, justified by a narrative of winning battles against communism, polio, and cancer. Although countries do fund curiosity-driven research, in the United States the majority of research funding is directed through mission-oriented agencies such as the National Aeronautics and Space Administration, National Institutes of Health, and Departments of Defense and of Energy. 
Contemporary perspectives on public funding for research derive from seeing knowledge as a public good. The market is expected to under-invest in research due to indivisibility, uncertainty, and externalities associated with the creation of new knowledge (Arrow 1962). Some benefits will accrue, not to the firms that underwrite it, but to others that copy or use the knowledge derived from such research (Helpman 2004). Furthermore firms tend to invest in near-market research for novel products and services that can create new demand and enjoy temporary rents. There is less incentive for firms to invest in basic or fundamental research that cannot be easily captured or utilized by its sponsor. Thus the state has a role to play correcting this "market failure", funding research that is valuable to the public, but not provided for by the market.

\subsubsection{Shift to market-inspired governance}

With the pressure to rationalize public expenditures, governments became more proactive in directing their investments to areas expected to generate higher returns. They want to know more about the effectiveness and efficiency of the research they fund, forcing researchers — and the organizations that support them—-to identify how their work benefits others (Boden et al 2006, Jansen 2007, Schubert 2009, Stephan 2012). UNESCO (2010) notes policymakers question whether the "research they support is relevant to current public issues, and regret the lack of evidence to inform their policy decisions." Looking again at the United States, Slaughter and Rhoades (1996) identify shift in the 1980s towards a competitiveness agenda under the neoliberal state, justified by a 
narrative of increasing the number of jobs and growing the country's share of global markets.

The result was market-inspired turn in research governance: governments began to experiment with different ways of reallocating public funds, and funding and goals became increasingly negotiated among policymakers, stakeholders, and research 'consumers'. The role of government shifted from science patrons to knowledge broker: connecting suppliers and users of research-based knowledge (Gibbons et al. 1994). Where the research community once held the authority for allocating public funds, more recent approaches rely on greater government involvement to specify obligations through formal grant contracts and set priorities towards which researchers are expected to dedicate their efforts (Braun 2003). Granting councils began to consider user involvement, policy relevance, and potential for commercialization, alongside the traditional criteria of peer review and academic credentials (Shove and Redclift 2001). There was a move towards more top-down rather than bottom-up approaches to priority setting (OECD 2003). Similarly there has been greater attention to "demand pull" based on the societal relevance of research, over "science push" based on researchers' autonomy in setting their agenda. In short, control over the research agenda moved away from the scientific community and expert opinion (endogenous) towards the realm of public policy and government decision (exogenous).

This new governance is not without its critics, who fear research funding has veered towards seeking profit instead of truth. Demeritt (2000) laments the shift "from a 
metaphorical market of ideas... to an actual market system". Shove and Redclift (2001) argue that "academics now have to 'sell' research ideas to policy communities and respond to non-academic competition, whilst maintaining conventional academic credentials". Generic calls to demonstrate 'value for money' gloss over potentially incommensurable ways of understanding research and its utility to society. Research is not only a production process, assessed according to the quantity of publication or selling price of patents. It is also a process of discovery, assessed according to the evidence of progress on problems. Society is concerned about a cure for cancer, not the number of articles written about it. Rip (2003) suggests that the literature is already moving away from a narrow focus on static efficiency and effectiveness, towards a more dynamic interest in the appropriateness of past actions and improving performance over time.

Meyer and Kearnes (2013) observe an increased attention in academia to the policy instruments employed by science intermediaries, such as funding formulae, which these authors see as affecting the "institutional contexts of scientific practice", including the incentives that shape the behaviour of researchers. Extending the arguments put forward by these authors, these incentives even shape the career decisions of young professionals, for example choosing to specialize in lab-based genomic research focused on developing new crops versus field-based extension work focused on the practices of farmers in rural areas. While Meyer and Kearnes specifically identify funding formulae as a policy instrument worthy of study, the methods employed in this thesis gives attention to the program theories, grantmaking practices, and selection criteria employed by research funders. 


\subsubsection{Trends among funders of public research}

This shift towards market-inspired governance was accompanied by changes in legal and funding structures. Polster (2003) and Benner (2011) observe that Canada and other Anglo-Saxon countries have concentrated funding, leading to fewer areas of research, each of which is investigated more intensively by smaller number of increasingly specialized units. The United Kingdom, Canada, and Australia all progressively scaled back on the portion of research performed within government department and laboratories. Consequently universities became the primary location of publicly-funded research in each of these countries. Wagner (2008) argues that the research process has become much more networked as individuals increasingly collaborate to share funding, data, tasks, and infrastructure. Whitley and Glaser (2007) note a rise in competitive bidding for research projects, and cautions that it can reduce the researcher's time horizon and heighten the importance of performance assessment. They note that OECD countries have complemented ex ante evaluation of research proposals with ex post evaluation of project results.

As governments change their expectations of public research, funders have to adapt or face the prospect of decreasing political support and financial resources. At the same time, funders need to maintain their credibility within the research community or risk losing their attention. Over time, funders have altered their grantmaking practices in five ways: 
(1) A move to induce competition among researchers by allocating funding through open calls for proposals or a ranking exercise among research centres. Research performing organizations, such as universities and laboratories, are placed at arms-length from government and must compete to secure funding. Competitions are open to allow new entrants into the research funding 'market' and avoid capture by established actors.

(2) Greater use of time-limited project grants to work on a specific problem. Projects typically involve a small team of researchers, whether within a single organization or spread across multiple ones. Consequently there is less opportunity for institutional block grants, where research organizations receive general purpose funding that they can allocate internally among departments and projects.

(3) More targeted programs that earmark funding to priority areas of perceived public interest or economic benefit. Rather than passive response to priorities set within the research community, there was a turn towards more priority setting by policymakers. Even beyond specific for-purpose programs, funders incorporate public policy objectives into their competitions, including explicit objectives to develop new technology and contribute to economic growth.

(4) Expanded selection criteria for deciding which proposals receive funding. While traditionally academic quality (excellence) was paramount, notions of relevance and 
usefulness $^{3}$ became more prominent in such decisions. Recipients were also expected contribute a larger share of the costs involved and/or secure additional funding from other sources. This was intended to reduce the overall burden of costs on the public purse and provide a 'market test' that the proposed work was valued by others.

(5) More elaborate systems for performance assessment and greater scrutiny of what government gains from the research funded. Research productivity began to be assessed by the number of publications or patents produced, and their quality in terms of citations or licences. There was also increased interest in research outcomes: the value of patents and licences as an indicator of its utility to firms and industry, or how research findings were adopted by practitioners or inform the thinking and actions of policymakers.

If R4D experienced a similar shift towards market-inspired governance, it may have strengthened the upwards accountability of funders to their home governments, and weakened their downwards accountability to host countries and research communities. The criteria by which R4D funders are judged, and on which they base their decisions, might be expected to turn towards the utility of research for home governments and away from its relevance and contribution to the host society. Inspired by earlier policy ideas, R4D was once seen as empowering host societies: building their capability to create and adapt knowledge in order to address the needs of their citizens and shape their own future. Yet if home governments came to expect to more direct benefit from R4D

\footnotetext{
${ }^{3}$ Ravallion and Gelb (2010) describe these as external validity, arguing that the policy question should drive the research agenda, rather than the researcher's disciplinary background or favourite method.
} 
spending, they may favour research that informs decision making on how to invest their foreign aid dollars or how to address shared global challenges. If so, this shift has implications for how funders operate.

First, it may de-politicize research and narrow the R4D agenda. Research might be seen as an input into the production function of official development assistance, akin to labour or capital. It may be assumed to provide neutral evidence on what works (and what does not). Such a narrow view would exclude understanding of how the wider process of development unfolds and ignore the politics of knowledge: its ability to contest and reframe how societies understand themselves as well as the problems they face and their potential solutions. It would risk directing funding to politically-safe questions of technological innovation and away from more contentious questions regarding social norms or how power is distributed and used in society. Improving crops or vaccines hold the potential to provide more food or lessen the burden of disease, yet no amount of technological innovation can solve poverty if its conditions are rooted in larger social inequalities and deprivation (Edwards 2010). If R4D is devoid of politics, it would ignore the constraints poor people face and their potential to affect change in their lives.

Second, research funders may have less discretion over their goals and practices, including who and what they fund. Historically, public research funders enjoyed some autonomy from the short-term concerns of the home government, in order to adapt to the changing frontier of knowledge and address longer-term priorities in societies. Yet this space may be squeezed if home governments became more proactive in identifying the 
research priorities, and even particular projects, that they wished to support. Governments might have shifted from core support (left to the funder's discretion) to targeted programs (pre-committed to particular priorities). Home governments may have also required research funders to be more critical of their grants, to justify their existence by demonstrating the value and cost-effectiveness of the work they supported.

\subsection{Overview}

This introductory chapter defined 'research-for-development' (R4D) and presented the research question: how do funders decide on their approach to R4D, and why do these approaches vary over time and between funders? The hypothesis proposed is that funders continually adjust to the changing expectations of their governments and the research community, as well as the experience gained from past programming. The contextual drivers of resource availability, public management, and research governance provide a means of operationalizing the concept of "performance regime" which is introduced in chapter two as part of the theoretical framework. This introductory chapter also identified some key ideas from the literature - principal-agent relations and a shift to marketinspired governance - as well as some trends among funders of public research.

Chapter two builds on these ideas to construct a theoretical framework to analyze how public research is governed. Research funders are seen to exist within a performance regime (Talbot 2010) of various expectations as to what they are meant to achieve, to which they respond selectively as adaptive organizations. Chapter two also provides an 
overview of the data sources and methods of analysis used in the three case studies that follow.

Chapter three examines the United Kingdom's support to R4D, from the beginning of the twentieth century to recent reforms in the Department for International Development (DFID). The chapter identifies four distinct periods when R4D was subjected to different expectations and adopted different goals, ranging from maintaining UK scientific expertise on tropical climates, to fostering competition among researchers to provide knowledge and outcomes of interest to the aid agency. When DFID was created in 1997, research was cast a form of public good at the service of the global development agenda. A move to untie funding saw an increase in support to researchers outside the country, and a shift to larger projects, networks or "consortia" of grantees. More recently, the UK sought to generate technologies for poor people and saw research as informing an evidence-based approach to policy, emphasizing notions of scientific excellence and demonstrating the "value of money" of aid investments.

Chapter four examines Canada's support to R4D, through the International Development Research Centre (IDRC), a Crown corporation created in 1970 and inspired by the grantmaking practices within private philanthropic foundations. The chapter identifies three distinct periods. Initially, IDRC was afforded a substantial degree of autonomy and developed a perspective focused on capacity building of researchers in developing countries. Central agencies occasionally sought to reassert control over IDRC, but management countered by cultivating a network of allies within the federal bureaucracy. 
Budget cutbacks in the 1990s heightened demands to control operating costs and to demonstrate the utility of research, inspiring a shift towards notions of policy influence and expecting recipients to connect with an audience that would act on their findings. The final period, during this century, emphasized alignment with Canada's foreign policy and eroded the role of the IDRC Board as programming decisions were increasingly tied to decisions within the bureaucracy or pre-committed to programs jointly funded by donors outside Canada. This period valued R4D for its actual contribution to changed policy and practice in the developing world, and witnessed a rise in competitive calls for proposals alongside the older "foundation" approach to grantmaking.

Chapter five examines the Australia's support to R4D, through the Australian Centre for International Agriculture Research (ACIAR), a statutory authority that -while inspired by IDRC- adopted a distinct approach which sought to partner researchers in Australian with counterparts abroad. The chapter identifies three distinct periods. After ACIAR was founded in 1982, the Centre sought to prove its worth in terms of the potential increases in agricultural productivity stemming from its work. The Centre initially focused on mobilizing Australian scientists within state-level government departments. During the 1990s, Australia enshrined poverty reduction as the purpose of foreign aid, requiring ACIAR to demonstrate how its work contributed to increases in rural incomes and reallife adoption of new technologies and techniques. At the same time, changes in Australian science policy forced ACIAR to rely increasingly on researchers in universities, rather than government departments. During its third decade, ACIAR was expected to fit within whole-of-government strategies towards Australia's engagement 
within developing countries, particularly in response to the "war on terror" and the global food crisis. Meanwhile, public research was expected to align with national priorities and contribute to program-level outcomes - such as contributing to Australia's economy and security—rather than simply pursuing individual projects based on their own merit. ACIAR placed a stronger emphasis on engaging government colleagues and embassies, and needed to work in countries with a weak or nonexistent domestic research community.

Chapter six brings together the case studies, assessing them against the contextual drivers and the theoretical framework. The availability of public resources, trends in public management, and changes in research governance are shown to alter the performance regime over time. Research funders responded to these changes by altering their perspective and pattern, or the program theory of how research is understood to contribute to development and the grantmaking practices enacted. Each funder responded to a changing context by adapting their definition and means of supporting $\mathrm{R} 4 \mathrm{D}$, and/or sought to alter the performance regime by lobbying in favour of the funder's way of conducting business. The chapter also identifies three main findings. First, R4D funders selectively adopted market-based thinking into their program theory and grantmaking practices as they faced greater competition in accessing government funding. Second, funders to increasingly sought shorter-term development results and policy influence, moving away from governmental recipients in favour of working more with academic institutions. Third, funders strived to remain faithful to their underlining philosophy of 
what constituted 'research-for-development' and what they viewed as their responsibilities towards researchers at home and abroad.

Chapter seven revisits the problem statement, hypothesis, and theoretical framework. A public funder periodically changes how it defines and funds research-for-development (R4D) in order to maintain its credibility among — and support from—-the home government and the research communities at home and abroad. The chapter presents some weaknesses in the theoretical framework, including its inattention to international drivers, acceptance of government's motives, and an exaggerated sense of the funder's autonomy. The framework also failed to anticipate the ability of R4D funders to reshape their policy environment and how influential individual persons are to this process. The latter part of the chapter discusses the future of R4D. The field is both closing as donor countries squeeze public expenditure, and opening with an expanding set of "global challenges" that affect all people. One lesson offered by this thesis is that funders craft their program theories and grantmaking practices in part to respond to different national policy contexts. This necessarily limits their ability to "buy-in" to a common global research agenda and shared program design. 


\section{Chapter: Framework and Methods}

This chapter serves two purposes: it introduces the theoretical framework developed for the thesis, and it provides an overview of the data sources and methods of analysis used in the case studies that follow. At its simplest, the theoretical framework integrates the ideas of context and agency to analyze how public research is governed. In terms of context, public organizations can be seen to exist within a performance regime (Talbot 2010) of various expectations as to what the public entity is meant to achieve: what is worth doing and how to do it. In terms of agency, research funders can be described as adaptive organizations which choose whether and how to respond to these various expectations. This framework was used for content analysis of 217 written documentsincluding annual reports, white papers, and management memos - and 38 semi-structured interviews conducted in the spring and summer of 2012. The collected data informed the construction of historical narratives presented in chapters three, four, and five on a R4D funder in each of the United Kingdom, Canada, and Australia. The experiences of these three organizations are analyzed in chapter six to answer the research question and reflect upon the theoretical framework.

\subsection{Theoretical framework}

In terms of context, a "performance regime" (Talbot 2010) includes the potentially conflicting expectations emanating from multiple sources, such as Parliament, ministers, line departments, central agencies, beneficiaries, and public opinion. At any given moment, the viability of a public organization depends on achieving a connection between what the organization does and what such entities consider to be good 
performance. In essence, there is not a single government voice telling public organizations what to do, instead they have to contend with multiple principals shaping various dimensions of the policy space within which the organization operates. Yet performance regimes are not static, and the notions of what constitutes good performance do change over time.

In terms of agency, "adaptive organizations" build upon past experience and selectively decide how to respond to changing expectations. Research funders periodically renew their priorities and programs, and evolve certain patterns in how they engage with the research community and support research activities. In this way, R4D funders learn: testing and refining different program theories (how they understand their actions contribute to international development). Successful experiences are codified into the grantmaking practices the funder uses to support research: who is eligible for funding, how to support them, and how research is used.

\subsubsection{Performance Regimes}

Dismayed at the diversity of approaches to performance management, Talbot (2010) argues for a coming together of theories. He posits that such a unified framework could involve three parts: performance models that identify both results and the factors that enable them, attention to performance regimes of power-holders and the tools they utilize to shape performance of public organizations, and the public values that guide these power-holders and public servants. He defines a "performance regime" as the ensemble of such formal and informal influences that direct public sector service delivery, through 
formal and informal cooperation and competition (Talbot 2008). While this definition is somewhat generic, it opens the possibility of tailoring the performance regime to the context of the public entity under study, whether a R4D funder or a health ministry. This regime of expectations is akin to the institutional setting (cf Ostrom 2005), but emphasizes the model of performance held by influential actors and how their understanding is grounded in public values.

Talbot draws attention to the first principles underpinning a study of performance, the often unstated assumptions regarding the nature of reality (ontology), how one can know this reality (epistemology), and the techniques for knowing (methodology). He argues that many studies of performance start from weak or distorted theoretical assumptions about the behaviour and motivations of individuals and organizations. He identifies four key problems: what is the unit of analysis and the boundaries around it, what is included (and excluded) from the concept of performance, what technique is used to measure it (qualitatively, quantitatively, client satisfaction), and what are the political implications of pursuing multiple values simultaneously.

His concept of a performance regime combines the institutional context of actors and the powers they possess to steer public organizations, with performance interventions or the actions these actors undertake to influence the performance of public organizations. Talbot $(2010,83)$ identifies this as a realist approach, based in historical institutionalism that can be used to analyze changing governance of performance over time. He sees performance as both "brute facts" and socially-constructed meanings attached to such 
facts. The dimensions of performance are epistemologically real, as are the positions, attitudes, and beliefs held by real groups and individuals. Talbot cites Moore's triad of public value (1995) as delivering public services, achieving social outcomes, and maintaining trust and legitimacy; as well as Fried's triad of ethics (1976) including responsiveness to public demand (democratic ethic), compliance with rules (legal ethic), and economy in the use of resources (work ethic). His argument is that the sum of such varied influences shapes or steers performance for specific organizations.

Talbot draws on resource-dependence theory (Pfeffer and Salanick 1978) which sees organizations as successful if they can gather resources from their external environment, meeting competing demands from external stakeholders in exchange for the supply of resources. He also cites resource-based theories of the firm that concentrate on the internal capabilities, capacities, and resources of the organization (Barney and Clark 2007). In addressing position vis-à-vis other entities, the concept of a performance regime can be seen to embody insights from organizational studies. For example, Baum (1996) argues for understanding an organization's niche, benchmarking it against comparator firms, identifying how its services differ from what is offered by others. Poister et al (2010) argue that organizational performance is a matter of fit with the surrounding context and operating environment; thus part of the value of strategy is periodically repositioning the organization to ensure such a fit. 


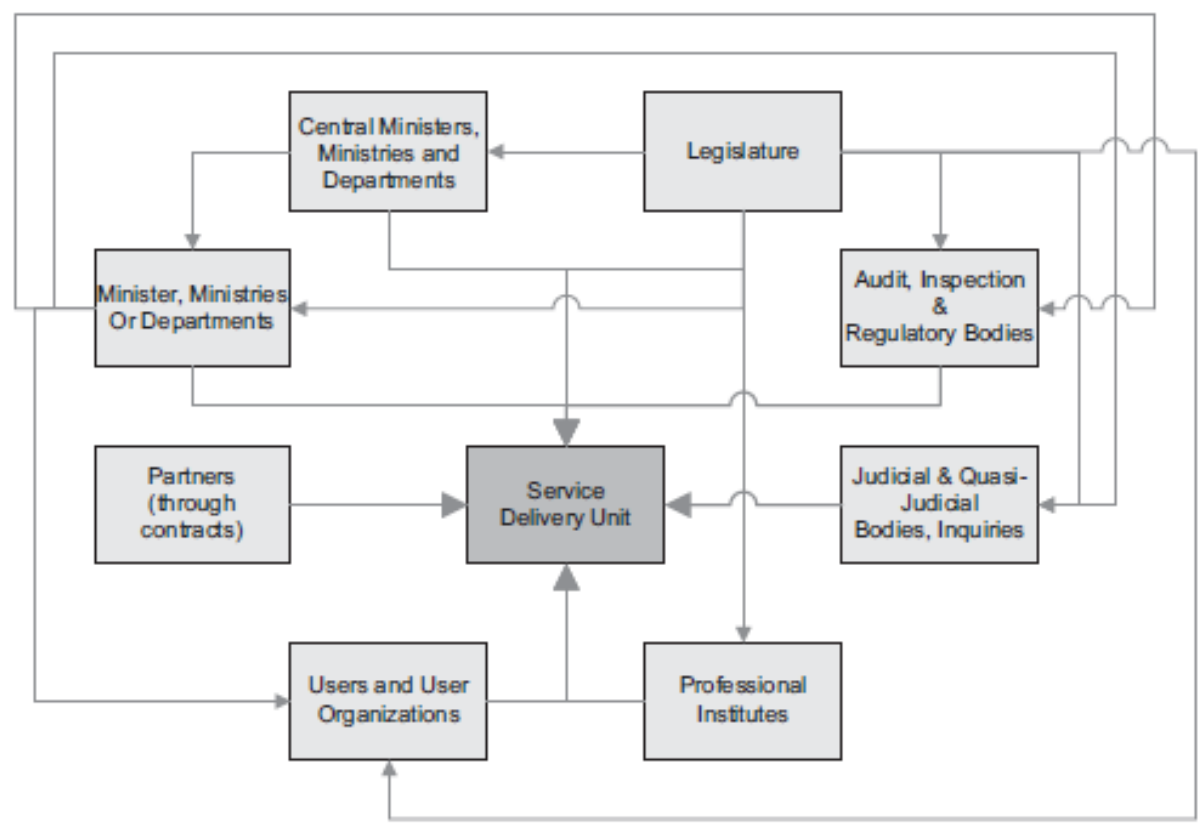

Figure 4: Talbot's model of performance regime

The concept of performance regime acknowledges the institutional landscape within which a public organization finds itself. At its simplest, this means identifying where an organization fits within the bureaucracy, including its reliance on other entities for information, resources, and legitimacy (figure 4). As a first step, one can adapt Talbot's general regime to the policy space surrounding R4D funders (figure 1), identifying how these actors bridge the public and private sector, at home and in host countries overseas. This provides an initial map of which organizations might influence the performance expectations of a R4D funder, but stops short of uncovering what those expectations might be. What matters is whether the R4D funder organizes its performance in a way that resonates with the expectations of such actors, which in turn requires an understanding of their behaviour and motivations. 
A drawback of Talbot's initial diagram (figure 4) is that all the lines of influence appear to be of equal weight. In practice, public organizations will tend to more responsive to certain actors, such as the Cabinet office and Treasury, and less so to line departments that lie outside the portfolio of their minister or disconnected with their mandate. In funding research intended to benefit developing countries, R4D bridges the domains of public research and foreign policy. Thus a point of departure for analyzing the performance regime is to understand the structure, rationale, and performance within each of these policy domains.

Table 3 lists the indicators used in this thesis to analyze the performance regime. "Structure" refers to the legal entities occupying these policy domains and how they are organized, such as granting councils or special-purpose programs in public research, or the foreign office and aid agency within foreign policy. "Rationale" refers to the narrative used to justify government spending in these areas, including the stated goals and focus of each, such as the existence of national research or foreign policy priorities. These provide the setting for how each policy domain defines "performance," including the mechanisms used to allocate funding, the intended outcomes, and the tools used to assess such. One can expect that the performance criteria will differ between public research and foreign policy, yet the R4D funder will need to strike some sort of balance to at least partially satisfy both. 
Understanding these two policy domains is necessary, but not sufficient, for analyzing the performance regime surrounding a R4D funder. For this reason, table 3 includes "other influences" emanating from actors that hold expectations of the funder's performance and possess mechanisms to enforce them. The most obvious of these include the Prime Minister and political party in power, which introduce cross-government policy agendas with potentially far-reaching impacts. Also salient are the central agencies, such as the Cabinet office or Treasury, which can issues directives and ultimately control the public purse-strings. Less obvious are the science lobby and the research community: the former actively courts government seeking to influence public research funding, while the latter can ignore the funder if it is seen to be too bureaucratic or too distant from their professional interests. Once again, as a public entity, the R4D funder must maintain credibility with various actors. Such considerations contribute to the "definition" of how R4D is understood among different influential actors: the product of their own views and the vision offered by the R4D funder that proves successful in garnering support from the performance regime.

As noted in chapter one, the idea of research intended to benefit developing countries can be expressed in various ways. The theoretical framework used here posits that the funder will adopt a definition that resonates with the multiple performance expectations of influential actors, within and beyond the domains of public research and foreign policy. Thus particular attention is paid to the stated purpose of R4D, including statements regarding the perceived research strengths of the home country. 
Table 3: Indicators for performance regime

\begin{tabular}{|c|c|c|}
\hline \multirow{3}{*}{ 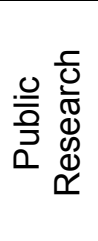 } & Structure & $\begin{array}{l}\text { The legal and organizational structure of public research funding (e.g. } \\
\text { granting councils, special programs) }\end{array}$ \\
\hline & Rationale & $\begin{array}{l}\text { Narrative used to justify research funding, including stated goals and } \\
\text { focus areas }\end{array}$ \\
\hline & Performance & $\begin{array}{l}\text { Mechanisms for allocating research grants, including the intended } \\
\text { outcomes and the tools used to assess such }\end{array}$ \\
\hline \multirow{3}{*}{ 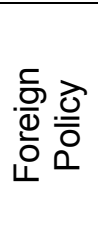 } & Structure & $\begin{array}{l}\text { The legal and organizational structure of foreign aid (e.g. within ministry } \\
\text { of foreign affairs or stand-alone aid agency) }\end{array}$ \\
\hline & Rationale & $\begin{array}{l}\text { Narrative used to justify foreign aid, including stated goals and focus } \\
\text { areas (e.g. thematic and geographic priorities) }\end{array}$ \\
\hline & Performance & $\begin{array}{l}\text { Mechanisms for allocating aid (e.g. sectors or bilateral programs), } \\
\text { including the intended outcomes and the tools used to assess such }\end{array}$ \\
\hline \multicolumn{2}{|c|}{ Other Influences } & $\begin{array}{l}\text { Which actors have expectations of funder's performance and used } \\
\text { mechanisms to influence it (e.g. such as treasury or Cabinet) }\end{array}$ \\
\hline \multicolumn{2}{|c|}{ Definition } & $\begin{array}{l}\text { Narrative used to describe research-for-development, including its } \\
\text { purpose and the perceived strengths of home country }\end{array}$ \\
\hline
\end{tabular}

\subsubsection{Adaptive Organizations}

The performance regime provides the context within which the R4D funder continually renegotiates how it will implement its mandate. Yet outside influences do not automatically translate into new directions for the research funder. To gain traction and affect the organization's behaviour, these influences must be taken up and integrated into the funder's internal process for setting priorities and locking resources into particular programs. This involves an iterative cycle of organizational decisions: what problems to invest in, how to invest in them, and what types of support to offer recipients. This inside view can be built by drawing on ideas from strategic planning and program evaluation.

Corporate strategy provides a first entry point into exploring this sense of organizational agency. The concept of strategy has evolved over time through a sequence of ideas, 
including: managing by objectives, creating synergies among complementary lines of business, maximizing shareholder value, and identifying core competencies (Faulker and Campbell 2003). A recent definition describes strategic planning within public management "as a process for clarifying mandates and goals, scanning the environment for threats and opportunities, identifying strategic issues and ways of dealing with them, developing outcome measures and how to track progress" (KPMG 2008). Mintzberg (2007) differentiates among four ways of understanding strategy in the field of organizational studies: as a plan to guide the organization's future action, its position compared to other organizations in the same industry, its perspective or understanding of its role and purpose, and the unconscious pattern of organizational routines that emerged from past experience. Together these ideas on strategy argue for understanding organizations as having agency, mediating the various expectations placed upon them in order to actively shape their operational space, rather than passively responding to the whims of others.

The second part of the theoretical framework employed here builds on Mintzberg's distinction between abstract perspective and unconscious pattern. The former is embodied within program theory, or the proposed casual explanation of how change occurs, and how the organization's actions are understood to contribute to that change (Rogers 2000). Within R4D, program theory is used by the funding organization to guide its interactions with prospective recipients. It involves assumptions regarding how an organization's activities are intended to contribute to real-world results. In contrast, the 
latter (pattern) is embodied within the grantmaking practices the organization pursues, the everyday operations and routines that stem in part from past experience.

Funnel and Rogers (2011) define program theory as "an explicit theory or model of how an intervention, such as a project, a program, a strategy, an initiative, or a policy, contributes to a chain of intermediate results and finally to the intended or observed outcomes". These authors identify a set of research-based theories about how change occurs - reasoned action, empowerment, diffusion, and socio-ecological networks-each of which address different mechanisms. Reasoned action focuses on how human behaviour is shaped by beliefs and attitudes regarding the consequences of that behaviour (for example, through health and safety training). Empowerment focuses on agency, or how the people affected by a particular problem can organize and act to address that problem (for example, community development projects). Diffusion focuses on how ideas and innovations are invented, shared, adopted or rejected among people (for example, the spread of agricultural techniques). Networks focus how relationships among actors can enhance or constrain their actions (for example, promoting policy change through political coalitions). Each of these theories can address different levels where change is expected to occur, whether at the level of individuals, organizations, policies, or communities. Funnel and Rogers (2011) also caution "that every Theory of Change...carries with it particular values and ideological positions".

Based on these theories, Funnel and Rogers (2011) identify some common archetypes, or underlining logic behind different classes of interventions. These authors see archetypes 
"as a heuristic device" that helps managers identify "the basic elements of the program theory". For example, an information archetype seeks outcomes through educating a client by providing advice and understanding that encourages the client to adopt the desired change. The carrot-and-stick archetype seeks outcomes by providing various incentives and sanctions intended to facilitate the desired change. The case management archetype is a tailor-made approach that "works with each case in a way that recognizes that where significant behavior changes is required, there are likely to be many and varied factors, many individualized intermediate outcomes, and many different processes for getting there". The capacity-building archetype seeks outcomes by empowering clients to enhance their skills and ability over time so they are able to exercise greater control over their lives, while the direct delivery archetype seeks outcomes by providing a product or service.

At a theoretical level, the idea of R4D is underpinned by the information archetype, the belief that research can provide new knowledge and technology that will change the opportunities for international development (Arrow 1962, World Bank 1998, Helpman 2004, Molenaar et al. 2009). Yet, as shown in subsequent chapters, an organization can simultaneous embody multiple program theories and grantmaking practices, as well as shift between different ones over time. Funnel and Rogers' theories of change and common program archetypes will be revisited in at the end of each case study and in the synthesis (chapter 3-6). 
Chen (2005) distinguishes between the theory of change and its implementation, which he refers to a change model and an action model. The change model includes the goals and outcomes, the determinants understood to cause the problem the organization seeks to address, and the interventions employed by the organization to change those determinants. In contrast, Chen defines an action model as the delivery protocols and plans for arranging the organization and ensuring a supportive environment. For Chen, the action model is based upon, and flows from, the change model. The framework reinterprets this duality, using the labels of program theory and grantmaking practice (akin to Mintzberg's perspective and pattern), acknowledging the possibility for the latter to evolve independently of the former. Mintzberg (2007) cautions that many intended actions are unrealized and many realized actions are unintended. In program evaluation, the absence of an expected outcome may be due to failure of strategy or implementation. The former is related to how one expects the world to work, while the latter is related to how one organizes to bring about that change. Thus it is possible to correctly implement an action model that fails due to incorrect assumptions in the change model, and it is possible to have an accurate change model that is incorrectly implemented. Chen (2005, 247) describes this distinction as faulty implementation of sound causality (action theory failure) versus the sound implementation of faulty causality (conceptual model failure).

This thesis is not concerned with the validity of the program theory per se, but seeks to identify when and why a research funder might have changed its understanding of how R4D contributes to change and to organize itself to bring about that change. For this purpose, it is sufficient to identify distinctive program theories and grantmaking practices 
that were in use at different times, and moments of disjuncture when they changed. Mintzberg would identify these as moments when the organization changed its strategic perspective and/or pattern. Such transitions can represent an instance of the organization adapting to a shift in the surrounding performance regime. As shown in the following chapters, while R4D funders do describe their perspective and pattern, these are not always specified in sufficient detail to serve as a basis for program evaluation.

Attention to grantmaking practice is warranted for two reasons. First, while a research funder might pursue multiple program theories simultaneously—using different funding envelopes - the range of grantmaking practices is more limited. Second, organizational pattern can be more persistent than strategic perspective, as the grantmaking practices that guide staff may endure even when corporate strategy and program theory change. Indeed, Nelson and Winter (1977) define research strategy as an heuristic search process, or "the procedures used to identify and screen research projects". This understanding differs from the common view of research strategy as the high-level choice of which problems to work on or a calculation of expected return from research. Shove (2003) cautions that programs are co-created as the funders' ambitions are mediated by the response from researchers who apply for support. A funder's programs is akin to a dialogue with the research community, and can grow and unfold in unpredictable ways, as each project carries with it the recipient's interests and history of prior research. Paarlberg and Bielfeld (2009) similarly argue that strategy evolves as formal rules imposed by management meet informal rules that emerge from operations. These rules include heuristics that guide staff in identifying priority (what is important), boundaries 
(what is in/out of limits), timing (when to act), and exit (when to stop). Such rules are given life through the norms created by staff in carrying out their daily work of selecting proposals, setting funding procedures, monitoring current grants, and reporting on their work.

Grantmaking practices emerge from organizational learning, a process through which staff reflect on their shared experiences and collectively modify their behavior and organizational routines (Argyris and Schön 1978). Such learning can circulate back into performance regime, as subsequent generations of explicit corporate strategy are a means by which an organization formalizes what it has learned and adapts to the expectations of others. In other words, organizations do not necessarily reinvent themselves to match what the performance regime judges to be politically feasible, but instead rally their learned experience to improve operations. This understanding of grantmaking practices echoes Nelson and Winter's $(1977,1982)$ description of how markets select among competing innovations and reinforce the position of certain standards over time. The result is that innovations are influenced in part by past successes and failures: some are ignored while other are picked up and 'locked-in' over time. Building on this insight, the literature on the economics of innovation (cf Lundvall 1988) argues that past learning from experience is embodied in the daily routines of staff. ${ }^{4}$

\footnotetext{
${ }^{4}$ One such innovation is the use of a 'milestone' approach which ties grant payments to different deliverables or progress markers during the project. Milestones provide evidence on how the research is progressing and, if necessary, offer an opportunity to redesign or reschedule future milestones to respond to any difficulties encountered. This approach requires staff with the expertise needed to engage recipients in the substance of their work.
} 
Table 4: Indicators for adaptive organization

\begin{tabular}{|c|c|c|}
\hline \multicolumn{2}{|c|}{ Position within Regime } & $\begin{array}{l}\text { Substantial changes in the funder's organizational structure, } \\
\text { staffing, budget, leadership, or reporting relations }\end{array}$ \\
\hline \multirow{3}{*}{ 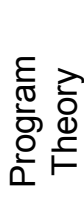 } & Theory of Change & $\begin{array}{l}\text { What the R4D funder sought to achieve, including the focus of its } \\
\text { grant-making programs }\end{array}$ \\
\hline & $\begin{array}{l}\text { Role in Research } \\
\text { Process }\end{array}$ & $\begin{array}{l}\text { The R4D funder's value proposition, including its perceived role in } \\
\text { research process and its relationship with funding recipients }\end{array}$ \\
\hline & Evidence Used & The evidence cited to demonstrate the R4D funder's performance \\
\hline \multirow{3}{*}{ 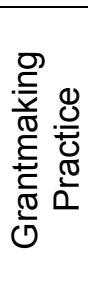 } & Selection & $\begin{array}{l}\text { The criteria and process used to choose among potential } \\
\text { recipients and funding proposals (e.g. location, nationality, } \\
\text { excellence, relevance) }\end{array}$ \\
\hline & Portfolio & $\begin{array}{l}\text { Description of the grants made by the funder, including the } \\
\text { recipients and types of support offered }\end{array}$ \\
\hline & Implications & $\begin{array}{l}\text { The incentives provided to the research community, including what } \\
\text { the R4D funder expected of its recipients }\end{array}$ \\
\hline
\end{tabular}

Table 4 lists the indicators used in this thesis to analyze a research funder as an adaptive organization, building on the distinction between program theory and grantmaking practice.

Position within the performance regime describes how the R4D funder organized itself, noting when there were significant changes in staffing, budget, leadership, organizational structure, or reporting relationships. The sum of these attributes speak to where the R4D funder fitted into the performance regime, and suggests the relative influence of external actors in prompting such changes. Admittedly this grouping unites a number of discrete phenomena, but the purpose is to identify when there was continuity or when the funder was undergoing a period of transformation, highlighting moments of disjuncture that warrant further attention. 
Program Theory is analyzed using three indicators labelled as theory of change, role in the research process, and evidence used in assessing performance. "Theory of change" refers to program theory as revealed through statements of what the funder sought to achieve and its choice of programs, which in turn showed how the funder opted to address certain problems over others. If available, data gathered for this indicator captured the criteria under which the funder selected which grantmaking programs to develop and approve. On occasion this was stated explicitly in written documents, but more often than not had to be uncovered in interviews or deduced from program choice. "Role" refers to how the funder viewed its participation in the research process. A granting council can take a hands-off role, merely providing resources for proposals chosen through peer review within the research community. Yet R4D funders often seek a more engaged relationship with their recipients, inspired by philanthropic foundations, intending to build the capacity of developing country researchers or to ensure research reaches a policy audience able to act on its findings. Finally, "evidence" refers to the information cited by the R4D funder to demonstrate its performance. This indicator noted the arguments employed at a corporate level to justify the funder publicly, as well as the type of information the funder sought to collect in order to determine the extent to which its programs were successful.

Grantmaking practice is similarly analyzed using three indicators labelled as selection, portfolio, and implications. Again the overall purpose is to look beyond intentions to examine what the R4D funder did in practice and how it used resources. In this sense, 
"grantmaking practice" is tailored to the work performed by R4D funders; whereas this part of the theoretical framework could easily have been titled "organizational routines" (cf Lundvall). "Selection" refers to the criteria and process used to choose potential recipients and funding proposals. This indicator was used to collect information on whether access to funding was restricted to particular countries (eligibility), and the criteria by which funding proposals were judged, such as: the qualifications and expertise of the proponent; the feasibility, originality and relevance of the proposed work; engagement with stakeholders in the research process; and the work's potential contribution to knowledge or development outcomes. In terms of process, this indicator also noted the extent to which the R4D funder relied on competitive calls for proposals, the submission of unsolicited proposals, or actively encouraged proposals from particular researchers.

Portfolio refers to the actual grants made by the R4D funder, including the types of support offered and the profile of recipients. DFID and IDRC provide publicly-available grant databases which specify the location and type of institution that received each grant (e.g. universities, government, for-profits, and not-for-profits located in the home country, in an advanced economy, or in a developing country). In all three case studies, annual reports and other sources occasionally provided summary data regarding such analysis of the grant portfolio. Finally "implications" refers to what the R4D funder expected of its recipients, and the consequence of providing incentives for certain types of work, to certain segments of the research community. As will be seen in subsequent chapters, R4D funders can fail to attract the attention of prospective recipients if there is a 
mismatch between its programs, and the career aspirations or other incentives shaping the research community.

\subsection{Methods}

The remainder of this chapter reviews the methods used to analyze and gather data. The core of the thesis is a set of three comparative case studies, each of which traces the history of a different R4D funder and how it related to the wider performance regime surrounding it. This method is introduced below along with the justification for choosing it. The source material for these case studies came from a review of written documents and a series of semi-structured interviews, which required fieldwork in the capital cities of London, Ottawa, and Canberra. As an employee of IDRC at the time, I describe the steps taken to ensure appropriate identification before respondents, and to mitigate the potential for bias in my analysis. The case studies are built upon three levels of analysis: constructing a timeline denoting periods of continuity and change (figure 16), mapping of the performance regime surrounding the R4D funder, and assessing the extent to which changes in program theory and grantmaking practice might have respond to such. This section concludes with a description of the databases used to collect and organize data.

\subsubsection{Comparative case studies}

The next three chapters examine how three different R4D funders - one in each of the United Kingdom, Canada, and Australia_ - operated and used their resources over the past three decades. While the exact timing of changes varied between countries, this period 
coincides with a shift towards market-inspired governance of public research.

Governments became more proactive in directing their investments to areas expected to generate higher returns. Yet instead of generalizing about the normative expectations based upon an abstract 'research funder' (see section 1.2.4), it can be more useful to examine the actual experiences of real-life organizations.

The case study method is appropriate given the nature of the research question (see section 1.1.2 and table 2). Answering this question requires a detailed understanding of the context surrounding research funders and the internal processes used to determine their program theory and grantmaking practices. This type of understanding is not easily obtained through large-N surveys, nor is it reflected in available statistical data. The thesis examines the mechanism of how funders adapted to changing performance regime, rather than seeking to establish the measure of how much change occurred. In other words, the analysis focused on elucidating function (how and why) rather than determining magnitude (how much). Historical case studies offer insights into the political dimension of how research funders operated, which cannot be easily captured in simple correlations or regressions.

Case studies are often used in organization studies. As Ferlie and Mark (2002) argue a case study can "trace how particular strategic decisions have been taken or implemented... through time" and it "enables the researcher to take account of the impact of history on the present." As the subject of the study is the performance regime surrounding R4D funders, and the program theory and grantmaking practices embodied 
by these organizations, the thesis must grapple with the potential messiness of how people perceived their situation, the motivations and incentives that encouraged certain behaviour, the aspirations and intentions behind their actions, and the potentially irrational and unintended consequences of what actually occurred in practice. Uncovering this tale - the interplay between performance expectations, program theory, and grantmaking - requires understanding research funders as human organizations.

The case study approach is also warranted given the limited number of organizations worldwide dedicated to funding R4D. To borrow from economics research, the existence of several thousand companies can be abstracted to an average 'firm' whose behaviour is representative of each company. Yet when seeking to understand the dynamics within particular sectors, the experience of individual firms can be more insightful. For example, one can look to Bombardier and Embraer for insights on aviation, or to Toyota and Tata Motors for insights on the automotive industry. Applying the same principle to the public research, it is possible to survey a large number of granting councils from different countries, yet the specialized field of R4D is dominated by a few organizations. Each one operates in a different performance regime and evolved distinct program theories and grantmaking practices, resulting in varied ways of defining and funding R4D.

Reflecting the two-part theoretical framework, the unit of analysis for each case study is two-fold. "Performance regime" encompasses the UK, Canadian, and Australian landscapes for public research and foreign policy. Rather than a detailed mapping, the salient features are introduced as they proved salient for understanding the history of the 
R4D funder. Meanwhile "adaptive organization," focuses on a particular organization that funds R4D: the Department for International Development (DFID), Canada's International Development Research Centre (IDRC), and the Australian Centre for International Agricultural Research (ACIAR). The latter two are a stand-alone organizations created for the purposes of R4D, whereas the UK case study focuses on the research division within the aid agency. As will be seen in chapter three, the United Kingdom has persistently funded research in and for developing countries, yet the organizational home of this function evolved over time. Prior to establishing DFID in 1997, the UK aid program was known as at different times as the Overseas Development Administration (ODA), the Ministry of Overseas Development (ODM), or Department for Technical Cooperation. Regardless of the name changes, there was continuity in the function of funding R4D.

The starting point differs for each case study and reflects when the United Kingdom, Canada, and Australia entered into R4D. The emphasis is placed on how the performance regime evolved over the past three decades, and how the R4D funder responded (or not) with changes in its program theory and grantmaking practices. Indeed the historical roots of UK funding stretches back to the Imperial Institute in the late $19^{\text {th }}$ century and the Colonial Office in the early $20^{\text {th }}$ century. In contrast, the history of R4D in Canada and Australia is much shorter. Canada's IDRC was established in 1970 as Crown corporation with a mandate to "support and conduct research into the problems of the developing regions of the world". Meanwhile Australia established ACIAR in 1982 as statutory authority with a mandate for "identifying agricultural problems of developing countries 
and finding solutions to them" (Australia 1982). Both IDRC and ACIAR began with a board of directors responsible for overseeing the organization and reporting to Parliament through the minister of foreign affairs. Whereas IDRC tended to support three-to-four fields of research at any one time (such as environment, economy, health), ACIAR maintained a persistent focus on agriculture (broadening from a narrow focus on raising productivity to wider concerns of food security). Also where IDRC choose to focus on supporting local researchers in developing country, ACIAR adopted a partnership model to connect local and Australian researchers in joint projects.

All three case studies are English-speaking countries with parliamentary systems. This choice was intended to control for variance between political systems and intellectual traditions, as the three countries share a common pool of ideas on public management and shared a shift towards market-inspired governance of public research. Benner (2011) notes the style of research governance in this set of countries is distinction from that in Continental Europe or Nordic countries. For example, France and Sweden also provide public funding to $\mathrm{R} 4 \mathrm{D}$ through the Institut de recherche pour le développement (IRD) and the Swedish International Development Agency (Sida), yet these countries also have distinct traditions in how public research is organized and funded. As parliamentary systems, the three case studies have a Minister who exercises significant degree of discretion in managing her or his portfolio. This contrasts with R4D funding in the 
United States, where government funding for R4D has been more episodic ${ }^{5}$ and R4D is mostly the purview of private philanthropies, such as the Rockefeller Foundation, Ford Foundation, and more recently Bill \& Melinda Gates Foundation.

\subsubsection{Sources}

Two hundred and seventeen $(\mathrm{n}=217)$ primary-source written documents were consulted and coded for content analysis. Documents were included if they offered data concerning the variables within the theoretical framework. Consequently, a much larger number of documents were also consulted, but did not contribute data that aided this research. An initial piloting of the theoretical framework against a range of documents allowed for a more precise identification of which ones were more useful. Documents that were useful for the indicators of "performance regime" included founding legislation, national budgets, annual reports, and White Papers on public research and foreign policy. Documents that were useful for the indicators of "adaptive organization" were annual reports, published corporate strategies, management memos, and internal think-pieces produced by staff. These documents were largely available publicly through the British Library, National Archives of Australia, government websites, or the website of each of the case study organizations. This information was supplemented by data on the portfolio of grants made by each R4D funder over time, to understand the types of support provided, the balance between recipients at home and abroad, and the type of recipients (e.g. educational, NGOs, government).

\footnotetext{
${ }^{5}$ The National Science Foundation hosted a "Board on Science and Technology in International Development" (BOSTID) during the 1980s, and the United States Agency for International Development (USAID) began to re-engage funding for science and innovation under the Obama Administration.
} 
Further information was obtained through thirty-eight $(\mathrm{n}=38)$ by semi-structured interviews, for which an ethics protocol was prepared and approved by Carleton University. Respondents included current and past employees of each R4D funder, as well as people who had been associated with the performance regime, whether from the side of government or the research community. These interviews helped to verify and supplement information from written documents and provided insights on part of the theoretical framework for which written documentation was found lacking, such as the relationship between staff and recipients.

The semi-structured interview technique used a series of open-ended questions to guide a discussion between the interviewer and respondent. This allowed the respondent to add as little or as much detail as they wished, and permitted the interviewer to ask follow-up questions to probe for additional detail or clarification as needed (Patton 2002). This technique also allowed respondents to use their own words to describe the phenomenon under study, tapping into how they viewed it rather than relying on how the interview framed it. Care was exercised to ensure the questions were impartial and did not lead the respondent, implying that certain responses were correct or wrong. The interview guide (see annex) was based on the theoretical framework, focusing on those indicators where written documents did not provide a definitive answer.

Respondents were selected purposefully in order to seek out diverse views and establish range of responses, and targeting individuals with direct experience with the events under 
study. Thus interviews were not pursued with indirect observers or people that just happened to have worked at a R4D funder, but were not involved with the matters of strategic planning or the funder's relationship with government. Starting from an initial list of individuals identified from written documents, a 'snowball' sampling technique was used to identify additional respondents, including those affiliated with key organizations in the performance regime. At the end of the interview, each respondent was asked to identify individuals that could provide additional insight into the questions discussed. Most interviews were conducted in-person through field visits to Ottawa, London, and Canberra during the spring and summer of 2012 (three interviews were conducted by phone or video-conference).

Respondents received a summary of the research proposal and interview guide in advance, and gave their informed consent prior to being interviewed. The nature of the information gathered was not expected to be controversial, given that the thesis inquired about historical experience rather than critiquing present practice. Any references to an individual used in the following chapters is either a matter of public record-easily verified by public documentation — or by a general descriptor that is not attributable to a particular person. When respondents consented to such, an audio recording was made of each interview, for partial transcription and coding. The audio file was kept on an external hard drive in a secure location, using a unique identifier as the file name rather than the individual's name. 
During the research and writing of this dissertation, the author was employed by IDRC, one of case study organizations. This fact introduces two points that warrant further discussion: identification before interview respondents, and the potential for bias in the analysis. Being an IDRC official presented the risk of respondents identifying me as a peer, or fellow 'insider', sharing sensitive information they might not otherwise reveal. This risk was mitigated in part by declaring my employment status up-front in the protocol provided to prospective respondents, and by ensuring IDRC would not have access to the interviews. The nature of the research, reviewing the past three decades, meant most respondents were at a relatively more advanced point in their careers, I was junior and thus had minimal influence on them. In many cases, the respondents had moved on to other employers, thus the interview concerned an earlier-now closed — part of their career.

With a decade of my own experience at IDRC, I invariably bring some 'insider' knowledge to that case study. To minimize the potential for bias, I purposefully conducted the UK and Australian case studies first, in order to refine my methods. This meant I tended to reflect more on the IDRC experience based what I had seen of the other two countries, rather than comparing them to what I had lived at IDRC. In carrying out the IDRC case study, I conducted a minimal number of interviews, choosing instead to rely substantially on previous histories prepared by Stockdale (1995) and Muirhead and Harpelle (2010). Indeed the existence of these histories permitted for a concise case study of the IDRC, where the absence of comparable histories for DFID and ACIAR necessitated greater primary research. Muirhead and Harpelle provided access to their 
transcripts of "for-the-record" interviews they had previously conducted. I assumed financial responsibility for my tuition and fieldwork expenses in country. In terms of airfare, I purchased my own travel to Australia, and extended a business trip to the UK at my own expense in order to conduct the fieldwork. In principle, IDRC offered up to a half-day per week of time as part of my professional development, but in practice the majority of time invested in preparing this thesis was on weekends, evenings, and annual leave.

\subsubsection{Analysis}

Applying the theoretical framework described above involved three stages of analysis. The first and simplest stage was to establish a timeline for each of the case study organizations, what happened when, in order to identify distinct time periods and the moments when the funder changed how it defined and funded R4D. This appears implicitly in the structure of the next three chapters (figures 5, 9, 13 and 16). The handling of time and the creation of periods is then an important task, requiring the interpretative skill of a historian rather than a mere gathering of data (Ferlie and Mark 2002). A simple spreadsheet was maintained for each case study, with a separate row for each year and columns for recording data on staffing and budget, the government-inpower, salient developments in the life of the organization, and key milestones in public research and foreign policy. This spreadsheet provided an initial overview of the organization's history that was otherwise difficult to see in the more detailed databases described below. 
The second stage of analysis was to map the performance regime surrounding each funder. The purpose was to identify the various expectations emanating from the social network of actors that influenced the R4D funder through flows of resources, authority, or information. While civil society organizations can offer informal information and advice, the formal government channels of budget approval and ministerial reporting were expected to be more influential. This analysis examined the processes used for strategic planning, expenditure management, and performance reporting. The thesis did not aspire to provide a full description of the machinery of government in each of the three countries, but rather to situate each R4D funder within the government's portfolio of public research and foreign policy.

The third level of analysis is a narrative of how the R4D funder adapted (or not) to changes over time: how and why the funder periodically changed its program theory and grantmaking practices in its support of R4D, and the extent to which this was in response to the performance regime. This part of the analysis examined the interplay between the external context within which funders operate, and internal processes that determined grantmaking practices. On the surface, this appears to be merely an exercise in correlation, yet written documents and interview respondents often cited factors that inspired the R4D funder to change when it did. In this respect, this is a piece of historical research, rebuilding an account of the past to provide insights on the research question (table 2). 
Reflecting the division between public and confidential information, two parallel databases were created building on the theoretical framework described in tables 3 and 4 . Each database contained two separate pages for each case study: one for the indicators related to "performance regime" describing the external context, and one for those related to "adaptive organization" focused on what happened inside the R4D funder (respecting the different unit of analysis between these two parts of the theoretical framework). Each of the six resulting spreadsheets used the indicators as columns, and recorded discrete quotes or data points under each. The databases thus served as a repository for content analysis, coding relevant information to particular indicator(s). The database for publiclyavailable information contained an additional two pages: one for the timeline described above, and another for recording the full bibliographic information of each source along with a short identifier used for tagging each entry back to its source. ${ }^{6}$ This "do-ityourself" approach meant that a standard spreadsheet application was sufficient for data gathering and analysis (including frequent use of chronological ordering and text search), eliminating the need for more specialized qualitative research software, such as Nvivo.

Confidential information gathered through interviews was treated somewhat differently. First, a second database was kept in a password-protected file on an external hard drive kept in a secure location. Access to this file was restricted to the researcher, as per the Carleton-approved ethics protocol. Second, the file did not provide direct attribution to respondents. Instead a unique code was created for each interview and data within the

\footnotetext{
${ }^{6}$ Each publicly-available source was given a unique code consisting of country, year of publication, and order in which it was consulted. Thus an entry tagged as AU-1996-035 pertained to Australia, was published in 1996 and was the thirty-fifth document consulted in that case study.
} 
spreadsheet was merely tagged with this identifier. A separate password-protected file contained the information relating these codes to the individuals involved and their contact information. Beyond these differences, the spreadsheet file for interviews continued to contain the six pages for "performance regime" and "adaptive organizations" covering the three case studies. Chapter six contains a cross-case analysis that compares and contrasts the experiences of the three funders.

\subsection{Conclusion}

This chapter introduced the theoretical framework employed in the following case studies drawing on the concepts of context and agency. The former is inspired by Talbot's "performance regime", or the multiple expectations shaping public organizations. The latter is inspired by program evaluation and argues that funders selectively adapt to context by renewing their program theory on R4D and the grantmaking practices used to support such. This framework encompasses a two-part unit of analysis, including both the national policy landscape for public research and foreign policy, and the particular R4D funding organization in each country. The chapter provided details on the separate indicators under which data was gathered for each part of the analysis. The thesis employs comparative case studies, a choice based on the nature of the research question and the limited number of organizations that specialize in R4D. The case studies draw on primary sources including written documents and semi-structured interviews. While the author worked at one of the case study organizations, measures were taken to ensure interviews were kept confidential and to minimize the potential for bias. 


\section{Chapter: United Kingdom}

Among the three case studies, the United Kingdom has the longest history of supporting research in the developing world. Early milestones include the founding of the Asiatic Society in 1784 and the Imperial Institute in 1887. Long before the modern era of foreign aid began after the World War II, support for research was a well-established part of colonial administration, fragmented among different government departments. The Overseas Development Administration (ODA) thus inherited a tradition of R4D funding, which it divided into different thematic divisions. In this century, the new Department for International Development (DFID) consolidated its R4D funding into a single unit within its policy division. Throughout these organizational changes, research had to compete for space and budget within an agency that was also responsible for bilateral, multilateral, and humanitarian assistance.

This chapter identifies four distinct periods when R4D was subjected to different expectations and adopted different goals. In the first period, the performance regime was characterized by self-governance of research funding, under which scientific communities allocated funding among peers. The program theory guiding R4D funding was focused on maintaining a base of UK science specialized in the problems of tropical climates. This inspired grantmaking around core support to highly qualified people and established centres within the UK research community, part of which resided within government laboratories. In the second period, starting in the 1970s, the performance regime encouraged a division between those who performed research and those who commissioned it. This period saw government exit service delivery, spinning-off its 
scientific units to the academic or private sector. The program theory guiding R4D funding was to purchase the knowledge and outcomes of interest to the aid agency. This gave rise to a quasi-market pattern of project funding under which researchers would bid for the opportunity to contribute to the aid agency's work programmes.

During the third period, beginning in the 2000s, the performance regime invested the aid agency with an increasing level of resources and a legislated mandate to contribute to global poverty reduction. The program theory that guided funding decisions saw research as a form of public good, placed at the service of furthering a global development agenda negotiated with other donors. The grantmaking practice that evolved saw an increase in support to recipients located outside the UK and a move to larger projects, networks or "consortia" of grantees. During the fourth period, the performance regime reemphasized ties with UK science, including notions of scientific excellence, rising scrutiny of foreign aid, and including downward pressure on operating costs. The program theory guiding funding decisions embraced the potential for technology to change the lives of poor women and men, as well as the potential for research to inform an evidence-based approach to policy. Corresponding, grantmaking expanded to include partnerships with the UK research councils, continued rise in average project size, and renewed consideration of how research informs the "value of money" of aid investments. 


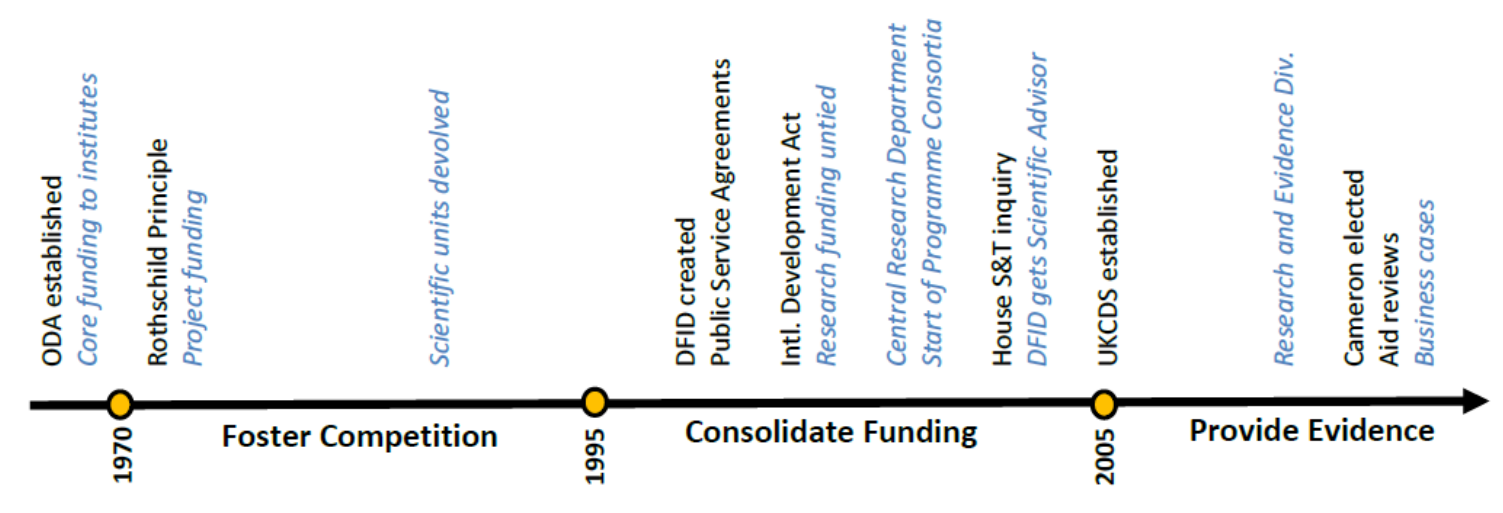

Figure 5: Timeline of UK case study

\subsection{Origins}

R4D emerged out of the political reality of the British Empire. UK science expanded in the 18th and 19th centuries as the industrial revolution reshaped the economy at home, and Britain coordinated a global network of colonies abroad. Researchers roamed around the empire to study local phenomenon different than what was found at home. Colonial administrators - driven by the goal of producing resources for trade — saw value in geology, land surveys, medicine, and agriculture to better understand and exploit the holdings they were responsible for. In short, research helped Britain understand and run the world, supported by an array of scientific institutions at home and abroad.

The Haldane reports in 1905 and 1918 mark a key point in UK science policy. As Secretary of State for War, and later Lord Chancellor, Richard Haldane chaired parliamentary committees that shaped the research funding landscape. The first report led to the creation of the University Grants Committee, providing block grants to institutions 
of higher education. The second report led to the UK research councils, providing scholarships and project funding for individual researchers. This second report $(\mathrm{Cd}$ 9230) ${ }^{7}$ established a distinction between funding allocated by scientists (to further the frontiers of knowledge) and funding allocated by government (for work that responded to the needs of each department). Haldane was thus responsible for introducing a distinction between basic and applied research, and providing different funding streams for each. In this way, Haldane hoped to address a lag in UK military technology revealed by in World War I. Inspired by the new science of aviation — which integrated both basic and applied science - he sought to prepare the country for future challenges. Over time, the first part of this idea was reinterpreted as a "Haldane principle" that the research community should collectively determine its own priorities and allocate public funding. To this day, the Haldane Principle is seen as a right to self-governance in the sciences, invoked to defend against the threat of government interference. This interpretation is not entirely accurate of Haldane's recommendations (Edgerton 2009). Indeed the future of R4D was influenced more by the second part of Haldane's idea which led to government departments obtaining a budget line for applied research.

Between 1919 and 1930, the Colonial Office funded "poorer Colonies and Protectorates in conducting the necessary researches". Overseen by a Colonial Research Committee, the primary focus was the study and exploitation of local minerals, agriculture, animal

\footnotetext{
7 In the UK, "command papers" include policies, government responses to committee reports, and other documents addressed to Parliament that are not mandated by legislation. The term originally reflected a work requested by "Command of the sovereign", but in practice usually originate with a government minister. The acronym 'Cd' was employed prior to 1956, 'Cmnd' during 1956-1986, and 'Cm' since 1986.
} 
health, forestry, and fisheries. The Colonial Development Act 1929 provided grants and loans for the promotion of scientific research, complementing the Rockefeller Foundation funding in the 1920s to expand the London School of Hygiene and Tropical Medicine. In 1938, Lord Hailey's “African Survey” called for investing in research, drawing on British institutions which were seen as having better-qualified personnel and "the conditions, facilities and atmosphere necessary for good research work" (Jefferies 1964). The Colonial Development and Welfare Act (1940) included a call for $£ 50$ million over ten years for development, and a separate amount of $£ 5$ million for research. By establishing this dedicated budget line, the Act recognized research as a distinct activity from building roads or infrastructure. This research fund was subsequently doubled to $£ 1$ million per year in 1946 with no time limits. Jefferies (1964) notes the Act embodied a conviction that research much be conceived on a long-term basis, noting:

The initiating of a project frequently involves a commitment for years ahead, and can only be undertaken if there is certainty that the necessary funds will be available and not subject to the hazards of a periodical re-submission to Parliament.

Hence the initial performance regime privileged natural science inquiry to optimize the use of natural resources abroad, drawing on the research community at home. Britain established local institutions abroad to provide knowledge needed to plan and exploit local resources, and cultivated world-class research centres at home knowledgeable about the places and problems in tropical climates. 


\subsection{Maintaining Science at Home}

After World War II, the performance regime sought the independence of former colonies and gained new faith in mission-oriented science. Britain and other war-weary economies had utilized their overseas colonies to draw in resources and benefit from world trade, yet the colonies were now more of a burden than a bounty. It was more cost-effective to let the colonies run their own affairs. ${ }^{8}$ At the same time, the war had injected optimism in the potential for public research. New technologies, such as radar, had emerged from government funding and concentrated effort, a model that would inspire research policy for decades.

As Britain negotiated the independence of its former colonies, scientific infrastructure abroad was akin to the children of couple filing for divorce. The product of an earlier era, the soon-to-be independent countries had an array of local scientific establishments, ranging from departments of agriculture and health, to universities and field stations. With the newfound faith in science, there were great expectations that these establishments would be a motor for development: informing local government with needed knowledge and providing local industries with useful technologies. Britain could not simply abandon this infrastructure, as it relied on outside funding and skilled personnel. Thus Britain initially accepted an ongoing responsibility for research abroad, until the local economy could take over.

\footnotetext{
${ }^{8}$ This argument had been made since Adam Smith's Wealth of Nations, but became particularly influential as the country struggled with the double burden of paying for the war effort and reconstruction.
} 
Between 1940 and 1960, Britain allocated $£ 24$ million to R4D at home and abroad. ${ }^{9}$ Funds were allocated through six different committees ${ }^{10}$ drawing in members from across multiple government departments. ${ }^{11}$ Together the committees formed a Colonial Research Council which provided financial support for local scientific institutions abroad. It also supported scientific units at home, including the Commonwealth Agricultural Bureaux, the London School of Hygiene and Tropical Medicine, and government labs, such as the Transport Research Laboratory. These units, specialized in the problems of tropical climates, were seen as a unique, 'world-class' service that was not available abroad.

The next decade saw a number of organizational changes. The council replaced the word "colonial" in its name, to become the Overseas Research Council. Its updated mandate was "to advise on... policy in respect of scientific research undertaken in or for overseas territories ... of methods of making the results of research available in these territories; and of assistance to the scientific services of those territories" (Jefferies 1964). The council initially provided budget support for the operating costs of local institutes abroad, as well as travel grants that enabled visits by expatriate specialists to work and train abroad. The former loose, cross-government structure was replaced with a formal

\footnotetext{
${ }^{9}$ One-third of this amount was dedicated to agriculture, veterinary medicine, and forestry. A further quarter was dedicated to medical research and tropical diseases, such as tsetse and trypanosomiasis. The remainder was divided three ways among pesticides, fisheries, and social and economic research (Jefferies 1964).

${ }^{10}$ One for each of: colonial products, social science, medicine, economics, insecticides, and agricultureforestry-animal health.

11 In the early 1940s, the Hansard records debate about whether the appointment of key individuals to these committees would detract from their work on the war effort.
} 
Department of Technical Cooperation, bringing together expertise on colonial development and incorporating a number of previously independent research centres. ${ }^{12}$ In 1964, this department became the Ministry of Overseas Development, recognizable as Britain's foreign aid agency.

In summary, during this first period, the performance regime was characterized by selfgovernance of research funding, under which scientific communities allocated funding among peers. The program theory guiding R4D funding was focused on maintaining a base of UK science specialized in the problems of tropical climates. This inspired grantmaking around core support to highly qualified people and established centres within the UK research community, part of which resided within government laboratories.

\subsection{Fostering Competition}

In the 1970s, the performance regime for funding public research began to shift towards fostering competition among researchers. Edward Heath's conservative government (1970-74) created a Central Policy Review team in the Cabinet Office as an internal think tank to aid government problem solving (Duffy 1986). Lord Victor Rothschild was appointed to lead this team and introduced the largest shift in UK research policy since

\footnotetext{
${ }^{12}$ These included the Anti-Locust Research Centre, the Tropical Products Institute (formerly part of the Imperial Institute), and Land Resources Development Centre (formerly part of the Directorate of Colonial Surveys).
} 
Haldane. Rothschild's framework called for customer-contractor relationships between those that funded and performed research. Under his vision:

Departments, as customers, define their requirements; contractors advise on the feasibility of meeting them and undertake the work; and the arrangements between them must be such as to ensure that the objectives remain attainable within reasonable cost (Cmnd 5046, 1972)

Rothschild's principle of customer-contractor relations became the new cornerstone of UK research policy. Government was now seen as a purchaser of knowledge services within a marketplace, in which there were assumed to be a large number of potential service providers. Government was no longer expected to be a mere patron of research, but an "intelligent consumer" of it: able to absorb available knowledge and independently determine the need for new research. Yet the Rothschild principle faced three issues during implementation. First, the research 'market' for specialized fields—such as trypanosomiasis and locust control — was oligopolist, with a small number of wellconnected researchers at one or two institutes. Second, few departments had the technical expertise required to review and synthesize existing knowledge, much less design a call for proposals and conduct merit review. Third, departments faced the dilemma of what to do with the scientists on staff and research centres dependent on government funding.

The first two issues were addressed by establishing teams of advisors within each department on the scientific aspects of government policy. These advisors were to act as honest brokers, taking in ideas from the outside, to define competitive bids based on departmental objectives. Advisors consulted the research community on the feasibility of 
meeting particular requirements, yet excluded that community from government's priority setting and funding decisions. The third issue provide more difficult. Departments faced a practical reality of needing to provide for the short-term survival of their scientific units while reducing their medium-term reliance on government funding. In practice, calls for proposals need to provide some support to preferred providers. Such was the challenge that $\mathrm{R} 4 \mathrm{D}$ would soon face.

Yet foreign aid was initially protected as government looked first at defense and health. After merging into Foreign and Commonwealth Office, Britain's foreign aid agency was renamed the Overseas Development Administration (ODA). ${ }^{13}$ The Administration housed a number of scientific units and provided core funding for many more. It even began to prepare an annual report on its research activities noting that "British scientists have a long history of achievement in helping to tackle the problems of the tropical and semitropical areas", and describing R4D as "adaptation of existing technologies to the circumstances of countries which are tropical and under-developed" (ODM 1974). R4D funding grew fourfold over the decade, from under $£ 4$ million to almost $£ 14$ million per year. The bulk of this funding was dedicated to grants for research projects carried out on a contract basis by individual researchers or teams ${ }^{14}$ and the recurrent costs of centres in Britain which gave scientific and technical help to the developing countries. ${ }^{15}$ ODA also

\footnotetext{
${ }^{13}$ The aid program would briefly become an independent ministry again between 1974 and 1979, before being once again folded into FCO.

${ }^{14}$ Similar to the Colonial Office, research continued to have its own budget line within the Overseas Aid Vote, known as subhead D5 (UK 1974, 1987).

15 ODA's scientific units were the Tropical Products Initiative, the Centre for Overseas Pest Research, the Building Research Station, the Hydraulics Research Station, and the overseas units of the Ordnance Survey
} 
provided support for international research cooperation ${ }^{16}$ and research in developing countries. ODA initially provided core funding to maintain research institutes abroad, yet soon switched to project funding "to solve specific problems... outside the financial or technical capacity of local programmes" (ODA 1980). Local governments were expected to assume responsibility for the ongoing operating costs.

By the mid-70s, ODA acknowledged the Rothschild principle, but implemented it halfheartedly. ODA argued that it “....interprets to its research 'contractors' the needs of its overseas 'customers' and commissions work on their behalf" (ODM 1975). In other words, ODA saw itself as a proxy customer, representing the demands of developing countries, which were limited in their ability to fund research or influence the UK research community. Project ideas were assessed according to "scientific soundness..., the degree to which they met the Ministry's criteria, and their claims for financial support" (ODM 1975). ODA began to emphasize the potential for research to inform practice abroad: "the results should filter down to those who really need to know-the farmer in the field, the workers at the bench and the doctors and nurses in the bush" (ODM 1977).

\footnotetext{
and the Transport and Road Research Lab. Other institutes outside of government included the Institute of Geological Studies, the Intermediate Technology Development Group (ITDG), the Centre for Tropical Veterinary Medicine in Edinburgh, the Tsetse Research Lab in Bristol, the London School of Hygiene and Tropical Medicine, the Institute of Development Studies in Sussex, and Queen Elizabeth House at Oxford University (ODM 1977, 1978, ODA 1979)

${ }^{16}$ Including the Collaborative Group on International Agricultural Research (CGIAR) and the World Health Organization's Tropical Diseases Research program (WHO-TDR)
} 
Yet the presence of a Labour-majority government (1974-79) temporarily reduced the pressure to implement Rothschild. ODA continued to deal incrementally with the array of funding relations it had inherited at home and abroad, with a large number of scientists relying on ODA directly as government employees or indirectly through research grants.

\subsubsection{Neoliberal values ascendant}

The United Kingdom then entered a period of reforms under Margaret Thatcher's Conservative government (1979-87) which revived the Rothschild principle. The House of Commons (1983) noted that "scientific research. . . should be subject to 'customercontractor' relationships, whereby work is commissioned by a paying customer". The result was a "marketization of research" with changes in the form of public ownership, its organization, and governance (Boden et al. 2004). In the words of one respondent, "there was a sword of Damocles hanging over social sciences in Britain” (UK-17). Thatcher's government felt public research had a "provider mentality" pursuing its own curiosity, oblivious to whether or not it had any public impact. Government expected every public institution to be aware of its costs and able to demonstrate public benefit. ${ }^{17}$ As the reforms curtailed research performed with government, a greater portion of public research was performed within universities.

\footnotetext{
${ }^{17}$ For example, the Social Science Research Council was converted into the Economic and Social Research Council (ESRC) in 1983, following recommendations by Rothschild (again) for a stronger focus on empirical research and on research considered of "public concern" (rather than researcher curiosity).
} 
The Conservative government soon called for scrutiny reports on ODA's scientific units. In 1980, the R4D budget exceeded $£ 15$ million per year and the in-house scientific units employed more than one thousand scientists and support staff. As a result of the reports, the Directorate of Overseas Surveys - which provided mapping services to developing countries - lost two-thirds of its staff and began to commission aerial surveys from private companies rather than conducting them in-house. Similarly, two of ODA's units were merged to form the Tropical Development and Research Institute. The House of Commons complained that "though purporting to deal with efficiency, [the reports] largely ignored benefits and were concerned almost exclusively with costs... the 'Rothschild principle' is of only limited applicability to the kind of work [these units] do" (House of Commons 1983). Yet the complaint fell on deaf ears. Indeed a subsequent wave of reforms starting in 1988 would see government move a number of functions out of the bureaucracy into quasi-independent 'executive agencies' to be run as corporations. This Next Steps initiative essentially split the role of providing advice and implementing policy, establishing market-inspired arrangements between ministries and these executive agencies.

ODA needed to demonstrate that it was serious about the government's concerns, including the usefulness of outputs and a commitment to efficiency. It adopted an "emphasis is on research likely to be of practical use in a reasonable period of time, and... of direct relevance to the poorer sectors of poorer countries" (ODA 1988). More significantly, ODA began to divest itself of its scientific units, particularly those related to agriculture and the natural environment. To ease the transition, ODA needed a find a 
way of supporting its former scientific units while also presenting the image of consumer-contractor relations with the research community. In the words of one respondent:

we had to develop a funding model for a lot of institutions that were either in the process of going into new ownership or [going] away [entirely]. The prerequisite... was that there should be enough money... to make it a viable agency... the size of investment was determined by how much do these institutions required to survive... therefore how do we rationalize it? (UK-08)

The response was five thematic work programmes ${ }^{18}$ which laid out priorities towards which research grants were supposed to contribute. In the words of one respondent, these programmes were "based on a logframe: we would define purpose and goals, and we would then contract out; the competing bodies would come back with objectives, activities and resources" (UK-08). The largest was the Renewable Natural Resources Research Strategy — affectionately known as the "yellow brick"19 — which lasted for fifteen years. In short, where ODA had previously been a fairly responsive funder, allowing recipients to pursue their own goals, it became more proactive, expecting recipients to contribute to a program of its own design. In essence, ODA altered its relationship with the research community. Having already shifted from core to project funding abroad, it now similarly revised its offer to research community at home, requiring them to fit their interests within a larger thematic strategy. Reflecting this shift, ODA stopped describing its research portfolio as "support to British scientific

\footnotetext{
${ }^{18}$ Renewable natural resources; engineering (water, energy, transport); health and population; economic and social research; and education

${ }^{19}$ Due to the colour of its cover page and for being a three-centimetre thick stack of paper.
} 
establishments" in favour of " $R \& D$ programmes... managed and carried out by centres in the UK" (ODA 1992). The model of R4D funding moved to a combination of competitively awarded projects and progressive independence of organizations reliant on ODA.

\subsubsection{The End of an era}

Reforms to UK research policy accelerated further under John Major's Conservative government (1987-97). The "Realising Our Potential" White Paper called for public research money to be directed towards contributing to wealth creation and quality of life. This imperative was even applied to the UK research councils, requiring them to reformulate their missions towards these goals and towards responding to "users" including "industrial or service sectors, private and public, as well as central and local Government" (Cm 2250, 1993). Two of the research councils were merged to create the Biotechnology and Biological Sciences Research Council (BBSRC) and the Economic and Social Research Council (ESRC) began to relate part its budget to national priorities in order to satisfy its political masters and retain some freedom to hold more open grant competitions (UK-17). With respect to ministries, "Realising Our Potential" reaffirmed and strengthened the customer-contractor principle. Departments were to be intelligent

customers: determining their own needs and commissioning the work from suppliers who competed to meet the government's specifications. Departments were "expected to mount competitive tenders wherever practicable, and to seek value for money" in order to achieve "the utility and quality of research needed" (Cm2250, 1993). 
The dual impact of the Next Steps Initiative and "Realising Our Potential" was keenly felt within ODA's natural resources programme. In the early 1980s, a rich array of scientific units within and outside ODA could trace their legacy back to the colonial period. By 1990, many of them were consolidated under the Natural Resources Institute (NRI), an executive agency. NRI was expected to survive selling its research and consultancy services, chiefly to Britain's overseas aid, but also to the World Bank and the European Commission. NRI was required to charge prices that reflected the full cost of its services, rather than relying on ODA for indirect costs. In the words of Anthony Beattie (1994), the director of NRI:

What is new in recent years is the involvement of ODA headquarters in setting the agenda and commissioning programmes of work - or projects - under quasicontractual arrangements. We have moved... the service provider's discretion has been considerably curtailed — on the argument that client involvement will enhance effectiveness and efficiency.

The agricultural research community initially believed that "what it does will not fit easily or satisfactorily into the world of contractual relations and markets", and that sooner or later the pressure would go away "leaving researchers to go back to a golden age" (Beattie 1994). Yet the government continued to see the market for research services as intrinsically similar to the market for other professional services. Six years after becoming an executive agency, the remnants of NRI were transferred to the University of Greenwich. While the Institute continues to exist today, it is a ghost of its former self, 
with just one-tenth the number of staff it had in the $1980 \mathrm{~s}^{20}$ and little sign of its lineage back to the Imperial Institute.

The health research community fared somewhat better. The London and Liverpool Schools of Tropical Medicine were less vulnerable given their connection to higher education. Their employees were not civil servants and their back office services relied on university administration. ODA entered into a 'concordats', or partnerships, with the Medical Research Council, which became an intermediary between ODA and the health research at home.

ODA began to encourage its recipients to take on a role in championing the adoption of their findings. ODA believed that "effective dissemination of research outputs is essential if research is to have any impact... In the past... dissemination to policymakers and practitioners has often been less effective" (ODA 1993). The focus on outcomes within work programmes meant the "good" research practice saw researchers engaged in the field, as advisors or agents promoting particular policies or techniques, rather than the disinterested third parties largely outside of development practice. This also meant working through additional intermediaries, such as non-governmental organization, like Oxfam or ActionAid. The distinction between a R4D project and a development project was blurred as both were expected to achieve real-life change abroad. Looking back at

\footnotetext{
${ }^{20}$ In 1993, the Natural Resources Institute had 550 employees. Shortly after merging with the University of Greenwich, this number would be halved reaching 250 in 1999. In 2012, the Institute would have 60 employees and win all its income competitively from a combination of DFID, the European Union, World Bank, United Nations, charities, and the UK Research Councils.
} 
UK research in development studies since 1980, Meier (1994) lamented that basic research was being crowded out, as funding directed the research efforts towards shorterterm projects and the "quicker payoff" in which "standards of technical rigour have, at times, been ignored... less concerned with high theory, relatively weak in quantitative and econometric techniques of analysis." Changes in the UK approach to research funding were beginning to alter what counted as R4D.

In summary, during this second period, the performance regime encouraged a division between those who performed research and those who commissioned it. This period saw government exit service delivery, spinning-off its scientific units to the academic or private sector. The program theory guiding R4D funding was to purchase the knowledge and outcomes of interest to the aid agency. This gave rise to a quasi-market pattern of project funding under which researchers would bid for the opportunity to contribute to the aid agency's work programmes.

Under the old era, ODA provided core funding to maintain world-class science at home (some of which was inside government) and contribute to capacity abroad. Yet the waves of reform under Conservative governments shifted ODA towards project funding based on consumer-contractor relations. Work programmes embraced government-defined objectives, in which ODA considered itself as a proxy client, purchasing services on behalf of developing countries. The roles of research funder and performer were divided, with ODA retaining the former and divesting itself of the latter. The work programmes 
also included a covert lifeline to some of ODA's scientific units, to ease their transition into a new reality in which they needed to sell their services to survive. Many of them experienced mergers and privatization, and some simply ceased to exist. Meanwhile ODA needed to show that its research funding was applied and practical, and consequently began to press its recipients to play a role in getting "research into use".

\subsection{Research as a Public Good}

After seventeen years of Conservative rule under Thatcher and Major, anyone hoping for a return to the blind government patronage of the sciences would be disappointed. Market relations had been introduced to govern publicly-funded research. Blair's Labour government (1997-2005) would not turn back the clock, but instead saw further changes affecting R4D. The first was to create the Department for International Development (DFID), separate from the foreign office and represented by a senior-level minister in Cabinet. The second was to introduce new performance management tools and an "evidence-based" approach to policy. The third was to critique DFID use of science, prompting the department to give research funding more prominence within its hierarchy. This section describes each of these changes in more detail.

Since 1979, the foreign aid program had been part of the Foreign and Commonwealth Office. Despite a brief period of independence under the Callaghan government (197679), the aid program had been subservient to foreign policy and commercial relations throughout much of its history. Yet the new Labour quickly redefined the purpose of 
foreign aid as "the elimination of poverty and encouragement of economic growth which benefits the poor" (Cm 3789, 1997). The UK was an early advocate for, and adopter of, the Millennium Development Goals (MDGs), and entrenched its new aid policy into legislation. The International Development Act 2002 required that the Secretary of State be satisfied that development assistance was likely to contribute to a reduction in poverty. Such assistance was to further sustainable development in poorer countries or improve the welfare of their people. The Act also formally untied aid, removing any requirement to prefer UK companies or providers in the delivery of development programming. DFID was also given remit to examine all government policy affecting developing countries, including migration, defense, and trade. Thus the aid program went from being a standalone portfolio to being a key ministry with a sweeping role across government. With its new mandate, DFID was connected to a network of actors across Whitehall, including the Department of Trade and Industry, Department for Environment, Food and Agriculture (DEFRA), Office of Science and Technology, UK Research Councils, British Council, and the Chief Scientific Advisers.

DFID saw research as knowledge management: a means to "know what will work and what will not work" and a source of solutions that could be replicated elsewhere. The 1997 White Paper cited various examples of research impact, including: conditions necessary for microcredit, effectiveness in treating HIV, deploying low-cost water treatment, nutrient analysis of crops, controlling pests in rice and aquaculture, new design for wood stoves ( $\mathrm{Cm} 3789)$. The elimination of poverty and protection of the environment was seen to require improved access to knowledge and technologies by poor 
people. DFID would also adapt existing knowledge to the particular circumstances of developing countries and, where necessary, invest in developing new technology. Finally research was also expected to "find local solutions to local problems" by better understanding of social, economic, political and physical environments (Cm 3789, 1997). Yet DFID senior management also feared research funding had been captured by the research community at home. One respondent recounts that Secretary of State Clare Short "was fed up with meeting little old men in white coats who thanked her for forty years of research on the hind leg of a mosquito" (UK-03).

Research became prominent within DFID: R4D was no longer the poorer cousin to bilateral aid. The bar was raised again with the release of a second White Paper focused on the impacts of globalization. It identified "research that benefits the poor" as a global public good which was underfunded. Most research and development capacity was located in developed countries and oriented to their needs. This is most clearly illustrated in drug development, where the problems of rich consumers - such as male impotenceattracts substantial investment while the problems of poor consumers - such as tropical diseases - are largely ignored or 'neglected'. To address this market failure, the Blair government committed to "help focus more of the UK and global research effort on the needs of the poor" and "strengthen the capability of developing countries to produce, adapt and use knowledge, whether produced locally or internationally" (Cm 5000, 2000). The International Development Act 2002 untied aid, include research funding, allowing DFID to go anywhere to obtain the knowledge it needed, without preference for UK researchers. Development assistance was expected to be untied, country-owned, and 
demand-led: characteristics that encouraged greater participation of developing countries and continued attention to the "uptake" of research into policy and practice.

R4D had been given a new mandate and heightened expectations. In the words of one respondent, "DFID decided it would service the international development agenda... It drove the agenda around development objectives rather than making the best use of existing capacity" at home (UK-02). Staff began reimagining DFID's approach to research funding, inspired in part by the Blair's government introduction of new tools for performance management and "evidence-based" policy. A cornerstone of this approach was the "Modernising Government" White Paper.

Where the Conservatives had sought to emulate a market, Labour sought the "use of evidence and research so that we understand better the problems we are trying to address... [and] pilot schemes to encourage innovations and test whether they work" (Cm $4310,1999)$.

UK policymaking experienced a positivist shift, with greater expectations that research would lead to improved social policy, particularly in health, education, and policing (Sparrow 2011). To simplify somewhat, the previous test for government policy and programs had been: was it affordable and did government consider it the right thing to do. Under an evidence-based approach, this test became: what is known about the problem, how was the proposed solution supposed to work, and how would government know if indeed it worked. Assumptions that were previously accepted as common sense were 
now open to questioning. The importance placed on the experience of public servants diminished, as the evidence-based approach demanded support in the form of baseline studies, empirical data, and evaluation.

In short, it created a new demand for public research.

\subsubsection{A contract with the Treasury}

Blair's government also vowed to continuously improve value for money in service delivery. Echoing the language used by Rothschild, the "Modernising Government" White Paper cautioned that "public services can be organized too much around the structure of the providers rather than the users" ( $\mathrm{Cm} 4310,1999)$. To address the perceived bias, Blair's government brought in new tools for performance management. First were Public Service Agreements (PSA), or four-year contracts between the Treasury and line departments defining the service that the government 'purchased' through the budget process. Second there were subsequent Comprehensive Spending Reviews through which Treasury assessed the extent to which line departments delivered on their contracts, in order to set a new agreement and budget for the following four years. Thus spending reviews provided a periodic opportunity to refine the performance framework against which the line department would report against. Where the Conservative government had introduced contractual relations between a line department and its executive agencies, the Labour government extended this practice to the relations between Treasury and line departments. 
DFID quickly adopted the Millennium Development Goals (MDGs) as the basis for its Public Service Agreement, committing to reducing poverty and improving health in developing countries. This was a courageous move for two reasons. Firstly, there was a mismatch in timetables. While the MDG timetable aimed for results by 2015 , the Treasury used annual and four-year cycles for budgeting and performance reporting. Secondly, the department could not guarantee these outcomes, but merely contribute towards them as a member of the international community. Yet the PSA gave the illusion of certainty, implying that government was purchasing a particular outcome, such as longer life expectancy in Tanzania. The subsequent spending reviews inevitably revealed a "failure" to achieve some of these targets, as they were disconnected from what the department could actually control. The National Audit Office cautioned that DFID staff "may not know exactly what impact their efforts are having given the wide range of other agencies and external political, economic and social factors involved" (UK 2002). The Comprehensive Spending Reviews also allowed the Treasury to introduce crossgovernment directives to control operating costs: DFID soon faced the triple challenge of managing a growing aid budget, while decreasing its staff and internal costs, and decentralizing to offices outside of London. ${ }^{21}$

With respect to research funding, the Labour government built upon Rothschild's idea of the intelligent consumer. The UK Comptroller and Auditor General asserted that all government departments were expected "to be clear about their strategic research aims

\footnotetext{
${ }^{21}$ An increasing portion of DFID staff and operation were relocated to East Kilbride in Scotland.
} 
and establish coherent systems for procuring research — including its commissioning, quality assurance, and use" (UK 2003). In particular, the comptroller argued that those responsible for research had to ensure its quality and relevance, and that findings were used to improve service delivery and to inform policy. Furthermore, departments were expected to have a clear understanding of future demand and supply of researchpertinent questions and the capability of potential providers - and to consult research users to identify and prioritize their requirements. Meanwhile in academia, the UK Research Assessment Exercise began to encouraging researchers to move on rapidly to new research projects, effectively discouraging longer-term dissemination of their work (Surr et al. 2002).

\subsubsection{Towards a Central Research Department}

DFID began to examine its approach in light of these new expectations. A Knowledge Policy Unit was established in 1998 to learn from the research being funded, yet the dayto-day management remained dispersed across the policy division, including separate teams for economic and social research, health and population, education, engineering, renewable natural resources, and social development. Each of these teams had evolved their own "strategy, with distinct procedures... including separate guidance to applicants, reporting procedures... how to set research priorities... how to disseminate research findings; how to assess impact, and so on" (Surr et al. 2002). An evaluation of R4D found that when a project failed it was due to: inadequate depth and rigour in proposals, insufficient attention to connecting with potential users, and lack of effort spent in collaboration and capacity (DFID 2000a). 
A Science Innovation Strategy was adopted which mostly described the status quo, rather than laying out a vision for the future. It noted that funding was mostly allocated through competitions targeted to meet specific policy needs, yet at times DFID responded to researcher interest through peer review involving internal and external assessors (DFID 2000b). The annual research budget reached $£ 147$ million in 2001-02, equivalent to over $4 \%$ of the UK budget for official development assistance. At the time, the largest beneficiaries were universities (accounting for 70\% of all recipients), followed by notfor-profits (20\%) and others (3\%), including foreign governments (Surr et al. 2002). While DFID expressed a desire to increase private-sector involvement, for-profits represented just $3 \%$ of its recipients. ${ }^{22}$

DFID decided to improve its research management skills, understood as its ability to define a research policy and strategy, identify projects, monitor budgets, and assess research impact (Surr et al 2002). R4D was defined as (1) correcting for market failure by providing incentives or otherwise stimulating demand for research that addresses problems of the poor; (2) providing evidence on the effectiveness and efficiency of donor and host government interventions; and (3) empowering poor countries to decide their own path; and modernization via knowledge to boost productivity (Surr et al 2002). To rationalize internal costs, DFID also wanted to fund fewer, larger value projectsinvolving networks of organizations - and partner with other research funders, such as

\footnotetext{
${ }^{22}$ It is interesting to compare these portions to figure 7, which demonstrates that a significant shift occurred towards for-profits, multilateral or international initiatives, and the UK research councils.
} 
the UK Research Councils and the European Union. DFID decided to consolidate its existing research programmes into a single research group:

...headed by a senior civil servant who would be responsible for the overall strategic management of research and for representing DFID in Whitehall and the EU and other international fora... Bids for priorities and resources of research programmes would... focus on outcomes and themes consistent with DFID's objectives, rather than on sectors. Advisors would be both in research teams and within policy themes (as well as linked with country programmes via their advisory networks). This should keep research informed by DFID's priorities and vice versa, and improve the relevance of research and its effective dissemination and promotion (Surr et al. 2002).

The Central Research Department (CRD) was established in 2003 within the policy division. It began with just seven full-time employees led by Paul Spray who, despite a rich career within the foreign aid program, identified himself more as a development generalist than a research specialist. The MDGs also imparted new ideas on aid effectiveness: development assistance was expected to be untied, country-owned, and demand-led. These characteristics encouraged DFID to place increased emphasis on the participation of developing countries in its research funding, and continued attention to the "uptake" of research into policy and practice.

\subsubsection{Science strikes back}

DFID's use of science soon became the subject of an inquiry under the House committee on science and technology. Parliament, encouraged by the government's Chief Scientific Advisor, was concerned that DFID was disconnected from the government departments responsible for science, under-resourced to fully participate in research partnerships, and in dire need to scientific staff (Sivadasan et al. 2003). 
At one level, the inquiry was concerned about DFID's ability to act as an intelligent customer. In the words of one respondent: "there was really no apparatus for assimilating, dealing with, and disseminating results of the research that was done" (UK-12). This situation had been aggravated by the move towards fewer, larger projects. DFID had begun to fund Research Programme Consortia, or networks comprised of four-to-six institutions, some of which were located in developing countries. This type of grantmaking moved more funds in each project, but also shifted research management partially to the recipients. DFID would interact more with the lead managers within each consortium, who in turn coordinated the researchers involved. Staff had limited interaction with individual researchers, which was feared to erode DFID's ability to use the results of the research it funded (House of Commons 2004). In the words of one respondent, the relationship with research community had, "moved gradually from working-on-top-of-you, to working-with-you, and then let's-give-you-money to do research" (UK-12).

At another level, the inquiry sought to reverse a perceived move away from supporting researchers at home in the UK. The inquiry report introduced the term "development sciences" to refer to "the full spectrum of social and natural sciences, engineering and technology undertaken with the purpose of informing, supporting or promoting international development" (House of Commons 2004). Development sciences were seen as distinct from "development studies." Witnesses argued that the UK had strong experience in agricultural, biotechnology and medical research. David King, the 
government's Chief Scientific Advisor, cautioned that "DFID's untying of research may well compromise the sustainability of the UK research base operating in areas of particular relevance to the developing world". In its report, the select committee argued that the "erosion of the UK research base in development sciences is now endangering the future ability of the UK to sustain this leadership role" (House of Commons 2004). Discontent over previous shifts in R4D grantmaking, a strong lobby emerged to argue for the participation of the domestic research community within foreign aid, arguing that science:

make[s] an invaluable contribution to development by, reducing disease burdens and food insecurity; facilitating communications; enabling monitoring of global and national environments to minimise conflicts and give warning of natural disasters, and developing new ways of using water, energy and other natural resources... [and] engender a culture of inquiry, openness and respect for evidence (House of Commons 2004, 9)

Although the bulk of the inquiry focused on research management within DFID, it also made other recommendations. First was to give greater prominence to capacity building. The inquiry report argues that "the UK has an obligation to support capacity building in science and technology for development" in developing countries, including human resources, physical infrastructure, and stronger research and education systems. Second was to appoint a Chief Scientific Adviser, following a 2002 recommendation in the government's "Investing in Innovation" strategy called for such a position in all departments that used or commissioned significant amounts of research. 


\subsubsection{New directions}

DFID responded with an increase in research funding. The aid budget was growing rapidly, particularly in the run up to the UK hosting the 2005 G8 meeting in Gleneagles with its focus on aid to Africa. The country's official development assistance had reached $£ 4.1$ billion by $2004-05$, and was projected to reach $£ 6.5$ billion within three years. The House committee argued that there should be a "commensurate increase in the availability of funding for development sciences R\&D in the UK, in order to strengthen the evidence base available for international development policy-making, and to safeguard the UK's ability to maintain a leadership role in the field" (House of Commons 2004, 82).

As for a Chief Scientific Advisor, the title was initially added to job description of the director of the Central Research Department. Now wearing these two hats, Paul Spray prepared the Research Funding Framework 2005-07. By the end of this period, DFID expected to dedicate at least $£ 100$ million per year to research, and the framework described how to direct this new spending. Two-thirds was dedicated to four priority themes: sustainable agriculture, "killer diseases" (HIV, malaria and tuberculosis), state fragility and governance, and climate change. These themes mapped closely to the various interests within DFID and were intended to ensure that everyone-DFID management and the UK research community alike - felt they had a stake them. The remaining one-third of funding was spread across other MDG-related research, as well as 
smaller policy-oriented projects ( $£ 100,000$ to $£ 300,000$ each) which provided a window for responding to ideas proposed by the research community (DFID 2004).

Research began to enjoy a rising profile within DFID. Despite the minor portion of DFID spending invested, research projects contributed many of the examples highlighted in the department's annual report to Parliament. This was in part because research projects were more directly tied to results, compared to budget support in partner countries. Meanwhile Secretary of State Hilary Benn was keen that DFID research be seen as credible in the eyes of the UK research community, not least owing to the fact that his brother was an active member in the Royal Society of Chemistry. By 2006, the CRD staff grew to thirty people, divided between Program Managers responsible for administrative and financial aspects of funded project, and Research Advisors responsible for program development, monitoring, and evaluation. They would prepare concise descriptions of an underresearched area that served as the basis for competitive tenders. Projects were selected using a two-stage process with an internal review for identifying promising concept notes, followed by external peer review of the subsequent, more detailed proposals.

In summary, during this third period, the performance regime invested the aid agency with an increasing level of resources and a legislated mandate to contribute to global poverty reduction. The program theory guiding funding decisions saw research as a form of public good, placed at the service of furthering a global development agenda negotiated with other donors. The grantmaking practice that evolved saw an increase in 
support to recipients located outside the UK and a move to larger projects, networks or "consortia" of grantees.

The Labour government adopted the rhetoric of an evidence-based approach to policy, heightening expectations that research would demonstrate and enhance government performance. DFID saw research as a global public good, part of the UK contribution towards the Millennium Development Goals. Yet subsequent spending reviews required the department control its operating costs: to manage a growing budget with fewer staff. Research funding switched from individual projects with single recipients, towards much larger-value research consortia involving multiple recipients. Consequently much of the responsibility for shaping a research programme was effectively transferred to recipients. This move attracted new criticism regarding DFID's use of science. Whereas ODA research advisors previously fostered competition among potential providersestablishing market-inspired relationships between government and researchers-DFID was now expected to have a coherent approach to its research funding that contributed to development, informed DFID practice, and engaged actors in UK research policy. 


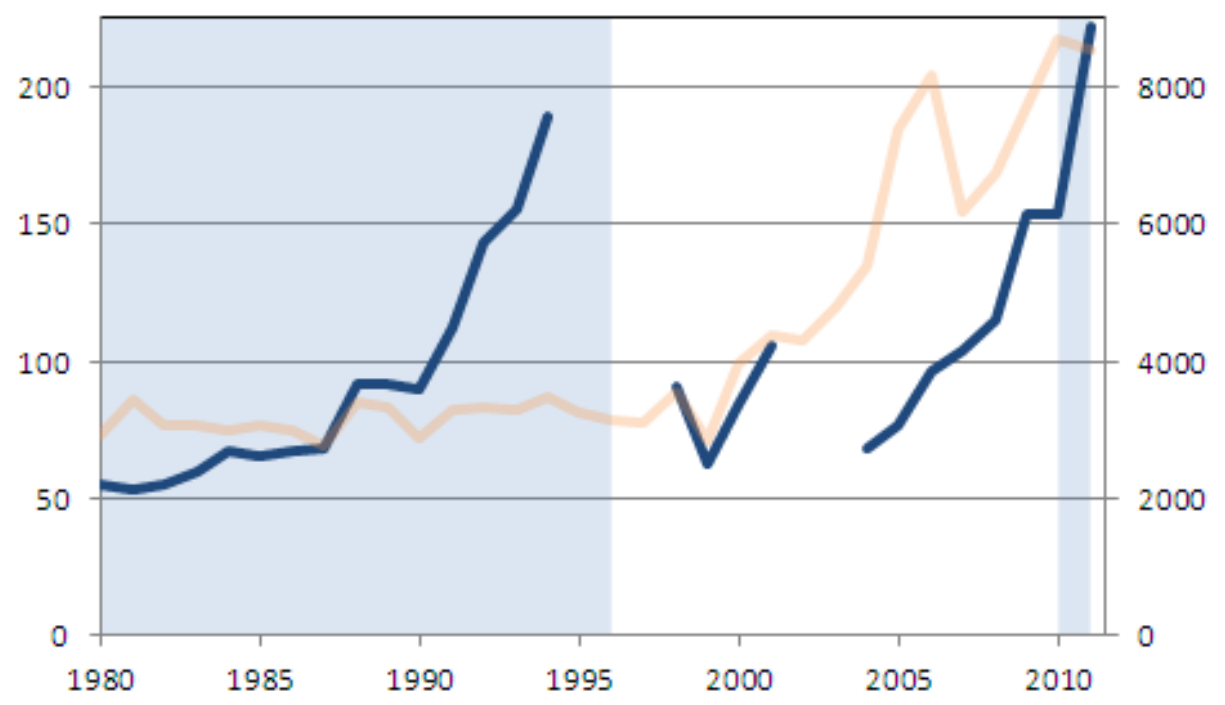

Figure 6: United Kingdom's R4D spending since 1980. ODA/DFID grants to research in dark (left axis) compared to UK's official development assistance (right axis). All amounts are expressed as million GBP adjusted to 2011. Gaps represent times when research spending was not reported separately. The shaded years represent time when Conservative party was in power. (Sources: ODA Report on Research, DFID Annual Reports and OECD statistics)

\subsection{The Promise of Technology and Evidence}

The year 2005 marked a peak in public support for development. The UK chose to focus the G8 summit on development in Africa. Many donor countries were increasing their aid budgets, and civil society campaigned to "make poverty history." The world was seen to have the resources, and now the political will, to eliminate absolute poverty and achieve the MDG agenda. This optimism cascaded over into DFID, which had established itself as the cutting-edge of the public service. It drew young, career-minded professionals away from traditionally more popular departments, including Treasury and the Foreign Office. R4D enjoyed pride of place within the department, responsible for a portion of the growing aid budget. 
R4D was entering a new period. DFID recruited its first full-time Chief Scientific Advisor: Gordon Conway, former President of the Rockefeller Foundation and a fellow of the Royal Society who had pioneered the science of integrated pest management. Responding to the House committee inquiry, his tenure saw DFID take a greater interest in so-called platform technologies ${ }^{23}$ and expand its partnerships with the UK research councils. These steps re-established ties with the natural sciences in the UK, embracing the promise of technology to make create new opportunities for poor people abroad. Yet DFID also expected research to inform the department to become more effective and efficient in its bilateral, multilateral and humanitarian aid. Government continued to press departments to control their operating costs, limiting the amount of time staff could invest in research management and monitoring.

Towards the end of the decade, DFID's program theory for research would shift away from an approach framed by development studies, and towards a way of thinking based more on clinical medicine. David Cameron's Conservative-Liberal coalition government (2010-) arrived in power just as the developed world faced its worst financial crisis since the 1930s Great Depression. This marked the beginning of austerity budgets and saw the Public Sector Agreements replaced with new tools for performance management. Foreign aid was initially "ring fenced" and protected from budget cuts, yet this heightened the scrutiny to which DFID spending was subjected. Research would be increasingly seen as providing evidence on which forms of spending offered the best "value for money."

\footnotetext{
${ }^{23}$ Emerging fields such as bio- and nano-technology that promised a variety of applications (Conway and Waage 2010)
} 


\subsubsection{Partnering with research councils}

The Blair government's third White Paper on development policy promised to double DFID funding for research. Responding to the House committee inquiry, the White Paper argued DFID would "exploit science to fight poverty" such as the potential for upstream natural sciences and technological advances. Research promised to lead to "a new generation of drugs, vaccines and treatment methods... new technologies for water treatment and purification... and adapting to the impact of climate change" $(\mathrm{Cm} 6876$, 2006). The White Paper also reiterated an expectation that research would provide developing countries access to international expertise and encourage local researchers to address the needs of the poorest members of their societies. Researchers were not expected to work in isolation, but to link with a variety of partners that could help ensure the uptake of research into practice, including community groups, the media and private sector. Recipients were not only expected to be highly-qualified researchers, but also adept networkers, entrepreneurs, and innovators.

The government's Chief Scientific Advisor, David King, convened a "Development Science Working Group" to reflect on how the government might better coordinate UK support to medical, agricultural, environmental and other areas of research. At one point, this group considered a new research council dedicated to development sciences. Yet this option would have redirected funding from DFID and the existing research councils, without necessarily improving coherence among the various offerings of these funders. The government instead opted to create a UK Collaborative on Development Sciences 
(UKCDS) to "maximise the impact of UK research on international development". Its initial members included DFID, Wellcome Trust, the line departments for health and for innovation, and the research councils for the natural environment, biosciences, medical research, and economic and social research. The Collaborative had a modest staff of roughly five persons, considered employees of the bioscience research council (BBSRC) but working out of the offices of Wellcome Trust, a private charity dedicated to medical research. UKCDS sought to help its members identify future research needs, improve coordination, and share good practice. While it did not have any formal powers, the Collaborative was expected to both enhance DFID's links with other research funders, and ensure the UK research councils supported opportunities for work on international development.

DFID began to issue joint calls for proposals with a greater number of the UK research councils. Such partnerships were a win-win for DFID: it was perceived to be commissioning high-quality science, and doing so by buying into the existing peer review process, rather than setting up and running such competitions itself. Consequently, part of DFID's portfolio moved towards more upstream research, including plant genomics and human vaccines. The pool of potential grantees grew from the former "development studies" community interested in poor countries abroad, to take in a wide "platform technology" community with skills in lab-based sciences at home that could be applied abroad. In the words of one respondent, it widened the field to "anyone who can slice in a salt-tolerant gene" (UK-02). Yet a new tension emerged: proposals with the best science did not necessarily have the greatest relevance to development. 
The councils were already struggling to balance the criteria of 'research quality' and 'impact'. Each of the councils had its own program theory for research, but faced a common performance regime. In 2006, all the councils were asked "to make funding decisions based on assessments of research excellence and the potential economic impact" (Holmes and Harris 2010). Consequently the councils had embarked on an “excellence with impact” agenda, which emphasized demonstrating impact, engagement with research users, and support for people in knowledge brokering roles. Hence the opportunity to work with DFID was attractive: it would provide an example of 'demand' from a government department, and DFID funding would match or exceed those offered by the councils. Yet the councils' program theory continued to privilege quality ahead of impact, while DFID expected research to be relevant and have practical application. The Secretary of State argued that DFID was not interested in funding research per se, but in its benefit for developing countries (UK-01).

Somehow the peer review process had to reconcile the criteria of quality and impact. Early competitions used parallel review committees, one focused on the scientific quality of proposals and the other on their relevance to development. The project ideas that were ranked highly by both committees were invited to submit full proposals. Yet the result was perceived as disappointing to both sides, projects midway between the comfort zones of basic and applied science preferred by the councils and DFID. This move also reestablished the prominence of UK researchers in DFID funding. To be eligible for council funding, project ideas needed to include a UK researcher. Furthermore, 
developing country colleagues were at a disadvantage, lacking experience in presenting their ideas for consideration in UK peer review.

Additional differences between DFID and the councils surfaced after the selection process. The councils were accustomed to relying on academic incentives of tenure and university careers to encourage recipients to get on with their research, yet DFID was accustomed to playing an active role in monitoring progress of the funded work. In some instances, the grantees were asked to revisit their project design in order retrofit logical frameworks, milestones, and deliverables. Furthermore, recipients were expected to provide regular updates on their work and respond to periodic requests for information.

\subsubsection{Funding global science and informing aid}

The promise of upstream science and new technology was also present elsewhere in DFID's research portfolio, with new support to a variety of international alliances and product development partnerships (PDPs). These partnerships combined funding from the public and private sectors to identify, refine, and take to market medicines and other technologies for poor countries. They were intended to address the 'market failure' created by the low financial demand exercised by poor people, which meant that certain technologies were not profitable for the private sector to invest in. PDPs were seen as a means to coordinate across government, academia, companies and civil society to underwrite the R\&D costs and facilitate the discovery and diffusion of new technologies. Such partnerships operated as virtual non-profit R\&D organizations, outsourcing activities to academic or private firms and providing technical oversight and research 
management (Grace 2010). PDPs also sought in-kind contributions from private firms in the form of staff time, use of laboratories and production facilities, and access to proprietary information (such as candidates molecules for new drugs). Examples included the International AIDS Vaccine Initiative (IAVI), Global Alliance for Vaccines and Immunisation (GAVI) and Global Alliance for Livestock Veterinary Medicines (GALVmed).

Two factors encouraged DFID to adopt this approach to grantmaking. The first was the beliefs and convictions of DFID's Chief Scientific Advisor. Gordon Conway championed these initiatives based on his experience with the Rockefeller Foundation, which had been an early supporter of PDPs inspired in part by delays in public research through the United Nations. The second factor was the opportunity to minimize operating costs by moving large amounts of funding in single grants. Thus the DFID research portfolio now included a greater diversity of approaches, with research programme consortia, collaboration with the research councils, and product development partnerships adding to the more traditional research projects with single recipients or contributions to multilateral programs, such as the Collaborative Group on International Agricultural Research (CGIAR) or World Health Organization (WHO). ${ }^{24}$

Meanwhile, under the Blair and Brown governments, Whitehall expected that public research funding would provide an input into an evidence-based approach to policy

\footnotetext{
${ }^{24}$ Figure 7 combines funding to international initiatives and the research programs led by multilateral institutions.
} 
making. The Cabinet Office defined evidence as "expert knowledge, published research, existing statistics, stakeholder consultations, previous policy evaluations, the Internet, outcomes from consultations, costings of policy options, output from economic and statistical modelling" (Davies and Nutley 2002). Much of the public sector adopted a new concern for gathering evidence to substantiate policy objectives, instruments, and monitoring.

Clinical medicine was held up as an ideal for this approach. Clinical medicine starts with a clear outcome which allows practitioners to establish a clear hierarchy among different methods. For example, if the desired outcome is reduced mortality or disease, the mechanism is a drug or vaccine candidate. Randomized experimentation is the preferred means of establishing validity, or 'truth', followed by observational studies and professional consensus. Within government, this clinical medicine philosophy was increasingly applied more widely within health policy, as well as other areas of social policy, including justice and education. Yet, similar to international development, these sectors simultaneously seek multiple outcomes, often negating the possibility of establishing a clear hierarchy among methods and types of knowledge that counts as “evidence" (Davies and Nutley 2002).

Yet the performance regime in the UK required "evidence" to underpin all decisions. For example, the policy process required some form of evidence as to the extent of a particular problem or the effectiveness of some form of intervention. There had to be some proof before the problem was accepted as deserving to be on the government 
agenda, or before an intervention was accepted as deserving of public funding. In other words, policy goal X was important, or policy instrument Y worked, because of evidence Z. Consequentially, experience-based knowledge or expert opinion counted for much less than they had in the past. The emphasis was very much on the instrumental use of empirical evidence to inform practice, rather than the conceptual use of theoretical knowledge to frame policy (Nutley et al 2007).

\subsubsection{Setting a research strategy and seeing RED}

The twin promises of technology and evidence were integrated into the DFID Research Strategy 2008-13. DFID expected to spend up to $£ 1$ billion on research within this fiveyear period, thus the stakes were high and there was opportunity to move beyond the department's previous directions. The Director General of Research and Policy, Andrew Steer, described DFID priorities as a product of "where would research have the greatest potential impact on changing the way one tackles poverty, new priorities set by the Minister, what other research funders do, what is the opportunity cost of research in one area versus another" (House of Lords 2010)

Following a substantial consultation with research communities at home and abroad, the strategy included some substantial continuity. It defined R4D as a means to "make faster progress in fighting poverty and achieving the MDGs" and called for continued support to health and agriculture. These two themes continued to account for the largest shares of the portfolio, at $£ 50$ million and $£ 40$ million in $2007-08$. Next in size was research on economic growth and on fragile states — which accounted for $£ 10$ million and $£ 12$ million 
respectively — which could trace their lineage back to the old work programmes. The strategy also laid out new investment in the areas of research communications, climate change, and future post-2015 challenges. Collectively these themes accounted for $£ 16$ million in 2007-08.

The focus on research communications responded to demand for evidence-informed practice. The strategy argued that it was "more likely that people will act on evidence that is built up over many years, in different contexts, once this has been communicated effectively" (emphasis added). Thus part of the value of research was seen to lie in bridging this last mile, to reach a potential audience that could "use research to bring about real change" (DFID 2008). Accordingly, the strategy called for investing up to 30\% of the research budget into making research "available, accessible, and useable".

Recipients and DFID were both responsible for research communication. Funds were earmarked within each grant for recipients to share their findings, while DFID increased its own spending on research communication and synthesis. In the short term, DFID's approach was framed by the experience of development practitioners — based on a belief that each country's development experience was unique-yet it increasing adopted the philosophy of clinical medicine- based on a belief in universal facts about what worked and what did not.

DFID's new strategy outlined four intended results: policy knowledge for developing countries, the international community and DFID; evidence to inform decision-making 
about international development; technologies developed and used in developing countries; and capabilities to do and use research. DFID sought a proactive role in shaping the R4D agenda, asserting that its staff would "take the lead intellectually in delivering high-quality research that shapes ideas, policy, and practice” (DFID 2008). Research would focus on DFID partner countries in Africa and South Asia, responding to local 'demand' and improving the capability of these countries to carry out research. Yet in practice, it would be difficult for the London-based research staff to feed into spending by local country programs or tap into local knowledge of host society research needs and potential recipients.

Gordon Brown's Labour government (2007-10) released yet another White Paper on international development, establishing the DFID priorities as economic growth, climate change, and conflict. Foreign aid was to be directed "based on the principles of country income, population size and confidence that resources will be used effectively." (Cm $7656,2009)$. DFID continued to be squeezed on operating costs, with a promise to "deliver an additional $£ 155$ million of value for money savings by $2010-11$ ". These savings were to be found in part by "improving value for money in the research budget".

Echoing the optimism over the promised of technology and evidence, the White Paper argued for focusing research on "best bets... innovations with the greatest potential to lift poor people out of poverty". The examples cited included drought-resistant maize and vitamin-enriched crops. Meanwhile DFID research was also expected "to ensure that decision makers have the best evidence of what works" $(\mathrm{Cm} 7656,2009)$. 
In 2009, Chris Whitty was recruited to DFID to occupy the now recombined post of Chief Scientific Advisor and Head of Research. This included both a corporate role to facilitate the use of science throughout DFID, as well as direct oversight of the staff responsible for the research funding decisions. This post was just two levels from the top of DFID management, reporting to the Director General of Policy and Research, which in turn reported to the Permanent Secretary. Whereas the past directors of DFID research were career public servants, Whitty was trained as a medical doctor and would continue to keep a foot in academia, teaching part-time at the London School of Hygiene \& Tropical Medicine. He had the gravitas of coming from the other side of the fence, being part of the medical research community and seeing research management from that point of view.

To meet the expectation of informing DFID policy and operations, the Central Research Department (CRD) was soon renamed the Research and Evidence Division (RED). Under the new division, research was not only for reducing poverty, but for "doing more with available funds, [to] avoid developing expensive ideas that do not work" (DFID 2009). The division began to fund systematic reviews on questions facing DFID operation across the department. The method of 'systematic review' compiles a synthesis of past research findings by: asking a precise question, establishing an explicit protocol for how to identify and include previous studies, and conducting a meta-analysis of the data from these studies. A systematic review assesses the rigour of previous studies, and excludes from the meta-analysis those studies that are considered to have poor-quality designs. 
Systematic reviews originated in clinical medicine, as a means to look at effectiveness of a particular drug or intervention, with the aim of informing practice and better targeting future research effort. RED collected a series of questions from across DFID, which were then tendered to the research community to apply for. RED also worked with donor agencies in Australia, the United States, and Canada on additional calls.

The use of systematic reviews was controversial. Drug effectiveness could be established by a controlled context and causation rooted in biochemistry and human physiology. Yet changes in poverty happen in an uncontrolled context due to multiple causal mechanisms stemming from the interaction of economics, politics, and the actions of donors, partner governments, and poor people themselves. Some of the questions identified for a systematic review were fairly general in nature, such as "what factors limit the use of cleaner cookstoves". This made it difficult to identify which past studies were appropriate to include in the meta-analysis. Conversely, the focus on high-quality studies led to reviews that included a very small number of findings or that excluded studies that were seen as pertinent by development practitioners considered and (UK-03, Hagen-Zanker et al. 2012). As the reviews were conducted by outsiders, they tended to lack the nuance needed to tailor their presentation the practical needs of DFID staff. Furthermore, adapting Sparrow's argument on evidence-based policing (2011), a systematic review selects a tiny fraction of scientific methods applicable to international development and narrows the range of solutions available. 
DFID continued to move towards targeted research, becoming less responsive to researcher interest. Prior to the 1990s, ODA projects had been primarily determined by the research community, while under RED the research themes - and increasing the research questions — were determined primarily by government.

Yet a more nuanced balance of Rothschild and Haldane visions was emerging in UK research policy. A House of Lords inquiry into public research (2010) argued that "plurality and diversity... allows multiple opportunities for the best research to be funded". Those responsible for research funding were to exercise careful judgment about how to deploy "limited funds between competing priorities so that the pursuit of knowledge and its translation into practical applications meet the needs of society". Echoing earlier concerns, government departments were seen to lack the ability to know "who to ask or what to ask". A targeted approach risked funding "poorer quality" or even "mediocre" research $(2010,194)$. Applying this concern to DFID, one respondent lamented, "the way [researchers] are being funded is turning everyone into a short-term consultant and analyst" (UK-04).

Having worked hard to establish its scientific credibility, this was not a desirable image for DFID. Despite continued pressure to control operating costs, research management required skilled people. RED soon grew to over a hundred employees and began to give evidence to Parliamentary inquiries in the areas of health and food security. 
DFID was well positioned to respond to an emerging concern with global challenges, common to UK and developing countries. In 2009, the government's Chief Scientific Advisor, now Sir John Bebbington, argued that the twin forces of climate and demographic change would provoke a "perfect storm" of food, water, and energy scarcity within twenty years. The scale and urgency of these problems was seen to require greater collaboration across government and with other countries. The House of Lords argued that "highly competitive" funding systems discouraged such collaboration, instead rewarding individual pursuits and providing an incentive to keep research progress private until peer-reviewed publication. The inquiry further lamented that "research councils do not reward or facilitate interdisciplinary or ground-breaking work [and] departmental priorities outweighed cross-Government priorities" (2010).

\subsubsection{Research under austerity}

David Cameron's Conservative-Liberal government (2010-) inherited the consequences of the 2008 financial crisis that had rocked North America and Europe. The G20 response had seen the UK and other countries introduce two years of stimulus spending. By 2010, reduced revenue from a slowed economy had forced government finances into deficit with national debt increasing by $50 \%$, to over $£ 760$ billion. The new government crafted an austerity budget, introducing tax hikes and cutting departmental spending by up to 25\%. It also replaced the Public Service Agreements with a new requirement for departments to prepare "business plans." Spending proposals were subjected to a new set 
of tools developed by HM Treasury ${ }^{25}$, framed around a "five case model" of concise arguments outlining how the proposals contributed to government strategy, optimized value-for-money, and were commercially viable, financially affordable, and achievable (UK 2011).

The international development budget was not only protected, or "ring fenced," and further increased as the new government maintained a commitment to spend $0.7 \%$ of gross national income towards official development assistance by 2013. Yet this continued growth in foreign aid meant that DFID would be subjected to intense scrutiny.

Transparency and value-for-money were the priorities for DFID under its new Secretary of State, Andrew Mitchell, with an Independent Commission for Aid Impact (ICAI) reporting directly to Parliament on the effectiveness of various aid programmes. The government also quickly launched "root and branch" reviews of bilateral and multilateral aid. The bilateral review saw DFID end its aid to sixteen countries, including China and Russia, and refocus on twenty-seven other countries, primarily in South Asia and eastern Africa. The multilateral review identified agencies DFID would stop funding or place under special measures. It prioritized support for the World Bank, regional development banks, UNICEF, the GAVI alliance, and the Global Fund to fight AIDS, tuberculosis and malaria (DFID 2011).

25 Also known as the 'Green Book'. Other 'coloured' volumes used in UK public management include the red book of financial statements, orange book on risk management, magenta book on evaluation, and the blue book covering DFID's own rules and tools 
Value-for-money became the prominent watch word within the department. In releasing the reviews, the Secretary of State argued they represented a "determination to deliver the greatest possible return on investment, both for the world's poorest people and for the British taxpayer" (DFID 2011). The DFID Business Plan 2011-15 asserts that it "will no longer support projects that are failing to perform... spend as much money on marketing and communications... [or] provide substantial aid to countries that do not need it”. DFID re-emphasized the use of results-based management and quantitative commitments, including numbers of children to be enrolled in school and women to receive access to family planning. In such cases, value-for-money meant achieving these targets at a minimal cost. Yet DFID also wanted to help protect livelihoods from the effects of climate change and make countries safer from violent conflict. Such goals were not so easily measured or verified. They lacked a counterfactual of how conditions might otherwise evolve without UK intervention and it was difficult to distinguish DFID's contribution from the efforts of others.

RED's work was to commission research on key questions in development. It was expected to develop new technologies (such as new drugs, vaccines, or drought-tolerant crops), find better and more cost-effective ways of delivering aid, and help DFID and partner countries make the best policy choices. The latter goals assumed an internal demand for research. Every DFID project was expected to be justified through statements summarizing evidence on the need for the intervention, as well as evidence on its potential or real impact (House of Lords 2012). By 2012, RED had an annual budget of 
$£ 235$ million, up from $£ 130$ million in 2008, and expected to reach $£ 320$ million by 2014 (House of Commons 2012). Up to one-third of this budget was to be directed to ensuring that "research evidence from any source gets to the policy makers and end users who need it" (DFID 2009).

RED staff had a role in synthesizing evidence from a variety of sources, assessing its quality, and communicating the findings. The division's work now involved producing four types of "evidence products", including systematic reviews contracted out to universities, in-house evidence papers providing DFID's own perspective of the state of the science, classical literature reviews, and rapid reviews intended to respond to urgent policy needs (House of Commons 2012). Chris Whitty described himself as having three roles (1) ensuring that the evidence base was strong and reached users across DFID, (2) contributing to the professional development of RED staff, and (3) strengthening DFID's peer review and "proper mechanisms for commissioning research rather than a slightly ad hoc process" (House of Lords 2012). Yet Whitty also cautioned that uncertainty continued to exist. It was often impossible to answer a Minister's question or provide a definitive recommendation "either because the studies are not there or because they have not been done to a high enough quality" (House of Commons 2012). ${ }^{26}$

DFID had strengthened its engagement with academics, despite some clear challenges. The incentives for academics were to compete for Haldane-style funding from the

\footnotetext{
${ }^{26}$ Oral evidence given to Parliamentary committee on 25 June 2012
} 
research councils, and to publish to enhance their university's standing in the Research Assessment Exercise. Despite the rise in demand for academic input from evidence-based agenda, government departments continued with Rothschild-style contracts focused on their own needs. The potential to participate in, and contribute to, policymaking held some attraction, but many academics were reluctant to chase after government contracts at the cost of progressing in their own careers.

DFID sought to break this impasse in three ways. First was through senior research fellowships offering established academics an opportunity to work within the department for limited time (DFID 2009). Second, some DFID posts were modified to permit staff to hold both academic and public service responsibilities. Chris Whitty and his deputy continued to hold their university jobs, albeit with reduced teaching and research responsibilities. This meant that staff would not have to forego their standing in the world of academia while contributing to DFID. Third, Whitty convened an informal Research Advisory Group (iRAG) of outside academics, chaired by the Vice-Chancellor of Cambridge University, to provide ongoing independent advice on the current and future relevance of DFID's research agenda.

In summary, during this period, the performance regime reemphasized ties with UK science, including notions of scientific excellence, and witnessed rising scrutiny of foreign aid, including downward pressure on operating costs. The program theory guiding funding decisions embraced the potential for generating technologies to change the lives of poor women and men, as well as the potential for research to inform an 
evidence-based approach to policy. Corresponding, grantmaking expanded to include partnerships with the UK research councils, continued rise in average project size, and renewed consideration of how research inform the "value of money" of aid investments.

Table 5: Research grants made by ODA/DFID Annual research granting increased nearly three-fold in real terms. As the number of grants fell by two-thirds, the average size of each grant increased substantially to over three million pounds (Authors calculation with data from http://r4d.dfid.gov.uk/).

\begin{tabular}{cccc}
\hline Time Period & $\begin{array}{c}\text { Grants per } \\
\text { year }\end{array}$ & $\begin{array}{c}\text { Annually } \\
\text { Granted } \\
\text { (£ thousand) }\end{array}$ & $\begin{array}{c}\text { Average } \\
\text { Grant (£ } \\
\text { thousand) }\end{array}$ \\
\hline $\mathbf{2 0 0 4 - 1 0}$ & 75 & 273,900 & 3,673 \\
$\mathbf{1 9 9 7 - 0 3}$ & 243 & 183,700 & 756 \\
$\mathbf{1 9 9 0 - 9 6}$ & 226 & 98,300 & 435 \\
\hline
\end{tabular}

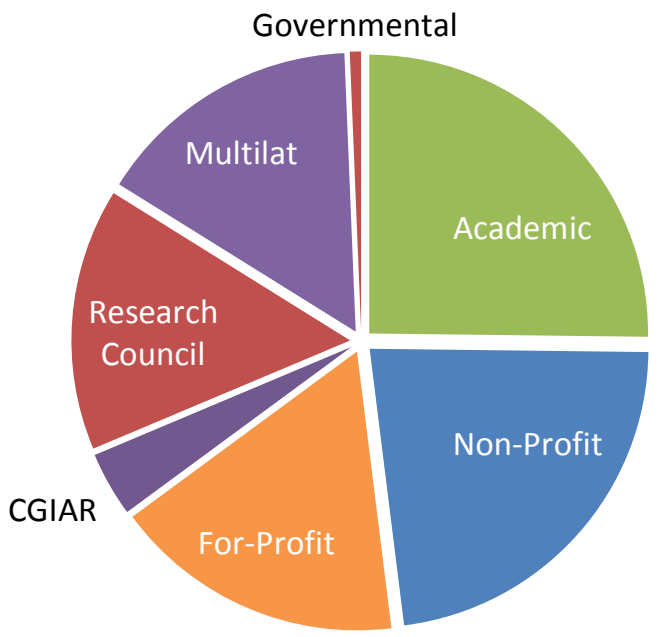

Figure 7: Top institutions funded by ODA/DFID The top 109 recipients received a total of $£ 1.6$ billion in real terms since 1990: almost half (48\%) went to academic and non-profit institutions, and one-fifth for-profits (17\%) and one-fifth (19\%) to multilaterals, including CGIAR and international initiatives. 


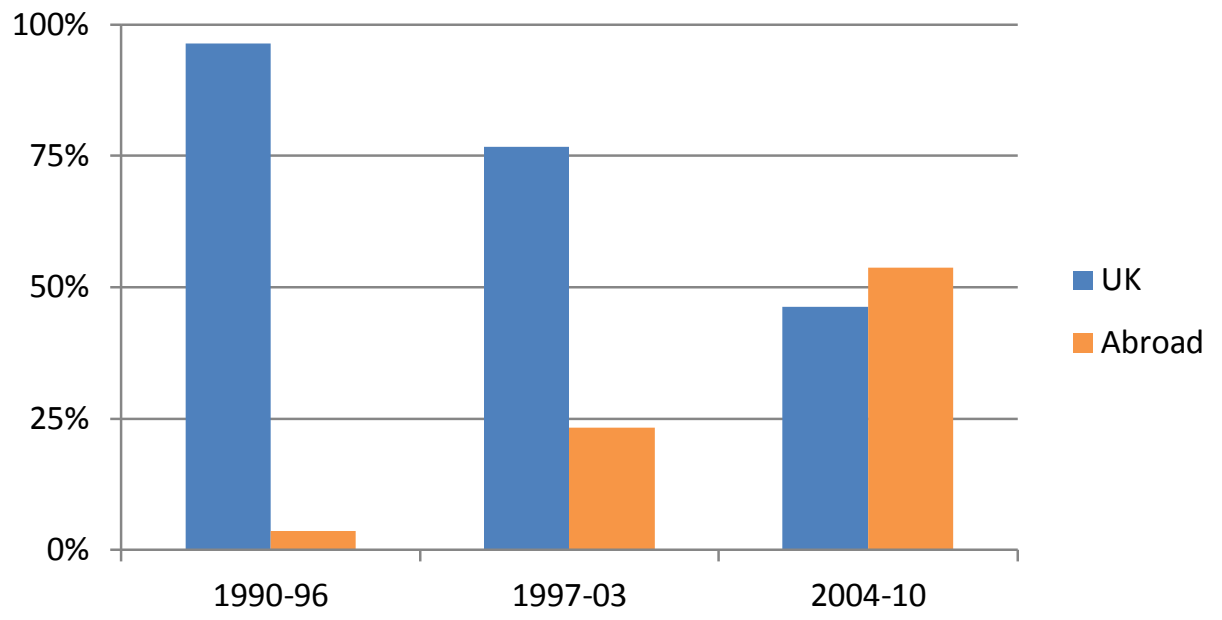

Figure 8: Location of ODA/DFID recipients The portion of funding awarded to UK recipients fell precipitously after the created of DFID in 1997 and the International Development Act in 2002.

\subsection{Conclusion}

Over time, R4D was subject to a tug-of-war within UK research policy between the Haldane principle - under which the research community is essentially self-governedand the Rothschild principle — under which research is for hire. Haldane divided research commissioned by departments for a specific purpose from research funded by councils for more general use (Cd 9230). Lord Rothschild saw applied research as having "a practical application as its objective", best governed by the principle of "the customer says what he wants; the contractor does it (if he can) and the customer pays" (Cmnd 4814). After 1979, Conservative governments pursued an agenda to make the public service more economical, efficient, and effective. Reforms saw the government's scientific units spun off into quasi-independent entities. These agencies were expected to 
fend for themselves, with their access to public funds governed by a customer-contractor relationship. Pressure mounted for competitive tendering of public funding, and for the measurement and audit of outcomes utilizing performance indicators.

R4D has deep historical roots in the United Kingdom. The current arrangements with DFID trace their lineage back to the early twentieth century, predating the era of foreign aid. Upon its creation, the Overseas Development Administration (ODA) inherited a legacy of funding relations from the previous Colonial Research Council, including scientific units within government, 'world-class' centres at home, and a host of institutes abroad.

R4D initially focused on maintaining the UK science base and reducing the dependency of institutes abroad by switching its offer from core funding to project funding. With the advent of the Rothschild principle, ODA established an arm's-length relationship with the scientific units previously part of government. ODA kept its research funding fragmented among policy divisions responsible for agriculture, health, economics, etc. The adoption of work programmes after 1993 saw a more deliberate attempt to set the research agenda and foster competition within the research community.

Following the creation of the Department for International Development (DFID) in 1997, R4D was subject to mounting critique from inside and outside the department. In response, a Central Research Department was established to strengthen DFID's ability to manage its research funding. R4D benefited from an increasing foreign aid budget, yet 
struggled with the Treasury's efforts to control operating costs. R4D funding moved from "retail to wholesale", away from small grants with individual research teams, and towards larger grants with either consortia of recipients or international alliances. The International Development Act in 2002 untied foreign aid, and saw an increase in research funding to recipients abroad.

Later in the decade, DFID sought to reestablish its scientific credibility, working more closely with the research councils to promote the promise of new technology, and positioning itself as the provider of evidence upon which to base foreign aid investments. This latter role became particularly pronounced in the follow-up to the Labour push for evidence-based policy and the Conservative focus on value-for-money during times of austerity.

The R4D context, or performance regime, can be described in terms of resource availability, public management, and research governance.

In terms of resource availability, the UK initially supported the costs of local research facilities abroad and world-class centres of excellence at home. By mid-century, the UK government sought to reduce overall costs by encouraging the governments of the newlyindependent countries to fund local research. Meanwhile, the move from core funding to competitive work programmes was a means of rationalizing government expenditure on UK recipients. The rise of official development assistance this century saw a disproportionate increase in the R4D funding. Yet the New Labour discipline of spending 
reviews saw strict controls on the resources available for staffing and internal costs, encouraging a move from "retail to wholesale" funding: supporting larger projects, networks or "consortia" of grantees, and co-funding with the UK research granting councils. Recent austerity budgets saw R4D as providing evidence on the "value-formoney' of aid investments.

In terms of public management, Haldane established that line departments should have a budget line for research, which ODA initially used to maintain the UK research centres specialized in the problems of tropical climates. The market-inspired thinking of Rothschild and Thatcher eventually led to a split between those who performed research and those who commissioned it. ODA exited service delivery entirely, spinning-off its scientific units to the academic or private sector. Following the creation of DFID, research was seen as a public good contributing the international agenda beyond the UK. R4D benefited from an outside "science lobby" as domestic researchers were primary beneficiaries of ODA grantmaking until the untying of aid. The shift away from domestic research providers provoked an attack on DFID's use of science, leading to the creation of a Chief Scientific Advisor, the first of whom brought in a focus on platform technologies, such as ICTs and genomics. His successor imparted a model inspired by clinical medicine, resonating with an evidence-based approach to policy championed by Blair. The result was a shift to seeing research as an internal service to demonstrate the ‘value-for-money' of foreign aid. 
In terms of governance, the research community invented a "Haldane principle" of selfgovernance under which government was merely a benign benefactor. Later Rothschild's ideal of "customer-contractor" expected government to be an intelligent consumer, specifying exactly what it needed from the research community. R4D shifted from responding to the interests of the research community to instead encouraging work on the interests of government. The UK research community was initially seen as a close ally worthy of support, but later re-cast as a consultant to be managed through contractual relations. These two forms of governance coexist in a dynamic tension between what government wants done, and what researchers are interested in doing. Even when ODA adopted competitive funding mechanisms, the relationship with the research community was not entirely arm's length. Government officials would turn to the research community in crafting the terms of references. Meanwhile researchers are judged more on their publication record, than on their participation in government funding opportunities.

The agency of ODA and DFID is seen in how these organizations responded to a changing context through the evolution of the program theory guiding funding decisions and grantmaking practices.

In terms of program theory, ODA initially focused on the science base at home, maintaining highly-qualified people and established centres within the UK research community. Later the work programmes offered competitive funding for projects to further outcomes of interest to the aid agency. DFID initially shifted away from the 
domestic research community in favour of the global development agenda negotiated with other donors. More recently, DFID embraced perspectives based on the promise of technology and a clinical approach which sees research as providing evidence as to what is needed and what works. Both of these perspectives opened up R4D to recipients beyond those that self-identified as working on international development. Yet new perspectives did not completely displace older ones, instead there has been a layering of grantmaking logics over time. For example, DFID continued to provide core funding to the Overseas Development Institution despite long abandoning a perspective of maintaining the UK science base. A growing research budget provided space for multiple program theories to coexist and thrive.

Drawing Funnel and Rogers' (2011) concepts of program theory, the UK approach to R4D was often based on a diffusion theory of change, initially underpinned by a direct delivery archetype. ODA inherited a set of scientific units at home that saw government responsible for conducting R4D. In the 1980s and 1990s, the importance of this archetype eroded with the slow move to competitively-awarded work programmes and the eventual phasing out of direct delivery during Next Steps agenda. With the establishment of DFID and substantial budget growth, R4D oscillated between diffusion and reasoned-action theories of change, which interpreted R4D as technical innovation and evidenced-based policy. In both cases, R4D was underpinned by carrot-and-stick archetype, correcting a 'market failure' by providing researchers with a financial incentive to do work that benefitted developing countries. 
In terms of grantmaking practices, ODA's initially provided core support to highlyspecialized senior researchers and research centres, based on historic relationships with institutes at home and abroad. Slowly ODA sought to rationalize these relationships, initially shifting from core funding to project funding for institutes abroad, which were increasingly expected to provide their own operating costs. A similar shift occurred in the relationship with domestic research community, with the work programmes moving UK institutes from core funding to project funding based on competitive calls for proposals. The work programmes saw the overall pool of recipients contract as some entities merged and others ceased to exist. The staff role of a "research advisor" evolved from a subject matter expert engaging with the external research community, towards an internal role providing technical support within DFID. Meanwhile the recipients of UK funding needed to satisfy an increasing number of expectations, including scientific quality, relevance to developing countries, and getting "research into use". Beyond generating new knowledge and technologies, R4D projects were expected to actually deliver development, demonstrating their contribution to outcomes such as raised incomes and improved well-being. 


\section{Chapter: Canada}

Canada began to fund research-for-development in 1970, building on a short history of foreign aid that started with the Colombo Plan. Even as Canada established its donor agency, prominent individuals were envisioning a separate organization specialized in research. The founders of Canada's International Development Research Centre (IDRC) were inspired by private think tanks and philanthropic foundations in the United States. In large part, IDRC would adopt the grantmaking practices of the latter, with a substantial role for its program officers interacting with recipients. Yet while IDRC staff focused their gaze on the developing world, management would have to cultivate a network of allies within bureaucracy, and would periodically reposition or restructure the Centre to adjust to a changing performance regime.

This chapter identifies three distinct periods when R4D was subjected to different expectations and adopted different goals. During the first period, the performance regime afforded IDRC a substantial degree of autonomy. Central agencies occasionally sought to reassert control over the Crown Corporation, but the Centre defended its niche within foreign aid by cultivating a network of allies in the bureaucracy. The program theory that guided R4D funding was based on capacity building: strengthening research communities in developing countries to address their own problems. The grantmaking practice was to provide direct project funding to southern recipients, loosely linked to the themes of information, health, agricultural or social science. During the second period, starting in 1991, the performance regime was characterized by waves of budget cuts in the federal government, heightening demands to control operating costs and to demonstrate the 
utility of research. The program theory that guided R4D funding emphasized policy influence: seeing research as an input into local efforts to address poverty abroad and expecting recipients to connect with an audience that would act on their findings.

Following restructuring, IDRC continued to offer project funding, but required that these contribute to Board-approved program strategies. During the third period, starting in the early 2000s, the performance regime emphasized alignment with the priorities of Canada's foreign policy. The role of the IDRC Board eroded as programming decisions were increasingly tied to government funding decisions, or committed to programs partially funded by CIDA and donors outside Canada. The program theory that guided R4D funding valued research for its actual contribution to changed policy and practice in the developing world, with an increasing array of expectations placed upon its recipients. Competitive calls for proposals joined the older grantmaking practices based on proactive project development by IDRC staff and responding to unsolicited proposals and partnerships.

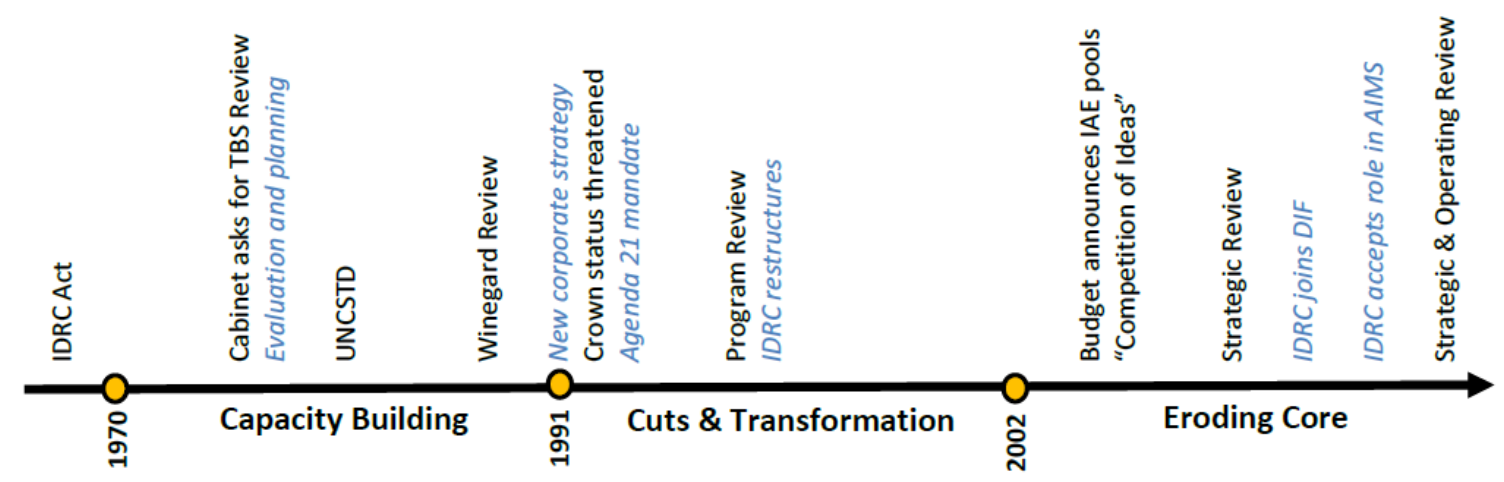

Figure 9: Timeline for Canada case study 


\subsection{Origins}

Canada entered the field of "research-for-development" much later than the United Kingdom, opting to create a for-purpose organization outside of the donor agency and separate from foreign aid. The idea for what would become Canada's R4D funder originated in the 1960s. At home, Lester B. Pearson's Liberal government (1963-68) rewrote the social contract with the introduction of universal health care and the Canada Pension Plan. Abroad, Canada established itself as an independent actor in foreign policy, championing the concept of peacekeeping following the Suez crisis and avoiding involvement in the Vietnam War. Canadian pride hit a peak in 1967, with the centennial celebrations and hosting of the World Exposition in Montreal. The time was ripe for bold thinking about the country's role in the world.

The Canadian International Development Agency (CIDA) was established in 1968, formed from the External Aid Office within the Department of External Affairs which had coordinated Canada's participation in the Colombo Plan in 1950. Maurice Strong became Director General of this office in 1966 and, coming from a background in industry, he questioned the lack of a research branch. When Strong met Barbara Ward, author of the book "Spaceship Earth", the two began to conceive of a foundation or think tank, a Canadian equivalent to the Brookings Institute or the Hudson Institute (Stockdale 1995). Ward enticed Pearson to support the idea, who announced the government's intention at Carleton University in June 1967. With the blessing of Cabinet, Strong convened a steering committee of deputy ministers to refine the idea further (Seward 
1974).$^{27}$ The committee retained A.F. Wynne Plumptre, a former executive director to the World Bank, to prepare a feasibility study of a centre "for the promotion of research directed towards developing countries."

Plumptre (1968) interviewed various officials in Canada and abroad, and found there was substantial support for the idea of applying and adapting new technology to the problems of developing countries. He found less enthusiasm for alternative mandates, such as reviewing the results of past programs to improve future aid, or acting as a databank to coordinate international research efforts. Plumptre also discouraged gathering operations into a single location, cautioning that "useful research... will take place in the developing countries themselves... where the results of the research will have to be applied." $\mathrm{He}$ argued that the Canadian government should provide a "substantial and reasonably assured" flow of funds that simultaneously responded to the needs of developing countries and "had application to Canadian experience and Canadian problems".

Following the transition to Prime Minister Pierre Trudeau, a new Secretary of State, Mitchell Sharp, proposed that Cabinet approve an independent corporation, focused on the problems of underdeveloped countries, drawing on Canadian expertise and experience (Canada 1968). The Cabinet memo described the work of the Centre as "action... [and] solution-oriented" leading to "policy options and their presentation in usable form to the decision-makers". Reflecting the tenor of the times, the new Centre

\footnotetext{
${ }^{27}$ Strong also drew on the UK experience by including Geoffrey Oldham (University of Sussex) in this work. Oldham would continue to contribute to Centre's work throughout its first decade.
} 
was expected to make a uniquely Canadian contribution to the world, reflecting the “country's experience of bilingualism, biculturalism, multi-racialism and federalism.”

Simultaneously in 1968 World Bank President Robert McNamara invited Pearson to chair a commission reviewing the effectiveness of the previous twenty years of development assistance. The resulting report—-Partners in Development"—noted a sense of aid fatigue: "international support for development is... flagging... its feasibility, even its very purpose is in question. The climate surrounding foreign aid is heavy with disillusion and distrust" (Pearson et al. 1969: 4). Among the many concerns raised ${ }^{28}$, the Commission called for greater assistance to research, arguing that "a large effort is needed to absorb, adapt, and develop scientific and technical knowledge in developing countries" (Pearson et al. 1969: 21, 202-7).

\subsubsection{Legislated mandate}

As the Pearson Commission report was going to press, back home the Trudeau's Liberal government (1968-79) introduced legislation into the House of Commons for debate. Based on frustrated attempts to fund research through CIDA, Strong ensured the Bill granted the Centre a degree of political independence, as a Crown corporation with its own Board of Governors. While the Board would be appointed by federal government, ten of its twenty-one members could be non-Canadians, thus ensuring the voice of

\footnotetext{
${ }^{28}$ The report critiqued the use of tied aid, foresaw the problem of external debt among developing countries, and calling for "structural adjustment" on behalf of industrialized countries to absorb an increase in imports from developing countries (Smillie 2011).
} 
developing countries in its governance. The Centre would also submit an annual report directly to Parliament. In January 1970, Sharp moved the Bill to second reading, describing its role to "assist the developing countries to build their own scientific and technological capabilities so that they will [be]... contributors in their own right to the solution of their own problems" (Seward 1974). The bill was passed unanimously and, with Royal Assent in May 1970, the International Development Research Centre (IDRC) was born.

Under the Act, IDRC was "to initiate, encourage, support and conduct research into the problems of the developing regions of the world". It was granted a four-part mandate to: a) enlist the talents of natural and social scientists and technologists in Canada and other countries; b) assist the developing regions to build up the research capabilities, the innovative skills, and the institutions required to solve their problems; c) encourage generally the coordination of international development research; and d) foster cooperation in research on development problems between the developed and developing regions for their mutual benefit (Canada 1970, s4.1). The challenge ahead was to put this broad mandate into practice.

That job fell to the Board of Governors, particularly the Chairman and President. Indeed the Act describes "IDRC" as the Board, with the power to appoint such employees as they felt necessary (Canada 1970, s3 and s14). Pearson became the first Chairman, providing him with an opportunity to pursue his Commission's recommendations. As a former head of state and Noble laureate, he provided the political gravitas necessary to 
ensure the new Centre was taken seriously. In contrast, following another of Plumptre's insights, the first IDRC President would command respect within the world of research, rather than politics. Strong recruited David Hopper for the job, a Canadian engaged in India's "Green Revolution" to boost agricultural productivity. Hopper had a background in agricultural economics from McGill and Cornell Universities, and had worked with both the Ford and Rockefeller Foundations. Strong had been impressed when he met Hopper in 1967 and sought to emulate the foundation model in the new Centre.

The legacy of preparing the IDRC Act gave Pearson and Hopper a "smorgasbord of ideas" (Seward 1974), a diverse variety of perspectives on R4D upon which to model the new Centre. Yet it would prove to be Hopper's interpretation that would have a lasting influence on the Centre's philosophy and operations.

\subsection{Capacity Building}

Behind the scenes, ahead of the first meeting of the Board of Governors, Pearson advocated for his vision of a think tank that mobilized Canadian expertise. Given the positive reputation of the Overseas Development Institute (ODI) in the United Kingdom, there were some who thought that IDRC should become the "ODI on the Rideau" River. Yet Pearson's perspective was quickly eclipsed by an alliance between Strong and Hopper. As the IDRC Board of Governors convened for the first time, the FLQ crisis was in full swing, highlighting the demands of the Quebec people for greater autonomy over their own affairs. Under the protection of bodyguards and beginning to experience ill- 
health, Pearson was less strenuous in defending his vision for the Centre. As the IDRC Act was drafted the year before, Strong had written that IDRC's purpose would be "to help developing countries to acquire their own problem-solving capabilities" (Stockdale 1995). Meanwhile, Hopper's years of working abroad, side-by-side with Indian scientists and farmers, had instilled in him a deep conviction that lasting change depended on supporting the people of developing countries to take control of their own development.

This conviction permeated Hopper's inaugural speech to the Board in October 1970, in which he argued for a conscious choice: emphasizing the second part of the mandate (building research capabilities abroad) by adopting a particular approach to the first part (enlisting the talents of scientists abroad). He saw the Centre's role as "expanding the horizons of indigenous research workers by giving them improved facilities and greater opportunities to collaborate closely with associates elsewhere in the world engaged in similar problems" (IDRC 1970). His vision was based on the conviction that "they, not we, are the best judges of what is relevant to their circumstances" and aspired to a grantmaking practice that would "leave the direct management of our support in the hands of our partners". ${ }^{29}$ This speech became the cornerstone of the IDRC's program theory, serving as the de facto corporate strategy for the next twenty years. In it, Hopper foreshadowed aspects of the organization that would emerge, including a focus on rural

\footnotetext{
${ }^{29}$ Hopper (1979) would later reflect upon his experience at IDRC and concede that at certain times it was necessary to simply tap the best minds to matter where they were to quickly address a pressing need, rather than wait years for building up new local capability to address development problems.
} 
people, on addressing problems common to multiple countries, and locating a significant part of IDRC operations in developing countries.

\subsubsection{Getting started}

Having a legislated mandate and high-level champions in the world of politics and research granted the young IDRC a certain degree of protection. Given Hopper's direction, the Centre focused on funding research performed by organizations in developing countries, rather than engaging in its own work or funding Canadian organizations. Canadian scientists might find their way into IDRC projects, but the tendency was to place a developing country researcher as the principal investigator. Under Hopper's guidance, and that of the management team he assembled, emphasis was placed on addressing problems that affected more than one country. Rather than bilateral programming, IDRC's perspective was regional, and the Centre established offices in Asia, Africa, and Latin America. ${ }^{30}$

Management organized the Centre into four program divisions corresponding to agriculture, health, information, and social sciences. Early projects were rooted in one of these four divisions and tended to focus on enhancing a single commodity, crop, or economic activity, typically within a single scientific discipline. For example, the first decade included projects to develop new crop varieties, hand pumps, biogas digesters,

\footnotetext{
${ }^{30}$ Within the first five years, IDRC established regional offices in Singapore, Bogota, Dakar, Beirut, and Nairobi. Security concerns prompted the Centre to leave Beirut and Bogota, relocating these offices to Cairo (1975) and Montevideo (1989) respectively. IDRC also opened an office in New Delhi in 1983.
} 
cooking stoves, and pit latrines, as well as economic studies of how poor people made their living, such as through informal trade or as rickshaw drivers (IDRC 2000). The result was a balance of being proactive in the pursuit of thematic priorities, yet responsive to the particular circumstances in developing countries and the ideas of particular researchers.

Under the Act, IDRC was not "an agent of Her Majesty" (Canada 1970, s18.1) and its employees were not public servants. A significant portion was not even Canadian, as management actively recruited program officers based on their experience and expertise, regardless of nationality. Today it is difficult to imagine how program officers plied their trade in an age before fax machines, computers, and Internet. The role of a program officer was very much to seek out project ideas, scouting developing countries to identify their needs, and spotting talented people and organizations that could address them. Staff would regularly work with prospective recipients on their project proposals, elaborating ideas to the stage where they could be taken to the Board of Governors for approval.

As Hopper had directed, most projects looked beyond the national level, to foster collaboration among researchers located in different countries; helping to overcome the isolation from peers, resources, and literature that then plagued scientists working in developing countries. In the words of one employee, program officers acted as "wandering minstrels", painstakingly building networks by sharing what they had seen, and who they had met as they travelled from one location to another (Muirhead and Harpelle 2010,96). During the course of a project, program officers would regularly 
travel to visit recipients in the field, to monitor how the project was progressing, offer mentoring in research techniques, access to academic literature not available locally, and brokering contact with peers abroad.

\subsubsection{Renewing relations with Ottawa}

Financial and administrative autonomy from the rest of the federal government had allowed management the freedom to design the Centre as they saw fit. Yet by the late 1970s, this autonomy was questioned as central agencies attempted to reassert control over IDRC. The Centre’s annual budget had grown rapidly, from $\$ 2.5$ million to $\$ 36.9$ million during the seven years between 1971 and 1978. As IDRC's budget grew and the initial euphoria of its creation wore off, Ministers began to ask what Canada was getting in return for its investment. In considering the allocation of external aid in 1977, Cabinet made two requests: calling on the Treasury Board Secretariat to conduct an evaluation of IDRC activities, and calling on the Privy Council Office to clarify IDRC's relationship with CIDA and the Minister of State for Science and Technology (IDRC 1977).

The TBS evaluation was largely positive in its assessment of IDRC programming. Nonetheless, it was critical of the somewhat ad-hoc manner in which the Centre had evolved. In response, IDRC established an Office of Planning and Evaluation, which soon began an annual process of "Program and Policy Reviews" to satisfy the TBS requirement for three-year operational plans. Meanwhile the Privy Council Office began a process to reschedule Crown corporations, and include them under provisions of the Financial Administration Act. Close contact between IDRC management and Privy 
Council officials allowed the Centre to successfully argue for preserving its autonomy in order to receive funds from non-Canadian sources and to engage developing countries independently of the federal government. The Centre would be covered by the Financial Administration Act, but given certain exemptions, comparable to the Canadian Broadcasting Corporation and Bank of Canada.

The challenge to its status revealed a need for IDRC to pay as much attention to concerns within official Ottawa as it did to the needs of developing countries. At home, the optimism over Canada's role in the world had been replaced by concern over the price of oil and the emerging phenomenon of economic stagflation. One of IDRC's original champions, Pearson, had passed away and Hopper left in 1978 to accept a senior position within the World Bank. IDRC management, particularly Strong who was now the Chairman, realized it was not enough to be well-regarded outside of Canada; IDRC needed a domestic constituency within Canada and allies within the government.

This task formed part of the mandate for Ivan Head, who arrived as IDRC's new President in 1978. Trained as a lawyer and having previously served as Trudeau's foreign policy advisor, Head was the mirror opposite of Hopper: someone from the world of politics rather than the world of science. Nonetheless Head was experienced in navigating official Ottawa and knew the importance of positioning IDRC not as wholly independent, but as useful to government. He would publicly speak of IDRC as an expression of Canadian foreign policy, rather than an instrument of it. While the program officer might be focused on IDRC's relationship with researchers in developing countries, management 
and the Board needed to be attentive to the Centre's relationship with the Canadian government.

IDRC was under the portfolio of the Minister of State for External Affairs, and formally the Centre connected to the machinery of government at two levels: the Chairman was accountable to the Minister; and IDRC officials interacted with their counterparts in the department responsible for development assistance. In practice, IDRC maintained a wider range of ties with CIDA, the Department of Finance, and central agencies, at the levels of

deputy ministers, ADMs, and director generals with geographic responsibility for parts of the developing world. Management invested time in a deliberate attempt to cultivate "friends of IDRC," an influential network that knew of and appreciated the Centre's work. It was also a practical means of gathering insights into the government's decision making and policy processes, purposefully fact-checking what came through official channels. Much of this lobbying on behalf of the Centre was invisible to IDRC staff: it tended to ebb in good years, but increase to a fever pitch on occasions when the Centre felt threatened.

\subsubsection{An expression of foreign policy}

In the late 1970s, IDRC repositioned itself as Canada's response to an international agenda. In 1979, the United Nations convened a Conference on Science and Technology for Development (UNCSTD). These were heady times as the rise of oil wealth in parts of the developing world fueled the rise of the non-aligned movement and talk of a new international economic order. For the Canadian government, IDRC was a ready-made 
platform for Canada going into the conference and was a palatable alternative to establishing a new multilateral agency or fund under the UN system. IDRC jumped at the chance to assert itself as such, convening a preparatory meeting in Toronto (Gordon 1979) and working closely with External Affairs to prepare positions and briefings, acting as the Department brain trust on such issues.

A new pattern had emerged. IDRC could not take its existence for granted merely because of the Act. It needed to constantly renew its ties to official Ottawa and reposition itself as contributing to the government's priorities of the day. The implicit contract was that government provided funding to allow IDRC to support researchers abroad, but in exchange the Centre would be attentive to the exigencies of foreign policy.

Throughout the 1970s and 1980s, IDRC proved its usefulness to the Department of External Affairs in other ways, such as sustaining critical social science inside countries experiencing dictatorship. In Chile, Argentina, and Uruguay, IDRC supported organizations that allowed economists and political scientists to continue doing their work at home. Alternatively, in Uganda, the Centre provided an "underground railway for intellectuals" to escape persecution and work in other countries (Muirhead and Harpelle 2010, 76). IDRC's arm-length status was useful for government, allowing it the means to engage in situations where it did not or could not take an official position. The most prominent instance would occur on South Africa in the late 1980s when, with the blessing of the Prime Minister, IDRC assisted the African National Congress and Mass Democratic Movement to prepare the policies needed for a post-Apartheid era. 
With its own position in Canada's foreign policy family, IDRC was somewhat insulated from the periodic shift in CIDA's priorities. It was even more isolated from Canada's science policy. The Centre would occasionally reach out to the Minister of State for Science and Technology, and later Industry Canada, but these were relationships were of little consequence in determining the Centre's fortunes.

Canadian universities resented that the Centre did not dedicate more of its resources to Canadian researchers. In response, Ivan Head's tenure saw IDRC's agricultural division station five program officers within Canadian universities, and the Centre adopted a "cooperative program" in 1981 specifically aimed at encouraging collaboration between Canadian researchers and peers in developing countries (Muirhead and Harpelle 2010, 113 and 119). Whereas IDRC in the 1970s had spent under two percent of its funding at Canadian universities, in later years Canadian institutions were involved in as much as one-fifth of IDRC projects. Nonetheless, as IDRC management and Board felt that funding for Canadian scientists should come through the established research granting councils.

\subsubsection{Serving a new master}

The arrival of Prime Minister Brian Mulroney's Progressive Conservative government (1984-93) presented IDRC with a new challenge. While the passage of the IDRC Act had enjoyed unanimous support in Parliament in 1970, the Centre had been conceived under the previous government and had been closely associated with Pearson and Trudeau. 
Indeed the Centre's budget had doubled under Trudeau's second government (19801984) from forty million dollars to over eighty million. The challenge was to position the Centre as an organization the new government could see itself in and continue supporting.

That opportunity came when the new government launched a review of Canada's foreign aid, chaired by William Winegard. A former President of Guelph University, Winegard had been an IDRC governor in the late 1970s, prior to being elected as a conservative Member of Parliament in 1984. Unsurprisingly the committee report endorsed the IDRC's raison d'être. Titled "for whose benefit", the report noted IDRC helped developing countries overcome dependency on "technology conceived and produced outside their borders and without reference to their needs" (Canada 1987). While critical of a number of aspects of foreign aid program, the report simply encouraged IDRC to do more "to ensure the practical application of its research," suggesting staff exchanges with CIDA and greater use IDRC research in CIDA projects. ${ }^{31}$

A more ringing endorsement came the following year as the Office of the Auditor General (OAG) included IDRC in a special report focused on well-performing organizations:

IDRC is considered worldwide to be one of the best organizations of its kind. Its high performance is based on a number of elements: people who are competent,

\footnotetext{
${ }^{31}$ The desire for greater synergy between IDRC and CIDA was a running theme in future reviews, up to the 2007 OECD-DAC Peer Review of Canada.
} 
committed and value-driven; continuity of leadership; a clear and strong sense of mission and purpose; a strong client focus; autonomy and flexibility at all levels; risk-taking and innovation; freedom from political and central agency interference; tailor-made internal regulations and reporting requirements; and continual self-scrutiny of strategies and activities. (OAG 1988)

IDRC thus continued to thrive in the first years of the Conservative government, by 1988 it reached a budget that exceeded $\$ 110$ million per year. Yet continued growth began to strain the organization which had retained essentially the same structure and strategy for almost two decades despite having tripled in the size of budget and staff. Each of the four divisions operated more or less independently of each other, seeking out and proposing projects based on their individual merit, but with little sense of how they might complement each other or contribute to corporate goals.

\subsubsection{New exigencies}

In 1985, management and the Board endorsed a mission and set of objectives for IDRC through the seventh Policy and Program Review: "to support research of direct relevance to and demonstrable potential for Third World development, with relative emphasis on poverty problems; and...to assist developing countries to build and maintain indigenous research... capacity... mainly in terms of human resources." On the surface, these objectives were quite broad, describing the status quo rather than suggesting a change in the direction the Centre intended to pursue. Nonetheless a careful read of this document shows that Centre was struggling with some fundamental questions:

In the early years of IDRC, strategic planning was characterised by a commonly shared philosophy based on a generous mandate allowing considerable freedom to explore, innovate and create... it is now timely to evolve further and to develop 
clearer strategic policy guidelines, beginning with more formal statements of broad Centre objectives (IDRC 1985).

In particular, the Policy and Program Review (PPR) reveals greater emphasis on demonstrating how projects were expected to contribute to development outcomes. The document states bluntly, that the "'burden of proof' for all proposals lies with the proponents, who should explain the socio-economic context and implication of each activity, including how the potential outputs could contribute to the Centre's mission" (IDRC 1985). IDRC would begin layering new expectations on its recipients, not just to conduct sound science with respect to disciplinary norms, but to show alignment with the Centre's programs and to define and reach an audience for their work.

The document also shows that management struggled with the question of geographic balance in its programming. Lower-income countries with higher levels of poverty were arguably in greater need of support, but had a relatively meager base of local researchers and organizations with which to engage. So-called emerging economies, such as India and Brazil, had rising incomes, rising inequality, and an increasingly rich array of research talent. Given the Centre's tendency to be attentive to local researchers, the voices from latter threatened to drown out the former and, given IDRC's limited budget, it was tempting to work where such talent already existed rather than build it from scratch. As had become the Centre's practice, the policy decision was not cast as a choice 
between two extremes, but a question of balance. ${ }^{32}$ At the time, management and the Board decided that in principle IDRC could fund work any developing country, yet proposals from more advanced economies would receive proportionately greater scrutiny and be eligible for less comprehensive support.

In 1986, Head convened a ten-week seminar to re-examine the mandate and function, highlighting a new concern for interdisciplinarity and utilization of research results. $\mathrm{He}$ encouraged the divisions to identify the results of their work and to consider research as a means to achieve development, rather than an ends in its own right. Yet these incremental changes were largely invisible outside of IDRC and hardly sufficient to demonstrate that organization was keeping up with expectations within government. The Centre's involvement in South Africa was useful, but would not be enough to protect IDRC as the government financial situation deteriorated.

In summary, during the first period, the performance regime afforded IDRC a substantial degree of autonomy. Central agencies occasionally sought to reassert control over the Crown Corporation, but the Centre defended its niche within foreign aid by cultivating a network of allies in the bureaucracy. The program theory that guided R4D funding was based on capacity building: strengthening research communities in developing countries to address their own problems. Grantmaking favoured direct project funding to southern

\footnotetext{
${ }^{32}$ Hopper (1973) had set this pattern with an essay identifying 'Eleven policy issues' on which IDRC needed to choose a path incorporating competing goals, such as: support research at home and abroad, on topics identified by proponents and those selected by IDRC staff.
} 
recipients, loosely linked to the themes of information, health, agricultural or social science.

\subsection{Budget Cuts and Transformation}

When Keith Bezanson became the IDRC President in 1991, he inherited a Centre that had changed little over time. Over two decades, the Parliamentary appropriation for IDRC had grown from $\$ 5$ million to $\$ 114$ million/year, and the number of staff had expanded to over six hundred (IDRC 1991; Beemans 1999). Nonetheless the Centre retained thematic

divisions that would have been easily recognizable to Hopper or any of the original IDRC governors. In contrast, the coming decade would be a turbulent period that would see IDRC's status threatened once again and its budget slashed on two occasions. The combination of these shocks, along with changing ideas on how to organize science, provoked a substantial restructuring of the Centre.

Whereas Head had come from the world of politics, Bezanson came from the public service. He had worked for CIDA for much of his career, and served as Canada's ambassador to Bolivia and Peru in the mid-1980s, before joining the Inter-American Development Bank. He knew about development and foreign policy, and came to IDRC with definitive views that the Centre had grown too complacent: confident in its own inherent value, but with little sense of how it connected to the rest of government (Muirhead and Harpelle 2010, 208). 
With the approach of the Centre's twentieth anniversary, Bezanson was the lead author of a new strategy for IDRC (1991), finally replacing Hopper's inaugural speech. IDRC's mandate was recast as "empowerment through knowledge": encouraging "the creation, adaptation, and ownership of the knowledge that people of developing countries judge to be of the greatest relevance to their own prosperity, security and equity." While the strategy retained the essence of Hopper's original program theory, Bezanson was convinced that the concept of development had to fundamentally change with the end of the Cold War and rise of globalization.

\subsubsection{Response to a bear market}

Bezanson was determined to focus programs and reduce operational expenses. Upon taking office, he was shocked to learn that the Centre was spending close to $40 \%$ of its budget on operating expenses and staffing. He immediately set a target ratio of 70:30 between programming and operational expenses. His approach was two-fold. First, Bezanson sought to boost the value of programming handled by each program officer, by encouraging southern institutions to manage the day-to-day technical and financial management of projects. Second, Bezanson obtained commitment from the Board of Governors to reduce the staff by twenty percent, taking the unprecedented step of sending a copy of the new strategy to the Paul Tellier, Clerk of the Privy Council, along with a written note promising this reduction (Stockdale 1995). 
While such steps would not make Bezanson popular among staff, he would prove to be the right person to adapt the Centre to a changing performance regime. Canada's foreign aid budget had grown at seven percent per year throughout much of the 1980s, much above the rate of growth of the national economy. By the 1990s, the national debt was a rising concern and the decade ahead would see reductions in government spending in order to balance the books. Furthermore, the government faced new pressures with the collapse of the Soviet Union. The 1991 federal budget scaled back the growth of aid to three percent and announced that aid would be embedded into a new "International Assistance Envelope" which allowed for non-ODA spending in Eastern Europe. Facing slower growth and new pressures, it was only a matter of time before there were implications for IDRC. The first impact came in April 1991 when it was informed that \$7 million of its budget would be repurposed to help Canada address famine in Africa (IDRC 1992). In nominal terms, this returned the parliamentary funding for IDRC back to 1988 level, making a reduction in spending inevitable.

By the end of the fiscal year, the number of IDRC staff went from 592 to 486 persons. Bezanson encouraged the Centre seek out opportunities to do contract research on behalf of other organizations, as well as co-funding from other donors in IDRC projects. Referred to in-house as "resource expansion," the intent was to diversify IDRC's sources of revenue: to compensate for the reduction of parliamentary funding by hosting big ideas that would leverage funding from outside sources. Pierre Beemans, then an IDRC vicepresident, (1999) would later note "rather than cut our programs to fit our budget cloth, we decided to try to attract other funding agencies to invest in our activities or to join 
with us in jointly-managed ones." Within a few years, Bezanson would boost that "about a fifth of all IDRC projects now involve at least one other funding agency. In addition, most Centre projects provide for contributions in cash or kind from recipient institutions" (IDRC 1994). IDRC would argue that its status as a Crown corporation was justified in order to receive such funds.

A key example was IDRC hosting a "Micronutrient Initiative", started in 1992, to address deficiencies in vitamin $\mathrm{A}$, iron, and iodine in the diets of people in developing countries. The initiative attracted support from the World Bank and would be the first time that the government provided a special purpose appropriation to the Centre, essentially earmarking funding to this specific initiative rather than providing core support to the IDRC Board. The Micronutrient Initiative would eventually leave IDRC in 2002 as a stand-alone legal entity. Another example was the "essential health interventions" project under which IDRC, World Bank, and CIDA set out to test the assertion in the 1993 World Development Report that a small increment of funding could dramatically reduce mortality through better targeting of health care to the local burden of disease. Over the decade, pilot results in two districts of Tanzania, including a 40\% decline in child deaths, provided the proof of concept that attracted support from the UK charity Comic Relief to scale up the efforts across the country.

\subsubsection{Renewed mandate under Rio}

No sooner had IDRC begun to adjust to a smaller budget, than its status as a Crown corporation was once again threatened. Since the late 1980s, the Mulroney government 
had been reviewing Crown corporations, in an effort to reduce government spending and "letting market forces take the initiative to enhance Canada's competitiveness" (Canada 1991, 76). The effect was to eliminate many Crown corporations altogether through privatization, merging their operations into line departments, or simply reducing government funding to them. The federal budget in 1992 announced the elimination of forty-six government entities. Small and less visible to Canadian citizens, IDRC was originally considered for inclusion in this list (Muirhead and Harpelle 2010, 209).

Last minute efforts by Hugh Segal, then Mulroney's Chief of Staff, modified the budget's reference to IDRC (Stockdale 1995). Instead of eliminating the Centre, the government now intended to "introduce legislation to change the IDRC's legal status to that of a departmental corporation... [to] bring its administrative regime into conformity with that of the rest of the public service, while maintaining the Centre's distinctive research function and its international board" (Canada 1992, 128). Pierre Beemans would subsequently recall the lack of domestic outcry "gave us a vivid idea of how alienated IDRC had become from its Canadian roots," and management once again learned the need to "cultivate senior decision-makers in DFAIT, CIDA, PMO/PCO, [and] Finance" (Beemans 1999).

The threat to IDRC's status was short-lived and the promised legislation was never introduced. Instead IDRC was granted a new lease on life in June 1992, just months after the February budget. 
As world leaders convened in Rio de Janeiro for the United Nations' Conference on Environment and Development (UNCED), the relationship between developing countries and industrialized ones was once again in the forefront of international relations. The model of IDRC, investing in local researchers to address their problems, was a good fit with the emerging discourse of North-South cooperation. More importantly, one of IDRC's original champions, Maurice Strong, was chairing the conference and had numerous opportunities to engage the Canadian delegation and Mulroney himself (Muirhead and Harpelle 2010, 228).

Whether through policy fit or personal lobbying, the Prime Minister announced that IDRC's mandate would be broadened "to emphasize sustainable development issues... [and] help to ensure a quick start on implementation of the UNCED Agenda 21 program”. Furthermore, the Prime Minister committed to provide \$115 million annually in core support to the organization, noting that this would total more than $\$ 1$ billion over the next ten years. Bezanson grabbed hold of the Prime Minister's endorsement, and within a month IDRC released a volume describing how it current and future work contributed to this "expanded" mandate.

Agenda 21 was an unwieldy six-hundred page document, which made it fairly easy for management to find a link between the projects IDRC already supported and the various entry points it provided. The match was hardly accidental either as IDRC had hosted part of the Brundtland commission's consultations in the mid-1980s and was the repository of the commission's archives following the publication of "Our Common Future." The year 
1992 would nonetheless become a turning point as the Centre embraced "sustainable and equitable development" as the principle underpinning all its work. While the Centre continued to be organized along thematic divisions, a new three-year corporate program framework emphasized how projects contributed to sustainable development, under the themes of biodiversity, food, technology, policies, and information. The long-standing focus on agriculture and rural development began to evolve towards environmental and natural resource management. Meanwhile, the Centre began to offer training and support in environmental economics in Southeast Asia, and contributed to the new field of environmental health by tracing the cause of mercury contamination through the food chain in the Amazon.

\subsubsection{Redefining the value of research}

Mulroney's promise of sustained funding for IDRC would disappear with election of Jean Chrétien's Liberal government (1993-2003). Within two years the federal government conducted a sweeping "program review" that reduced spending across the public service. Between 1995 and 1997, the International Assistance Envelope was scheduled to reduce from $\$ 2.6$ billion to $\$ 2.1$ billion a year, equivalent to a $21 \%$ cut (Canada 1995). In nominal terms, the Parliamentary appropriation for IDRC was reduced from \$112 million to $\$ 96$ million. In real terms, the combination of cuts during the 1990 s had now reduced the appropriation by $35 \%$ (IDRC 1995a). Furthermore, as much of its funding in any given year went to pay expenses on projects approved in previous years, IDRC had to cut its 1995 allocation budget for new projects by $30 \%$. 
By the summer of 1995, Bezanson led management through an exercise that John Hardie (director of planning) would later describe as simultaneously downsizing, restructuring, and reorienting thinking to new philosophy (quoted in Muirhead and Harpelle 2010, 259). A smaller budget meant a further need to reduce expenses: the number of IDRC staff would shrink to 427 by the end of the fiscal year, and to 347 by 1998 . The health sciences division disappeared almost entirely: reduced to the single project on health care in Tanzania and the modest set of projects on human-environmental health. After twentyfive years, the old disciplinary divisions were collapsed into a single "programs branch."

Program officers were now assigned to time-limited teams, or "program initiatives". The Board of Governors would no longer approve individual projects; instead Board approval of a program-level strategy for each of these initiatives would authorize IDRC staff to approve projects in line with that strategy. Programs were expected to "define a research problematique and... address it over a given time period (3-5 years); establish networks among recipient institutions... [and] bring in external funding" (IDRC 1995b). In return, each program would undergo an evaluation, called an external review, at the end of its life which would inform the Board's decision whether to renew, modify, or close the program.

More generally, the structure of program initiatives was expected to address changing ideas about what constituted effective research. IDRC management was particularly taken with the idea of 'mode 2' science (Slaymaker et al. 1998; Steele 2002). The old division structure was seen to have focused on researchers working in isolation producing 
disciplinary knowledge on problems defined in academia, what Gibbons et al (1994) refer to as 'mode 1', whereas the new program initiatives were expected to support participation of poor people and policymakers in jointly solving interdisciplinary problems identified in society, or 'mode 2'. More generally, the program initiatives were IDRC's response to a changing performance regime. A few years earlier, staff had noted that "[t]he competition for funds is rising" requiring managers to "ensure utilization of research results and use evidence of impact to convince the public and decision-makers of the value of research efforts" (Daniels and Dottridge 1993). Management would subsequently caution that "[i]n a period of scarcer resources, science has had to become more accountable. Inputs and outputs were to be measured and science supply was to be integrated with market demand" (Slaymaker et al. 1998).

The program initiatives were IDRC's new way of doing business. While IDRC continued to fund research projects, the list of expectations of what these projects were supposed to achieve had grown. While often referred to as "capacity building", this was described as IDRC assistance to developing country researchers in "designing and monitoring projects, interdisciplinarity and research utilization, linkages with peers and scientific networks to access new ideas and methods, [gain] greater confidence and experience, [and] enhanced profile and credibility" (IDRC 1996). More generally, in a second corporate program framework, adopted in 1996, IDRC placed 'research capacity' second to an emphasis on "policies and technologies that enhance the lives of people in the developing regions". Research-for-development was expected to lead "directly to 
sustainable improvement in the quality of human existence, or... improved understanding of factors that affect development" (Slaymaker et al. 1998).

\subsubsection{New leadership, new ambition}

In 1996, Bezanson was given a new, one-year term as IDRC President, fuelling rumours that the government intended to close the Centre. Sensing an opportunity, the University of British Columbia proposed to host a 'virtual centre' that would essentially replace IDRC, retaining some of the research funding and tapping into expertise across Canada, not unlike Pearson's vision. The proposal was led by UBC President David Strangway, and supported by former IDRC President Ivan Head then based at the university. The threat to IDRC was once again neutralized by Strong, who led a task force examining how Canada connected to the world. The task force report argued that stature on the international stage was increasingly linked to intellectual capacity and less on the size of the economy, and positioned IDRC as strategic asset for Canada acting as a knowledge broker with emerging economies. In receiving the report, the new foreign minister Lloyd Axworthy rejected the UBC proposal and offered Bezanson an additional mandate (Muirhead and Harpelle 2010, 263-64). Yet the turbulence at IDRC had taken its toll, and Bezanson already had plans to move to the University of Sussex as the director of its Institute of Development Studies.

In his place, Maureen O’Neil was appointed as IDRC President in April 1997. With a list of accomplishments that included President of the North-South Institute and Deputy Minister for Citizenship in the Ontario government, O’Neil combined an understanding 
of international development and knowledge of how to navigate the machinery of government. She was soon joined in June by the appointment of Gordon Smith as chairman of the IDRC Board. A former Deputy Minister of Foreign Affairs, Smith once again provided IDRC with the high-level gravitas that would convince government that a steady hand was in charge overseeing IDRC management.

Following the trauma of the program review years, the end of the decade was the beginning of a period of calm. The federal government started realizing surplus budgets once more. Over the next twelve years, the government would invest an additional $\$ 13$ billion in Canadian research (Doern and Stoney 2009, 10-11). The expanding resources benefited the granting councils and funded new mechanisms including the Canadian Foundation for Innovation (for science infrastructure at universities), Genome Canada (for the genetic sciences), and Canadian Research Chairs (to attract Canadian talent to stay or return home). The new funding also enhanced the importance of university-based research in Canada, as the boom in spending largely bypassed government labs and science-based departments.

As the parliamentary appropriation for IDRC came from the foreign aid budget, the Centre did not directly benefit from increased science spending, but indirectly it enhanced the legitimacy of the Centre's work. Research was recognized as important for Canada's own development, therefore it followed that it should be important to the development of other countries as well. This message as reinforced by the World Bank which served to provide an external validation of the message IDRC had long preached. 
In 1996, World Bank President James Wolfensohn outlined a vision for changing the organization into a "knowledge bank" - echoing one of competing perspectives for IDRC at its origins - and in 1998 the Bank's flagship World Development Report was dedicated to the theme of "knowledge for development."

It was in this more favourable performance regime that O'Neil guided the Centre to prepare a new five-year corporate strategy (2000-05). The program initiatives were regrouped under three areas: environmental and natural resource management, social and economic equity, and information and communication technologies for development (ICT4D). O'Neil also continued to shift IDRC's value proposition towards 'influencing policy' rather than merely 'building capacity'. The phrase "closing the loop" entered the corporate vocabulary representing a conscious push to ensure that findings reached policymakers and other audiences able to act on such findings. This goal was subsequently described rather bluntly as "IDRC wants to be able to demonstrate to those who influence or control our funding that we support research that produces useful development results" (IDRC 2002).

In summary, during the second period, starting in 1991, the performance regime was characterized by waves of budget cuts in the federal government, heightening demands to control operating costs and to demonstrate the utility of research. The program theory that guided R4D funding emphasized policy influence, seeing research as an input into local efforts to address poverty abroad and expecting recipients to connect with an audience 
that would act on their findings. Following restructuring, IDRC continued to offer project funding, but required that these contributed to Board-approved program strategies.

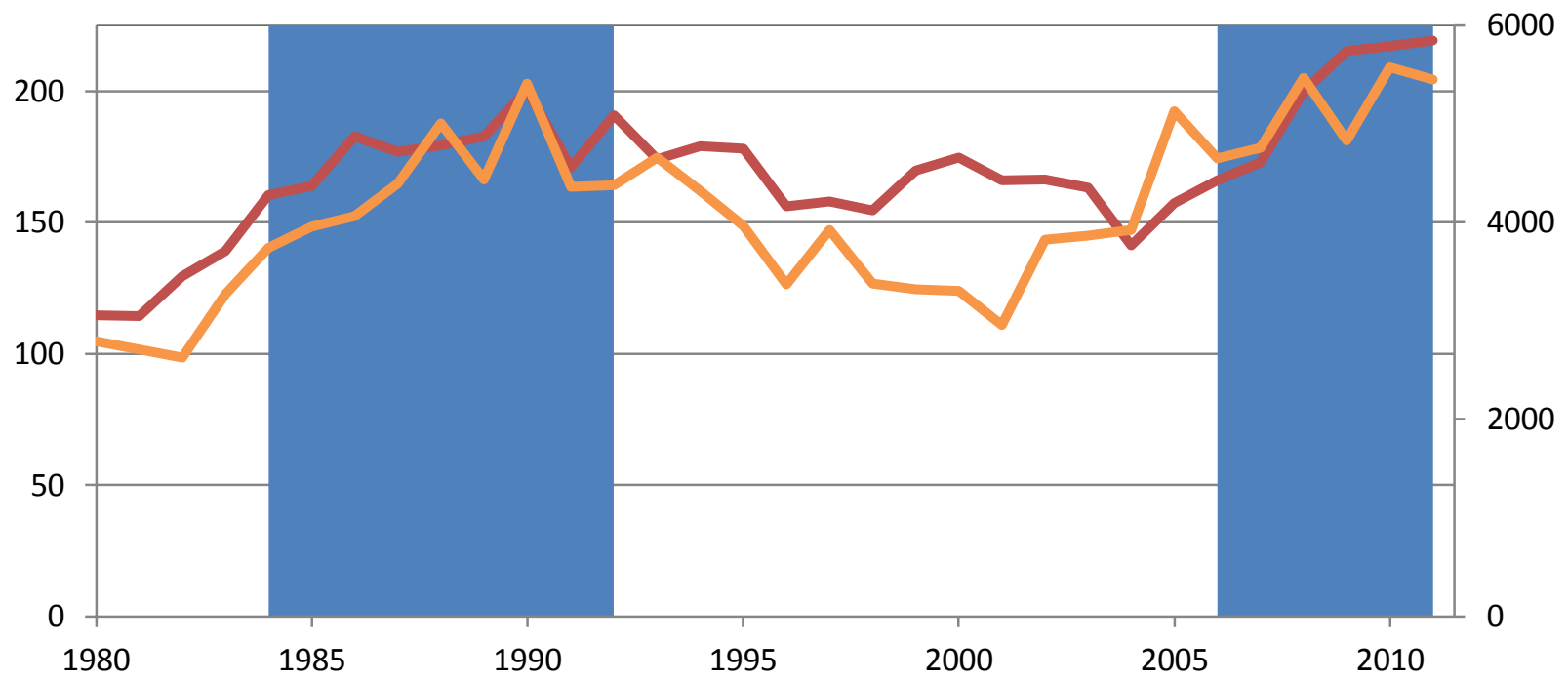

Figure 10: Canada's R4D spending since 1980. IDRC expenditures in red (left axis) compared to Canada's official development assistance (right axis). A push to diversify sources of revenue softened the reduction in Parliamentary appropriation in the 1990s. The allocation dedicated to the Micronutrient Initiative (1997-2002) hides the low point and slow increase in IDRC 'core' funding. All amounts are expressed in real terms as million CAD adjusted to 2011. The years shaded in blue represent time when Conservative party was in power. (Sources: IDRC Annual Reports and OECD statistics) 


\subsection{Eroding Core}

The year 2002 would prove to be the start of a decade that would transform the performance regime surrounding IDRC. After the turbulence of the 1990s, the arrival of Maureen O'Neil and launch of a five-year strategy was a new beginning for the Centre. Coming out of the Monterrey conference on financing development, Canada committed to doubling its official development assistance, and soon established a timetable for doing so via annual eight percent increments to its aid budget. The next federal budget committed that IDRC would receive a proportional eight percent increase in its funding during each of the next two years (Canada 2003, 169), thus cutting through the old haggling with CIDA over the amount of the parliamentary appropriation. IDRC and central agencies had advocated for greater transparency in how funding decisions were made, and behind the scenes DFAIT and CIDA began work on a new management framework for the international assistance envelope (IAE).

IDRC's second five-year strategy started in 2005 which attempted to tidy the structure inherited from the previous ten years. The Centre retained the three program areasICTs, environment, and socio-economic — each of which housed a small number of program initiatives, now firmly entrenched as the Centre's preferred way of organizing its work. Despite the increasing budget, the overall number of program initiatives was reduced, with the intent to have larger teams - that would be less vulnerable to turnover in IDRC staff-with a global remit, rather than focusing exclusively on Africa, Asia, or the Americas. A diverse array of corporate projects, explorations, and secretariats had 
evolved in the late 1990s and early 2000s as part of the Centre push to diversify revenue. These were now systematically pared back, converted into stand-alone legal entities, merged into program initiatives, or transferred to institutions outside of IDRC. For example, the Model Forests Secretariat moved back to Natural Resources Canada, and the Institute for Connectivity in the Americas was integrated into the ICT4D program area.

Beyond such changes in organization, O'Neil continued to press a change in purpose, reinforcing the new mantra of "research for policy influence." This goal was enshrined in the new strategy (IDRC 2004, para 62) and the work funded by the various programs was expected to be informing policy making that would benefit poor women and men (Carden 2009). The Centre continued to view the world in terms of geographic regions, rather than focusing on particular countries. The earlier 2000-05 strategy had committed the Centre to spending half of its budget in Africa, and a quarter in each of Asia and the Americas. These notional targets continued to guide management as a rule-of-thumb, but the formal tracking and reporting on such was abandoned in the 2005-10 strategy. This was due to the simple difficulty of trying to parse project spending that involved multiple regions or that did not have an obvious geographic footprint, for example the benefits of new seeds could touch multiple regions no matter where the initial research was carried out. 


\subsubsection{Competing for new funds}

Budget 2005 introduced the new management framework for the international assistance envelope (IAE). The framework distinguished five categories, or "pools," of activities eligible for funding: development assistance to poorer countries, initiatives to enhance global peace and security, contributions to the international financial institutions, responses to humanitarian crises, and support for development research (Canada 2005, 217). At one level, the framework simply affirmed the status quo, recognizing the distinct interests of CIDA, DFAIT, the Department of Finance, and IDRC. Yet, at another level, beyond what was contained in the Budget, the framework laid out a process for allocating the promised increases of funding in future years.

No one minister would control the IAE, instead senior officials would facilitate a "competition of ideas," collecting and assessing proposals for how the incremental funds could be used. Government officials would then prepare options, or packages of proposals, for deputy ministers who would prepare a recommendation for Cabinet that was supported jointly by the three minsters for international cooperation, foreign affairs, and finance.

De jure, IDRC held a weak position within this competition of ideas. Budget 2005 assigned a lead manager for each of the "pools," making DFAIT responsible for development research. IDRC was expected to submit its ideas through DFAIT, placing that department in the dual roles of both representing IDRC interests while also 
presenting arguments in favour of its own initiatives. On occasion, IDRC might be invited to attend part of a meeting, at the working level or ADMs, to provide a fuller description of its proposals, but the Centre was always excluded from the final negotiation among deputy ministers.

Yet IDRC found ways to enhance its de facto position within the IAE away from the negotiating table by interacting with — and seeking support from-CIDA, DFAIT, and Finance. The Centre had constructive relations with all three organizations, aided by the fact that CIDA, DFAIT and Finance were genuinely interested in parts of the IDRC program framework, whether health and environment, peace and conflict, or development economics. At the same time, the IDRC requests for additional funding were modest and at a scale that did not necessarily compete with these organizations' own funding requests. This was an intentional tactic on behalf of IDRC management, which sought to maintain the Centre's parliamentary grant at roughly four percent of the envelope, pitching for incremental funding to expand existing programs.

IDRC staff also interacted with Privy Council Office and Treasury Board officials. These central agencies did not have a vested interest in the allocation of new IAE money, and often advocated in favour of including IDRC, up to the point of decision-making. They would also provide further feedback on how the allocation process was unfolding, clarifying the evolving criteria used to assess proposals. 
The arrival of Stephen Harper's Conservative government (2006-) did not immediately alter this "competition of ideas" process. The new government was quick to dissociate itself from the Liberal's international policy statement, released in 2005, yet the IAE framework persisted and IDRC was initially able to continue its strategy of modest requests for incremental funding. The Centre would trawl through its pipeline of proposed projects and identify items that resonated with what government was interested in funding. While the justification for the funding request was based on what each IAE partner promised to do in the short-term (one-to-three years), the allocation of incremental resources was ongoing. In the words of one official, it was "forever money" that was added to the organization's reference level, which TBS used as a base for departmental spending in future years. Thus any funds allocated to IDRC amounted to an ongoing increase in its Parliamentary appropriation. In the medium term, these new resources promised to become core funding available for the IDRC Board to allocate as it saw fit.

\subsubsection{Donor partnerships and government agendas}

In the short term, IDRC obtained new resources for projects the Centre largely wanted to fund anyway. Thus the 'competition of ideas' freed up existing resources. One way the Centre used this new-found freedom was to negotiate a new round of program-level partnerships with other donors, including on climate change adaptation in Africa with the DFID, and an initiative to support policy research "think tanks" with the William and 
Flora Hewlett Foundation. ${ }^{33}$ Such partnerships represented a conscious move away from the indiscriminate "resource expansion" of the 1990s which had focused on time-limited project funding from any organization, toward ongoing program-level collaboration with like-minded organizations. The new practice focused on a select set of "donor partners," avoiding those that had proven difficult to work with, whether due to conditions placed on their funding or a tendency to micro-manage how IDRC used the funds. IDRC's intention was to enter into true partnerships with other funders, investing Centre funds in order to avoid being seen as merely an implementing agency.

Within official Ottawa, such donor partnerships were a double-edged sword. On occasion the Department of Finance suggested that since IDRC was successful at raising funds abroad, it did not require as much support from taxpayers. IDRC management responded, not inaccurately, that it was the ability to leverage Canadian funding that had allowed these partnerships to occur. More often than not, however, IDRC's ability to attract funding from outside Canada was viewed positively and interpreted as passing a form of "market" test. After all, if UK taxpayers and private philanthropists thought working with IDRC was a good use of their funds, why should it not also be good for Canadian taxpayers?

The new government's initial priorities for foreign policy emphasized Canada's NATO mission in Afghanistan, asserting Canada's sovereignty in the Arctic, and enhancing

\footnotetext{
${ }^{33}$ The first example with DFID represented over CAD\$ 50 million over five years, while the second example eventually grew to CAD $\$ 115$ million when the Bill \& Melinda Gates Foundation joined.
} 
commercial and security relations in the Americas. IDRC management picked up on the imperative to contribute to rebuilding Afghanistan, but conditions on the ground presented a challenge to IDRC's usual "hands-on" approach. Security concerns restricted the ability of IDRC staff to visit that country and much of the Afghan research community had already emigrated. The Centre eventually funded a handful of projects, including modest support to Kabul University to collaborate with other institutions of higher education throughout the Hindu-Kush mountain range. Yet these projects were largely designed and supported through the IDRC Regional Office in New Delhi, with no engagement in the cross-government task force, initially led by DFAIT, and later coordinated out of Privy Council Office.

IDRC was much better positioned to engage the government's agenda on the Americas. Once again, the IDRC Regional Office in Montevideo played a vital role, keeping IDRC programming visible with Canada's ambassadors in the region and designing an initiative that engaged think tanks in Latin American countries to analyze their countries contributions to Haitian security and development. By and large, however, such efforts were considered a modest nod towards government priorities, in the words of one IDRC official, "an investment of two percent of the budget to protect the remaining ninety-eight percent" of IDRC programs (CA-01). 


\subsubsection{Re-engaging natural sciences}

The change in government did encourage a shift in IDRC programming on science and technology policy. After a long absence from the field, IDRC created a new program area in 2005 , motivated in part by renewed enthusiasm for advances in science to help achieve development goals (UN 2005) echoing the discourse of the 1970s. IDRC management sought to seize upon the Prime Minister Paul Martin's promise to devote five percent of Canada's R\&D to "a knowledge-based approach to develop assistance for less fortunate countries" (Canada 2004). Initially, IDRC expected this new program area to enhance the positive impact of new technologies, strengthen innovation and science policy in developing countries, and foster collaboration with Canada's research granting councils.

Under Harper's Conservative government, the international tone of Canada's science policy soon turned from altruistic assistance to poorer countries, toward enhancing Canadian participation in international collaboration. In 2007, a new federal science and technology strategy identified four thematic priorities - including environment, natural resources, health, and ICTs - which closely matched IDRC's own priorities. Over the coming years, the government would express an expectation that public research funding would enhance the competitiveness of Canada's industry.

A substantial amount of the work funded under the new program area soon came to focus on international collaboration, including an initiative to twin southern researchers with Canadian Research Chairs and joint calls with the Canadian Institute for Health Research 
(CIHR) and the Social Sciences and Humanities Research Council (SSHRC). In each case, the granting council funded the participation of Canadians while IDRC funded the participation by developing country scientists. Whether by coincidence or following the shift in government priority, IDRC placed proportionately less emphasis on new technologies or S\&T policy in other countries.

While the foreign aid budget had increased since 2002, Canada's science budget had been growing since 1997 and there was a growing appetite among Canadian universities for international collaboration. IDRC encouraged joint calls with the granting councils out of a mixture of self-interest and altruism. On the one hand, such partnerships helped raise the Centre's profile within Canada, tapping into the positive image and support the government afforded to science funding. Launch events became opportunities for ministerial announcements that put IDRC in the spotlight, including one event held within the Parliamentary precinct. On the other hand, IDRC genuinely sought to share its experience on international research collaboration. When the Centre explained its procedures for grant administration, including how it dealt with multiple recipients in multiple countries and currencies, the reaction of one granting council official was "IDRC manages nightmare projects" due the complexity involved. Furthermore the granting councils were used to focusing on the front-end in terms of peer-review selection of grant proposals, and were surprised to learn of the amount of attention IDRC invested in on-going project monitoring. 
An expanding budget for IDRC allowed health programming to thrive once again. The project on essential health interventions in the Tanzania slowly expanded to a new program initiative working on the governance of health systems and financing health care. This work was initially housed under the social-economic program area, but soon grew beyond it as IDRC also began to tackle electronic information systems and the use of mobile devices in health care. In 2008, IDRC re-established health as a separate program area, no longer subsumed under social and economic policy.

\subsubsection{Government looks inside}

Starting in 2007, the Conservative government launched a series of "strategic reviews" under which each year a number of departments were asked to assess the entirety of their existing programs. Each review was to identify at least five percent of department spending that was performing less well, or was considered a relatively lower priority. The initial intention was to identify opportunities to redesign programs and better align them with government priorities, yet over the subsequent four years, the reviews came to focus more on simply reducing government spending.

In this respect, IDRC was fortunate to be included in the first year of the strategic review, when the process still permitted departments to propose options for reinvesting the five percent of funding under examination. DFAIT and CIDA were already included in this round which launched in spring 2007. IDRC was added as an afterthought in early summer, as PCO considered it useful to look across the entirety of the international assistance envelope. Coming into the process late, IDRC conducted its own review, 
coordinating with DFAIT and CIDA, but preparing its own submission to Treasury Board. The Centre was allowed to retain its funding, which was to be reallocated to programming more closely aligned with government priorities. The quality of the IDRC submission no doubt helped, as did the opportunity for O'Neil to plead her case directly before Treasury Board ministers. ${ }^{34}$

The logic of the strategic review worked against the ongoing growth in the international assistance budget. Any savings identified among the IAE organizations would have to be replaced if Canada's was to meet its ongoing commitment to double foreign aid. Indeed, the "competition of ideas" process continued parallel to, and disconnected from, the strategic review. ${ }^{35}$ Yet the Cabinet-driven strategic review was arguably the higher-level of the two processes. Ministers had begun to see the "competition of ideas" as captured by the bureaucracy; a collusion among officials on how to divide IAE funding among themselves and their departments' interests. The strategic review previewed an interest among IAE ministers to get beyond merely allocating the incremental eight percent increases in funding and instead review the entirety of what was funded under the IAE.

In 2008-09, Cabinet established a new set of five thematic priorities for the envelope: stimulating economic growth, increasing food security, securing the future of children

\footnotetext{
${ }^{34}$ The IDRC Chairman, Gordon Smith, was originally intended to make this presentation, but - - being based in British Columbia - he was unable to attend when the Treasury Board meeting finally occurred after being rescheduled and postponed due to other Parliamentary business.

${ }^{35}$ During the summer of 2007, IDRC was also subject to a Special Examination by the Office of the Auditor General. Treasury Board Secretariat and OAG officials did not coordinate their separate reviews, and required IDRC management to keep each process confidential.
} 
and youth, ensuring security and stability, and advancing democracy. CIDA was considered the lead agency for the first three priorities: responding to the twin crisis in global finance and food prices then rippling across the world. The banner of "children and youth" combined the agency's long-standing work in education and health. In contrast, DFAIT was considered the lead for the latter two priorities, given the department's interest in global security and international relations. Whereas the previous Liberal government had emphasized "good governance," the Conservative government was interested in "democracy promotion". The 2008 Speech from the Throne contained a promise to establish a new agency for this purpose (Canada 2008).

As part of the thematic review, IAE ministers defined new criteria to assess the spending proposals, including the extent which they: aligned with the government's thematic and geographic priorities, placed Canada in a leadership position, built on proven approaches, were able to demonstrate clear and measurable results, and fostered innovation by leveraging funding and efforts from beyond government.

\subsubsection{Finance drives innovation}

IDRC was inherently well placed to take advantage of the criteria of innovation and partnership. Yet in practice, the Department of Finance drove the definition of "innovation" in two distinct ways. First, it was an explicit challenge to CIDA and DFAIT to avoid proposals that simply sought more resources to do the same type of programming as in the past. Ministers were interested in using the IAE to do things that were new, different, and transformational. Second, the Department of Finance brought 
forward its own proposals for using Canada's foreign aid dollars, not as grants to developing countries or contributions to international organizations, but as an incentive to encourage the private sector to develop new technologies and services.

An early example of this approach was the announcement in 2007 of an advance market commitment (AMC) in which Canada and other donor countries would offer a guaranteed price for a successful pneumococcal vaccine (Canada 2007, 265). The idea was to overcome the market failure caused by the high costs of research required to develop such a vaccine, which could not easily be recovered from the price required if the product was to remain affordable in developing countries where it was most needed. Rather than underwrite the costs of research up front, which may or may not be successful, the AMC approach sought to transfer this risk to pharmaceutical firms, guaranteeing a price that would suitably reimburse costs once a successful product was developed. The appeal of such an approach was the availability of information on the number of potential beneficiaries and estimated R\&D costs, which permit the calculation of the required price.

Using similar logic, the Department of Finance subsequently championed an "agricultural pull mechanism"- later rebranded as "AgResults"- to encourage the private sector to develop and distribute technologies that could boost harvest quality (such as reducing aflatoxins in groundnuts) or reduce post-harvest loss (such as grain storage bags). The design of AgResults contemplated not only a prize for developing such products, but also a premium based on the numbers of farmers that adopted it (AusAID 2012a). 
IDRC found itself outside of IAE management, and increasingly sidelined in shaping Canada's policy for "innovation" and "development research".

Unique among the IAE organizations, the Department of Finance played a dual role as not only a proponent of its own ideas, but as a central agency shaping funding decisions. On more than one occasion, the department simply bypassed the seemingly consensual "competition of ideas," to pre-commit IAE funding through the federal budget without consulting CIDA or DFAIT. For example, Budget 2008 dedicated an initial $\$ 50$ million for a new Development Innovation Fund "to create breakthrough discoveries with the potential to significantly improve the lives of millions in the developing world" (Canada 2008, 182-83). While the budget text mentions that this fund would be implemented by "partners in the research community working with" IDRC, the announcement came as a surprise to the Centre, as well as to CIDA and DFAIT.

The idea had originated with Dr. Peter Singer at the University of Toronto, a recipient of funding from the Bill \& Melinda Gates Foundation's Grand Challenges in Global Health program. Singer proposed to establish a similar initiative in Canada in the form of an independent foundation. The previous Liberal government had established a number of such for-purpose organizations, including Genome Canada and the Canadian Foundation for Innovation. Yet, under the Conservatives, there was little appetite for creating new organizations, especially as the OAG (2005) had recently critiqued the lack of government oversight and the accountability of such foundations. 
The Development Innovation Fund would not become operational until 2010, as a fiveyear, \$225-million initiative. Part of the intervening time involved haggling among IAE partners to strike a deal that saw responsibility for the fund transferred to the Minister of Foreign Affairs from the Minister of Finance, who had championed the idea and whose riding included the University of Toronto. A new entity was established-Grand Challenges Canada - the funding for which would be routed through IDRC. The Centre would be responsible for evaluation and reporting on the Fund, while the Canadian Institutes of Health Research (CIHR) would manage the peer review process towards selecting new projects. Both IDRC and CIHR would participate in the board of directors governing Grand Challenges Canada.

The Development Innovation Fund announcement marked two distinct turning points for IDRC. First, it confirmed the Centre no longer held a monopoly over "development research." IDRC had to compete not just with other uses of foreign aid budget, but also with other entities and initiatives with different approaches to R4D. Second, the Centre could no longer simply argue for an increase in its core funding. IAE decisions were increasingly bound to discrete, time-limited initiatives. Moving forward, once an initiative expired — or "sunset" — its funding would no longer automatically remain in the entity's reference level, but was in principle "free" to be allocated anywhere in the envelope for any purpose. In the medium-term, this was supposed to increase the amount of the foreign aid budget which ministers could allocate as they saw fit, rather than tying it up in department budgets. 


\subsubsection{Updating the business model}

In mid-2008, David Malone took over as the IDRC President. A career diplomat, Malone's experience spanned decades and included postings as Canada's ambassador to the United Nations and to India. ${ }^{36}$ He admired how the legacy of IDRC programming created a network of influential people who thought well of Canada. Malone defined himself as a scholar, previously taking leave from government to manage the International Peace Academy in New York, and continuously writing books and articles on international relations. Fresh from the Strategic Review experience, the IDRC Board of Governors expected Malone to cultivate contacts in official Ottawa who appreciated the Centre as aligned and useful to the government's agenda. The OAG completed a Special Examination of the Centre in 2008 which gave IDRC a clean bill of health. Thus the challenge facing the new President was more about external relations than internal management.

In 2009, IDRC once again crafted a five-year strategy. The biggest shift was a decision to discontinue the program area dedicated to information and communication technologies for development (ICT4D). Having justified itself as overcoming the "digital divide," the explosion of Internet access and mobile phone use in developing countries was seen by IDRC management to have partially satisfied this objective. What ICT4D required now was deeper investment in scaling-up, which was beyond IDRC's niche of incubating new

\footnotetext{
${ }^{36}$ Malone was also the Assistant Deputy Minister responsible for international assistance when the IAE 'competition of ideas' was introduced.
} 
ideas and pilot projects (Canada 1970, s2b). Some employees were transferred to work on ICT applications in health or agriculture, while a smaller team was retained in the science program to address issues related to open government, science, and education.

Meanwhile the global crisis in food prices in 2008-09 encouraged a shift back to agriculture, through a new partnership with CIDA to establish a competitive food security research fund for collaborative projects involving Canadian and developing country scientists.

Apart from these shifts, the Strategic Framework 2010-15 brought about incremental change in IDRC's structure and programming on the environment, health, and social and economic policy. The Board and management chose to persist with its practice of thematic programming, first choosing the problems to address, then finding prospective recipients with interesting ideas, which determined the geographic footprint of its programming. CIDA announced a new list of focus countries for Canada's bilateral aid in 2009. Yet IDRC did not see itself as bound to this list, as its projects involved and benefited multiple countries. In this regard, IDRC enjoyed the passive endorsement of senior government officials—including the CIDA President—who saw the list as governing CIDA spending and considered IDRC too small to warrant much attention. ${ }^{37}$ At the working level, officials from CIDA and Treasury Board Secretariat were often less understanding, and the list played a role in shaping which countries were eligible for joint CIDA-IDRC partnerships, such as a new food security research fund. Meanwhile, DFAIT

\footnotetext{
${ }^{37}$ IDRC managers spoke with these officials and obtained verbal commitments, but no public or written statements, that the Centre was exempt from the list.
} 
officials appreciated IDRC's presence in countries where CIDA was not present, which gave them something concrete to point to in terms of cooperation with Canada.

With the encouragement of the Board of Governors, IDRC restated its business model as a "grants-plus" approach: not only funding new opportunities for research, but engaging with its recipients throughout the research process as a mentor, and facilitating their access to both peers and policy audiences (IDRC 2009, para 42). Rather than a new direction or break with the past, "grants-plus" simply restated how IDRC already saw itself.

In practice, Centre staff pursued multiple expressions of this model. At one extreme, many projects still resulted from talent-spotting by program officers seeking out or responding to promising developing country researchers, working with them to refine their ideas through multiple iterations on project proposals. This approach placed the IDRC program officer as an engaged mentor working directly with southern scientists to boost their skills over time. At the other extreme were projects that resulted from competitive calls in which written proposals were assessed against explicit eligibility and selection criteria. Such competitions were often structured as a two-stage process: an initial call for short concept notes—-describing the project idea—followed by an invitation for the more promising proponents to prepare full proposals.

Under such competitive mechanisms, engagement with IDRC staff was much more restricted so as ensure all proponents were treated equally and received the same 
information. The application process had to be explicitly described in the calls for proposals and any additional information provided in frequently asked questions (FAQs) posted on the Internet. There was initially some resistance among IDRC staff who feared that this approach would give an advantage to more experienced applicants better able to express themselves in written English or French. At the same time, IDRC management initially expected competitive calls to be less labour intensive and allow the Centre to optimize the balance between research grants and internal costs. The value of competitively-allocated projects was commonly over twice that of talent-scouting projects (in excess of $\$ 1$ million over five years versus $\$ 300,000$ over three years). Assuming the costs of monitoring and administering a project were fixed, boosting the average value per project would control internal costs.

With experience, both staff and management learned that these assumptions were partially false. The selection criteria for competitively-allocated projects could include consideration of the potential for training younger and developing country scientists; drawing on senior researchers in the project to act as mentors, rather than assuming this was a task for IDRC staff. Indeed in the 2000s, IDRC had earlier outsourced some competitive grant competitions to trusted organizations in developing countries in order to provide opportunities for young researchers and for new grantees unknown to IDRC staff (IDRC 2006). Meanwhile competitive calls did not necessarily save on workload in the near-term, as there was a substantial workload in setting up the call and coordinating the peer-review process. Furthermore, a million-dollar project, that involved two or three recipient institutions, meant each institution received $\$ 300,000$ to $\$ 500,000$. Thus the 
push for fewer, larger projects did not necessarily translate into fewer, larger grants. To some extent, this negated the expected saving on administration costs.

\subsubsection{Foreign aid in times of austerity}

Between 2008 and 2010, the Government of Canada once again moved from surplus to deficit. The financial crisis of 2008-09 saw government revenues decrease and stimulus spending as Canada's part of the coordinated response among G20 countries. The 2010 federal budget announced that "future IAE spending levels will be capped at 2010-11 levels and will be assessed alongside all other government priorities on a year-by-year basis in the budget" (Canada 2010, 142). Having fulfilled the Monterrey commitment to double foreign aid to five billion dollars, the government would stop the yearly practice of eight percent increases. The careful wording of the budget also left the door open to future reductions in international assistance.

Management of the International Assistance Envelope was also evolving. Within official Ottawa, there was no longer any support for the five purposes — or "pools" — of IAE spending. Funding for crises was fixed at \$200 million per year, and funding for IFIs was

determined by the level of Canada's contributions to World Bank, IMF, and the regional development banks. Despite the historic record of IDRC accounting for three-to-four percent of Canada's foreign aid, there was no support for assigning a fixed share of the IAE to development research, and much less that this should go to any single organization. More generally, there was a tension between DFAIT and CIDA regarding the appropriate balance between spending on each other's thematic priorities, pitting 
"food security, economic growth, and children \& youth" against "peace \& security and promoting democracy."

The process of allocating IAE funds was no longer a competition of ideas within government departments, but an allocation among "competing pressures" imposed from outside, such as commitments at leaders' summits or to international organizations. Through the 2010 budget, the Minister of Finance asserted control over his colleagues. Now part of the regular process of preparing the federal budget, IAE funding would no longer be decided between the Ministers of International Cooperation and of Foreign Affairs. De facto, CIDA and DFAIT lost their exclusive access and could no longer simply allocate it to proposals they themselves had developed without passing the scrutiny of finance officials.

The final year of the IAE increment was largely dedicated to initiatives related to the G8 and G20 summits, which Canada would host during the summer. At the World Economic Forum, the Prime Minister announced a major push to reduce maternal and child mortality, two of the Millennium Development Goals that lagged behind on progress towards the 2015 targets. Despite a long process among government departments to identify and shape a variety of proposals for the summit, the push on maternal and child health—or "Muskoka Initiative" - swept up much of the available funding for the year.

During preparations for the summit serious attention was given to the theme of “innovation for development.” While DFAIT officials consulted IDRC, negotiations 
among G8 members eventually focused on two potential proposals, one to establish a program of research chairs in African universities, and another to create a network of African Institute of Mathematical Sciences (AIMS).

The AIMS proposal was championed by Neil Turok, a South African physicist living in Canada as director of the Perimeter Institute for Theoretical Physics, an organization established with a donation from Mihal Lazaridis, co-founder of Research in Motion (Blackberry). Turok had established the first AIMS-Centre in Cape Town in 2003 to provide a training facility that enabled African students to pursue graduate-level training in mathematics. AIMS-Cape Town was a single building which included classrooms, computer labs, and dormitories. Turok had pulled upon his professional contacts to bring in renowned professors to give short courses. Given the success of this first AIMSCentre, Turok proposed to create a pan-African network with similar centres in different parts of the continent. In 2008, Turok's gave a passionate lecture as recipient of the Technology, Entertainment and Design (TED) prize based on the idea that the "next Einstein" could be an African who would produce future leaps in scientific understanding.

Through preparations for the G8 summit, DFAIT officials sought to entice financial support from other countries. When it became clear that others would not offer new funding pledges, the AIMS proposal was dropped from the G8 agenda. Yet Turok's personal diplomacy with the Prime Minister resulted in a decision that Canada would make its own \$20 million dollar contribution towards establishing the next three AIMS 
centres in Senegal, Ghana, and Ethiopia. One can speculate that Prime Minister's decision resulted from Turok's ability to raise private funding from foundations and companies, the tangible targets in terms of numbers of potential students trained, and Turok's connection to Canada. Not only was Turok based in Canada, but his parents had been part of the anti-Apartheid movement supported by the Mulroney government.

DFAIT officials turned to IDRC with a "take it or leave it" offer of being responsible for Canada's contribution to AIMS. ${ }^{38}$ Similar to the earlier Development Innovation Fund (DIF), the proposal was generated outside of government. It also enjoyed the support of a high-level champion who bypassed the machinery of government and the customary process of bottom-up policy development and budgeting. DIF and AIMS were both outside IDRC's accustomed grantmaking practice of engaging proponents in crafting their proposals. As ready-made initiatives, it was initially difficult to see how the Centre would add to it beyond providing a channel for Canada's funding. Yet, both were now part of Canada's support for development research and refusing a role in them would have made IDRC increasingly marginal to the government's agenda.

A greater share of IDRC's budget was now pre-committed to specific initiatives, whether through partnerships with foreign donors or those designed outside of IDRC and endorsed by the Government of Canada. Consequently, a smaller portion of the Centre's

\footnotetext{
${ }^{38}$ IDRC accepted the offer, and ultimately the Centre did play a substantial role in AIMS, working with Turok to set up a secretariat for the new network, establishing the centres in Senegal and Ghana, and securing further funding from the UK government.
} 
budget could be considered "core" funding, available for the Board of Governors to assign to programming conceived by IDRC staff. In the corridors, staff were concerned that the Centre was become more attentive to donors and government, and less responsive to the voices of developing-country researchers. Furthermore both AIMS and DIF were time-limited initiatives, once they expired there was no guarantee that IDRC would continue to receive the funding they represented. After a decade of growing budgets, IDRC faced the prospect of needing to contract in future years.

The future arrived quicker than anticipated. By 2011, already critical of departmental program spending and still struggling to reduce the deficit, the Conservative government launched a 'Strategic and Operating Review'. The review involved all departments and agencies and sought proposals for reducing their budgets by five and ten percent. Whereas IDRC had the opportunity to present its own analysis and arguments in 2007, this time the Minister of International Cooperation was asked to lead a single, horizontal review of IAE spending. Officials from CIDA, DFAIT, the Department of Finance, TBS, PCO and IDRC met through the summer and into the fall to assess different proposals and negotiate how to share the pain of budget cuts. The results were released in Budget 2012 and represented an overall reduction of ten percent in Canada's international assistance, divided more or less proportionally across the IAE partners, slightly more for IDRC and none to Canada's contributions to the international financial institutions (Canada 2012, 213 and 272). 
The most visible of IDRC's reductions were the closure of two regional offices and of one research program. The regional office closures, in Singapore and Senegal, reflected an ongoing critique within IAE management over the balance within IDRC between the portion of its budget dedicated to research grants versus the portion dedicated to program officers and internal costs. Overall IDRC would eliminate over seventy positions between headquarters and the regional offices. Given the scale of the cuts, management also needed to scale back on programming and decided to concentrate the pain in the "Innovation for Inclusive Development" program. ${ }^{39}$ The program was typical of past IDRC work, something unique that was not being addressed by other funders. Yet the program became a victim of the new performance regime surrounding IDRC which emphasized alignment with government priorities. On this score, the program compared poorly to the rest of IDRC's portfolio which was arguable more clearly linked with food security, economic growth, or security concerns which figured among the IAE priorities.

The model that had served the Centre well in the past was based on the assumption that the Parliamentary appropriation was core funding available for the Board to allocate as it saw fit. Yet the IAE allocation process had begun to undermine this model, as access to new funding was restricted to specific, time-limited initiatives tied to government priorities. As a greater share of IDRC's budget was earmarked to specific government initiatives or donor partnerships, it squeezed the resources available to pursue original

\footnotetext{
${ }^{39}$ Approved by the Board of Governors in summer 2011, the program proposed to identify and scale-up example of grassroots — or frugal—innovation where poor people resorted to inventive means of addressing their needs, such as converting used cooking oil into fuel for taxis (Economist 2010).
} 
programming that did not align with the priorities of others. As one respondent lamented, "IDRC is mostly ignored, sometimes resented, and seldom appreciated... there is almost a conscious policy of eroding the Board's independence in taking decisions." (CA-01)

In summary, during this third period, starting in the early 2000 s, the performance regime emphasized alignment with the priorities of Canada's foreign policy. The role of the IDRC Board eroded as programming decisions were increasingly tied to government funding decisions or committed to programs partially funded by CIDA and donors outside Canada. The program theory that guided R4D funding valued research for its actual contribution to changed policy and practice in the developing world, with an increasing array of expectations placed upon its recipients. Grantmaking saw competitive calls for proposals join the older practices based on proactively project development by IDRC staff and responding to unsolicited proposals and partnerships.

Table 6: Research grants made by IDRC Program review led to a decrease in the number of grants in late 1990s, yet average grant value in real terms remained consistent over time.

\begin{tabular}{cccc}
\hline Time Period & $\begin{array}{c}\text { Grants per } \\
\text { year }\end{array}$ & $\begin{array}{c}\text { Annually } \\
\text { Granted } \\
\text { (\$ thousand) }\end{array}$ & $\begin{array}{c}\text { Average } \\
\text { Grant (\$ } \\
\text { thousand) }\end{array}$ \\
\hline $\mathbf{2 0 0 5 - 1 0}$ & 524 & 123,349 & 115 \\
$\mathbf{2 0 0 0 - 0 4}$ & 375 & 65,427 & 111 \\
$\mathbf{1 9 9 5 - 9 9}$ & 192 & 56,179 & 112 \\
$\mathbf{1 9 9 0 - 9 4}$ & 361 & 101,549 & 117 \\
$\mathbf{1 9 8 5 - 9 0}$ & 456 & 128,001 & 134 \\
\hline
\end{tabular}




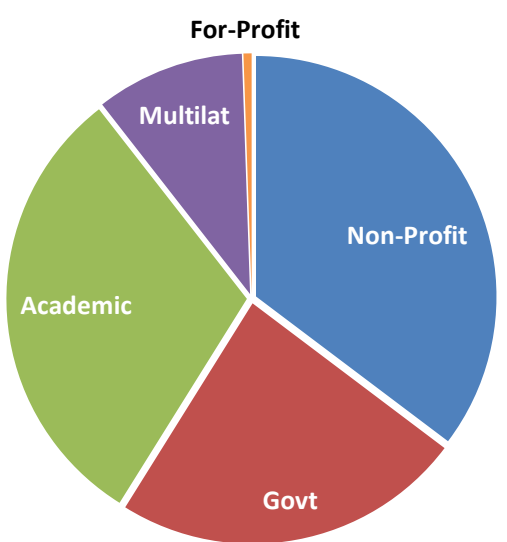

1985-89

$($ real value of grants $=\$ 640 \mathrm{~m})$

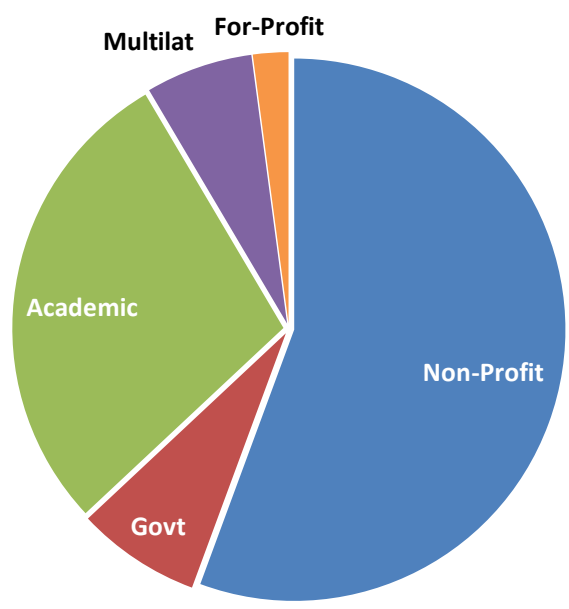

2005-10

$($ real value of grants $=\$ 730 \mathrm{~m})$

Figure 11: Type of institutions funded by IDRC The majority of funding went to non-profits and academic institutions. The portion going to governmental recipients decreased over time, while for-profits received no more than $2 \%$ of the funding granted by the Centre.

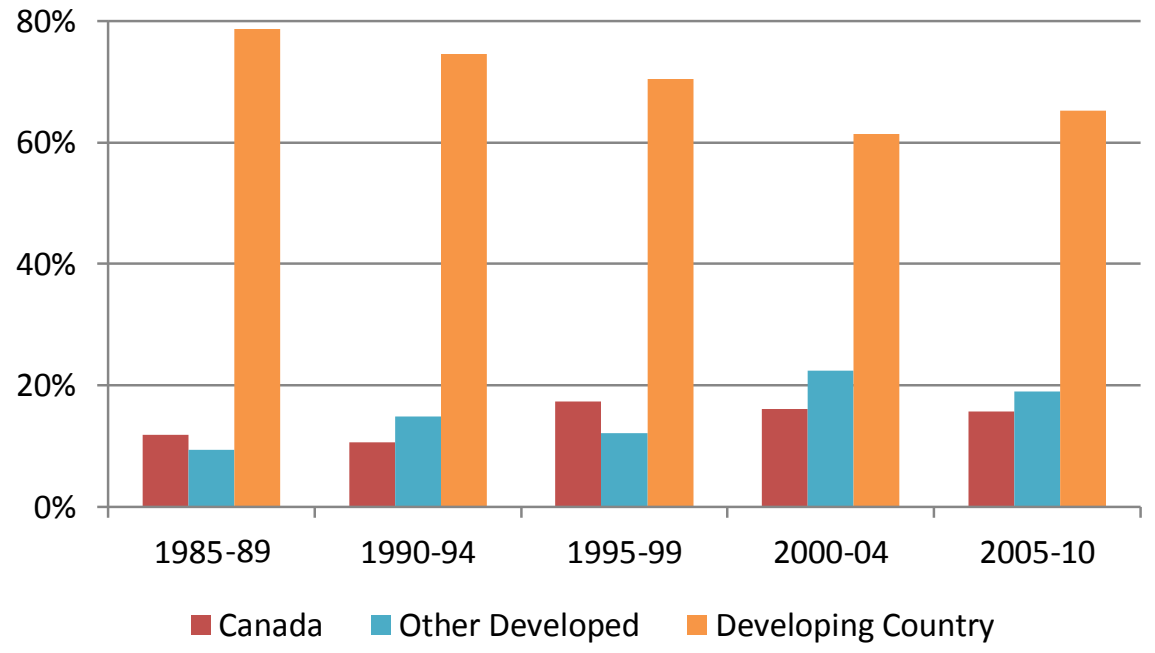

Figure 12: Location of IDRC recipients The majority of funding was awarded to recipients in developing countries, yet the portion located in Canada and other developed countries increased slightly. 


\subsection{Conclusion}

IDRC by and large preserved both Maurice Strong's vision of an independent research funder, as well as David Hopper's vision of an organization dedicated to supporting the ideas of researchers in the developing world. Both these traits became embedded in the organization's DNA: staff and management embodied these commitments. Yet Strong and Hopper were more than intellectual contributors to the IDRC mission and mandate. They proved to be the first in a line of high-level thought and opinion leaders that protected and nurtured the Centre over time, moving to rally their contacts to protect IDRC whenever it was threatened. Individual champions played a substantial role in how Canada defined and funded R4D over time. IDRC management would cultivate and periodically renew a network of allies among the federal bureaucracy, across foreign policy and inside central agencies. Contact with the Canada's research policy was less substantial and less critical to IDRC's fortunes.

Yet the federal government was never entirely at ease with IDRC's independence, and periodically moved to curtail its freedom. While the IDRC Act established the Centre at arm's-length from government, central agencies imposed the disciplines of planning and evaluation, as well as Ministerial responsibility for portfolio management. DFAIT, CIDA, and central agencies might not control IDRC governance, but they did influence the process through which the Centre obtained its funding. Over time, IDRC appeased these actors by positioning itself as an expression of Canada's foreign policy and contributing to the policy priorities of the day. For the most part, such positioning could be symbolic, a veneer of responsiveness covering a deeper program theory and 
grantmaking practices that proved largely persistent in type of recipients and average grant size (table 6 and figure 11)

The decade of program review in the 1990s triggered a substantial restructuring, intended in part to demonstrate that the Centre's work contributed to development results. Interdisciplinarity, research utilization, and policy influence became watchwords as the Centre redesigned and renewed its program framework. This century, a growing foreign aid budget initially allowed IDRC to preferentially expand those programs that aligned with government priorities or that leveraged outside funding through donor partnerships. As a result, the Centre's autonomy slowly eroded as outside actors play a larger role in designing programs and selecting projects.

In terms of resource availability, IDRC's budget rose for two decades, but fell in the 1990s with the government's efforts to reduce the deficit. Bezanson sought to reduce the Centre's reliance on government funding by securing project co-funding from other sources. The subsequent rise of IDRC's budget this century was largely due to the special-purpose allocations, such as the Micronutrient Initiative, and demonstrating the Centre's alignment to IAE priorities, including the joint food security fund with CIDA. Thus while the Centre was able to save itself from some of the pain of budget cuts and shared in the benefits of rising aid budget, in both cases new resources came with conditions, rather than core funding for the Centre's regular business model. 
In terms of public management, the original vision for IDRC was inspired by the philanthropic foundations in the United States, including their independence from government and political mandates. Yet as a Crown corporation largely dependent on an appropriation from Parliament, government periodically attempted to reassert control over the Centre. Survival relied on cultivating allies within the bureaucracy and demonstrating alignment with government's priorities, including two rounds of strategic review. IDRC was responsive to both Canada's foreign policy and S\&T priorities: supporting local researchers during political and economic transitions in the Southern Cone, South Africa, and Southeast Asia, and positioning itself as contributing to the “internationalization” Canadian research. IDRC was both inside and outside Canada's development policy process: it could request additional funding, but was excluded from the higher level decision-making. The Centre was also out-maneuvered by the Department of Finance and by outside proposals which increasingly defined R4D. The net result was an erosion of IDRC's discretion and autonomy as strategic decisions about program choice moved away from its Board of Governors and into Cabinet and senior government officials.

In terms of research governance, IDRC began to argue for its effectiveness based on a demand and client for its projects. The Centre adopted increasingly detailed program strategies which targeted funding to particular thematic priorities. Researchers needed to demonstrate how their work contributed to social or economic benefit, and the "utilization" of research results. Recipients were expected to identify and reach an audience of policymakers and practitioners. IDRC sought to demonstrate that its portfolio 
addressed real-world problems, rather than merely being motived by research interest, and that research contributed directly to development outcomes. IDRC also began to adopt competitive calls for proposals alongside its original "foundation" approach. This brought about more explicit deadlines, eligibility, and selection criteria rather than the former open-ended, talent-seeking, and selective response to unsolicited proposals.

In terms of program theory, IDRC remained close to the Strong-Hopper vision of building the capacity of developing country researchers. This initial emphasis meant the Centre expected its projects would generate new skills and strengthen local institutions. In terms of research outputs, these were not necessarily expected to be "world-class," instead IDRC was satisfied if local researchers were gaining experience and their outputs were seen as useful to local audiences. Over time, projects were also expected to: incorporate interdisciplinarity into their research design, "close the loop" in terms of influencing policy in developing countries, and demonstrate how their research contributed to positive change in the lives of poor women and men. IDRC expected its recipients to be good communicators, reaching not only their scientific peers, but also an audience of policymakers and practitioners.

Drawing on Funnel and Rogers' (2011), IDRC initially pursued an empowerment theory of change, underpinned by a capacity building archetype: supporting researchers in poor countries to exercise greater control over their own development. Such a perspective was dominant from Hopper's 1970 speech at the inaugural meeting of the Board of Governors through to Bezanson's 1991 strategy, appropriately titled 'empowerment through 
knowledge'. Under O'Neil, IDRC supplemented this core philosophy with a network theory of change underpinned by a case management archetype: recipients were encouraged to cultivate relationships towards informing policy abroad, with IDRC support adapting to the unique circumstance in each project. In contrast, the emergence of Grand Challenges Canada in 2010 exploited a gap in Canada's R4D landscape, embracing a diffusion theory of change underpinned by a carrots-and-sticks archetype.

In terms of grantmaking practice, IDRC consistently favoured recipients based in a range of developing countries. The role of an IDRC program officer evolved from "wandering minstrel" providing access to scientific literature and contacts not available locally, to "engaged peer" supporting the research interests of recipients. Projects were initially selected solely on their own merits, including its originality, potential contributions to a particular discipline, and its perceived relevance to the developing regions of the world. With the transition to program initiatives, staff placed greater emphasis on constructing a portfolio of projects that contributed towards a Boardapproved program strategy. Programs that overlapped with donor or Canadian interest tended to grow faster than those where the Centre was the sole investor. Yet the Centre resisted the trend to identify a select number of focus countries, instead it consistently selected programs and projects that addressed problems common to multiple countries or that spilled across borders entirely. The majority of its projects was coded as regional in scope and included recipients working in different countries. 


\section{Chapter: Australia}

The Australian Centre for International Agriculture Research (ACIAR) was created by an Act of Parliament in 1982. It is a statutory authority, a public entity entrusted with a particular policy objective and established at arm's-length from government. Statutory authorities are answerable to a Minister for their corporate performance, but largely autonomous in terms of its day-to-day operations.

This chapter identifies three distinct periods when R4D was subjected to different expectations and adopted different goals. During the first decade, the performance regime offered ACIAR a limited lifespan within which the Centre sought to prove its worth in terms of the potential increase in agricultural productivity stemming from its work. The program theory that guided R4D funding was labelled "doing well by doing good" through which ACIAR sought mutual benefits at home and abroad by mobilizing Australian talent in areas where the country was perceived to have a natural research advantage, including on tropical coastal and dryland climates. Grantmaking focused on a partnership model of commissioning projects that matched state-level government scientists with local partners abroad, primarily in Southeast Asia and the Pacific, with a tendency towards working in countries where there was an existing pool of researchers.

During the second decade, the performance regime enshrined poverty reduction as the purpose of foreign aid, requiring ACIAR to demonstrate how its work contributed to reallife adoption of new technologies and techniques. At the same time, changes in Australia's science policy began to hollow out the capacity of state-level government and 
shifted the centre of gravity in Australia towards university research. The program theory that guided R4D funding sought to boost rural incomes, linking poor women and men with markets beyond the farm gate and the valued added as food moved from "paddockto-plate". ACIAR continued its grantmaking practice of partnerships for mutual benefits, but increasingly relied on Australian researchers in academic settings. The Centre also modified its grantmaking to exit countries that attained middle-income status and enter countries that became a foreign policy priority.

During the third decade, the performance regime adopted whole-of-government strategies towards Australia's engagement within developing countries, particularly in response to the "war on terror" and later the global food crisis. Meanwhile, public research needed to justify itself within national priorities and program-level outcomes, such as contributing to Australia's economy and security, rather than simply pursuing individual projects based on their own merit. The program theory that guided R4D funding sought to bridge Australia's innovation system and foreign aid, emphasizing agricultural research-fordevelopment as a form of science diplomacy and as promoting stability and food security abroad. While ACIAR largely retained its grantmaking practice of commissioned partnerships, the Centre placed a stronger emphasis on country strategies, in order to give its staff a "passport to engage" government colleagues and embassies. Responding to foreign policy priorities also led ACIAR to support work in countries with a weak or nonexistent domestic research community. 


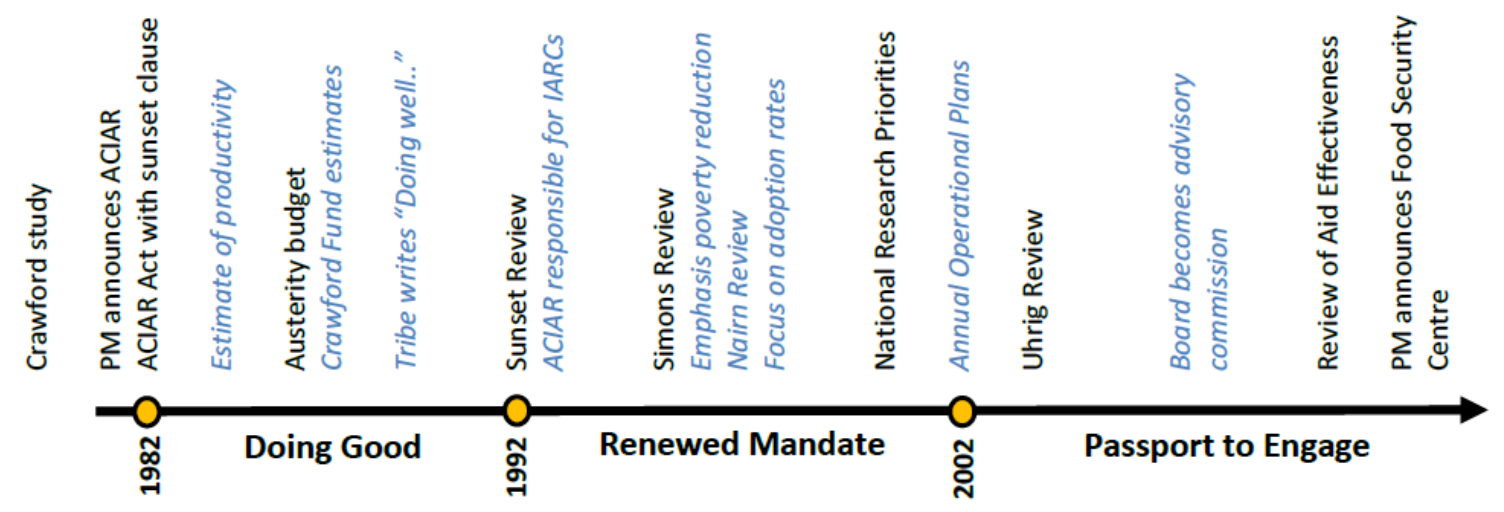

Figure 13: Timeline for Australia case study

\subsection{Origins}

The idea for ACIAR was born as Australia reassessed its role towards the developing world. Australia saw itself as both "a Western country... geographically isolated from the Western centres of power" and "distinctly Australian... a multicultural society in the southern hemisphere on the very fringe of the Third World" (Australia 1979, 117). With the decline of the UK in world affairs, and the rising influence of the Third World in international affairs, Australia's ties in Asia and elsewhere were increasingly important. Growth in the Third World offered an opportunity "to benefit from expanding trade, to exercise political initiatives, to demonstrate our technical skills and special experience, to exercise our idealism and to enrich our culture" (ibid). Australia's nascent foreign aid included calls for "applying scientific know-how to the Third World for mutual gain" (ibid). 
The Australian public, particularly farmers, was acutely aware of the benefits of research for rural people. Early in the country's history, each state government had established its own network of agricultural labs, research centres, and extension services. Upon forming the Commonwealth, Australian states retained and expanded these networks, tailored to the local mix of exports, crops, animals, and climates. Through the Commonwealth Scientific and Industrial Research Organisation (CSIRO), the national government supported some key efforts to aid farmers, including the introduction of myxomatosis virus to control rabbit populations and the introduction of dung beetles to remove breeding ground for bushflies (Collis 2002). Since the Wool Publicity and Research Act 1936, farmers and rural industries paid levies to finance research intended to benefit their industry as a whole, through enhanced productivity and advances in processing. In the 1980 s, a number of these arrangements would be formalized as rural research and development corporations (RDCs). The money raised through levies was matched on a dollar-for-dollar basis with funds from the national government (Farrar 2005, Core 2009). In short, the landscape for agricultural research enjoyed strong support from taxpayers and industry.

\subsubsection{Crawford's vision}

The idea for ACIAR was championed by Sir John Crawford, an influential economist and civil servant. Crawford had served as the Director of Research in the government's Department of Postwar Reconstruction, and as a senior official in the departments of Trade and Agriculture. He then entered the Australian National University from where he contributed to the creation of the Australian Development Assistance Agency and the 
Consultative Group on International Agricultural Research (CGIAR). In 1976, he chaired a committee which proposed that the country establish an international research assistance foundation. The committee included participants drawn from the Department of Foreign Affairs, World Bank, and CSIRO. This committee examined examples such as the UK Institute for Development Studies (IDS) and France's l'Office de la recherche scientifique et technique outre-mer (ORSTOM).

Yet Crawford was clearly inspired by Canada's IDRC, where he had been a board member. The committee identified a mandate focused on developing countries, "to build up their research capabilities and innovative skills as well as the institutions required to solve their problems". R4D was expected to enable developing countries to "provide food and the basic elements of decent living standards for their peoples", by enabling them to "to select and... import advanced knowledge, adapt it to local conditions as necessary, and expand it through indigenous research to meet their needs.”(Crawford Study 1976)

Yet the moment for establishing an Australian IDRC had already passed. ${ }^{40}$ Edward Gough Whitlam's Labor government (1972-75) had just lost power after a very active period that saw the introduction of universal health care, free university education, and the opening of relations with China. In contrast, Malcolm Fraser's Liberal-led ${ }^{41}$ government (1975-83) brought in a period of conservative policies, setting out to control

\footnotetext{
${ }^{40}$ ACIAR was influenced by IDRC in many ways: a first draft of the ACIAR legislation was based on a modified version of the IDRC Act (AU-15) and IDRC sent an employee, David Spurgeon, on secondment to help establish ACIAR's communication division.

${ }^{41}$ Australia's Liberal party is politically right-of-centre and akin to the conservatives in UK and Canada.
} 
the costs of government. The recently-established aid agency was converted into a bureau within the Foreign Affairs portfolio. There was very little political appetite to expand government, and none for such a broad and apparently altruistic mandate. It was in this context of restraint and modest ambition that James Ingram, head of the Australian Development Assistance Bureau (ADAB) established a Consultative Committee on Research and Development (CCRD). Once again Crawford chaired the committee, this time examining how Australia's health and agricultural research communities could contribute to the aid program.

An agricultural mission resonated with Australia's own history. Having struggled to become self-sufficient in agriculture, Australia emerged as a major exporter of food and fibre, sustaining the UK during two world wars. Australian experience was seen as relevant for developing countries seeking to feed their populations and grow their economies. Furthermore the arid Australian landscape was comparable to conditions found in parts of the developing world. Thus crops and techniques that worked at home might help agriculture thrive abroad.

Australia already had the National Health and Medical Research Council, but lacked a comparable platform for agricultural research. The country's research community was instead fragmented among different state-level departments of agriculture and various divisions of CSIRO. Arguably there was a need to coordinate these actors if Australia was to mobilize its expertise to aid developing countries. CSIRO had already established a livestock research centre in Indonesia as well as an office to market its research services 
to aid agencies abroad. CCRD visited the Indonesian lab and was concerned that it was isolated from grazers and the national agricultural research system. The committee felt that Australia needed to mobilize expertise in the CGIAR and existing institutes, rather than building new brick-and-mortar institutes. Crawford and Ingram gathered support for their vision from universities and state governments.

\subsubsection{Mutual benefit}

The opportunity to create ACIAR came during preparations for the 1981 Commonwealth Heads of Government Meeting. Prime Minister Fraser was keen to have an announcement and Crawford presented ACIAR as one of the short list of ideas. Fraser was himself a wool rancher and personally identified with agriculture. Furthermore his coalition government shared power with the National Country Party whose base of supporters came from rural areas. ACIAR offered an option that both highlighted Australian leadership abroad and would play well to voters at home.

By the time legislation was presented to Parliament, shortly after the Commonwealth meeting, the mandate focused on mobilizing Australian expertise for mutual benefit. Introducing the bill, Foreign Minister Tony Street described ACIAR as providing "a capacity to fund research by Australian persons and institutions... contracting research work to... universities, State departments of agriculture, CSIRO and suitably competent private individuals and organisations". Australia stood to gain in various ways, according to the minister, including enhanced contact with overseas colleagues, increased 
information on problems abroad, and an expectation that "some of the solutions... the Centre produces will be of direct and practical benefit to Australia" (Australia 1981).

ACIAR was created as a statutory authority in order to attract people who understood the problems facing agriculture abroad and who had professional networks at home to address them. In introducing the Act, the Minister argued "the Centre will require the capacity to identify needs and priorities for agricultural research in developing countries... to monitor critically progress of the research... staff of such stature as to command respect among scientists in Australia and in developing countries" (Australia 1981). Research program coordinators worked as brokers: conducting field visits or consultations abroad, and then scouted for talent at home that might prove useful. These coordinators worked closely with potential recipients to encourage, and later refine, proposals, including specifying objectives and responsibilities within the collaboration. Whereas government departments were seen as bureaucratic environments-driven by rules and regulation — the architects and early patrons of ACIAR saw a need to create an intellectual environment — driven by scientific collaboration. Early employees came from the aid bureau, CSIRO, universities and foreign affairs. All found that their new workplace was distinct from their previous one.

\subsection{Doing Well by Doing Good}

ACIAR governance included a Board of Management and a Policy Advisory Committee. The ACIAR Board included senior representatives from the academic community, the 
Australian aid bureau, CSIRO, state governments, and the national farmers' federation. Crawford's presence as the first Board Chairman provided the gravitas to attract senior representatives and build a common perspective on what the Centre was to become. The Policy Advisory Committee provided insights on the agricultural problems of developing countries and Australia's capacity to assist in their solution. It operated as a scientific advisor, with members selected for their knowledge of the subject matter. The Policy Advisory Committee included all the Board members, plus additional Australians drawn from universities and state governments, plus representatives from developing countries, often drawn from the agricultural science or policy departments within their national government.

ACIAR's governance reflected its performance regime. The Board brought together the stakeholders that were vital to the Centre's success, or those that might resist if ACIAR was perceived as detrimental to their interests. The Board held formal duties for oversight and strategic direction, and informally provided the crucible for ensuring that ACIAR was accepted and supported by these key stakeholders. Board approval was needed for all projects, thus ACIAR could not fund an activity that was seen to harm the interests of any member. Meanwhile the Policy Advisory Committee gave voice to additional Australian stakeholders as well as to the developing countries which were the intended beneficiaries. Beyond providing insights on potential priorities and partners, the Committee debated policy guidelines, instilling in its members a sense of ownership over the Centre's operation having contributed to its intellectual content. In sum, the governance structure 
bridged national funding, talent throughout Australia, and potential partners in developing countries.

ACIAR began operation in June 1982 with a small office within Canberra's Reserve Bank Building. Crawford continued to play a lead role as Chairman of ACIAR's Board of Management. He interviewed prospective staff members and hired the first Director, Jim McWilliams. ACIAR quickly established its thematic priorities, including soil \& water management and land use, plant improvement, plant protection, plant nutrition, animal \& fish production, animal health, farming systems, post-harvest technology, forestry, socioeconomics, and communications. To be eligible for support a project had to respond to the expressed needs of developing countries, address problems of national or regional significance, involve developing country scientists, and exploit Australian research capacity. The first project supported by the new Centre focused on pigeon pea improvement and involved participants in Thailand, Fiji, Indonesia, and the International Crop Research Institute for the semi-arid Tropics (ICRISAT) in India.

ACIAR followed the geographic priorities in Australia's foreign policy which focused on neighbouring countries. ACIAR's portfolio concentrated on the Pacific islands and southeast Asia, particularly Papua New Guinea which was governed by Australia until 1975. The Centre also supported work in South Asia and China, and to a lesser extent in a handful of African countries. ACIAR's Board established allocation targets for how project funding should be divided among these regions. Such targets were monitored on an ongoing basis, leading to a special effort to fast-track projects in any regions that 
appeared to be falling behind. ACIAR project selection started with those countries with a similar climate and agricultural problems to Australia. To emphasis the point, early consultations in China and Nigeria superimposed an inverted map of Australia over these countries to demonstrate similar latitudes and growing conditions to Australia.

While thematic priorities and selection criteria would evolve over time, these early directions would still influence ACIAR's practice thirty years later. On the surface, ACIAR remained remarkably consistent: a modest-sized organization that stayed true to its original purpose and design. Yet on closer examination, ACIAR was buffeted by changing expectations, navigated by successive managers who decided how to respond to the Canberra context.

\subsubsection{In-house review}

ACIAR pursued a partnership model of commissioning research, in which every project involved an Australian participant. Projects sought to match countries within the aid program with areas of expertise where Australia had a "natural research advantage." In other words, it addressed problems on which Australian researchers were perceived to be at least relatively strong, if not world-class. Projects aimed to boost agricultural productivity abroad, yet they were also expected to make a contribution at home. This pragmatic approach, based on mutual benefits, was needed to entice reluctant employers to permit their scientists to participate in ACIAR projects. Working with ACIAR presented direct costs and opportunity costs: they had to contribute financial or in-kind support (ACIAR limited its funding to $70 \%$ of direct costs) and time spent overseas or 
working on somebody else's problems detracted from support to farmers at home. ACIAR also had to dispel suspicion that was "giving away" hard-earned Australian know-how, aiding Australia's competitors in export markets. The new Centre unabashedly touted the benefits at home, such as improved control of pests abroad before they reached Australian shores.

ACIAR staff actively shaped the initial set of projects. They surveyed interest at home in working with developing countries, and drew on their networks of contacts to address needs abroad. As ACIAR became better known, researchers began to approach staff with their ideas. Concept notes describing project ideas were guided through an iterative inhouse review process in which they were critiqued among the coordinators to decide collectively if the idea was worth pursuing and how to enhance project design. Such feedback was shared with proponents and informed the preparation of a more detailed proposal specifying objectives, responsibilities, and budget. Detailed proposals were subjected to another round of in-house review before being recommended to the Board of Management for approval. This was a labour-intensive process-involving a number of hours of staff time on each project prior to approval—which was seen as a necessary investment to ensure an equitable partnership between counterparts at home and abroad.

The in-house review also ensured the quality of the research ACIAR supported. Basic game theory suggests that coordinators might collude among themselves to approve each other's preferred projects in a "tit-for-tat" fashion. Yet interviews suggest the process was intensely competitive, with staff being strongly critical of each other's proposals. This is 
understandable considering the disciplinary differences between ACIAR programs and some professional rivalry among the coordinators. For example, a crop scientist might find her or his project harshly critiqued by a soil scientist or agronomist. Each coordinator viewed project ideas through the lens of their own discipline, with subtly different views as to pertinent questions, methods, and standards of evidence. ACIAR's model of commissioned research consciously eschewed competitive calls for proposals, based on the belief that staff needed to broker the partnerships to ensure mutual benefit. This left ACIAR open to potential resentment by members of the research community that might have been interested in bidding on a particular project, if it had been tendered. The in-house review partially addressed this concern as coordinators identified experts and organizations that could contribute to the projects under consideration.

\subsubsection{Feeling vulnerable}

The new Centre had established its governance structure, program priorities, staff roles, and grantmaking practices; yet there was no guarantee that any of it would survive. The ACIAR Act contained a "sunset" clause which limited the Centre to a lifespan of twelve years. If ACIAR was to continue into the future, it needed to convince Parliament that its work was worth renewing. This motivated the Centre to establish a unit focused on economic evaluation, first to help identify research priorities and subsequently to assess the benefits derived from the research supported. Early studies looked at ex ante priorities, comparing different crops and countries, estimating the potential benefits based on the expected gains in overall agricultural production and its likely effect on local 
markets. ${ }^{42}$ This information fed into ACIAR's priority setting and was shared with partner countries and international organizations. As the first generation of projects came to completion, attention turned to ex post valuation of the results of that work: quantifying the value of new or increased production, or of the inputs saved - such as fertilizers or machinery — by using more efficient techniques. It was hoped that such studies would establish whether project successes justified the funds invested.

While the Centre had been established with much political support, it soon acquired an acute sense of vulnerability. Not only did its face a possible expiration date, government had only committed funding for the first three years, totalling A $\$ 25$ million. From there the Centre's fortunes were subject to the annual budgeting process and reliant on allies within the bureaucracy and Parliament. The latter eroded as Bob Hawke's Labor government came to power in 1983, and Sir John Crawford passed away in 1984, depriving ACIAR of its intellectual grandfather and most powerful ally. The new government introduced an austerity budget in 1986 which reduced spending in all departments, including health and public services. After four years of growth, ACIAR suddenly had to absorb the loss of one-fifth of its budget. The honeymoon was over: political support for ACIAR's mission could no longer be taken for granted, and it was far from certain that a future government would renew the Centre.

\footnotetext{
42 These studies considered changes in marginal supply and demand. Prices might decrease with increases in production, yet advances in agricultural productivity could still generate substantial overall gains.
} 


\subsubsection{New allies}

ACIAR's found a new ally in Derek Tribe, former dean at the University of Melbourne, fellow of the Australian Academy of Technological Science and Engineering (ATSE), and member of the Order of the British Empire. Tribe proposed that ATSE create a new organization dedicated to promoting agricultural research. The creation of the CGIAR at the international level had revealed a need for national-level counterparts that could build awareness of its work and encourage links with domestic researchers. In 1987, Tribe's idea became the Crawford Fund for International Agricultural Research.

The Crawford Fund drew financial support from governments, companies, and individual Australians; and engaged Parliamentarians to raise awareness of Australia's support for research abroad. Whereas ACIAR focused on partnerships between Australian and developing country researchers, the Fund provided scholarships and training abroad. More importantly, where ACIAR was part of the machinery of government, the Fund was able to lobby Parliamentarians and build a domestic constituency for research abroad. It launched a series of annual seminars in Parliament House, to encourage bipartisan support by presenting how Australia benefited from such research. Doug Anthony, former leader of the National Party, agreed to serve as the Fund's Chairman, and the Fund later attract former deputy Prime Ministers Tim Fisher and John Anderson.

The end of decade saw ACIAR's budget recover and exceed its pre-1986 level. By 1989, the Board of Management had received a mid-term review of ACIAR's strengths and 
weakness. This review set the stage for the first leadership transition as George Rothschild succeeded Jim McWilliams as the ACIAR director. The review was largely positive, yet echoed the sense of vulnerability from the 1986 budget cut and upcoming sunset review. In particular, the review suggested a need "to strengthen the mechanisms that provide parliamentary awareness of ACIAR [such as] briefings with MPs" (Arnold 1989). It also analyzed the Centre's research portfolio, finding it had evolved in response to: (1) "the frequency of requests for collaboration [and] the availability of scientific expertise" at home; (2) "the historical sequence of recruitment of ACIAR staff of different disciplinary backgrounds and experience"; and (3) "the scientific and economic assessments of the intrinsic worth of the projects" (ibid).

The late 1980s also saw a number of changes in Australian research policy, including a slow shifting to aligning government support with industry. The Australian Research Council was established to fund university research, and a Chief Scientist position was created to advise government on its use of — and support for — science and technology. The Primary Industries and Energy Research and Development Act gave industry a formal role in governing and funding the rural research and development corporations (RDCs). A previous program of direct support for industrial R\&D was replaced with a $150 \%$ tax credit, and CSIRO was required to raise $30 \%$ of its funding from outside of its Parliamentary appropriation, by selling its services to government departments or the private sector. A new program of Cooperative Research Centres drew together science performers from universities, industries and government to work on priority areas. The 
watchwords for Australian research policy had become: priority, concentration, selectivity, accountability and evaluation (Australian S\&T Council 1990).

\subsubsection{Sunset review}

Yet ACIAR fortunes were looking up as Paul Keating took up leadership of the Labor government in 1991. The country had experienced the glow of its bicentennial celebrations and the mood of the country was optimistic. Derek Tribe penned an eloquent and influential argument for agricultural research abroad — entitled "Doing well by doing good". ${ }^{43}$ Rather than a technical report, the book was an accessible read intended for politicians and farmers, responding to domestic fears that the information and benefits from Australian know-how were being given away as part of foreign aid. Tribe (1991) argued that Australia received much more than it gave, citing the use of wheat germplasm from CGIAR, which had generated over two billion dollars of additional income for the Australian wheat industry.

The sunset review finally came in 1992, conducted under the parliamentary Joint Committee on Foreign Affairs, Defence and Trade. The review focused on the "effectiveness of ACIAR as an element of Australia's official development assistance" and the desirability of its continued existence. The review was exceedingly positive. It praised ACIAR's ability to craft collaborative partnerships that both mobilized research expertise and improved the well-being of people at home and abroad. This performance

\footnotetext{
${ }^{43}$ Tribe wrote this short book during his time as a scholar-in-residence at Rockefeller's Bellagio Centre in northern Italy.
} 
was attributed to the Centre's independence as a statutory authority, and the reviewers recommended that similar organizations be established for R\&D assistance other fields, such as manufacturing and human resource development. The review even called for the ACIAR to receive a fixed share $(3.5 \%)$ of the aid budget, with an additional sum $(1.5 \%)$ dedicated to provide international agricultural research centres with core funding (Australia 1992).

In response, the government removed the sunset clause from the ACIAR Act and expanded the Centre's mandate to include project-related training. It also made ACIAR responsible for Australian funding to the international agricultural research centres, transferring this function away from the aid bureau. ACIAR began its second decade with a renewed lease on life, adopting a longer-term perspective signaled by a move in its corporate planning from an annual to a three-year cycle.

In summary, during this first decade, the performance regime offered ACIAR a limited lifespan within which the Centre needed to prove its worth, based on the potential increase in agricultural productivity stemming from its work. The program theory that guided R4D funding was labelled "doing well by doing good" through which ACIAR sought mutual benefits at home and abroad by mobilizing Australian talent in areas where the country was perceived to have a natural research advantage, including on tropical coastal and dryland climates. Grantmaking focused on a partnership model of commissioning projects that matched state-level government scientists with local partners 
abroad, primarily in Southeast Asia and the Pacific, with a tendency to work in countries where there was an existing pool of researchers.

\subsection{Renewed Mandate}

ACIAR's budget doubled between 1992 and 2002, but increased resources came with greater expectations. While the thematic programs of commissioned research were the main line of business, it was not the only one. Some of the new funding came from the aid bureau, and was tied to specific activities rather than core funding for the ACIAR Board to allocate as it saw fit. A further portion of new funding was Australia's support to international research centres: the CGIAR and others. ${ }^{44}$ ACIAR began to incubate the Centre for International Forestry Research (CIFOR) — inspired by expertise at home with tree plantations - which would move to Indonesia to become part of the CGIAR. ACIAR was charged with allocating a set amount of funding among these various centres, based in part on their affinity with Australian expertise and interests.

ACIAR recruited a new Board chairman and a new Director, with Ross Garnaut and Bob Clements joining in 1994 and 1995. Garnaut had served as Prime Minister Hawke's senior economic adviser, as Ambassador to China, and later as chairman of Lihir Gold Ltd. Clements came from CSIRO, having led its work on tropical crops and pastures. Together Garnaut and Clements brought in strong links with government, business, and

\footnotetext{
${ }^{44}$ Such as the Asian Vegetable Research \& Development Centre (AVDRC), or World Vegetable Centre
} 
science. ACIAR moved its Canberra headquarters to Fern Hill Park in 1996, and new representatives were appointed within Australia's embassies in Papua New Guinea, South Africa, and India.

ACIAR also shifted the geographic coverage of its work, withdrawing from some rapidly-growing countries and expanding further afield. Australia's aid program was critiqued for being involved in over sixty countries, and was encouraged to focus on fewer countries, 'graduating' from those that could fund their own development (Australia 1997). ACIAR followed suit and discontinued its programming in Malaysia and Thailand. Yet the Department of Foreign Affairs and Trade (DFAT) was also eager to see ACIAR expand, seeing it as "a useful contribution to Australia's overall diplomatic impact" (Arnold 1989). The majority of ACIAR's programming involved the neighbouring countries of Southeast Asia and Pacific, yet expanded to cover work in the dryland climates of the Middle East and Sub-Saharan Africa.

ACIAR also responded to other policy signals, particularly verbal feedback from the Minister. One respondent (AU-03) recounted how the Minister might note that ACIAR seemed overly invested in China or India, and request if it could fund something in North Korea or East Timor. ACIAR management took such signals seriously. Collaboration among scientists was a form of "track two" diplomacy, seen as technical and safe compared to the political and sometimes tense dialogue among diplomats. ACIAR could play a role in opening relations with countries that were of interest to Australia and the Minister. The implicit understanding was that such efforts enhanced the Centre's standing 
with the Minister, helping secure funding for ACIAR to continue what it saw as its core work. Programming was thus the product of both scientific and diplomatic interests.

ACIAR programming also embraced the concept of sustainable development. Following the United Nations' Conference on Environment and Development in 1992, ACIAR began to downplay its previous emphasis on boosting agricultural yields. Instead the Centre gave new attention to the environmental costs involved with projects on conserving natural resources and minimizing impacts on the environment, such as zerotillage planting or avoiding the use of pesticides.

\subsubsection{Simons review}

Coming to power, John Howard's Liberal-National government (1996-2007) commissioned the Simons Review ${ }^{45}$ —entitled "One clear objective"—which recommended focusing foreign aid solely on reducing poverty. Foreign Minister Alexander Downer saw aid as a means "to advance Australia's national interest by assisting developing countries to reduce poverty and achieve sustainable development”. He argued that "it is in our self-interest to help... the aid program helps foster stability and expand trade and investment opportunities for Australia. Through aid, we are also addressing many threats to our own prosperity" (Australia 1997). In responding to the

\footnotetext{
${ }^{45}$ The review was to inform the new Australian Agency for International Development (AusAID), created near the end Paul Keating's Labor government (1991-96), with greater independence of DFAT.
} 
Simons Review, the government identified agriculture and rural development as a priority, justified by:

The returns to developing countries from agricultural research and development are very high and include social and economic benefits beyond the agricultural sector. The benefits to Australia from international agricultural research are also enormous, estimated at $\$ 3$ billion over the last 20 years. This is a tangible demonstration of how effective development is in our national interest. (ibid, emphasis added)

ACIAR shifted its evaluation to demonstrate how its efforts were linked to poverty reduction. It began to look at the diffusion of new techniques and the extent to which farmers adopted them in practice. In other words, the criteria of success became the actual use of ACIAR work by poor women and men, rather than the potential benefits that might occur if research results were applied in practice. This was a challenge as the Centre could control the extent to which research outcomes and training came about, but only contributed to the extent these impacted on farming practices or the livelihoods of poor people. In 1998, ACIAR converted its unit on "economic evaluation" into the "impact assessment" program, which began to commission adoption studies on previous projects. These studies were carried out by the principal investigators of closed projects, who assigned a qualitative rank to describe the degree to which the findings had been taken up by different audiences. The Centre also abandoned its tendency to "cherry-pick" the most successful projects, in favour of a random sample of all projects.

Yet the old argument — that ACIAR generated rates of return far exceeding its costs - had proven successful in rallying a domestic constituency. Despite the new pressure to show 
reduced poverty among the most disadvantaged, ACIAR would continue to calculate economic benefits. Greater yields and new crops meant new income. This income could be invested in the farm and family to acquire access to new lands, afford a better diet or health care, and support children to go to school. ACIAR also continued to refine the argument for how Australia benefitted from its work, including the control of pests and diseases - such as fruit flies or guava rust — to ensure they did not appear in Australia (or at least ensuring there would be expertise at home if they did). Such arguments were vital for ensuring the support of its domestic constituency of farmers and politicians.

\subsubsection{Research policy}

Meanwhile Australian policy shifted towards shorter-term research and reduced autonomy for researchers. Australia removed many of the agricultural subsidies at home, expecting its farmers and industry to compete with the world. This heightened the importance of the rural Research and Development Corporations (RDCs) which had a budget of A $\$ 262$ million in 1993-94 (Industry Commission 1994). This budget came from a levy paid by producers, matched dollar-for-dollar by the national government, plus additional funding from industry. Government decided to limit its share to $0.5 \%$ of the gross value of production, which made industry relatively more influential in the RDC governance. A number of the RDCs were even privatized, becoming industryowned companies, without government nominees on their boards, and aligned with commodity marketing corporations. Over the decade, the RDCs moved towards shorterterm improvement of existing production techniques, rather than longer-term invention of new products and techniques. These moves signaled a shift away from the original 
mission of research, development, and extension, towards a new role of marketing, promotion, and industry representation (Kerin 2010).

By the mid-1990s, the national and state governments were reassessing their role in research policy. At the national level, the Industry Commission (1994) identified principles for designing public research: building on private incentives where possible, and encouraging "contestability" or ensuring that research funding opportunities were open to all researchers. Researchers were expected to compete for public funds through market-like mechanisms, yet government was seen to be a poor judge of what specific research projects needed to be done and who should perform them. To address this gap, the Prime Minister established a Science, Engineering and Innovation Council to formulate national science priorities. The state began to identify higher-level themes for the national research effort, leaving the allocation of funds to peer review and industry.

At the state level, lean budget and new priorities combined to squeeze the resources available for agricultural research. A number of states transformed their department of agriculture into departments of "primary industries", reflecting a horizontal shift to consider other sectors beyond agriculture, as well as a vertical shift to consider the value chain beyond the farm gate. Changes in government priorities, plus the rising influence of industrial funding, began to reshape research capacity at home. Government reduced the number of public servants working on agricultural extension. Scientists increasingly worked on industrial interests, and graduate students began to pursue new career paths. Consequently it would become more difficult for ACIAR to engage Australian 
researchers, as fewer of them worked on ACIAR's thematic programs or the kind of research needed in developing countries.

\subsubsection{Nairn review}

ACIAR continued with a matrix management approach that blended the topic and location of Centre-supported research. Projects were selected under different programs, while the budget was allocated by geographic region. Southeast Asia received more than half of ACIAR funding. The Pacific Islands, China, and South Asia each received between $10 \%$ and $20 \%$, while Africa received a modest $5 \%$ to $10 \%$ (ACIAR 1999 ). The program coordinators in Canberra were the senior staff, supported by a small number of junior representatives based in Australian embassies abroad. Nonetheless management sensed a need to update the Centre's approach, and commissioned an external review of the Centre's operations.

This review was once again largely positive, but recommended changes to ACIAR's program structure and staffing. Nairn et al. (1998) congratulated ACIAR on its "clever mix of proactivity and reactivity in project selection, working within developing-country research priorities and matching these to Australian research strengths". Yet they feared that the program structure inhibited multidisciplinary research, and that the modest size of research projects - an average of A $\$ 150,000$ over three-to-five years - encouraged a short-term "grant mentality". The Centre was advised to engage recipients in a longerterm dialogue regarding their research priorities and strategies. This would require an 
ongoing core of professional staff, rather than the existing practice of hiring program managers for a fixed term of three years—often as a secondment.

This review also identified challenges in ACIAR's grantmaking. The Centre found it difficult to work in countries where research infrastructure was weak. ACIAR's "partnership model" created a tendency to support work in countries that had a local research community, ideally one that already collaborated with Australian scientists. This was relatively easy in larger, middle-income countries, and more difficult in smaller, lesser developed countries. ACIAR's approach was predicated on working with local scientists, yet such talent was scarce or non-existent in the poorest countries that increasingly dominated the aid program. The review also recommended issuing calls for expressions of interest and offering to cover the indirect costs of conducting research.

With the review in hand, the ACIAR Board of Management prepared a policy statement to guide the Centre into the new millennium. ACIAR's mandate was reinterpreted as (1) encouraging scientists at home use their skills for the benefit of developing countries and to resolve Australia's own problems, and (2) helping developing countries to help themselves, thus contributing to their well-being and general economic growth. ACIAR's programs were intended to contribute to food security, poverty alleviation, and natural resource management. The Centre sought the outcomes of improved incomes, health, and skills. R4D was seen to contribute to these outcomes through adoptable technologies and policy influence; increases in the body of scientific knowledge; and increases in research capacity abroad. Moving forward, ACIAR's programs would address agricultural and 
natural resource economics, animal production, crop production, fisheries, forestry, management of land and water resources, and post-harvest technology (ACIAR 1999).

The Board also created a deputy director position, to take responsibility for managing the internal process of matching country needs with Australia's scientific capacity. This freed the director to manage external relationships with the Minister and AusAID, as well as with research providers within state government, universities, and CSIRO. Whereas ACIAR used to work independently, the Centre's fortunes depended on being well connected within the Australian research community.

In summary, during this second decade, the performance regime enshrined poverty reduction as the purpose of foreign aid, requiring ACIAR to demonstrate how its work contributed to real-life adoption of new technologies and techniques. At the same time, changes in Australia's science policy began to hollow out the capacity of state-level government and shift the centre of gravity in Australia towards university research. The program theory that guided R4D funding sought to boost rural incomes, linking poor women and men with markets beyond the farm gate and the valued added as food moved from "paddock-to-plate". ACIAR continued its grantmaking practice of partnerships for mutual benefits, but increasingly relied on Australian researchers in academic settings. The Centre also modified its grantmaking to exit countries that attained middle-income status and enter countries that became a foreign policy priority. 
After twenty years ACIAR remained a scaled-up version of Crawford's vision, but shifts were underway. The most obvious was the countries covered by the Centre's programming, which evolved to follow Australia's aid program and foreign policy interests. More subtle was an evolution in program theory and evaluation criteria. ACIAR had previously focused on boosting agricultural productivity as a direct contribution to fostering economic growth abroad and boosting trade. Research findings were examined for their potential value in terms of production added or costs averted. This argument had proven successful in budget discussions, allowing ACIAR to assert that its contribution greatly exceeded its costs. Yet as foreign aid refocused on poverty reduction, ACIAR refocused on generating benefits for poor farmers and the environment. Research findings were examined for their real-world impact in the lives of poor women and men. This new logic of impact assessment prompted ACIAR to carry out adoption studies to determine the extent to which research results were used in practice.

Australia experienced changes in the structure of, and incentives for, publicly-funded research. Budget pressures and competing priorities within the state departments "hollowed out" their research capacity in forestry, crop sciences, and veterinary medicine. Within the RDCs, industrial representatives became more influential, and moved funding towards the shorter-term practical concerns of producers. Within the Australian research community, the centre of gravity shifted towards universities, diminishing the relative weight of CSIRO and government departments. The conditions placed on these organizations required them to recover the full cost of research, rather than contributing in-kind or financial support. Meanwhile the Cooperative Research 
Centres emerged as the pre-eminent funding opportunity: offering greater prestige, larger budgets, and collaboration with industry. In short, ACIAR now needed to compete harder to gain the attention of a shrinking pool of researchers.

\subsection{Passport to Engage Government}

During the early 2000s, ACIAR's fortunes were increasingly tied to the aid program and foreign policy. Worldwide funding for agricultural research was on the decline, and Australia was soon drawn into the "war on terror" following the 9/11 attacks in the United States and the 2002 bombing of nightclubs on the island of Bali, Indonesia. The security agenda was ascendant in Canberra, prompting the aid program to pay greater attention to fragile states, recovery from conflict, and improved policing. ACIAR management feared the Centre was misunderstood, vulnerable, and had grown too distant from government. The relationship with the foreign minister had weakened, and ACIAR staff found it difficult to engage colleagues in AusAID and DFAT. The Board identified the Centre's main risks as "a mismatch between our program and Australian Government regional priorities; ...insufficient support, post project, to sustain project outputs to achieve impact; a lack of recognition by key groups of the Australian benefits from ACIAR operations; and a reduction in ACIAR's funding in the light of the above" 46 (ACIAR 2003).

\footnotetext{
${ }^{46}$ This is what the Board feared might come to pass, rather than their assessment of ACIAR at the time.
} 
In 2002, Peter Core was appointed as the new ACIAR director, replacing Bob Clement. Whereas Clement was a researcher at heart, Core came from the world of public management. Core had served as secretary ${ }^{47}$ of the federal departments of transport and of industrial relations, and as deputy secretary of the department of primary industries, before managing the Rural Industries Research and Development Corporation. Core was someone in tune with government expectations. His tenure would see a number of salient changes in ACIAR, including the adoption of an annual operational plan, greater emphasis on country programming, and reform of the Centre's governance model.

\subsubsection{Matrix reloaded}

Under Core's leadership, ACIAR adopted the government practice of preparing an Annual Operational Plan for the year ahead. This added to the existing five-year corporate plan looking into the future, and annual reports that reflected on the past. The new operational plan described the types of activities that ACIAR intended to fund and specified key performance indicators. This plan both encouraged greater interaction with the Minister — who signed off on it—and focused management's discussion with the Policy Advisory Committee — reviewing the plan's assessment of research needs abroad. The plan communicated ACIAR's priorities to potential recipients and was intended to focus staff attention, avoiding distraction due to unsolicited requests from Australian researchers. Before proceeding with a project idea, staff needed to determine whether it was compatible with the priorities in the plan.

\footnotetext{
47 equivalent to deputy minister in Canada
} 
The Operational Plan also shifted ACIAR's budgeting process. Country strategies became the budgeting unit, replacing the past practice of regional expenditure targets. Each strategy included an analysis of the country's context and identified a few priorities of ACIAR programming. The plan provided Australian and foreign embassies an overview of what the Centre intended to do in each country. Program managers were asked to specialize in a few countries, becoming knowledgeable about the research providers there. They were expected to visit Australia's diplomatic missions each time they went abroad, and link with embassies and desk officers in Canberra. In the words of one respondent, the intention was to give ACIAR a "passport... to dialogue with the Minister, AusAID, and heads of mission" (AU-12). Regular contact affirmed that ambassadors greatly appreciated ACIAR projects because, for relatively small amounts of money, they provided a tangible example of public diplomacy and collaboration between local people and Australians. The net effect was a shift within ACIAR's matrix management, strengthening the geographic axis and de-emphasizing the thematic axis.

The shift to country-based budgets also reflected the level at which the Minister was involved. Given his schedule, meetings with the ACIAR Director were often restricted to just twenty minutes. The Minister might request the Centre do more in a particular region or country, but there was no engagement in the technical aspects of the projects. While 
ACIAR remained focused on the Asia-Pacific, it was encouraged to further expand its work in Africa and the Middle East, including new projects in Iraq and Afghanistan. ${ }^{48}$

\subsubsection{Eroding autonomy}

ACIAR's third decade also witnessed a change of governance: as the role of its Board diminished from one of providing strategic direction, to one of advising the Minister. Analogous to a Crown corporation in Canada, a statutory authority in Australia is a public entity established to pursue a specific policy objective. Whereas a line department assumes a broad set of responsibilities and is tightly bound to ministerial direction, a statutory authority has a narrow mandate and operates under its own governing board. Statutory authorities were established in areas that were seen to demand technical skills and non-partisan policy implementation, at arm's-length from ministerial direction (such as the Central Bank). While ACIAR was unique within the aid program, it was just one of over 150 statutory authorities within government.

The Department of Finance began to review the governance of statutory authorities, with an eye to incorporating insights from the private sector. Known as the "Uhrig report", this review proposed that each statutory authority adopt one of two models: either a "governing board" (where the board had the power to determine and alter strategic direction) or an advisory committee (where this power remained with the Minister). This

\footnotetext{
${ }^{48}$ For example, work on controlling soil salinization outside Baghdad — announced ahead of a state visit by the Iraqi Prime Minister - and on dryland wheat farming across Iraq, Syria, and Western Australia.
} 
latter model was restricted to "ensuring alignment of operations with the specified delegation and the priorities of the Minister" (Uhrig 2003, 35). While the Board of Management was originally responsible for ACIAR's directions, over time the Centre had become more responsive to DFAT and AusAID interests. While the motivation was to access additional funding, this pursuit unintentionally enhanced the role of the Minister in setting ACIAR's directions. The report also expressed fears over including stakeholders on a board, as they might "fail to produce independent, critical and objective thinking" by being more "concerned with the interests of those they represent, rather than the success of the entity they are responsible for governing" (Uhrig 2003, 43).

The Uhrig reforms coincided with pressure to rebrand public entities within the Australian government. ACIAR began to de-emphasize its old logo (three hexagons) that had featured prominently on technical papers, annual reports, and website. In its place, central agencies required the coat of arms of the Commonwealth government featuring a kangaroo and emu. Some publications retained a stylized version of the old logo as a faded watermark in the background, but the Australian coat of arms soon adorned the office and business cards. It was a symbolic recognition that the performance regime was now less tolerant of independence, and ACIAR's fortunes were tied to being seen as part of - rather than apart from — the machinery of government.

The Howard government amended the ACIAR Act in 2007, converting the position of Director into a Chief Executive Officer, and transforming the Board of Management into a seven-member expert Commission. This CEO became directly accountable to the 
Minister for administrative and financial purposes. The Policy Advisory Council (PAC) was retained, including the presence of overseas stakeholders. The following Annual Report described the Commission's role as to ensure that ACIAR met the expectations of the Minister. The Commission was to advise "the Minister on the strategic directions of ACIAR, while the CEO provides operational leadership... [and] is now directly responsible to the Minister for managing the affairs of ACIAR in a way that ensures proper use of the Commonwealth resources" (ACIAR 2008). The change in governance model had the effect of enhancing the relationship between the CEO and the Minister, reducing the role of the Board chairperson.

There was a short-lived experiment with a public statement to clarify what the Minister expected of each statutory authority in his or her portfolio. Uhrig envisioned $(2003,7)$ "[t]his document would outline relevant government policies, including the Government's current objectives... and any expectations Government may have on how the authority should conduct its operations." ACIAR staff drafted such a statement in late 2008, calling on the Centre to keep the Minister "fully informed of ACIAR's activities... and provide timely information to the Secretary of DFAT and Director General of AusAID... to reinforce DFAT's role as the principal source of advice... on portfolio policy and program delivery matters" (ACIAR 2008). The statement envisioned the Minister receiving monthly reports on ACIAR operations, meeting annually with the new ACIAR Commission, and approving the Annual Operational Plan as well as those projects that were in new countries or in post-conflict/disaster situations. 
Two features of the statement were remarkable. First, it described a flow of information up to the Minister, but was silent on the reverse flow back down to ACIAR management. It thus did not contain any insight on how the Centre was expected to contribute to government policy. Second, the amount of reporting mechanisms enumerated in the statement implied a regular and deep contact with the Minister. Yet such frequent contact went against history: the Minister could not afford to dedicate much time to ACIAR, given the competing demands of being in Cabinet and Parliament, representing Australia's foreign policy abroad, and running the larger organizations of Department of Foreign Affairs (DFAT) and AusAID. It is thus hardly a surprise that the statement remained a one-time experiment. Kevin Rudd's Labor government (2007-10) subsequently discontinued any further reforms to the governance of statutory authorities.

\subsubsection{Bridging innovation and foreign aid}

In 2001, a new science and technology strategy_ “Backing Australia’s Ability"increased funding to the Australian Research Council and boosted the portion of publiclyfunded research performed within universities. Surprisingly, CSIRO was ignored in the new funding. Traditionally the powerhouse of public research, CSIRO operated as a loose collection of thematic divisions, each engaged in their own projects. The shock of being bypassed for new funding acted a wake-up call, prompting management to restructure CSIRO into a set of flagship programs. These were "multidisciplinary research partnerships... [with] external collaborators to tackle big, audacious goals in areas of major national significance”. For example, one program sought to achieve a ten-fold 
increase in the economic, social, and environmental benefits from water by 2025

(Sandland and Thompson 2012). These flagship programs were intended to recapture the imagination — and support — of government through ambition, relevance to national interest, and application of research findings. CSIRO benefitted from the subsequent edition of Backing Australia's Ability in 2004 which provided an additional five billion of funding over seven years. The lesson of CSIRO restructuring appeared to be "continually question your role and what your stakeholders expect of you" (ibid, 264).

In 2002, the government identified a set of four National Research Priorities. These were intended to set the agenda for the country's publicly-funded research and included: sustainability in the use of land, water and energy; promoting and maintaining good health; frontier technologies for building and transforming industry; and safeguarding Australia. ${ }^{49}$ The priorities were purposely broad, identifying themes whose importance was relatively self-evident and non-controversial. The Howard government appeared to feel that research done at public expenses should contribute to the government's agenda, yet did not feel that government was well-placed to select the best projects or providers. The appropriate role of government was seen as setting the agenda to guide the internal self-governance with the research community to select projects based on traditional notions of scientific excellence.

\footnotetext{
49 These general themes were supported by 21 sub-priorities including: biotechnology, ICTs, and advanced materials, as well as "understanding other cultures" and protecting against terrorism.
} 
Various government agencies, including ACIAR, began to report on how their activities contributed to these priorities. Between 2002 and 2007, the Centre's annual report tracked spending towards various sub-priorities, such as the sustainable use of soil and water, and protecting Australia from pests and disease. These priorities did not really shift ACIAR's research agenda, but allowed the Centre a new means to argue how its work contributed to the national interest beyond the aid program. ACIAR was attentive to the language of Australian research policy because it mattered to researchers at home, including universities, state government, and CSIRO. As senior managers in these organizations needed to justify the work in terms of the national research priorities, ACIAR recast its work in the same terms in order to mobilize in-kind and financial support for the Centre's projects.

The Centre began to describe itself as bridging innovation and foreign aid policy. ACIAR (2006) argued that it occupied "a unique position as a funder of R\&D... part of Australia's innovation system as well as part of the development assistance program". The Centre portrayed this position graphically (figure 14) showing connections to agriculture at home and abroad. This tactic seized upon rising government interest in promoting science as means of enhancing the country's economy. Public research enjoyed a rising budget and prestige, while foreign aid had a stable budget and the foreign policy portfolio was increasingly focused on security. ACIAR also needed to be sensitive to the incentives shaping the willingness of researchers at home to engage with ACIAR programming. From the in-house review process to the monitoring of ongoing projects, the organizational practices within ACIAR had more in common with CSIRO or 
the research council than with AusAID or DFAT. The Centre's routines involved crafting and managing a portfolio of research projects towards achieving change over the long term. By 2004, ACIAR decided to adjust its projects portfolio "so that 40 per cent of new projects are designed to have impacts within five years of completion, 40 per cent within ten years and 20 per cent within fifteen years". 50

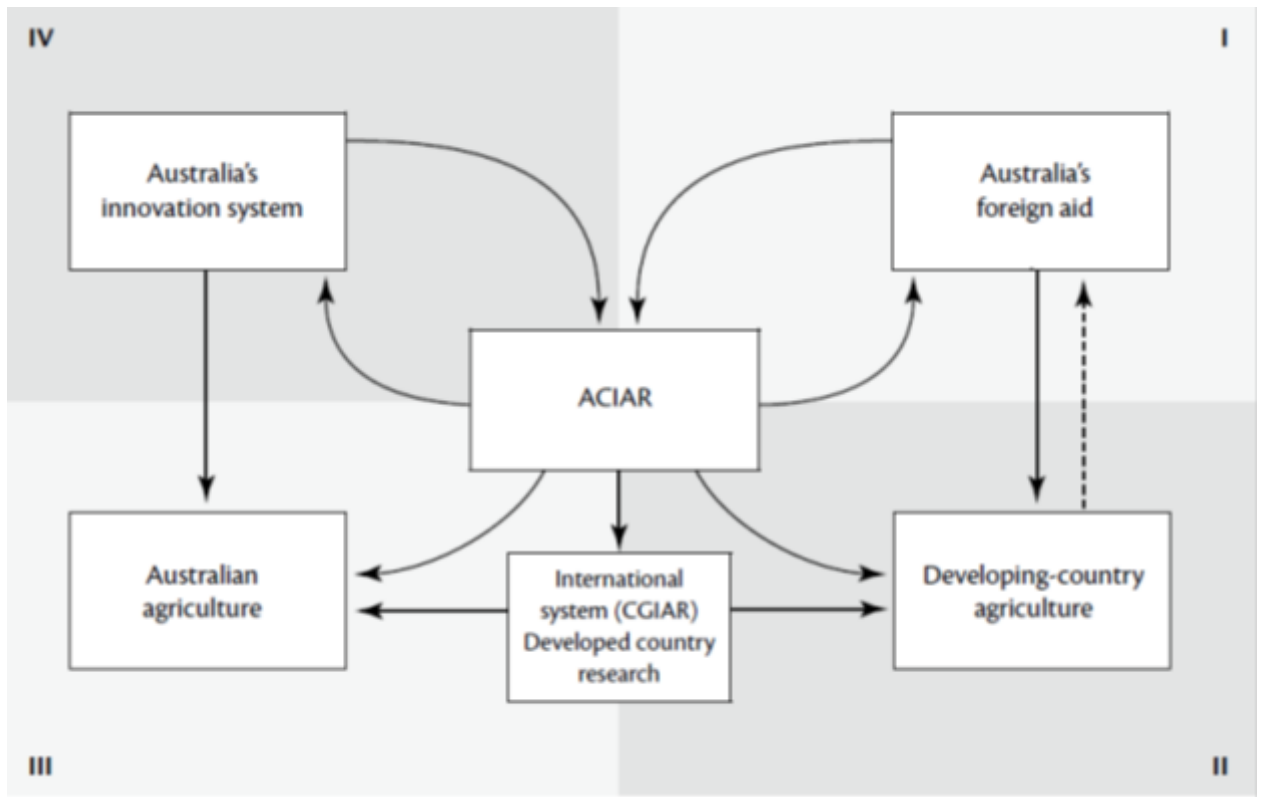

Figure 14: Bridging the innovation and foreign aid portfolios (ACIAR 2006)

The National Research Priorities were not without its critics. For example, Barlow (2006) notes that government policy was based on the assumption that Australia needed to "concentrate its resources within selected areas in order to maximise benefits". Yet scale

\footnotetext{
${ }^{50}$ Message from the Director in the Annual Report to Parliament.
} 
is not equally important in all scientific efforts, as evidenced by the number of Noble prizes awarded to small teams. Furthermore, the Australia's public sector would always be small compared to the amount of research performed in the private sector and in larger economies. The policy challenge was not to achieve a scale rivaling the world's largest research efforts, but to identify those projects with the potential to make a valued contribution to knowledge, technology, or skills. Barlow argues that the task facing research funders is to assemble promising people and ideas into portfolio that would enhance those contributions (rather than merely imposing priorities or a research agenda).

A Research Quality Framework (RQF) was introduced in 2005 as a performance measurement system for universities. The framework proposed to use narratives, examined by review panels, to assess wider benefits of publicly-funded research. The intention was to assess university research from the perspectives of both an academic audience (referred to as "quality") and end-users beyond academia (referred to as “impact"). As Donovan (2008) observes the "government wanted to link academic research to the concerns of industry and business".

The RQF offered mixed incentives for university researchers to work on R4D. On the one hand, performance was increasingly judged based on publications. Agricultural R4D often adapts known techniques to the agro-climatic conditions in a specific place. Such attributes make this work less attractive to top journals seeking to describe the frontiers of knowledge on topics that interest an international readership. Furthermore training and collaborating with colleagues abroad required time than otherwise could be invested in 
preparing publications. On the other hand, R4D was not merely curiosity-driven research, but intended to contribute to the economy and livelihoods. An ACIAR grant could serve as an example of how a researcher's work did more than merely adding to the scientific literature. It also offered an opportunity to travel overseas, see how science is performed in other countries, and expand one's network of professional contacts. University researchers appeared to respond by dividing their time between RQF criteria of "quality" and "impact": participating in one or two ACIAR projects once they had already a record of publications and an established academic career.

The overall context of research policy at home offered ACIAR an opportunity to articulate with the government's agenda beyond the confines of the aid program. Under Kevin Rudd's Labor government, the national research priorities and research quality framework temporarily lost some of the political weight behind them. Yet these imperatives later re-emerged: in 2010 with a new Excellence in Research for Australia (ERA) system to measure research quality in universities, and in 2012 with an effort which lead to a new set of strategic research priorities. The new expectations of public research and the incentives they created appeared to be here to stay. 


\subsubsection{Doubling foreign aid}

Australia's aid program began to grow. In 2005, the Howard government announced its intention to double aid by 2010 to reach over $\mathrm{A} \$ 4$ billion/year. It commissioned a review of the aid program to identify options for how to spend this increasing budget. The review recommended upgrading AusAID country strategies into "whole-of-government" strategies in order to provide a single framework for the delivery of Australian aid (Duncan et al. 2005). Whereas the Centre previously pursued its own priorities and projects, it now faced pressure to fit within—and justify its programming choices against - the strategies set by AusAID.

The review also recommended that AusAID prepare its own strategy to fund and use research. Part of the increase in aid would help expand the then-modest research budget within AusAID, providing funding for work on political governance, growth, health, and education. In keeping with the principle of untied aid, the review suggested that future calls for proposals be open to all nationalities. Duncan et al. (2005) noted that "[w]hile one would expect most applicants to be Australian... we do not recommend that participation be restricted only to Australian institutions". This recommendation stood in contrast to ACIAR's exclusive approach of commissioning partnerships with researchers at home.

These new directions in R4D were soon affirmed in a White Paper entitled "promoting growth and stability”. ACIAR was instructed to better integrate its work into AusAID's rural development strategy (AusAID 2006). The Centre was also asked to provide greater 
opportunity for private-sector participation, as its programming was perceived to be overly invested in universities and state governments.

Meanwhile AusAID increased its own research program "to improve the quality and effectiveness of Australian aid" by helping to "inform where and how our own and our partners' resources can most effectively be deployed" (AusAID 2012b). AusAID research was expected to inform development decision-making, find solutions to global problems, and strengthen the capacity of partner countries' to use research. Over the next five years, AusAID funding to research was expected to increase from A $\$ 30$ million/year to over A\$106 million/year (Australia 2011), exceeding ACIAR's budget and representing over two percent of the expanding aid budget. Competitive calls for proposals accounted for a rising portion of this funding, 14\% by 2011 and plans to reach 30\% by 2016 (AusAID 2012). As AusAID and ACIAR now both funded research, it would raise the question of how and why these organizations had adopted different approaches.

The White Paper also re-established the aid program as part of foreign policy. Australia's own peace and economic well-being were seen to rely on having stable neighbours, countries able to look after themselves, generate economic growth, and reduce poverty. The security agenda remained a key theme in the aid program, but increasingly focused on strengthening local police, rather than violent conflict and terrorism. Insecurity was seen as a product of dissatisfied rural people and minorities that had been largely excluded from the benefits of development. Aid was expected to improve stability with the Asia Pacific region and in turn enhance the safety of Australians. 


\subsubsection{Global food security}

After twenty five years, ACIAR found itself in a strange position: its former independence had eroded and its strategic direction was determined by AusAID-designed country strategies. The aid agency had also entered the research funding business, albeit with an approach distinct, and saw ACIAR as an add-on to its rural development strategy. The Centre's budget had grown modestly compared to rapid growth in the foreign aid. ACIAR was thus a shrinking portion of Australia's development assistance. Poverty reduction, economic growth, and international security were the watchwords of the moment, and had largely crowded out ACIAR's original mandate. Worldwide funding for agricultural research had declined. Arguably the importance of agriculture in Australia had also declined, as a boom in minerals and mining accounted for a larger share of the national economy.

At the same time, the field of "agricultural science" had expanded beyond the simple production of crops at the farm-level. ${ }^{51}$ ACIAR (2007) faced new demand to fund research on marketing and value-chains from "paddock-to-plate". Thus ACIAR also faced a tension between the expectations of development practitioners and research community. The former wanted to see local actions that improved the lives of poor

\footnotetext{
${ }^{51}$ During this period, ACIAR declined AusAID interest in funding a biosciences hub at the International Livestock Research Centre in Nairobi. The reasons appear to be a perceived mismatch in substance and modality, support for genomics research and ongoing laboratory infrastructure did not fit the business model of field-based, time-limited research projects. AusAID turned to CSIRO which eagerly accepted the funding and began an ongoing Africa-Australia collaboration with the new centre (ironically involving former ACIAR employees).
} 
people, while the latter sought opportunities for publication. In the words of one respondent, the tension was "between what research organizations and individuals need to do to maintain [their careers and funding] and what ACIAR needs to deliver in a development agenda" (AU-14). ACIAR needed to maintain its credibility with both audiences, yet the Centre's degree of freedom to do so was increasingly circumscribed.

Yet the latter half of ACIAR's third decade would see new demands placed upon the Centre. Kevin Rudd's Labor government came to power on a platform that promised to once again double foreign aid, this time towards a target of $0.5 \%$ GDP by $2015-16$. The world soon experienced a global crisis in $2007-08$ as food prices increased dramatically due to droughts, rising demand among middle-class consumers, low reserves within grain stockpiles, and increased prices for inputs of fuel and fertilizer. Whereas the threats of terrorism and failed states had captured headlines and policy agendas in the early decade, the spectre of hunger returned with a prominence that had not been seen since the 1980s. By 2011, famine would once again displace thousands of people in the Horn of Africa. Yet the understanding of food security had evolved. While humanitarian aid remained indispensable to attend to people's need in the short term, livelihoods and viable food markets were essential for the long term.

Food security was a good fit for ACIAR and provided the basis for renewing its program theory, reflecting an evolution of agricultural sciences. The Centre began to argue that:

food security is not only about providing enough food, but is also concerned with income generation driven by productivity and diversification. The flow-on effects 
of increasing productivity for smallholder farmers, who represent half the world's poor, achieve other outcomes, such as education for children, access to health services and, in many cases, gender equality. Progress in achieving productivity gains and the associated benefits are central to each of the eight MDGs (ACIAR 2010).

At home, the Rudd government's interest in food security extended beyond merely boosting its investment in ACIAR. In 2009, Nick Austin became ACIAR's Chief Executive Officer. The government's budget that year included a "Food Security through Rural Development" initiative which provided A $\$ 450$ million over four years. It provided additional funding for AusAID country strategies in Asia-Pacific and Africa, as well as additional funding for multilateral efforts of the World Food Programme, World Bank, and Asian Development Bank. ACIAR could no longer argue for budget increases solely on the basis of its own stand-alone programming, but instead needed to identify how its programming contributed to a whole-of-government strategy. The Centre also had to compete for attention against both the multilaterals and an international expectation that Australia would coordinate its response with other donor countries.

The commitment to reach $0.5 \%$ GDP would survive into Julia Gillard's Labor government (2010-13) which held onto power with the support of a handful of independent MPs. Another review of the aid program was launched to once again inform how to manage a growing budget. This review argued for organizing the aid program around the principle of value-for-money, understood as "the quality of the outcome achieved and the efficiency with which it is achieved" (Australia 2011). The reviewers found that more than 90 federal and state government agencies were engaged in the 
delivery of the aid program. This was seen as a strength "as it enhances linkages and networks across a wide range of specialised fields and is much better value-for-money than attempting to build in-house capabilities in AusAID” (Australia 2011). In other instances, value-for-money could lead Australia to get out of the aid delivery altogether investing instead in programs designed and managed by other donor countries. Such “delegated cooperation" arrangements were running or planned with New Zealand, the United Kingdom, the United States, Germany, and the European Union. In other words, the aid budget would not necessarily go to AusAID or ACIAR programming: indeed these organizations might only receive funding if they were able to present themselves as better value than both multilateral organizations and the bilateral programs of other donor countries.

Like its predecessor, this review was once again favourable to research, arguing that some of the biggest successes in foreign aid had involved deploying new technologies. The success of future development was seen to "increasingly hinge upon relevant and vibrant research... focused upon improving the condition of the world's poor.' Indeed the review recommended there should "be more aid funding for research by Australian and international institutions, particularly in agriculture and medicine” (Australia 2011). ACIAR seized upon this recommendation and commissioned the government's Chief Scientist, Ian Chubb, to design a framework for expanding support for international agricultural research, including rationale, geographic focus, priorities, and models for delivery. This framework reiterated some previous arguments noting that: 
Collaborative research with our neighbours serves our national interests, with direct benefits through improving our own agricultural productivity... and protecting crops and livestock from pests and diseases - there is a two-way flow of know-how. Furthermore, there are intangible benefits built up through the goodwill of overseas... scientists and students ... similar to that derived from the Colombo Plan (ACIAR 2011).

By the end of the year, Australia came full circle. Thirty years after the 1981 announcement in Melbourne to create ACIAR, the country once again hosted the Commonwealth Heads of Government Meeting in Perth. On this occasion, the Prime Minister announced A \$33 million over four years to establish an Australian International Food Security Centre, to be housed within ACIAR and dedicated to improving the adoption of agricultural innovations.

At first glance, it is unclear why the government would opt to establish a new "centre" rather than simply invest in the existing one. The announcement could be dismissed as perchance, a habit of politicians to announce something of their own creation, rather than acknowledge the works of their predecessors. Yet it also signalled discontent with the ACIAR approach. Compared to the scale of global food security challenges and the growing budget and ambition of the aid program, ACIAR programming was seen as too modest, too technical, and taking too long to contribute to development outcomes. The appetite within AusAID had turned towards more real-time research, such as mapping of value chains and piloting of modifications in them. The aid agency determined success based on the number of farmers who gained access to agricultural technologies, and addressing food security was seen to require more than business-as-usual from ACIAR. 
In summary, during this third decade, the performance regime adopted whole-ofgovernment strategies towards Australia's engagement within developing countries, particularly in response to the "war on terror" and later the global food crisis. Meanwhile, public research needed to justify itself within national priorities and program-level outcomes, such as contributing to Australia's economy and security, rather than simply pursuing individual projects based on their own merit. The program theory that guided R4D funding sought to bridge Australia's innovation system and foreign aid, emphasizing agricultural research-for-development as a form of science diplomacy, and as promoting stability and food security abroad. While ACIAR largely retained its grantmaking practice of commissioned partnerships, the Centre placed a stronger emphasis on country strategies, in order to give its staff a "passport to engage" government colleagues and embassies. Responding to foreign policy priorities also led ACIAR to support work in countries with a weak or nonexistent domestic research community. 


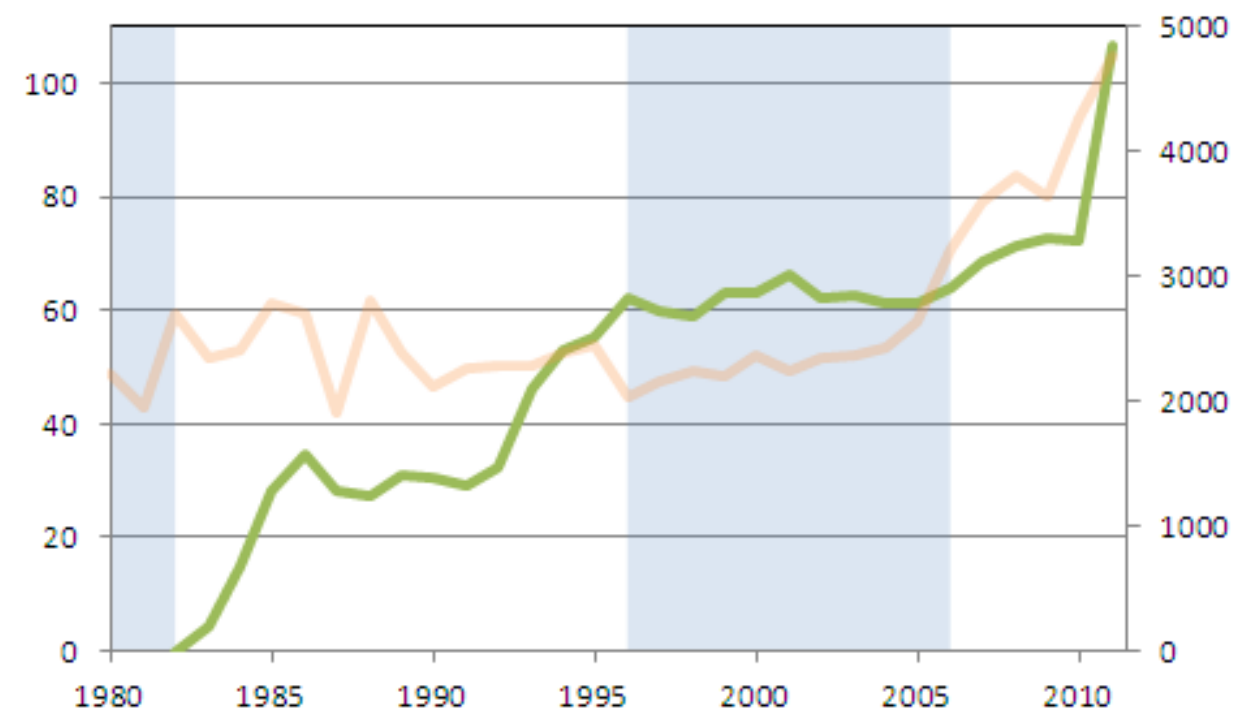

Figure 15: Australia's R4D spending since 1980. ACIAR expenditures in green (left axis) compared to Australia's official development assistance (right axis). All amounts are expressed in real terms in million \$A adjusted to 2011. The years shaded in blue represent time when Liberal, right-of-centre party was in power. (Sources: ACIAR Annual Reports and OECD statistics)

\subsection{Conclusion}

Looking across thirty years of history reveals three key ways that ACIAR both adapted and refused to adapt to changing expectations within the performance regime. On the one hand, the Centre clearly redefined its contribution to the government's agenda, redesigning how it measured success and responding to priorities of the day with science and foreign policy. On the other hand, the Centre responded less readily to forces shaping the research community, which hollowed out the capacity of state departments of agriculture which provided less extension service to domestic farmers. Furthermore, ACIAR remained dedicated to its stand-alone business model of commissioning research partnerships, despite rising expectations that research be awarded competitively and that ACIAR would fit within whole-of-government strategies. 
For its first few years, ACIAR was protected by the high-level government support that had led to its creation. ACIAR's initial value proposition was simply providing Australia with some degree of prestige on the world stage following its announcement at the Commonwealth Heads of Government Meeting. Yet the inclusion of a sunset clause in the Act meant the Centre could have ceased to exist after twelve years. ACIAR had to justify its existence, and based its argument on economic valuation of potential benefits new techniques to boost productivity. This measure played into the political economy then surrounding ACIAR, providing a means of articulating how the Centre benefited Australia, garnering support with farmers and the National Party. Helping agriculture in other countries was not just about helping others; it was in Australia's direct interest, as captured by Derek Tribe's phrase "doing well by doing good." This phrase remained part of ACIAR's discourse and, time and again, the Centre would describe its cost as more than justified by the tremendous benefits stemming from a handful of projects.

The weakness of this tactic was that it justified ACIAR on its own terms, but was modest in comparison to the overall aid program and disconnected from foreign policy interests. When the Simons Review enshrined poverty reduction as purpose of the aid, ACIAR responded by augmenting its evaluation techniques, adding consideration of real-life adoption of new techniques to its existing repertoire of assessing their potential benefits. The Centre also gave more consideration to who benefitted from its research, their linkages with markets beyond the farm gate, and how additional income could enable them to overcome poverty. 
ACIAR responded to the Minister's geographic priorities when necessary. Programming focused on the Asia Pacific, and - given its partnership approach — the Centre tended to work in countries where there was an already established research community, including a substantial portfolio of projects involving India and China. Yet ACIAR also sought out opportunities to support work in Papua New Guinea, East Timor, North Korea, Iraq, and Afghanistan. These countries had relatively weak domestic research communities, and attracted less interest from the Australian scientists, thus tended to required greater amount of proactive design by ACIAR staff. Strict adherence to a logic of "potential benefit of increased production" would lead ACIAR towards more important crops in more populous countries with domestic research communities. Yet over time the expectations of the aid program and foreign policy encouraged ACIAR to also support work on agriculture that was important to poor farmers in smaller, less developed countries, often with a weak or nonexistent domestic research community.

In the past decade, ACIAR had to fit into "whole-of-government" strategies that shape Australia's engagement within partner countries. In this sense, ACIAR became more restricted in responding to opportunities. Yet the Centre also needs to maintain its credibility with its home research community, leading management to position ACIAR at the interface of Australia's innovation and aid agendas. Yet even within science policy, the trend has been to move away from funding individual organizations, based on past performance, and more towards funding constellations of actors, based on their potential to contribute to the economy or to enhancing Australia's standing in world science. 
The cornerstone of the partnerships model was the existence of qualified Australian researchers with skills and knowledge that were applicable to agriculture overseas. Yet the landscape of Australian science evolved since 1982: universities became much more prominent, accounting for a larger share of research funding, and employing a greater share of scientists. In contrast, the state-level governments moved away from maintaining their own laboratories and research staff, and - like CSIRO — the capacity that remained was increasingly expected to justify itself within larger-scale priorities and program-level outcomes, rather than simply pursuing individual projects based on their own merit. Australian research policy shifted towards issues judged to be in the national interest by mobilizing capacity beyond government.

Involvement in ACIAR programming needed to offer Australian scientists an opportunity to get ahead in their careers. At a personal level, young researchers could find it personally rewarding to help reduce hunger in Africa rather than contribute to incremental production of sugar or beef at home. Yet such international work tends to be seen as a luxury, to be entertained only once their career is established with a core set of publications. Meanwhile, ACIAR relative influence and ability to command the attention of Australian researchers diminished as new funding programs emerged that were more interested in practical applications at home.

Within both the aid program and science policy, it is no longer sufficient to simply argue that taxpayers' dollars are being spent on good projects; instead politicians expect that 
spending is contributing to government's larger goals and the national interest. This used to be more rhetoric than substance, a means of framing what ACIAR did rather than changing it. Yet as new funding was tied to cross-government initiatives, the pressure upon the Centre became more pronounced. ACIAR is increasingly expected to be an instrument of Australian policy, rather than merely good at what it does.

In terms of resource availability, ACIAR experienced three periods of rapid growth separated by two periods of relatively flat budgets. Rapid expansion lasted until Australia's austerity budget in 1986, an event that inspired the creation of the Crawford Fund to renew public and political support for R4D. After passing its "sunset review", ACIAR gained responsibility for Australia's contribution to the international agricultural research centres. Access to additional resources was contingent on demonstrating the Centre was aligned with the government's geographic priorities, ending programming as countries attained middle income status and entering countries that were a foreign policy priority. Meanwhile changes in state-level departments "hollowed out" expertise in agricultural extension that were the source of ACIAR's partners. A more recent rise in ACIAR's budget was triggered by the global food crisis in 2008-09 and Australia's response to it.

In terms of public management, the "sunset" clause motivated ACIAR to continually demonstrate the benefits of its work for Australians. Over time, the Centre shifted from estimating potential benefits of increased productivity to examining real-life adoption of technologies, production techniques, and policies. Yet the ACIAR structure of thematic 
research programs was disconnected with DFAT and AusAID structure based on country desks. Over the past decade, ACIAR placed a stronger emphasis on country strategies, in order to give its staff a "passport to engage" government colleagues and embassies. Simultaneously, ACIAR adopted the government practice of annual operational plans, and its independent Board of Management was converted to an advisory Commission. Both these steps reinforced ACIAR's ties to government and reliance upon the Minister. While conceived as an autonomous statutory authority, ACIAR now justifies its existence based on its fit within whole-of-government strategies and Australian foreign policy.

In terms of research governance, ACIAR retained its original "foundation" approach, believing that staff needed to play an active role in ensuring a partnership of mutual benefit between developing countries researchers and their Australian counterparts. ACIAR saw demand as coming from developing country governments, and its clients as the researchers in these countries and at home in Australia. Nonetheless, as public universities and the Research Quality Framework became more prominent in Australia's research system, ACIAR funding became less prestigious and attractive. Contributing to capacity abroad did not necessarily contribute to an Australian researcher's career prospects at home. Academic incentives encourage researchers towards other funding opportunities, such as the Cooperative Research Centres, which multiplied inside a rising science budget. Meanwhile, decreased government funding for the rural development corporations (RDCs) increased the prominence of industry's goals, favouring more shortterm, incremental improvements to existing techniques over longer-term strategic research. Yet CSIRO's transformation from a "university without students" into a set of 
audacious challenge programs shows that there is still space for an ambitious research agenda. ACIAR also began to describe its work in terms of the national research priorities, and cited science policy as an additional source of legitimacy when its work was less connected with foreign policy priorities of the day.

In terms of program theory, ACIAR's perspective remained rooted in the concept of mutual benefit. This reflects the political reality at the time of ACIAR's founding, including an emphasis on benefits at home, rather merely building capacity abroad. ACIAR started with the agricultural needs of developing countries, and developed promising project ideas if there was an Australian partner with some "natural research advantage" on the topic at hand. Australian expertise was seen useful for enhancing productivity abroad given the similarities between the tropical coast and dryland climates at home and conditions in parts of Asia and Africa. The Centre portrayed itself as a bridge between Australia's innovation system and development assistance program. The role of ACIAR coordinators was to assess needs abroad and broker partnerships with talent at home. During its first two decades, ACIAR's focus expanded from the productivity of single crops or species, to the more efficient use of natural resources. With the advent of poverty reduction as the main goal of Australian aid, ACIAR strengthening its work on boosting rural incomes and the valued added as food moved from "paddock-to-plate". The advent of a new perspective did not completely displace programming based on older thinking, but rather examples of productivity, sustainability, and poverty remained visible in Centre's work. 
Drawing Funnel and Rogers' (2011), ACIAR based its approach to R4D on a combination of diffusion and networks theories of change, underpinned by capacity and carrots-and-sticks archetypes: brokering partnerships between Australian and local researchers to create and share new agricultural techniques and enhance the ability of partners in the host country.

In terms of grantmaking practice, ACIAR remained consistent in its partnership model of commissioning projects in response to the agricultural needs abroad. Research coordinators sought out expertise at home and brokered partnerships with local institutes abroad. The ACIAR portfolio initially included a number of state-level departments of agriculture, yet evolved as the centre of gravity in Australia's public research system shifted towards universities. Project approval depended on passing an in-house review process where proposals were submitted to cross-disciplinary critique, which could result in modifications to the research design to incorporate additional disciplines or partners. ACIAR concentrated the bulk of its support in Southeast Asia and the Pacific, yet expanded to Africa and China as budget permitted, as well as key countries within Australia's foreign policy. The Centre retained a narrow set of expectations on it recipients, namely that they would do "good science", there would be some transfer of skills and experiences, and the results would be useful abroad and at home. 


\section{Chapter: Synthesis and Findings}

The purpose of this chapter is to bring together the case studies, assessing them against the three drivers introduced in chapter one and their interaction with the theoretical framework introduced in chapter two.

The availability of public resources, trends in public management, and changes in research governance were proposed to contribute to an evolution in the performance regime over time. As an adaptive organization, the R4D funder in each case study could respond to these changes by altering its program theory and grantmaking practice. Program theory is the vision of how research is understood to contribute to development. In contrast, grantmaking practices reveal how the funder organized itself, and stems from the historical legacy of past experience as well as intentional efforts to implement the program theory. To preview the argument below, context is seen to affect the mechanism: the R4D funder's position within an evolving performance regime influenced the viability of its program theory and grantmaking practice. Yet the response was mediated by agency: each organization responded to a changing context in two ways: (1) adapting their definition and means of supporting R4D, and (2) engaging the performance regime head-on making the case for persisting with its way of conducting business. The first part of this chapter reviews the evidence presented in the case studies against the hypotheses using the theoretical framework.

Having completed this synthesis, the latter part of this chapter identifies three main findings that warrant further discussion. First, there was a shift towards market-inspired 
governance in all three countries. R4D funders selectively adopted market-based thinking into their program theory and grantmaking practice, and faced greater competition in their quest to access government funding.

Second, R4D funders changed their time-horizons, recipients, and point-of-delivery. R4D was traditionally a field-based activity aiming for longer-term changes abroad in terms of research capacity and the technology used in rural areas. The shift in governance encouraged funders to seek shorter-term development results and policy influence through NGOs and think tanks at home and abroad. Meanwhile, changes in the research system at home encouraged a shift away from governmental recipients in favour of working more with academic institutions, as well as greater attention to lab-based work on new technologies.

Third, despite an adverse context, R4D funders covertly continued to pursue their deeper program theory and grantmaking practice. They did not merely respond to the whims of government. They remained faithful to their underlining philosophy of what constituted 'research-for-development' and what they viewed as their responsibilities towards researchers at home and abroad. 
Table 7: Comparison of the case studies as performance regime

\begin{tabular}{|c|c|c|c|}
\hline & \multicolumn{3}{|c|}{ Why do funders periodically change... } \\
\hline & Resource Availability & Public Management & Research Governance \\
\hline$\stackrel{\searrow}{\supset}$ & $\begin{array}{l}\text { From colonial to } \\
\text { overseas development, } \\
\text { to reduce expenses } \\
\text { - } \quad \text { PSAs and Spending } \\
\text { reviews control internal } \\
\text { spending } \\
\text { - Rising aid budget in } \\
2000 \text { s }\end{array}$ & $\begin{array}{ll}\text { - } & \text { Government as } \\
\text { intelligent consumer } \\
\text { - } & \text { Progressive outsourcing } \\
\text { (retain funding and } \\
\text { privatize performing) } \\
\text { - } & \text { Evidence expected to } \\
& \text { show value for money }\end{array}$ & $\begin{array}{l}\text { Haldane principle of } \\
\text { research community } \\
\text { autonomy } \\
\text { - Rothschild principle of } \\
\text { customer-contractor } \\
\text { - Shift from responsive to } \\
\text { targeted funding }\end{array}$ \\
\hline & $\begin{array}{l}\text { Rise with aid budget, fall } \\
\text { with program review } \\
\text { and strategic review } \\
\text { Earmarking funds to } \\
\text { special purposes } \\
\text { (micronutrients, food } \\
\text { security) } \\
\text { Align with IAE priorities } \\
\text { to access new funding }\end{array}$ & $\begin{array}{l}\text { - } \\
\text { Adopt planning and } \\
\text { evaluation functions } \\
\text { Crown corporation: } \\
\text { outside IAE } \\
\text { management \& eroding } \\
\text { Board independence } \\
\text { "Court government" } \\
\text { outside proposals gain } \\
\text { traction (DIF, AIMS) }\end{array}$ & $\begin{array}{l}\text { From selecting projects } \\
\text { to designing program } \\
\text { portfolios } \\
\text { - Pressure to show that } \\
\text { research is applied \& } \\
\text { reaches "market" } \\
\text { - From talent-spotting to } \\
\text { competitive grants (w/ } \\
\text { explicit eligibility and } \\
\text { selection criteria) }\end{array}$ \\
\hline & $\begin{array}{l}\text { Austerity budget } 1986 \\
\text { cuts ACIAR funding, } \\
\text { inspires Crawford Fund } \\
\text { Access to funds } \\
\text { contingent on being } \\
\text { "useful" to Minister } \\
\text { Follow aid budget, (e.g. } \\
\text { graduate countries and } \\
\text { fragile states) }\end{array}$ & $\begin{array}{l}\text { - Sunset clause in Act } \\
\text { limits lifespan, raises } \\
\text { pressure to show results } \\
\text { - Fit into whole-of } \\
\text { government country } \\
\text { strategies "passport to } \\
\text { engage" } \\
\text { Change autonomy } \\
\text { Board into advisory } \\
\text { Commission }\end{array}$ & $\begin{array}{l}\text { - Industrial funding of } \\
\text { public research pushes } \\
\text { shorter-term tactical } \\
\text { issues } \\
\text { - Research moves from } \\
\text { government departments } \\
\text { to higher education } \\
\text { (change in career paths) } \\
\text { - Shift from responsive to } \\
\text { targeted funding (national } \\
\text { research priorities) }\end{array}$ \\
\hline
\end{tabular}

\subsection{Performance Regime}

Chapter one introduced three drivers that were proposed to encourage change among

R4D funders. The first is the availability of public resources: waves of budget growth

permit funders the opportunity to become more ambitious and expand their work, while

waves of budget cuts require being more focused and scaling back their work. The

second driver is the trends in public management: funders are embedded within

government and respond to waves of ideas from various sources on how to demonstrate 
performance and how the funder "fits" within whole-of-government initiatives. The third driver is research governance: efforts to get "more" out of publicly-funded research encouraged a shift from responsive to targeted funding and required that funders demonstrate how their work contributes to outcomes. This section reviews the extent to which each driver appears in each case study.

\subsubsection{Resource availability}

The importance of this driver is in some ways self-evident: R4D funders would cease to exist without money for their programs, and the rise and fall of budgets influences the scale of such programs. What is less evident is the conditions placed upon access to public funding, both the expectations placed on the funder when it receives additional funding and the scrutiny it receives when budgets are being slashed. In the first instance, the amount of R4D funding was determined by the government budget for official development assistance. Each of the funders grew when there were more aid dollars, and each experienced budget cuts when aid dollars were declining. Yet the relationship was by no means directly proportional (figures 5,8 and 12). Rising aid budgets did not automatically translate into more R4D funding: it required active engagement - even lobbying - by managers and their allies, constantly reasserting the importance and value of R4D. For IDRC and ACIAR, there was the added detail of implicit competition with their country's aid agency for the use of foreign aid dollars, and the need to canvass the support of the department for foreign affairs by asserting their contribution to the foreign policy agenda. During budget cuts, the ability to mount a campaign in favour of R4D 
helped preserve funding, or at least kept the cuts proportional to those experienced by others.

By the early $20^{\text {th }}$ century, the UK had firmly established programs for supporting research in and about its tropical colonies, including underwriting the costs of local research facilities abroad and world-class centres of excellence at home. By mid-century, support to "overseas development" was intended to reduce overall costs by getting the former colonies to manage their own affairs. Within R4D this meant scaling back on support to facilities abroad, encouraging the governments of the newly independent countries to assume the financial responsibility for running them. Up to the 1980s, the Overseas Development Administration provided funding for a number of research institutes in the UK that specialized in research on the problems of developing countries, yet the shift from core funding to competitive work programmes was justified in part as a means of rationalizing government expenditure. Later the precipitous rise of official development assistance in the 2000s enabled an even faster rise in the R4D funding. Yet the New Labour discipline of Public Service Agreements and Spending Reviews saw strict controls on the resources available for staffing and other internal costs. This encouraged DFID to move its R4D funding from "retail to wholesale," supporting larger projects, adopting the consortia model, and working with the granting councils. More recently, austerity budgets and decreasing resource availability across government heightened the scrutiny placed on DFID and inspired a perspective of R4D as providing evidence on the "value-for-money" of aid investments. 
In Canada, the fortunes of IDRC rose through its first two decades, but fell in 1991 and 1995 with the government's efforts to rationalize Crown corporations and reduce the deficit through program review. Under Bezanson, IDRC sought to reduce its reliance on government funding, contracting out its services and securing project co-funding from other sources. This helped mitigate the impact of a falling aid budget, yet meant that a share of resources was pre-committed to particular purposes. The first rise of IDRC's budget in the late 1990s is largely due to the special purpose allocation to the Micronutrient Initiative, while part of the rise in funding in the late 2000s was tied to demonstrating the Centre's alignment to IAE priorities, such as the joint food security fund with CIDA. Thus while the Centre was able to save itself from some of the pain of budget cuts, and share in benefits of rising aid budget, in both cases access to resources came with conditions, rather than core funding for the Centre's regular business model.

In Australia, the story of resource availability shows three periods of rapid growth separated by two periods of relatively flat budgets. For the first five years, ACIAR expanded rapidly to an early peak that coincided with Australia's austerity budget in 1986. While ACIAR was not singled out for attention, the budget cut nonetheless inspired the creation of the Crawford Fund to assert the case for Australian investment in agricultural R4D. Twelve years into its existence, ACIAR successfully passed its "sunset review" and earned a new lease on life, gaining responsibility for Australia's contribution to international agricultural research, including the CGIAR. This partially explains the second rapid rise in the early 1990s. Yet continued access to resources was partially contingent on demonstrating that ACIAR was aligned with the government's geographic 
priorities. This meant ending support to countries that attained middle income status. It also meant extending support to countries that were a foreign policy priority, either as science diplomacy (North Korea) or through the war of terror (Afghanistan and Iraq). The recent rise in ACIAR's budget was part of Australia's response to the global food crisis in 2008-09 and saw ACIAR more tightly connected to a whole-of-government strategy on food security.

All three countries saw a rise in their national science budget in the 1990s, predating a rise in official development assistance in the 2000s. Yet the science budget had little direct effect on DFID, IDRC, or ACIAR. Despite a similarity in function to the research granting councils, the structure of government placed R4D outside the science portfolio. These new resources nonetheless had an indirect impact on R4D, as they led to new funding programs and performance frameworks that reshaped the research community at home (see research governance below). For the UK, it served to strengthen the science lobby which soon argued for greater use of science within DFID. In the UK and Canada, DFID and IDRC subsequently partnered with the granting councils as a means to reengage the research community at home. In Australia, a rising science budget meant ACIAR faced greater competition for the attention of the domestic research community. It also slowly encouraged new fields of science, at the cost of "hollowing out" more traditional ones - such as agricultural extension - that were the source of ACIAR's partners. Furthermore, as government scaled back its investment in rural development corporations (RDCs), and industry funding became more prominent, it favoured more 
short-term tactical research goals over longer-term strategic research, again altering the incentives and careers of Australia's agricultural scientists.

\subsubsection{Public management}

Ideas on the purpose and role of government — and how to organize it_influenced the policy space of R4D. Detecting these shifts is one of the advantages of the historical sweep of this thesis, as old ideas remained influential even as the performance regime promoted new ones.

In the UK, Haldane's original concern following the First World War was to ensure the country was proficient in the new technologies that might prove decisive to future war efforts. He introduced the idea that government departments should have a budget line for research, to commission work that could directly inform or assist government in achieving its goals. Following the Second World War, the government shifted from administering “overseas colonies" to supporting "international development". The newlycreated ODA was expected to maintain the UK science base, inheriting a diverse array of research centres at home that had specialized in the problems of tropical climates. From the 1970s, market-inspired thinking called for a division of labour between those who performed research and those who commissioned it. Subsequently, Thatcher's government pressed for privatizing previously public services, and dividing policy making from its implementation. Yet it was not until the 1990s that these agendas led ODA to exit service delivery by progressively outsourcing research performance, as the specialized scientific units were slowly devolved to stand on their own, merge into 
universities, or fold entirely. Similarly the Blair government advocated for evidencebased approach to policy, yet this agenda reached fruition within R4D a decade later, shifting R4D from a public good - contributing the international agenda beyond the UK - to an internal service - providing the knowledge base that justified the aid agency's actions and investments. In each case, an existing idea within the performance regime was eventually applied to R4D, whether separating customer and contractor during the Next Steps initiative in the 1980s or demonstrating "value-for-money" during times of austerity since 2010 .

In Canada, the original vision for IDRC was inspired by the philanthropic foundations in the United States, including their independence from government and political mandates. Yet as a Crown corporation largely dependent on an appropriation from Parliament, government periodically attempted to reassert control over the Centre. While IDRC was intended to engage developing countries, by the end of the 1970s, Cabinet questioned the Centre's fit within Canada's science and foreign policy. Scrutiny by Treasury Board encouraged IDRC to adopt a planning and evaluation function, in line with what was then considered good practice in public management. By the early-1990s, efforts to rationalize Crown corporations saw a proposal to eliminate IDRC or convert it into a departmental corporation. The Centre avoided this fate by cultivating allies within the bureaucracy and associating itself with a new government mandate (implementing Agenda 21). In this century, access to funding required demonstrating alignment with government's foreign aid priorities. Initially applied to the annual increment of a rising aid budget, this test was applied to the entire International Assistance Envelope (IAE) through two rounds of 
strategic review. As a Crown corporation, IDRC was both inside and outside the IAE management framework and policy process. IDRC was allowed to make proposals and participate in working-level discussions, but it was excluded from the higher-level decision-making. Furthermore, the Centre was out-maneuvered in defining the policy space of “development research". Instead the Department of Finance promoted innovative financing mechanisms, and outside proposals gained favour with Ministers, including the Development Innovation Fund and the African Institutes of Mathematical Sciences. The net result was a move of strategic decisions about program choice away from the Board of Governors, and towards Cabinet and senior government officials. This erosion of the Board's discretion and autonomy was reinforced by decreasing its size from 21 to 14 members.

In Australia, the inclusion of a "sunset" clause in the ACIAR Act initially limited the Centre to a twelve-year lifespan. This motivated management in two ways: first to continually show the benefit to Australians—-both as participants and beneficiaries_-and second to focus evaluation on demonstrating those benefits. In its early years, ACIAR estimated the potential value of increased productivity as a means to decide which crops represented the biggest potential gains from an investment in research. As the Centre's first generation of projects came to fruition, attention shifted from ex ante estimates to ex post evaluation of research findings. After the Centre passed the sunset review, evaluation increasingly examined the real-life adoption of technologies, production techniques, and policies. In this century, ACIAR found its structure of thematic programs out of step with DFAT and AusAID structures based on country desks. Management 
responded by reinforcing the geographic axis of its matrix management, seeking a "passport to engage" government colleagues and embassies. Simultaneously, ACIAR became more reliant on the Minister, as the independent Board of Management became an advisory Commission, and ACIAR adopted the government practice of annual operational plans. Conceived as an autonomous statutory authority, ACIAR now had to justify its existence based on its fit within whole-of-government strategies and Australian foreign policy.

In all three cases, politics at home in the Capital mattered. In Canada and Australia, IDRC and ACIAR were championed by high-level individuals who were well connected and well respected. Strong and Crawford had long careers in public services and could navigate the machinery of government in their respective countries. They were both key to getting the founding legislation approved by Parliament and providing their young Centre with the autonomy to set their own program theory and grantmaking practice. They also continued to protect their creations at different times: Strong helped defend IDRC from proposals to change its status in 1992 and 1996, and Crawford's posthumous legacy proved instrumental to ensuring Canberra support. Over time, IDRC Presidents found their job to be as much about maintaining relationships at home as it was providing direction to their Centre's program abroad. While a degree of proficiency in scientific research and knowledge of international development is useful, the most essential competence of a CEO proved to be thick rolodex and network of contacts in key places across government, including the foreign ministry and central agencies. Interestingly, 
both IDRC and ACIAR continued to exist as independent organizations in 2013 when each country's government decided to merge their aid agency and foreign ministry.

In the UK, R4D benefited from both external and internal champions. Outside the aid agency, a "science lobby" pressed for research to be part of the country's foreign aid. Over time, the UK research community was the key beneficiary of R4D funding, with domestic recipients accounting for $96 \%$ of total value of research grants made by ODA (1990-96). With the untying of aid and DFID's focus on the international agenda, this portion fell to $46 \%$ of total value of grants (2004-10). The shift away from domestic research providers provoked an attack on DFID use of science, prompting the department to create the post of Chief Scientific Advisor and join the new UK Collaborative of Development Sciences (UKCDS). Inside ODA, staff crafted each work programme to ease the transition for existing recipients while moving towards competitive funding. They sought to maintain their credibility within the aid agency, as well as their standing in the research community. Later each Director of DFID research drew on their own backgrounds: Paul Spray massaged the Central Research Department together based on an intimate knowledge of the previous thematic programmes, Gordon Conway brought in a focus on platform technologies such as ICTs and genomics, while Chris Whitty imparted a model inspired by clinical medicine to provide evidence on development investments. They were all active policy entrepreneurs with the aid agency, picking up and acting upon certain signals within the performance regime. 
In short, individuals matter. This was a surprise: not predicted by the literature nor included in the theoretical framework, and suggest an opportunity to enhance the latter. The concepts of a performance regime and principal-agent relations suggested that program theory and grantmaking practice of R4D funders would be determined by the outside influences. The theoretical framework allowed for the potential that R4D funders are adaptive organizations, selectively responding to these influences by incorporated some and ignoring others. The surprise was how important individual persons were in guiding this process. Moreover, each R4D funder continued to adhere to the visions of its founders. It is impossible to understand DFID, IDRC, or ACIAR without acknowledging the visions of Haldane, Hopper, and Crawford. Not only does the research community speak back to government through R4D funders, the personalities and ideas of R4D staff and management play a tremendous role in shaping how R4D was defined and funded. Foreign policy and research policy at home delimited, but underdetermined, the space available for R4D. It was left to individual champions to play a dual role. They were the intellectual contributors that crafted program theory and grantmaking practices giving life somewhat ambiguous mandates. Yet they were also the policy entrepreneurs that mobilized support within the bureaucracy—brokering between what government wanted done and what the research community wanted to do-while staying true to an altruistic vision of R4D.

\subsubsection{Research governance}

The UK experienced the widest swings in research governance. The work led by Haldane in the early $20^{\text {th }}$ century led to funding streams for both block grants to universities and 
project funding to researchers. Over time, the research community was able to reinterpret a "Haldane principle" into self-governance under the guidance of peer review and the Mertonian norms of communality, universality, disinterestedness, originality, and skepticism. Government was merely a benign benefactor, providing the resources for scientists to carry out their work. Yet Haldane's motivation was to ensure the country had its own expertise on tap, and would not again be disadvantaged in terms of new technologies as it had been during the First World War. Beyond university grants and research councils, his ideas inspired a research budget within line departments to be used to commission work the government needed.

Later the work led by Rothschild defined the polar opposite in term of market governance guided by the principle of "customer-contractor". Government departments were expected to become intelligent consumers, specifying exactly what they needed from the research community, and demanding a competitive price for that service.

As a consequent of the swing from self-governance to market governance, the UK witnessed the largest changes in the performance regime. While funding for official development assistance was independent of the science budget, ODA/DFID's research funding was very much the Haldane-inspired research budget within a government department. Thus the evolution of R4D funding mirrors overall pressures upon each department for how they were expected to use this budget line.

A number of shifts are particularly prominent in this evolution. First was a shift from responsive to targeted funding: from responding to the interests of the research 
community—based on their curiosity and professional consensus about original and promising avenues of work - to instead encouraging work on the interests of government — based on the department's needs or perception of public good. Second was a shift from intellectual steward to intelligent consumer. Parts of the research community related to a department's mandate were considered a close ally worthy of support, whether in the fields of defense, health, or development. Yet with the advent of the Rothschild principle, this same research community was re-cast as a distant consultant, to be managed through contractual relations. Indeed the UK, Canada, and Australia all progressively scaled back on the portion of research performed within government departments and labs, which served to accentuate the predominance of universities as the primary location of publicly-funded research in each of the three countries.

Publicly-funded research in the UK lay in a dynamic tension between the extremes of self-governance and market governance. It was not simply a matter of the performance regime abandoning Haldane in favour of Rothschild. These names provide useful shorthand for describing extremes, but the two forms of governance coexisted: they were championed and undermined by different actors at different times. This was clear in the delays witnessed in implementing new policy imperatives. In the early 1970s, "customercontractor" called for a divide between government departments and the research community. Yet ODA initially resisted and continued to have part of the research community in-house in the scientific units. It was not until the late 1980s and early 1990s that ODA spun off these units and adopted competitive funding mechanisms. Even then, the relationship with the research community was not entirely arm's-length as the work 
programmes were initially crafted to wean these units off their dependence on core funding from government. Furthermore, government officials would turn to the research community to help it be an "intelligent consumer," identifying government's needs and crafting the terms of references for future funding opportunities. A similar time lag was seen between Blair's call for "evidence-based policy" in the late 1990s and the fruition of this agenda under Cameron in the early 2010s. R4D was now expected to inform "valuefor-money": researchers that wish to retain their professional standing_rather than becoming consultants for hire-were influenced by career prospects and the performance framework of the Research Assessment Exercise (RAE). Tenure and publication motivated the research community, and mitigated the self-interested aims of government departments.

This century was both Rothschild's triumph and Haldane's revenge: a dynamic tension between what government wanted done and what researchers were interested in doing. Government departments were a modest part of the overall funding landscape, allowing self-governance to survive and thrive. In the UK, the research community used each of Hirschman's (1970) three responses—exit, voice, and loyalty—when they were dissatisfied with the offerings of the "research funding" market. A talented researcher would exit by ignoring departmental funding, when the conditions were seen as onerous or misaligned from the researcher's own interests or career goals. The research community used its voice to aid government officials in crafting calls for proposals and to apply pressure in Parliament through the "science lobby". Finally—almost as a last 
resort-researchers demonstrated loyalty by aligning their efforts to what ODA/DFID required in its work programmes and funding competitions.

Research governance sought to create a marketplace between government funders and the research community. While most prominent in the UK, this thinking was also present in Canada and Australia. Over time, IDRC adopted competitive calls for proposals (with explicit deadlines, eligibility, and selection criteria) alongside its original "foundation" approach (which was open-ended, seeking out some proposals, and selectively responding to others). ACIAR retained the "foundation" approach, believing that staff needed to ensure mutual benefit between developing countries researchers and their Australian counterparts. As academic incentives became more influential in shaping a researcher's career prospects, ACIAR grants became less attractive relative to newer funding opportunities.

Market-inspired thinking also sought to ensure there was a "demand" and "client" for publicly-funded research. Demand was represented by privileging certain fields identified as particularly relevant to national interests, or in which the research community at home was assumed to have some form of national advantage compared to other countries. In terms of client, government encouraged collaboration with potential users and the private sector, and increasingly expected researchers to demonstrate how they contributed to social or economic benefit. ODA and IDRC shifted towards targeted funding: from an initial focus on particular disciplines, to a later focus on particular problems (e.g. from funding agriculture and health, to instead reducing micronutrient deficiency and 
combating specific "killer" diseases). In this way, funders sought to demonstrate that their grant portfolios addressed real-world problems, rather than merely responding to researcher curiosity. DFID and IDRC also emphasized the "uptake" or "utilization" of research results: recipients needed to identify and reach an audience of policymakers and practitioners. All three funders became progressively more explicit in arguing how the research they funded contributed to development outcomes.

In Australia, the increasing presence of industry funding (in the RDCs) and industrial partners (in the CRCs) was seen as placing "demand" within the research process. Yet it arguably pushed publicly-funded research from longer-term strategic goals (such as developing new crops and technologies) towards shorter-term tactical goals (such as incremental enhancements to existing technologies). CSIRO was initially burdened by its image as a "university without students", yet improved its standing with government by restructuring around "challenge programs" with audacious goals expressed as a specific target. "Demand" was tied to national priorities, such as enhancing the efficient use of scarce water on a dry continent. Meanwhile ACIAR continued to see "demand" as coming from developing country governments, and its "clients" as the researchers in these countries and at home in Australia.

In the UK, R4D shifted from "service delivery" towards being an "internal service." For example, R4D was originally a service to developing countries, whether directly through support to scientific units established overseas during the colonial period, or indirectly through support to research at home that specialized in tropical climates. Yet over the 
past two decades, the mantra of evidence-based policy saw publicly-funded research recast as an internal service providing the justification for government decisions and investments. Whereas ODA considered itself the "proxy consumer" for developing countries, DFID came to see itself as "the client" for the results from R4D funding.

The ties with research policy were relatively weaker in Canada and Australia. The absence of a colonial relationship meant the research community at home was less vested in work abroad. Neither Canada nor Australia had a historic specialization of research on the problems facing developing countries. Consequently, neither IDRC nor ACIAR had a domestic constituency inherently interested in and supportive of R4D. The founders of IDRC and ACIAR shaped these organizations as they saw fit: the former towards building the capacity scientists abroad, and the latter towards boosting agricultural productivity through partnerships. The lack of a domestic constituency meant R4D was less visible and inherently vulnerable to government cutbacks. Few voters depended on IDRC or ACIAR for their livelihood: instead each organization built up its own network of allies, whether within the bureaucracy or among Parliamentarians. Their sense of vulnerability was accentuated over time due to competition from new funding opportunities, such as the Canada Research Chairs or the Cooperative Research Centres.

Yet both organizations also linked their work to foreign policy and research policy. IDRC supported local researchers who contributed to political and economic transitions in the South America, South Africa, and Southeast Asia. ACIAR supported agricultural science in fragile states and North Korea. Neither IDRC nor ACIAR was directly funded by their 
country's science budget, but found refuge in the language provided in S\&T strategy. In their respective annual reports, IDRC highlighted how its program choice matched the perceived strengths of Canada's research community, while ACIAR described its work in terms of the national research priorities, including "frontier technologies for industry" and "safeguarding Australia."

Science policy provided an additional source of legitimacy to IDRC and ACIAR, especially when their programs appeared to be less aligned with foreign policy. More importantly, science policy mattered because it reshaped the research community: altering the career paths available to scientists at home and the incentives for working abroad.

\subsection{Adaptive Organizations}

As an adaptive organization, each of the three R4D funders responded to changes in the performance regime by altering their program theories and grantmaking practice: the "change model" of how research was understood to contribute to development, and the "action model" of how the funder supported that contribution. The previous section focused on the performance regime as context surrounding R4D funders: changes in resource availability, public management, and research governance. Yet these drivers did not determine program theory and grantmaking practice; instead funders were selective, responding to some signals and ignoring others. This section uses agency, looking inside 
at the decisions of whether, and how, to adapt to changing context. ${ }^{52}$ Tables 7 and 8 provide a guide to the content of the two sections on "performance regime" and "adaptive organizations" building on the framework introduced in chapter 2 .

Recall the concepts of program theory and grantmaking practice introduced in the theoretical framework. Program theory is the proposed casual explanation of how the organization's activities are intended to contribute to real-world results, while grantmaking practice is what actually happens in terms of everyday routines informed in part by past experience. Program theory is comparable to Chen's (2005) "change model" of the determinants understood to cause a problem the organization seeks to address, and the interventions employed by the organization to change those determinants. Program theory is embedded in sometimes ill-defined philosophy and ethos of how R4D was understood within the organization and the values that motivated employees. In contrast, grantmaking practice is comparable to Chen (2005) "action model" consisting of delivery protocols, plans for arranging the organization, and efforts to ensure a supportive environment. This practice evolved over time, including shifts in who received funding.

The first remarkable fact is that each of the case study organizations persisted over time: they continued to exist despite substantial change in public research and foreign policy. IDRC and ACIAR showed remarkable consistency in how they organized their grantmaking despite some variation in corporate strategies and priorities (program

\footnotetext{
${ }^{52}$ Inevitably, there is some repetition with the previous section when the same event or change was linked to both context and agency.
} 
theory). This reveals an ability to preserve elements of its business even while responding to a changing performance regime, more evolution rather than reinvention. In contrast, ODA/DFID's program theory and grantmaking practice fluctuated more widely, reflecting its more vulnerable position as a division within a government department rather than a stand-alone, for-purpose organization.

All three organizations were active participants in the performance regime, helping to shape a policy space conducive for their mandate. These were not passive actors simply responding to the whimsical expectations of diverse stakeholders. The fact that they persisted over time was aided by their ability to mount arguments in favour of their way of doing business. In the UK, willingly or not, ODA/DFID was a participant in the larger debates on science policy, a role that heightened when the head of DFID research became the department's Chief Scientific Advisor. In Canada, IDRC periodically formed and renewed its network of allies across the federal government reaching beyond foreign aid. It provided management with a critical early warning system regarding policy discussions and funding decisions with potential consequences for the Centre. In Australia, the creation of the Crawford Fund essentially provided an advocacy arm for ACIAR, renewing public and political support for its mission of agricultural R4D. The extent to which funders engaged government to create a favourable policy environment was unexpected. They exercised their agency to reshape context, suggesting a counter-balance to the literature's prediction that the performance regime drives the funder's program theory and grantmaking practice. 
Table 8: Comparison of the case studies as adaptive organization

\begin{tabular}{|c|c|c|}
\hline & \multicolumn{2}{|c|}{...how R4D defined and funded? } \\
\hline & Program theory & Grantmaking practices \\
\hline UK & $\begin{array}{l}\text { - } \quad \text { Maintain UK science base } \\
\text { - } \quad \text { Government as intelligent consumer } \\
\text { - } \quad \text { Nontribute to development agenda } \\
\text { - New technologies and evidence to } \\
\text { inform aid }\end{array}$ & $\begin{array}{l}\text { - Move from core support, to } \\
\text { competitively tendered projects and } \\
\text { larger consortia } \\
\text { - } \quad \text { Majority of funding to UK institutions } \\
\text { - } \text { Research advisor as grant } \\
\text { administrator and in-house expert } \\
\text { - Multiplying expectations of recipients }\end{array}$ \\
\hline Canada & $\begin{array}{l}\text { - } \quad \text { Build research capacity abroad } \\
\text { - } \quad \text { Empowerment through knowledge } \\
\text { - } \quad \text { "Grantuence policy abroad } \\
\quad \text { engagement, and access }\end{array}$ & $\begin{array}{l}\text { - Supportive of proponent interests that } \\
\text { contribute to an IDRC program } \\
\text { - Majority of funding to southern } \\
\text { institutions } \\
\text { - } \quad \text { Program Officer as talent scout and } \\
\text { knowledge broker } \\
\text { - Multiplying expectations of recipients }\end{array}$ \\
\hline Australia & $\begin{array}{l}\text { - Support mutual benefit between } \\
\text { South and Australia } \\
\text { - Build on Australia's "natural } \\
\text { research advantage" } \\
\text { - Evidence rallied includes increased } \\
\text { production, economic value, and } \\
\text { adoption rates }\end{array}$ & $\begin{array}{l}\text { - Partnership model of commissioning } \\
\text { research } \\
\text { - Portfolio balanced among regions and } \\
\text { themes } \\
\text { - Coordinator as talent scout } \\
\text { encouraging proposals } \\
\text { - Comparatively narrow expectations of } \\
\text { recipients }\end{array}$ \\
\hline
\end{tabular}

\subsubsection{Program theory}

Recall that chapter two describes program theory in terms of the theory of change that guided the organization, its perceived role in the research process, and the evidence rallied to demonstrate its performance. The first variable was found to be the most salient and is the primarily focus of table 8 . As previously cautioned, at a corporate-level, the notions of how research was expected to contribute to development were somewhat general and did not offer a formal theory of change (Funnell and Rogers 2011) or detailed change model (Chen 2005). These may have existed at the project or program level, but 
looking at the organization as a whole, one can identify general thrusts that subsequently guided grantmaking decisions of who received funding and what their activities were expected to achieve.

An initial vision guided each of the three organizations in the period before explicit corporate strategies. In the UK, Haldane provided that government departments should have a separate line item for research, and ODA inherited the colonial legacy of a research community at home specialized in the problems of tropical climates abroad. In Canada, Strong and Hopper saw the young IDRC focus on the second part of its mandate, building the capacity of developing countries researchers. In Australia, Crawford and McWilliams responded to the political reality of the times by focusing ACIAR on mutual benefit, including the application of findings at home. IDRC and ACIAR were established as for-purpose corporations, at arm's-length from government, in the belief that R4D was longer-term and required fundamentally different skills compared to the aid agency or foreign affairs. ODA, IDRC, and ACIAR began funding projects in general themes or disciplines. In later decades, each organization adopted time-limited corporate strategies containing multiple funding envelopes, each of which was underpinned by incrementally more detailed program theories. At any given time, each organization had a particular perspective on R4D and what it was expected to achieve, which provided a broad narrative that different programs, each of which elaborated more specific explanations of how their work contributed to change. Thus R4D was not aimless: corporate strategies may have appeared a bit vague and susceptible to outside influence, 
but at a lower level there were multiple programs which staff invested substantial time and effort in planning, implementing, and refining.

In the UK, ODA initially focused on the "science base" at home, maintaining highlyqualified people and established centres within the UK research community. Later the work programmes were a response to the Rothschild expectation of being an "intelligent consumer," and offered competitive funding for projects to further outcomes of interest to the aid agency. Since its creation in 1997, three distinct program theories cascaded through DFID. Initially the untying of aid encouraged a shift away from privileging the domestic research community to instead contribute to a larger "development agenda." This meant coordinating with other donors, encouraging research as a public good, and encouraging its use in development practice. The Parliamentary challenge to strengthen the use of science within DFID encouraged a theory of change based on the "promise of technology," particularly genomics and ICTs. This focus opened up R4D to recipients beyond those that self-identified as working on "international development." More recently, R4D adopted a "clinical approach" which sees research as providing evidence as to what is needed and what works. Yet new program theories did not completely displace older ones, instead there was a layering of grantmaking practices over time. For example, DFID continued to provide core funding to the Overseas Development Institution despite long abandoning a commitment to maintain the UK science base. Furthermore, despite the recent focus on evidence to inform internal decision making, DFID continued to fund vaccine research and product development partnerships 
representative of a "promise of technology." In short, a growing research budget provided space for multiple program theories to coexist and thrive.

In Canada, IDRC's program theory remained close to the Strong-Hopper vision of building the capacity of developing country researchers. Over time, this emphasis on capacity building was updated or revised, eventually interpreted by Bezanson as “empowerment though knowledge." Underneath this consistency in goal, the Centre refined its understanding of what made a project successful in contributing to development, preferring applied and interdisciplinary research with clear plans for "utilization." Consequently, IDRC avoided basic or disciplinary research that did not appear to have an audience. The program review and cutbacks of the 1990s triggered a substantial restructuring of the Centre, dissolving the divisions of agriculture, health, information, and social sciences and replacing them with problem-based program initiatives related to the Rio agenda of "sustainable and equitable development." IDRC's Annual Reports tended to describe the Centre's performance using anecdotal stories of either successful projects or the achievements of individual recipients. Yet the move to program initiatives also saw the Centre adopt program-level evaluation which encouraged staff to prepare progressively more detailed program theories.

The arrival of President O’Neil saw the objective of policy influence take prominence over that of capacity building. O'Neil saw the Centre become an early leader in promoting ICTs for development as well as research intended to enhance health care systems in developing countries. In the 2000 s, as IDRC sought to obtain additional 
resources, it became increasingly responsive to Canada's foreign aid priorities and opportunities to partner with other donors. This led the Centre to accept a role in incubating proposals initially championed by outsiders, such as the Micronutrient Initiative and the African Institutes of Mathematical Sciences, as well as an intentional scaling-up of programs that overlapped with the interests of others, such as research on climate change adaptation with DFID and on food security with CIDA. IDRC adopted a mantra of "innovating for development" and restated its business model as "grants-plus," signalling a continued commitment to supporting developing country researchers. The advent of the Internet reduced the program officer's role as "wandering minstrel" providing access to scientific literature and contacts not available locally, yet program officers continued as "engaged peer" supporting the research interests of recipients.

In Australia, ACIAR's program theory remained rooted in the concept of "mutual benefit." The Centre's thematic programs stretched across the agricultural sciences, including plants, animals, forestry, socio-economic aspects, and post-harvest technology. ACIAR started with the agricultural needs of developing countries, and developed promising project ideas if they satisfied three conditions: there was a local partner to work with, the potential benefits outweighed project costs, and there was an Australian partner with some "natural research advantage" in the field. Australia's tropical coast and dryland climates were seen as similar to local conditions in parts of Asia and Africa. Thus Australian experience and expertise were seen as direct applicable for identifying opportunities to enhance the productivity of local crops and farming abroad. This was explicit in how ACIAR engaged the international agricultural research centres, seeking to 
enhance their relation to Australia's climate (and farmers), and the Centre portrayed itself as a bridge between Australia's innovation system and development assistance program. The role of ACIAR coordinators was to assess the needs abroad and broker partnerships with talent at home. ACIAR expected its staff to be top minds in their respective fields, joining the Centre for a limited time_-as a secondment from government departments and universities-rather than career specialists in international development.

ACIAR incorporated multiple program theories into its programming over time. In the first decade, the Centre's initial focus was to enhance the productivity of single crops or species, citing the potential value of increased harvests as evidence for ACIAR's performance. Beyond the benefits accruing to developing countries, ACIAR also estimated the value of benefits to the Australian economy, arguing that this far outweighed the Centre's operating costs. In the 1990s, concern for the environment prompted ACIAR to support work on farming systems, soil conservation, and reducing the use of pesticides; with the intention of fostering better use of natural resources or halting their degradation. This period saw a shift from estimating the potential value of improved production to measuring the real-life adoption rates of new techniques and technology. When the Simons Review enshrined poverty reduction as the one purpose of Australian aid, ACIAR responded by strengthening its work on market chains and the value added from "paddock-to-plate". The evidence rallied to demonstrate the Centre's performance included the rise in income for the rural poor and its consequences for improving lives and escaping poverty. Similar to DFID, the advent of a new perspective did not completely displace programming based on older thinking, but rather examples of 
all three - improved production, environmental conservation, and poverty reductionremained visible in Centre's work.

\subsubsection{Grantmaking practice}

As hinted above, changes in program theory translated imperfectly into grantmaking practice, or the daily routines of the organization. It is one thing to espouse a new set of priorities or program theories; it is another thing to implement them within grantmaking practices. In chapter two, grantmaking practice was described in terms of: selection criteria guiding the choice among potential recipients and proposals, the portfolio of grants made by the funder, and the implications for the research community. This section also mentions the job description of the research advisor/officer/coordinator. In contrast to the organization's perceived role in the research process, the tasks of these men and women reflect the organization's real-life engagement with the research community at home and abroad.

In the United Kingdom, changes in program theory had direct consequences for grantmaking. ODA's initial practice was to provide core support to highly-specialized senior researchers and research centres. The Administration's initial selection criteria was given by the historic set of funding relationships with institutes abroad, particularly in the Commonwealth, and a subset of the research community at home that specialized in the problems of tropical climates. Slowly ODA sought to rationalize these relationships, initially shifting from core funding to project funding for institutes abroad, which were increasingly expected to provide their own operating costs. A similar shift occurred in the 
relationship with the domestic research community, with the work programmes intending to move UK institutes from core funding based on specialization and scientific merits of the recipient, to project funding based on alignment with the knowledge needs identified by government and the quality of a recipient's proposal in funding competitions.

In principle, the shift to work programmes reduced the exclusivity of the funding relationship, and ought to have encouraged the entry of new actors into the portfolio of grantees. Yet just the opposite happened: the overall pool of recipients contracted as some entities were merged together or with universities, and others ceased to exist. With the government's overall push to rationalize the public sector, the scientific units that were incorporated into ODA were eventually spun off to fend for themselves. ODA became exclusively a research funder, and no longer a performer. Meanwhile the staff role of a "research advisor" within ODA and DFID evolved from a subject-matter expert engaging with the external research community, towards a dual role as both grant manager monitoring the performance of recipients and as resource person providing technical support within DFID. Over the past decade, the London-based research staff faced difficulty in their attempts to inform spending by bilateral programmes and to tap into local knowledge on research needs and potential recipients abroad.

With the creation of DFID, the selection criteria initially shifted to focus on contributing to the international development agenda beyond the UK, and an increased willingness to fund research abroad. Where domestic recipients accounted for $96 \%$ of the value of grants during 1990-96, they were just 46\% in 2004-10 (figure 8). R4D funding followed 
the logic of focusing on poorer countries, emphasizing work in South Asia and Eastern Africa. DFID introduced two new modalities into its grantmaking beyond the traditional single-recipient project. The first was Research Programme Consortia, bringing together multiple recipients at home and abroad, around a shared agenda aligned with DFID's priorities, and involving larger amounts of funding. The second was to partner with the UK research councils, which required the participation of UK scientists and saw scientific merit return to prominence in the selection criteria. During the ODA years research funding was arguably captured by the usual suspects specialized in R4D. During the DFID years, there was a greater diversity of recipients at home and abroad, and greater openness to scientists who had skills that could be applied to the needs of poor countries, but who did not necessarily self-identify as engaging in "development research."

Over time, recipients of UK funding were expected to satisfy an increasing number of expectations. They were always expected to produce research that was of acceptable scientific quality and had some relevance to the needs of developing countries. The relative weight placed on each of these criteria, and how they were understood, varied over time and between disciplines. For example, agricultural sciences experienced a period in the 1980-90s that privileged participatory methods that involved the farmer in the research process, while the health sciences witnessed a rise of a "one world" understanding of global health and universal expectations of what constituted ethical research. Beyond merely performing "good science" with the potential for development impact, recipients of R4D funding were increasingly expected to play a role in realizing 
that potential: being effective communicators to help get "research into use". Beyond generating new knowledge and technologies, R4D projects were expected to actually deliver development, demonstrating their contribution to outcomes such as raised incomes and improved well-being. Within Research Programme Consortia, principal investigators were expected to play a managerial role, coordinating multiple activities, involving multiple participants, across multiple institutes. Meanwhile the terms of reference for other grants - particularly those aimed at informing DFID actions - cast researchers as mere "consultants," synthesizing existing knowledge rather than conducting original research.

In Canada, IDRC used a "foundation" approach to select projects. First, program officers would identify and encourage potential recipients, even engaging with them in proposal writing. Second, IDRC would respond to unsolicited proposals submitted by researchers seeking support for their ideas. If these ideas were deemed to be promising and found a champion among the program officers, they were added to the pipeline of potential projects submitted to the Board for approval. Initially the emphasis was placed on the originality of a project idea, its potential contributions to a particular discipline, and its perceived relevance to the problems facing the developing regions of the world. With the transition to program initiatives, staff received the delegated authority to approve projects that fit within a Board-approved prospectus, placing the emphasis on constructing a portfolio of projects that contributed towards this more defined program strategy. 
The IDRC portfolio consistently favoured recipients based in developing countries, accounting for between $98 \%$ and $82 \%$ of the amount of grants made. The use of competitive calls over the past decade saw IDRC express its selection criteria explicitly, including relevance to development priorities, the quality of research design and methods, and experience and qualifications of the applicants. Different countries were eligible depending on the nationality of the recipient institutions and/or where the work is carried out. Following cutbacks in the 1990s, IDRC sought to diversify revenue through donor partnerships which co-funded particular projects or programs. Meanwhile, access to additional resources from Canada's official development assistance required demonstrating alignment with government priorities. Those programs that overlapped with donor or Canadian interest grew faster in the IDRC portfolio than those in which the Centre was the sole investor. Yet unlike CIDA and other donors, IDRC did not identify a select number of "focus countries." Instead, it selected programs and projects that addressed problems common to multiple countries or that spilled across borders entirely. Many projects were coded as regional in scope and included recipients working in different countries. Thus the emphasis of an IDRC project was as much "learning by comparing" with other countries, as it was "learning by doing" through research within one country. Indeed, a significant portion of IDRC's portfolio supported networks of researchers across various countries.

Similar to the UK, IDRC multiplied the expectations it placed on recipients. The initial emphasis on capacity building meant the Centre expected projects to generate new skills and strengthen local institutions. In terms of research outputs, these were not necessarily 
expected to be "world-class," instead IDRC was satisfied if local researchers gained experience. Over time, projects were also expected to: incorporate inter-disciplinarity into their research design, influence policy abroad ("close the loop"), and contribute to positive change in the lives of poor women and men. IDRC further expected recipients to be good communicators: to reach policymakers and practitioners, rather than merely scientific peers.

In Australia, ACIAR remained consistent in its partnership model of commissioning projects in response to agricultural needs abroad, whether identified by staff in their travels or through the priorities expressed by the developing country governments. ACIAR staff (research coordinators) sought out expertise at home and brokered partnerships with local institutes abroad. Project approval depended on passing an inhouse review process where proposals were submitted to cross-disciplinary critique, which could result in modifications to the research design to incorporate additional disciplines or partners. Selection criteria included the skills of the prospective partners and an estimate of the economic value of the potential increase in agricultural production. Projects were championed under a particular research theme and the Centre crafted a portfolio that struck a balance among themes and regions.

ACIAR concentrated the bulk of its support to the countries of Southeast Asia and the Pacific. The Centre monitored the regional distribution of its funding against notional targets, and privileged project development for particular regions whenever they were seen to be underrepresented in the overall grant portfolio. Over time, ACIAR modified 
the list of countries eligible for research support, expanding to Africa and China, and exiting Malaysia and Thailand. The Centre also supported projects that engaged key countries in Australia's foreign policy, including: Papua New Guinea, East Timor, North Korea, Iraq, and Afghanistan. Over the most recent decade, ACIAR allocated its budget and identified priorities for each country, molded to fit within whole-of-government strategies.

In contrast to DFID and IDRC, ACIAR retained a narrow set of expectations of its recipients, namely that they would do "good science", transfer skills and experiences, and produce results that were useful abroad (and possibility at home). ACIAR staff conducted or commissioned studies on the economic value of successful projects, and later on the adoption rates of a random sample of projects. Recipients were expected to respond to surveys and questionnaires, but were not necessarily expected to play a role in promoting their findings. Recipients were expected to contribute to the projects costs both through in-kind and financial contributions. This was intended to ensure commitment on behalf of each participant, but became increasingly difficult at home as Australian researchers had less 'free' resources to invest and were encouraged to charge the full cost of their activities.

The ACIAR portfolio initially included a number of state-level departments of agriculture, yet evolved as the centre of gravity in Australia's public research system shift from government to universities. The Centre's projects tended to focus downstream on field-level extension to farmers, yet the agricultural sciences at home became 
increasingly upstream and bench-based with the genomics revolution. Simultaneously, ACIAR relied on the altruism of Australian researchers and their interest in "doing good" abroad. Yet with the predominance of universities as the institutional setting for researchers, they were increasingly driven by the academic requirements of "publish, patent, or perish." Dedicating substantial time and effort to working with less proficient peers abroad distracted from this imperative, forcing ACIAR to compete harder to attract the interest of Australian researchers. 

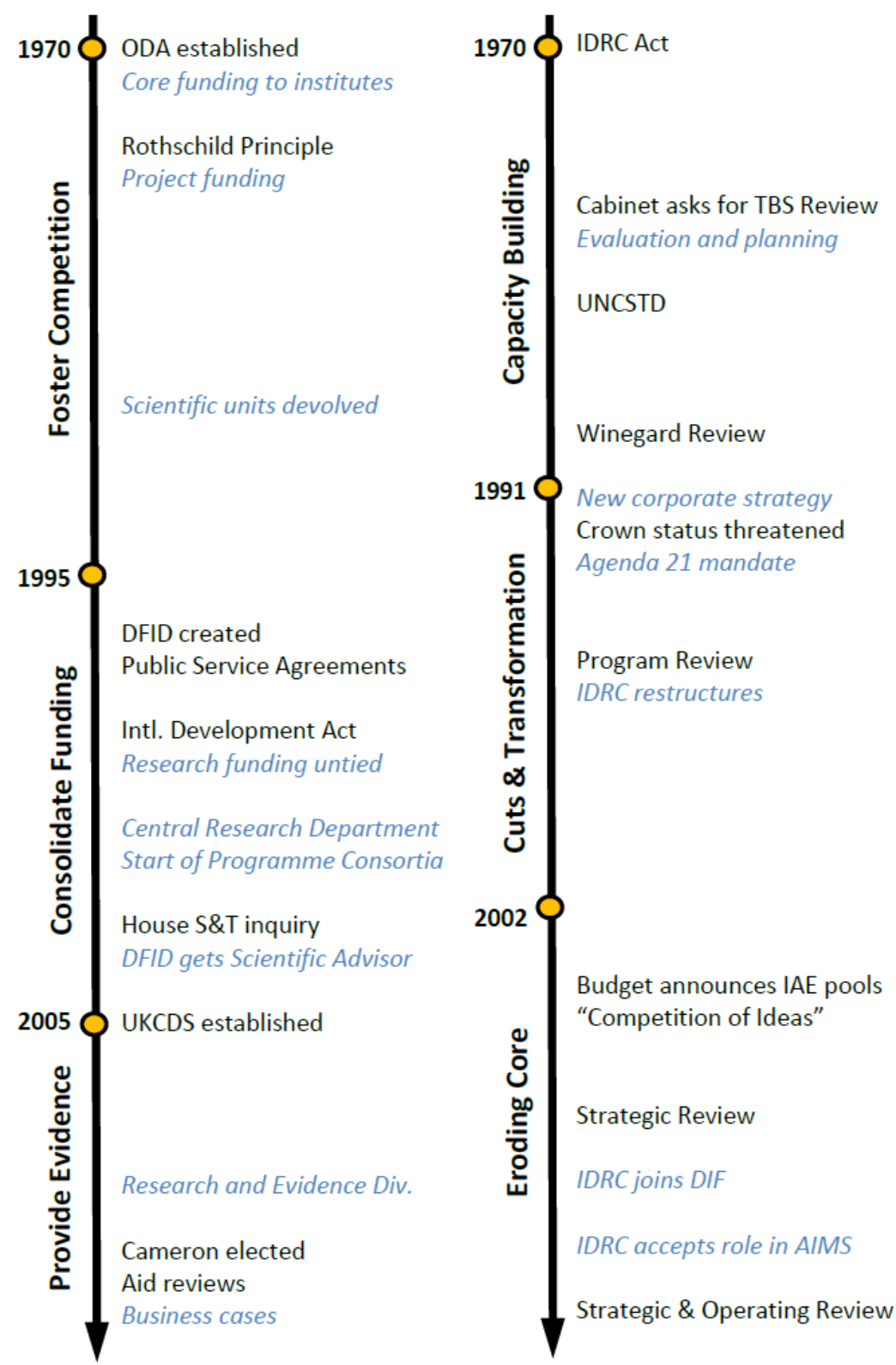

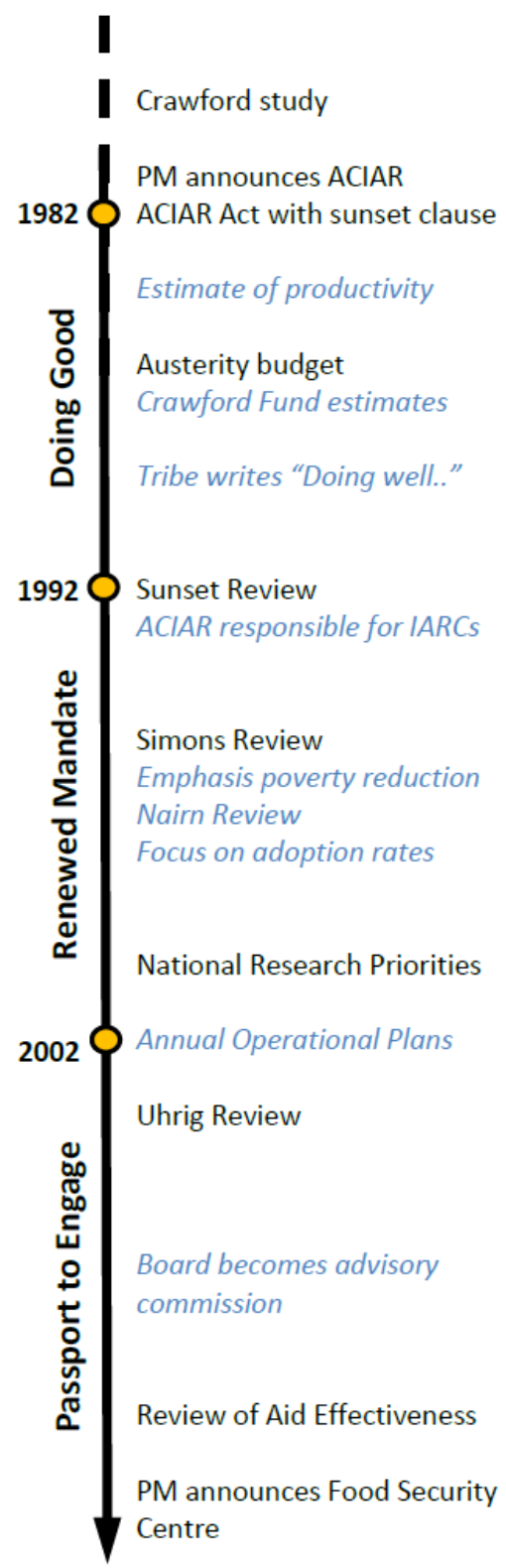

Figure 16: Timelines of Cases Studies Black text represents events in performance regime and blue text denotes how organization adapted. 


\subsection{Main Findings}

This latter part of the chapter builds upon the cross-case analysis to discuss the main findings that emerged. The United Kingdom, Canada, and Australia all experienced a shift towards market-inspired governance of public research, which favoured a shorter time-horizon. This context encouraged funders' to alter their program theory regarding whom to target for funding (researchers at home and abroad) and what constituted the point of delivery (between field and lab-based science). DFID, IDRC, and ACIAR resisted to a limited extent by adapting selectively to these pressures, inserting their own ideas into the performance regime, and covertly pursuing their existing program theory.

Yet performance regimes matter. Changes in performance expectations clearly led to fundamental changes in program theory and grantmaking practice. In previous decades, funders had some degree of freedom to interpret broad policy directions, and mediate between public research and international development, drawing on the ideas championed by the individuals that founded and led each organization. Yet performance regimes became increasingly prescriptive over time, with governments determining on what, for whom, and where research funding was to flow. With an eroded autonomy, funders had less opportunity to set and pursue their own program theory, consequently moving closer to government and further from the research community.

This section also describes how the theoretical framework provided insights towards these findings, or alternatively how the findings suggest opportunities to enhance theory. 


\subsubsection{Shift towards market-inspired governance}

R4D was not immune to the advent of a neoliberal value system as the justification for government action, including public investment in research. The extent of this influence did not reach the extremes seen elsewhere in public research, such as a focus on benefiting the private sector or on patents as a performance indicator. The fact that R4D budgets were official development assistance partially shielded R4D from the expectations shaping public research (section 1.2.4). Each case study organization nonetheless experienced an infusion of market-based vocabulary and thinking within the surrounding performance regime, which the R4D funder selectively adopted into its program theory and grantmaking practice.

The UK explicitly separated research performance and funding, outsourcing the former and spinning off ODA's scientific units. The work programmes were ODA's response to Rothschild's “customer-contractor" principle: the government tendered the research services it required, and the research community was expected to bid for the opportunity to do this work. Following the creation of DFID, R4D funding rose precipitously, yet restrictions on operating costs forced the department to move from "retail to wholesale": from funding projects with a single recipient and a limited budget, to supporting programme consortia with multiple recipients and a more substantial budget. Consequently the pool of potential bidders became smaller, requiring DFID to be less prescriptive in its tenders and allowing the research community an opportunity to incorporate its interests into the proposals. 
In Canada, IDRC saw its clients as the research community in the developing world. IDRC considered its recipients as intellectual partners, rather than merely grantees or service providers. IDRC staff invested time in working with prospective recipients to refine their proposals akin to preparing a joint business plan in which each of the parties was implicated. The recent advent of competitive calls for proposals brought more separation between funder and bidder, and required a cultural shift among staff. Competitive calls broadened the potential pool of recipients beyond those known to IDRC, yet required more discipline on behalf of staff: limiting their early engagement with prospective recipients, and identifying explicit criteria for eligibility and selection. Recent rounds of strategic planning saw the Centre borrow ideas, such as defining a business model and asserting a value proposition, yet despite the use of such vocabulary IDRC largely retained its program theory and grantmaking practice, avoiding the wide swings seen in the UK.

In Australia, the sunset clause in the ACIAR Act hung over the young Centre. From the beginning, management adopted cost-benefit analysis both as a guide to which crops and opportunities to invest in, and - more importantly - to prepare the argument that the flow of benefits from the Centre's projects far exceeded its overall costs. In comparison to ODA and IDRC, which justified themselves based on the benefits abroad, ACIAR unabashedly promoted the benefits accruing at home in Australia, aided in great part by the windfall for domestic farmers stemming from access to wheat strains through the international agricultural research centres. As in the UK and Canada, public research 
came to be increasingly directed to the national interest, defined as working with industry or aligned with the National Research Priorities. In this sense, ACIAR positioned itself as bridging two sources of demand, that of developing countries and that of the Australian government.

By the early 2000s, older funders such as CSIRO and ACIAR found their "market share" eroding as government chose to invest its rising science and aid budgets elsewhere. In response, CSIRO reinvented itself around flagship programs and audacious national goals. At first ACIAR needed to sell government on the indirect benefits of its work in terms of the war on terror, contributing to stability in rural areas of fragile states, and science diplomacy with countries of interest to Australia's foreign policy. The global food security crisis created a new demand for ACIAR's services, yet the government was no longer interested in purchasing from individual suppliers. Instead, the advent of whole-of-government country strategies and the Food Security through Rural Development initiative required ACIAR to insert itself into consortia with AusAID and other line ministries. This shift in foreign policy mirrored an evolution of science policy, which began to privilege scale and ever larger programs. The CSIRO flagship programs and Cooperative Research Centres implicitly argued that larger grants and more complex teams were required in order to contribute to the national interest. Yet size alone is a poor predictor of the societal or commercial value of research. While some Noble prizes are awarded to networked science, such as the Human Genome project or the Intergovernmental Panel on Climate Change, many others recognize the efforts of small teams making a unique contribution to science. 
All three of the case study organizations began with a monopoly over the government's funding of R4D. Yet this privileged position eroded over time as new mechanisms emerged and competed for policy space and budget. In the UK, DFID was brought into the UK Collaborative of Development Science which positioned the research councils and line departments as alternative channels for delivering R4D funds and services. Even earlier, the UK grantees found themselves competing with international initiatives, such as GAVI, which attracted a growing share of R4D funding after DFID was established (see figure 7). In Canada, the University of British Columbia attempted to displace IDRC in the 1997, and after 2010 IDRC shared Canada's R4D funding with Grand Challenges Canada. In Australia, AusAID launched and funded its own research strategy, and bypassed ACIAR to work with CSIRO on biosciences in East Africa.

The UK explicitly attempted to set up a marketplace between the demand of departmental knowledge needs and the supply of presumably numerous potential providers in the research community. Yet the market analogy was imperfect due to a lack of competition and independence. First, by definition, there are only a limited number of providers in specialized fields of science, giving rise to a supply that is more monopsony than competitive. For extremely specialized pursuits, such as a locust control research, it is arguably more efficient to have one national or world-class centre rather than support multiple competing efforts. Second, the research market is plagued by information asymmetries, such that government required the skills of the research community to identify its knowledge needs and understand the potential that exists to address them. 
Government officials could tender for research services blindly, but risked asking the impossible or casting researchers as mere consultants.

R4D funders surmounted the information asymmetries by drawing in research advisors, officers, or coordinators: staff who were themselves proficient in the required fields of sciences and who enjoyed some standing in the research community. This aided each R4D funder to become a more "intelligent consumer," but necessarily placed the funder in a position a tension, attempting to be simultaneously independent of, and connected to, the research community. Staff had dual identities: coming from the world of research, but working "on the other side" as grantmakers. They strived to maintain their credibility within the research community, which provided a future source of employment once they left the R4D funder. In this respect, principal-agent theory provided useful insights into relationships between government and the research community at home and abroad. Yet whereas this theory tends to be interpreted as a one-way line of control, the case studies show numerous instances of two-way accommodation: the research community could speak back to government, in part through R4D funders acting as intermediaries sensitive to both sides. In this respect, the concept of "role" is critical in the theoretical framework, as the tasks and responsibilities of staff offer a richer set of insights than suggested by the funder's written strategies or program theory alone.

\subsubsection{Changes in time-horizon, recipients, and point of delivery}

The advent of market-inspired governance prompted all three research funders to identify a source of "demand" which encouraged shorter time horizons in R4D planning. This 
accentuated two sets of changes in their grantmaking practices. The first was a change in who received funding to work on $\mathrm{R} 4 \mathrm{D}$, a move away from governmental recipients in favour of working more with academic institutions and NGOs. The second change was in the point of delivery, which moved away from rural field sites in the developing world, towards more work in laboratories on platform technologies and in urban capitals on policy advocacy.

In the UK, the "demand" for research was defined by the needs of the government department over time. Initially this need was to maintain the scientific expertise and infrastructure at home and abroad, sustaining centres of excellence in the UK and ensuring the survival of scientific units in former colonies. Subsequently, the UK saw demand coming from developing countries, casting the department as a proxy client that shaped its research agenda and purchased knowledge and technologies that responded to perceived needs abroad. This peaked with the advent of DFID and the untying of aid, during which the purpose of UK funding shifted from privileging fields of research in which the UK was perceived to excel, to instead contribute towards a global research agenda for international development negotiated through the UN, OECD, and other multilateral fora. More recently, DFID aimed to satisfy its own demand for evidencebecoming a direct client rather than a proxy client - to inform the design of bilateral development assistance. In the case of systematic reviews, DFID moved to purchasing a synthesis of existing knowledge, rather than funding the creation of new knowledge. 
As a consequence, there was considerable compression in the timeframe during which the research was expected to translate into development outcomes. Whereas the UK once funded "forty years of research on the hind leg of a mosquito" (UK-03), recent grants require annual, or even quarterly, reports to demonstrate that the research is progressing towards the promised results. The performance regime expects to see the quicker results from R4D funding, replacing the former "wait and see" approach with an expectation of early wins and an ongoing appetite for progress updates. In terms of recipients and point of delivery, academic institutions continued to play a sizable role in the ODA-DFID portfolio, yet the recent emphases on platform technologies and policy influence witnessed an increased funding to laboratories and think tanks. Meanwhile the shift to consortia grants and funding international initiatives favoured recipients with the administrative capacity to coordinate large budgets and multiple sub-grantees.

In Canada, IDRC was founded on the conviction that local research capacity was a public good worth encouraging in its own regard. Yet over time, IDRC encouraged its recipients to respond to some form of local "demand" for research. This was partially to demonstrate performance to central agencies in Ottawa, and became an explicit criterion in IDRC's selection processes. Recipients were required to demonstrate this ex ante and ex post demand: that the problems examined were relevant to local stakeholders, and that the results of the research reached and were utilized by some local audience. This mirrored a rising expectation in Canada that publicly-funded research would contribute to socio-economic benefit, yet IDRC eschewed pressure for publicly-funded research to enhance the competitiveness of the Canadian economy. 
IDRC also moved towards shorter time horizons in programming. Compared to its first two decades, IDRC's past fifteen years saw much more frequent turnover in its programs and recipients, both exiting and entering different areas of research more quickly. After restructuring during the late-1990s, IDRC adopted a regular cycle of program evaluation every five years, as well as an annual budgeting process in which the allocation to each program varied on management's assessment of its importance, quality, and the potential to make effective use of new funds.

In terms of recipients, the IDRC portfolio witnessed a shift away from governmental institutions, towards working with non-governmental organizations. While governmental institutions accounted for $24 \%$ of the total amount granted by IDRC during $1985-89$, this portion fell to 7\% during 2005-10 (calculations for figure 11). During the same period, the share of funding going to NGOs increased from $35 \%$ to $56 \%$. In terms of point of delivery, a simple scan over the names of these NGOs suggests that recipients combined research with policy advocacy and/or the delivery of development interventions, providing a link to a potential audience and use for the funded research. In contrast, government recipients are driven by their own cycle of policy formulation and implementation, while academic recipients are constrained by their own cycles of academic publication and supervising graduate students. In both cases, the time required for these activities could easily exceed the reduced time horizons during which IDRC programs had to demonstrate results. 
In Australia, ACIAR was initially analogous to the rural development corporations (RDCs), in which producers paid in a levy in return for the promise of improved production techniques. "Demand" was understood to come from farmers, and ministries of agriculture, for technologies that boosted productivity and income. Over time, the rising influence of industry directed the Australian RDCs towards shorter-term, incremental refinements of existing production techniques with a more immediate payoff, and away from the longer-term strategic research into novel crops and techniques with a more distant and uncertain payoff. ACIAR diverged from the RDCs, in part as its budget was part of Australia's foreign aid, without industry funding or direct representation by industry on the ACIAR Board.

Nonetheless, ACIAR was forced to adapt to shifts in Australia's science policy and the incentives it provided for potential grantees. The ACIAR portfolio initially included a number of state-level departments of agriculture, yet evolved as the centre of gravity in Australia's public research system shifted from government to universities. ACIAR projects tended to focus downstream on field-level extension to farmers, yet the genomics revolution saw the agricultural sciences in Australia become increasingly upstream and bench-based. Simultaneously, ACIAR initially relied on the altruism of Australian researchers and their interest in "doing good" abroad. Yet as more and more researchers relied on universities as their institutional home, they were increasingly driven by the academic requirements of "publish, patent, or perish." Dedicating substantial time and effort to working with less proficient peers abroad distracted from this imperative, forcing ACIAR to compete harder to attract the interest of Australian researchers. 
In summary, the shift in R4D governance resulted in changes in time-horizon, recipients, and point of delivery. The clear trend in all three funders was a compressed timeframe in which research funding was expected to lead to development outcomes. Where a former generation of programs aimed to achieve outcomes over decade or longer, current programs must demonstrate success within three-to-five years with regular signs of progress en route. In terms of recipients, all three case study organizations shifted away from funding government institutions. The UK directed a greater portion of funding to research councils at home and international initiatives abroad, as well as for-profits and non-profits of sufficient scale to administer large, complex projects. IDRC directed a greater portion of funding to non-governmental organizations in the developing countries, while ACIAR directed more of its funds to Australian universities. In terms of point of delivery, there was a trend towards diversification. While IDRC initially favoured fieldbased work in rural areas of developing countries, its portfolio grew over time to include laboratory-based work in Canada and abroad, as well as work performed by think tanks in urban centres. ACIAR largely retained its focus on field-based research and extension, yet Australia also began funding lab-based work in CSIRO and abroad. With the longest history and largest budget of the three, ODA-DFID funded research at various points of delivery, adding to its grantmaking practice and portfolio with each shift in its program theory. 


\subsubsection{Covert program implementation in adverse contexts}

The politics of the home capital influenced all three of the case study organizations in terms of the strategies they pursued and the practices used in their grantmaking. It is tempting to dismiss R4D funders as merely responding to the whims of government policy and budgeting processes, yet their historical experience is more nuanced. All three research funders invested substantial time and effort elaborating, enacting, and revising their program theory. Beyond formal corporate and program strategies, each held an underlining philosophy of what constituted 'research-for-development' and an ethos regarding their responsibilities towards researchers at home and abroad. Staff in all three organizations considered themselves first and foremost part of DFID, IDRC or ACIAR: a distinct identity apart from the public service, privileging poor countries and scientific excellence, over national interest and adherence to political agendas at home.

Drawing Funnel and Rogers' (2011) each research funder pursued distinct theories of change and program archetypes (table 9). The information archetype underpins R4D at a theoretical level, providing knowledge, technology or evidence that create new opportunities for international development (Arrow 1962, World Bank 1998, Helpman 2004, Molenaar et al. 2009). Yet the logic behind the observed program theory in each case study is better described by as diffusion, empowerment or network leading to grantmaking practices based on direct delivery through in-house scientific units, case management of projects tailored to particular recipients and problems, or providing carrot $\&$ sticks to incentivize the external research community. 
In the United Kingdom, R4D was most often based on a diffusion theory of change, initially underpinned by direct delivery. ODA inherited a set of scientific units at home that saw government responsible for conducting R4D. In the 1980s and 1990s, its importance eroded with the slow move to competitively-awarded work programmes and the eventual phasing out of direct delivery during Next Steps agenda. With the establishment of DFID and substantial budget growth, R4D oscillated between diffusion and reasoned-action theories of change, which interpreted R4D as technical innovation and evidenced-based policy. In both cases, R4D was underpinned by carrot-and-stick: correcting a 'market failure' by providing researchers with a financial incentive to do work that benefitted developing countries.

In Canada, IDRC initially pursued an empowerment theory of change, underpinned by capacity building: supporting researchers in poor countries to exercise greater control over their own development. Such a perspective was dominant from Hopper's 1970 speech at the inaugural meeting of the Board of Governors through to Bezanson's 1991 strategy, appropriately titled 'empowerment through knowledge'. Under O’Neil, IDRC supplemented this core philosophy with a network theory of change underpinned by case management: recipients were encouraged to cultivate relationships towards informing policy abroad, with IDRC support adapting to the unique circumstance in each project. In contrast, the emergence of Grand Challenges Canada in 2010 exploited a gap in Canada's R4D landscape, embracing a diffusion theory of change underpinned by carrot-and-stick. 
In Australia, ACIAR based its approach to R4D on a combination of diffusion and networks theories of change. ACIAR funding was underpinned by capacity and carrotand-stick archetypes: brokering partnerships between Australian and local researchers to create and share new agricultural techniques and enhance the ability of partners in the host country.

Table 9: Shifts in R4D program theory (based on Funnel and Rogers 2011)

\begin{tabular}{l|ll|ll|} 
Case Study & \multicolumn{2}{|c|}{ Theory of Change } & \multicolumn{2}{c|}{$\begin{array}{c}\text { Program Archetype } \\
\text { Initial }\end{array}$} \\
\hline United Kingdom & Diffusion & $\begin{array}{l}\text { Diffusion } \\
\text { Reasoned-action }\end{array}$ & Direct delivery & Carrot \& Stick \\
& & Recent & \\
Canada & Empowerment & Network & Capacity & Case \\
& & & & Management \\
Australia & Diffusion & Diffusion & Capacity & Capacity \\
& Network & Network & Carrot \& Stick & Carrot \& Stick \\
\hline
\end{tabular}

IDRC and ACIAR were initially granted the autonomy to express a distinct R4D identity openly and proudly. Similarly research was initially given pride of place when DFID was established. Yet the performance regime surrounding all three organizations progressively became less tolerant of such autonomy. The shift toward market-inspired governance eroded the political support for a distinct R4D mandate, forcing each of these organizations to find more covert ways of implementing their program theory. Each funder modified their program theory to more closely match what was politically viable at the time. For DFID and IDRC, these shifts occurred over the 1980s and 2000s. Meanwhile, the ACIAR Act in 1982 represented a revision on the IDRC Act in 1970, 
focused on mobilizing the domestic research community for mutual benefit at home and abroad. This vision of R4D could more readily pass through Australian Parliament at the time than could the Strong-Hopper vision of capacity building abroad.

Each organization continued to pursue its R4D program theory covertly in an otherwise hostile policy environment: connecting to other government priorities while remaining true to their core beliefs and the integrity of their research agenda. While ODA quickly adopted the rhetoric (and reluctantly the reality) of the 'customer-contractor' principal, it also covertly sought to ensure that the work programmes provided for the transition and survival of its scientific units. More recently, DFID appears to have become much more instrumental in its research funding, seeking first-and-foremost to inform its own operations. Yet an expanding budget for research allowed the department the space to pursue multiple program theories and grantmaking practices. Indeed the increase in the average project budget essentially re-delegated responsibility for program logic back to the research community, particular the lead institution with each Research Programme Consortium.

Since the 1990s, IDRC repeatedly referred to foreign policy and aid priorities to justify its program choices, yet the extent of this influence tended to be exaggerated. Corporate communications, such as the Annual Report, gave disproportionate attention to those projects related to such priorities. This exaggerated their apparent weight within IDRC's grant portfolio, which continued to fund work in line with the Centre's deeper program theory and grantmaking practice. In the words of one respondent, it was "an investment 
of two percent of the budget to protect the remaining ninety-eight percent" (CA-01). Thus the apparent shift towards greater alignment to government priorities was partially symbolic, providing space for IDRC to continue pursuing its core theory of change.

Similarly ACIAR revised the countries where it worked to respond to foreign policy priorities, and it consistently emphasized the benefits accruing to Australian researchers, farmers, and economy. Nonetheless, ACIAR consistently followed its model of 'partnerships for mutual benefits', continuing to pursue a theory of change in line with Tribe's philosophy of "doing well by doing good".

Analogous to private companies responding to diverse consumer demands, each research funder had to choose whether to diversify its offerings or focus on its core product. ODA and DFID were very responsive: reinventing its R4D division and diversifying its grantmaking with changes in leadership, rising budgets, and new demands in the performance regime. IDRC was moderately responsive, adding thematic programs and grantmaking mechanisms to reflect the perceived demands in developing countries and within Canadian foreign policy. As the smallest of the three case study organizations, ACIAR remained the most specialized, both in terms of thematic focus on agriculture and dedication to downstream application, even as the pool of Australian research providers began to privilege the more upstream science of genomics.

Nonetheless R4D funders formed a link in a chain of principal-actor relationships between government and the research communities at home and abroad. Each funder 
simultaneously competed for government funding against alternative uses of public funds, and competed for the attention of researchers against alternative demands for their time and ideas.

The case studies support a theoretical framing that views the research funder as an intermediary: simultaneously an agent to government and principal to the research community. This was not a passive role, as R4D funders actively brokered win-win opportunities that satisfied the interests on both sides of their 'client' base. They could not afford to alienate either side completely. Changes in performance regime occasionally inspired the funder to revise how it contributed to the government's agenda. Thus the funder catered to different actors in the performance regime, alternatively finding favour within science and foreign policy priorities or among central agencies. Meanwhile, periodic changes in program theory saw the funder switch which segments of the research community benefited most within its grant portfolio. For example, prior to the 1990s, IDRC strongly favoured and found support among the research community engaged in agriculture and health. During the decade, IDRC revised its program offerings, essentially switching its allegiance to the research community engaged in natural resource management and ICTs. More recently, in the 2000s, the Centre swung back to the agriculture and health segments of the research community.

Thus while the language of market competition and demand was adopted in the performance regime and program theory of funders, the grantmaking practice and behaviour of R4D funders is better explained in terms of political economy. R4D funders 
actively shaped a role for themselves as the interface between government and the research community, finding allies and building a coalition that provided the funder with financial resources, political support, and an audience of grant seekers willing to engage in its programs. On the surface, the different periods of time identified in the case studies reflect a shift in funder program theory following a change in the expectations of performance regime. Yet these changes also represent a realignment of coalition: the sets of actors that provided the R4D funder with its sustenance, substance, and legitimacy.

Thus the image of a discrete marketplace for research is an illusion. Funders were not the independent purchasers of knowledge among perfectively competitive providers, but the political interface between government and research communities, at home and abroad. To survive, R4D funders needed to partially satisfy the expectations of members within at least two of these four sets of actors (figure 17). In the UK, the focus was on a brokering between the interests of the home government and the domestic research community. In Canada, the focus was on providing opportunities for researchers abroad within the interests of home government. In Australia, the focus was on linking the interests of researchers abroad with the skills of those at home, within the limits of what the home government was willing to support. 


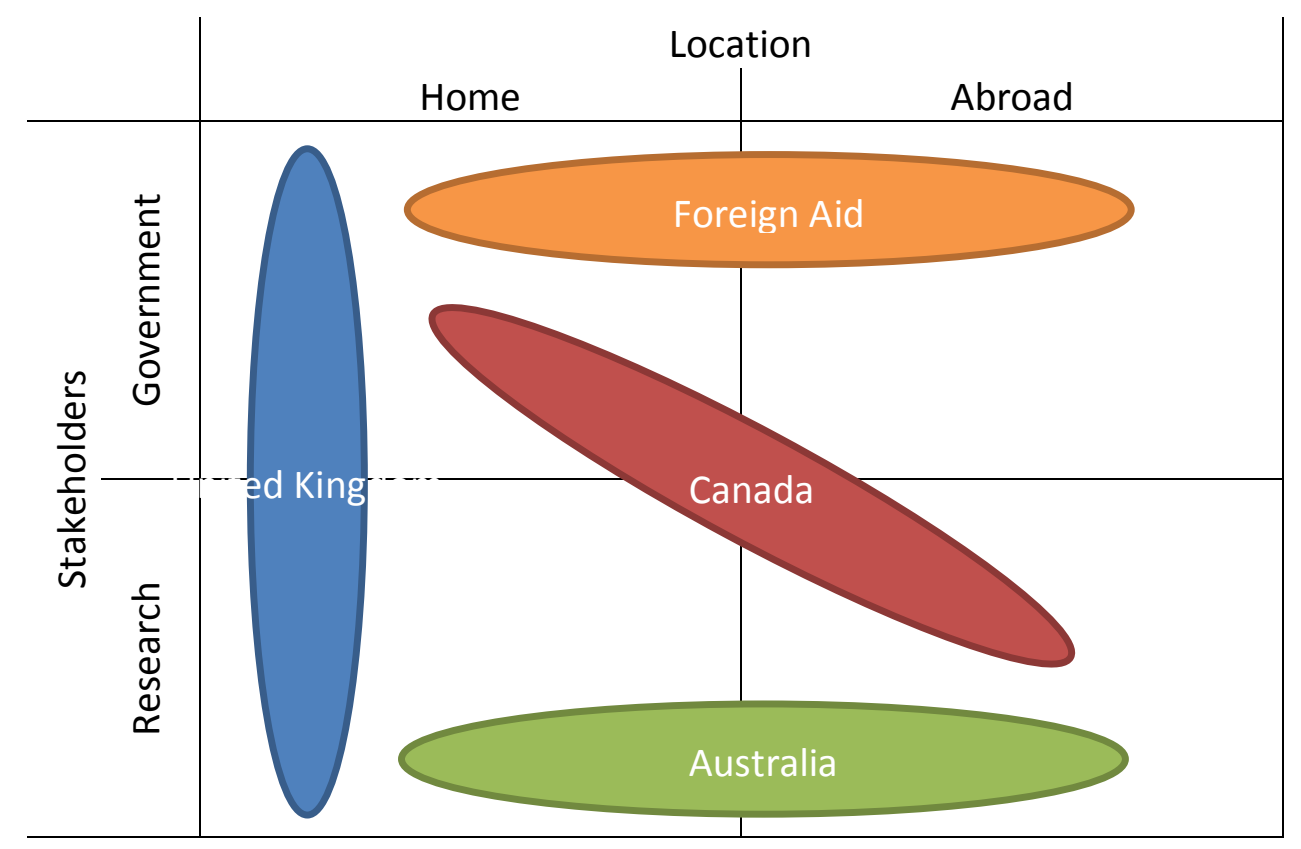

Figure 17: Support for R4D comes from partially satisfying the expectations of members within at least two of these four sets of actors.

\subsection{Conclusion}

The latter part of this chapter identified three main findings. First, there was a shift towards market-inspired governance in all three countries. R4D funders selectively adopted market-based thinking into their program theory and grantmaking practice, and faced greater competition in accessing government funding. Second, R4D funders changed their time-horizons, recipients, and point-of-delivery (the "when, who and where" of their program theory). R4D was traditionally a field-based activity aiming for longer-term changes abroad in terms of research capacity and the technology used in rural areas. The shift in governance encouraged funders to seek shorter-term development results and policy influence through with NGOs and think tanks at home and abroad. 
Meanwhile, changes in the research system at home encouraged a shift away from governmental recipients in favour of working more with academic institutions, as well as greater attention to lab-based work on new technologies and policy advocacy in urban centres. Third, despite an adverse context, R4D funders covertly continued to pursue their deeper program theory and grantmaking practice. They did not merely respond to the whims of government. They remained faithful to their underlining philosophy of what constituted 'research-for-development' and what they viewed as their responsibilities towards researchers at home and abroad.

In short, performance regimes matter. Changes in performance expectations clearly led to fundamental changes in program theory and grantmaking practice. In previous decades, funders had some degree of freedom to interpret broad policy directions, and mediate between public research and international development, drawing on the ideas championed by the individuals that founded and led each organization. Yet performance regimes became increasingly prescriptive over time, with governments determining on what, for whom, and where research funding was to flow. With an eroded autonomy, funders had less opportunity to set and pursue their own program theory, consequently moving closer to government and further from the research community. 


\section{Chapter: Contribution and Implications}

This final chapter begins by revisiting the research problem, hypothesis, and theoretical framework. The thesis asks "what drives funders to periodically change how they define and fund research-for-development (R4D)?” The answer is that funders seek to survive by maintaining a dynamic balance between government and the research communities at home and abroad. The theoretical framework uncovers how funders maintained this credibility, in part drawing on the policies guiding public research. Yet the framework is relatively blind to international drivers, uncritical of government's true motivations, and overestimates the funder's autonomy. Greater attention is needed to the daily tasks of employees, which are more revealing than the funder's perceived role in research process. Finally, the framework did not foresee the ability of R4D funders to reshape their policy environment and how individual persons are influential in this process.

The latter part of this short chapter revisits the discussion of research governance and contemplates the future of R4D. The choices R4D funders make matter as they affect who gets funding to do what, privileging certain lines of inquiry over others. R4D is at a critical juncture: closing as donor countries squeeze public expenditure, and opening with an expanding set of "global challenges" that affect all people. Given that funders are rooted in different national policy contexts, this limits their ability to buy into a shared program design. Instead it is easier for different funders to make their own contribution towards a common agenda in a way that respects their individual program theories and grantmaking practices. The future of $\mathrm{R} 4 \mathrm{D}$ requires funders to continue brokering the 
ideas of international development with the ideas of publicly-funded science, a relationship that is alternatively symbiotic and conflictive.

\subsection{Problem and hypothesis revisited}

This thesis asks "what drives funders to periodically change how they define and fund research-for-development (R4D)?" To answer this question, the thesis drew on concepts from the literature on research policy, organization studies, and public management. This helped to distinguish the performance regime surrounding a research funder (context), from the ability of funders to adapt their program theory and grantmaking practice (agency). The hypothesis proposed that three drivers contribute to change in the performance regime: the simple availability of financial resources, trends of what constitutes good practice in public management at any time, and the balance of interests within the governance of public research. Examining the historic evolution of R4D in the UK, Canada, and Australia revealed the presence of all three drivers during different periods.

On the surface, it appears axiomatic that funding organizations adapt their program theory and grantmaking practice in response to changes in the performance regime. Yet the consequences of this adaptation means that program theory - the generalized understanding underpinning the funder's change model—is influenced by the performance expectations of other actors, including aid agencies, foreign ministries, other line ministries, central agencies, and even the Prime Minister's agenda. Evaluation theory expects a logical framework to be constructed in a step-wise fashion, starting with 
objectives, and proceeding to activities, outputs, and outcomes. Yet examining the historic experience of three R4D funders suggests it is constructed to bridge a gap between government priorities on one side and the research community interests on the other. Objectives and outcomes are predetermined by the policy process. The funder is left to craft a program theory that provides space for researchers to populate funding opportunities with activities that bridge these predetermined objectives and outcomes.

Program theory incorporates generalized notions of how research is understood to contribute to change, and is underpinned by a series of more specific programs. Over time, some programs persist or evolve as they successfully broker the world of politics and science, while other programs are ended or created to respond to the closing or opening of opportunities to strike a dynamic balance between government priority and researcher interest. Deriving funds from official development assistance, R4D is much more prescriptive than funding offered to domestic researchers through the granting councils, with the expectations placed upon recipients multiplying over time in the UK and Canada. Nonetheless R4D funders seek to maintain their credibility within both government and the research community, facing challenges when it strays too far in either direction. Government occasionally requires the funder to refocus on the priorities of the day or take on new roles, such as special initiatives or science diplomacy, yet these pressures are counterbalanced by the research community which can ignore the funder's opportunities (exit) or mobilize a "science lobby" to press for change (voice). 
While a funder's program theory evolves to respond to changing expectations of the performance regime, its grantmaking practice is more resistant to change. Canada and Australia largely persisted with their grantmaking, with IDRC conserving a project-based approach focused on supporting and networking researchers abroad, while ACIAR maintained its partnership model matching researchers abroad with talent at home. The UK experienced a wider range of grantmaking practices, yet even as new ones were added, they did not completely displace older ones, leading to a hybrid portfolio. Similarly, responsibilities were added to the job description of an IDRC program officer or ACIAR coordinator, but the core competencies and function remained. Staff needed to represent the funder's interest, verifying that recipients completed their work and accounted for their budgets. Yet staff were also expected to engage the research community at an intellectual level as a peer, and not merely as a bureaucrat checking up on contractual compliance.

Ultimately, the answer to the research question is that funders periodically change how they define and fund R4D in order to survive: to maintain a dynamic balance between government and the research communities at home and abroad. The former provides the funder with the resources and authority required to operate, while the latter provides the real-life efforts that give the funder's program theory meaning. On the surface, the funder is simultaneously an agent to government and a principal to the research community. Yet the relationship is not one-way, as the research community can exercise influence on the funder, and the funder actively shapes the space for its activities within government. It is 
thus perhaps more accurate to cast the funder as an intermediary, rather than a simple link a chain of principal-agent relations.

\subsection{Theoretical framework revisited}

The key strength of the theoretical framework was its ability to go beyond the linear chain of principal-agent relations. A more nuanced picture emerged by examining on the interplay between context and agency. On the one side, there is the influence of multiple principals that form the performance regime of wider expectations of publicly-funded research. On the other side, the funding organization selectively adapts through modifying or persisting with its program theory and grantmaking practice. A simple interpretation of principal-agent relations would see each link as a "take it or leave it" offer: if the agent is not willing to accept the principal's terms, the principal simply moves on to find a new agent. Yet the public research "market" is plagued by a lack of competition and asymmetries in knowledge. This makes it difficult for either government to simple pass over an established funder in favour of alternative mechanisms, or for a funder to ignore the norms of self-governance within the research community. A public research funder is neither all powerful over the research community, nor a helpless pawn to the whims of government. The theoretical framework is useful for uncovering how funders maintain credibility with both government and research community.

An additional strength of the theoretical framework is identifying the link with science policy. In the three case studies, R4D was funded from official development assistance, and existed within the machinery of government under the Minister of Foreign Affairs or 
of International Cooperation. While science policy did not have a direct line of authority over R4D funding, it did have an indirect effect through its influence on resource availability and research governance. The importance of science policy to R4D varied with the level of participation by the research community at home within the funder's portfolio. The effect was strongest in the UK where the majority of recipients were researchers in the home country, moderate in Australia where the partnership model meant they were half the portfolio, and weakest in Canada where the majority of recipients were researchers abroad. The expectation that public research funding will contribute to a real-life impact is not exclusive to international development. While the thesis examined research-for-development (R4D), the theoretical framework could be applied to other fields such as research-for-health, for-energy, etc. Yet like R4D, the governance of such spaces involves both the policies particular to that sector and the policies guiding public research more generally.

There are four weaknesses in the theoretical framework that are worthy of note. First, the framework is relatively blind to international drivers beyond the home government. For example, the 2002 Monterrey conference saw an international commitment to double the resources dedicated to official development assistance, while the 2005 Paris Declaration saw the emergence of new norms including harmonizing donor activities with the priorities of host governments. Both these events influenced the opportunities for R4D, but were not immediately noted with the framework. Data from federal budgets and White Papers do not necessarily reveal what inspired the home government to change the resources or policies for international development. Moreover, the international context 
explains in part why countries maintained or even grew their foreign aid budgets during times of austerity. Similarly, the framework is blind to the performance regime abroad, in the host countries that are the intended beneficiaries of R4D. Substantial attention was paid to the incentives facing the research community at home in the donor country, yet future work should pay similar attention to the research community abroad: the factors that govern research, shape the behaviour of researchers, and influence how research is used in developing countries.

Second, the reliance on primary-source written documents means the theoretical framework was not always critical of government statements. White Papers and other documents were accepted at face value, as accurate descriptions of government intent and motivation. Future work should provide a more critical reading, questioning the extent to which primary source documents may represent a more acceptable public expression of government's true thinking and arguments. To a limited extent, interviews identified which policies and statements were more influential, and offered a 'view from the trenches' on what they represented for R4D practice. A deeper historical understanding could be achieved through greater grounding in the ideas and aspirations of particular administrations, such as the Blair years in the UK, or Howard years in Australia.

Third, the theoretical framework assumes that funders are in control of their program theory and grantmaking practice. Yet there were occasions when program design was determined outside and simply given to a funder for implementation. For example, the African Institutes of Mathematical Sciences (AIMS) was already formed before 
government made IDRC responsible for Canada's contribution to it. As a large amount of core funding for training, AIMS did not fit well with the IDRC grantmaking practice of more modest budget research projects. Similarly, the requirement for ACIAR to fit into whole-of-government strategies meant the funder's program theory was partially predetermined by outside actors. Furthermore, changes to the IDRC and ACIAR boards reduced the role of these bodies in determining strategic direction, heightening their dependence on government's direction. Thus future work could pay close attention to the extent that the performance regime and competing proposals constrain the funder's ability to set its own program theory or contradict the funder's established grantmaking practice.

Fourth, the indicator of "role" should focus more on the real-life tasks of staff, rather than what the funding organization perceives as its contribution to the research process. For the purposes of data collection, "role" was placed under program theory, or how the funding organization saw itself. This was rarely stated explicitly in written documents, and even when it was, it was not as rich as reviewing job descriptions or hearing former staff recount their personal experiences. A researcher's impression of a funder depends on their interaction with an individual program officer or coordinator, rather than IDRC or ACIAR in the abstract. "Role" is thus better considered a variable of grantmaking practice. The dynamic balance between government and the research community is reflected in how staff allocate their time, not only monitoring the progress toward project milestones, but making an intellectual contribution to the research community, through such tasks as: engaging recipients on research design and methods, connecting them to 
peers working on similar problems elsewhere, and ensuring that the funder's programs built upon the state-of-the-art in different fields of knowledge. Thus rather than starting with corporate strategy and looking how it was enacted by staff, future work could start with what staff do and seek what guides these efforts. The daily tasks of employees are more revealing than funder's perceived role in research process.

Finally, two surprises emerged that were not foreseen in the theoretical framework.

The first surprise was the ability of R4D funders to 'speak back', contributing ideas into the policy environment (cf Fischer 2003). These were no passive victims to shifts in government policy and discourse: they actively participated in the performance regime to reinsert the ideas underpinning their program theory back into the policy process. They also engaged powerful actors to reshape performance expectations, making the case for their way of doing business, rather than merely accepting that their grantmaking practices may no longer fit with contemporary fads in public management. In all three case studies, funders were able to persist somewhat with existing program theory, delaying or avoiding adjustment to changes in the performance regime. This ability was aided in part by government previously underdetermining the R4D policy space. Yet performance regimes matter: changes in the performance expectations over time led to fundamental changes in program theory and grantmaking practices. In previous decades, funders had a degree of freedom to interpret broad policy directions, and balance among competing goals, drawing on the ideas of public research and the ideas of international development. Yet performance regimes became increasingly prescriptive over time, with governments 
determining on what, to whom, and where research funding was to target. With an eroded autonomy, funders had less opportunity to set and pursue their own program theory, consequently they moved closer to government and away from the research community.

The second, related, surprise was how influential individual persons were to this process. Each R4D funder initially embodied the vision of their founders, benefitted from high-level champions, and incorporated new program theories from different directors over time. These two surprises - the funder's ability to shape the expectations of others, and the role of individuals in that process - offer insights for the literature on performance regimes, principal-agent relations, and the study of public research funding.

The theoretical framework offers an analytical tool to the literature. At first glance, the framework appears descriptive, as the thesis looked back upon the historical experience of three research funding organizations. Yet the framework also provides insights on research governance today, and allows one to look forward to the potential trajectories in which R4D funding might evolve in the future. This is the purpose of the next two sections.

\subsection{Research governance revisited}

The choices R4D funders make affect who gets funding to do what, privileging certain lines of research over other. The UK case study shows both a contraction and expansion in the pool of grantees. Initially ODA reduced the number of recipients with a progressive decline in core funding to institutes abroad, yet recent decades witnessed a 
gradual widening of grantees beyond those specialized in tropical climates or those selfidentified as studying international development. The Chief Scientific Advisor and work with the UK research councils led DFID to engage scientists engaged in platform technologies, such as genomics, ICTs and climate modelling, regardless of their experience in developing countries. IDRC also expanded the pool of potential grantees, through the use of competitive calls and partnerships with the granting councils, which similarly involved researchers that were not necessarily specialized in international development.

In the UK, there was greater openness to funding research efforts abroad following the passage of the International Development Act. This meant the domestic research community was no longer in a privileged position to receive DFID funding. Indeed the advent of the Research Programme Consortia required domestic researchers to form networks with developing country partners if they wanted to be eligible for funding. Meanwhile IDRC continued a grantmaking practice of privileging support to developing country researchers. Canadian researchers that wanted to access IDRC funding were often required to first find a partner abroad. In contrast, ACIAR took it upon itself to broker such partnerships, balancing the needs expressed by agricultural ministries in developing countries and perceived strengths within the Australian research community.

Despite changes in both program theory and grantmaking practice, the UK was remarkably consistent in privileging support for agriculture, health, and economics. As noted above, IDRC periodically switched which segments of the research community 
benefited from its support, continuously covering three or four different themes, but altering these occasionally. IDRC's initial structure of thematic divisions and subsequent program initiatives provided a general framework within which staff and prospective grantees prepared proposals that simultaneously contributed the Centre's corporate objectives while responded to local research interest and perceived development needs. In contrast, ACIAR sought to expand the opportunities for agriculture abroad and, if possible, also benefit "primary industries" in Australia.

Each funder requires a pool of candidates within the research community willing to apply for its grants. The funder provides a set of incentives to researchers to conduct work aligned with its program theory. At the same, individual researchers strive to define and pursue their own careers, choosing among, and drawing upon different sources of funding. A researcher's work surpasses the limits of any one project or grant, yet researchers rely on these as building blocks to construct their longer-term career path in a bricolage fashion. The increases in the budget of the research granting councils in all three countries made these sources much more significant than those offered by R4D funders. In Canada and Australia, being a Canada Research Chair or part of a Cooperative Research Centre carries greater prestige and arguably fewer constraints than a grant from IDRC or ACIAR. In the UK, the attractiveness of a DFID grant diminished somewhat as funding was seen to cast recipients as either an administrator coordinating the work of others in a consortium, or as a consultant responding to the department's interests. 
The gradual shift over time away from government-owned centres, and towards universities as the primary performer in the UK, Canada, and Australia introduced a tension for domestic grantees. On the one side, R4D embraced a growing list of expectations intended to enhance "development impact," requiring grantees to do more than merely good science, in a single discipline, accepted by their peers. Over time the definition of best practice in R4D evolved to: incorporate insights and methods from multiple disciplines, enhance the skills of developing country partners, communicate with lay audiences of policymakers and practitioners, and demonstrate that their work is used to benefit the lives of poor women and men. On the other side, the career prospects for many researchers is shaped by the incentive to "publish, patent, or perish" to demonstrate frequent, original, specialized, and highly-cited contributions to their chosen field. Some researchers escape this bind by working with non-governmental organizations or policy think tanks, where the expectations of their performance are more aligned with the R4D aims of influencing policy and informing practice. Whereas a previous generation of domestic researchers specialized in R4D, for many it is now something altruistic and fun, only to be entertained once their academic career is firmly established.

Within developing countries, R4D funding still provides a significant share of the overall funding available for research. There is less tension between the funder's expectations of "development impact" and the interests of the research community, as catering to the latter is seen as an indirect contribution to the former. This is especially so during times when the funder privileges R4D as "capacity building." Nonetheless as more developing countries establish and increase their own domestic research granting councils, the 
reliance on R4D funders is diminished and counter-balanced by other means available to support their work. Whether at home or abroad, any source of funding requires researchers to balance between responding to the funders priorities and expectations, perhaps at the cost of modifying their own research interests, or foregoing the offer of potential resources. The multiplication of research funding options at home and abroad arguably rebalances the public research "market", requiring funders to compete for the attention of scarce talent, as much as researchers need to compete for scarce funding.

\subsection{Future of R4D}

R4D is at a critical juncture. On the one hand, the policy space for R4D is closing. Each donor country is squeezing public expenditure, cutting back or slowing the rate of growth in their official development assistance. As resources become less readily available, there is a tendency to concentrate on core "development" business which increasingly framed by international consensus: the successor to Millennium Development Goals and a focus on fewer, least developed, and more fragile states. On the other hand, the potential for R4D is opening beyond official development assistance. "Donor" countries are diversifying their relations with developing countries: placing greater importance in economic and trade relations, educational mobility, and science collaboration. At the same time, there is a growing middle ground, with an increasing number of countries surpassing "low income" and an expanding set of "global challenges" or wicked problems of economy, environment, and health that affect all people. In short, R4D will decline if it is merely the R\&D of foreign aid, yet could grow as part of science diplomacy and global problem-solving. 
Which path is followed will be determined in part by what happens in the capital cites of each country. This is the key insight offered by this thesis. Looking back, the context of R4D at home permitted less discretion for funder organizations, translating into less autonomy for grantees. Looking forward, the response to calls for "one world" collaboration on global challenges will be constrained as funders must respond to different home contexts. As governments continue to expect "more" from publiclyfunded research, there is greater political demand to demonstrate how such research is contributing to real-life outcomes that matter to politicians and taxpayers, in such fields as health and energy, at home and abroad. The recent trend was towards emphasizing short-term 'practical' ends; in contrast a shift to R4D on "global challenges" requires moving 'up \& out' toward more ambitious goals, beyond researchers and narrow national interest, over a longer-time horizon aiming for results decades into the future.

The continuity and change witnessed in the case studies suggest some caution on the prospects for R4D. It will be inherently difficult to negotiate international partnerships among research funders. Different funders are rooted in different national policy contexts, which can limit their ability to buy into a shared program design. Instead it might be easier for different funders to make their own contribution towards a common agenda, but in a way that respects their individual program theory and grantmaking practice. As the R4D agenda turns towards "global challenges" there is arguably a need for more collaboration among like-minded funders. Yet being 'like-minded' is more than having similar interests in what to fund; it also relies on having a mutual understanding of 
how each participant expects research to make a difference, what constitutes success, and what evidence is needed to satisfy their home audiences.

This suggests a continued need to balance competing goals, something R4D funders have done for over three decades. In the near-term, R4D funders must remain agile, nimbly adjusting their management structure and funding opportunities to maintain their relevance to, and support from, both government and the research community. There is progressively less space for multiple program theories to co-exist or to preserve grantmaking practices that do not resonate with current expectations. Consequently, R4D funders may well become more corporativist: streamlining themselves to concentrate a greater portion of resources into fewer, larger programs that are more tightly aligned with the assumed contribution to the world beyond. IDRC and ACIAR already witnessed their boards' influence erode compared to outside influences. Similarly, compared to a generation ago, today's grantmakers enjoy less discretion and freedom in designing programs and identifying recipients.

Returning to the trends identified earlier (section 1.2.4), R4D has experienced a shift towards market-inspired governance, albeit not as severe or immediate as that experienced by other areas of public research. The criteria by which R4D funders are judged turned towards the utility of research. Once based on its intrinsic value for empowering developing countries, the utility of R4D is now based on its instrumental value for furthering whole-of-(donor)-government strategies. This shift has implications for how funders operate, narrowing the R4D agenda: privileging those programs that 
resonate with established foreign policy and reducing the opportunities for novel, curiosity-driven work based on local interest. The research agenda has become political safe, either by addressing questions of technological innovation or rooting itself in the accepted policy discourse of the donor capital. While 'science strikes back' on occasion - to resist government-led agendas - the plurality of voices within the larger research community opened R4D to a broader set of recipients beyond 'development studies'. Research funders have less control over their goals and practices, including over whom and what they fund. This space is squeezed as home governments proactively identify the themes, and even particular projects, they wished to support. Furthermore research funders are pressed to be more critical of their grants, to justify their existence by demonstrating the outcome and cost-effectiveness of their work.

R4D has never been a single, cohesive and coherent set of theories. Different individuals and organizations adopted distinct first principles, seeing R4D as generating evidence on the effectiveness of foreign aid, inventing new technologies that serve poor people, and strengthening research capabilities in poor countries. Given this multitude of competing goals, funders chose different ways of defining R4D and evolved distinct approaches to support it. At the extreme, R4D risks becoming an empty pool of funding, devoid of its own intellectual content, simply reflecting how others see the world. The turn towards market-inspired governance accentuated this risk, yet R4D persisted by both selectively adapting some ideas and ignoring others. 
The future of R4D requires funders to continue brokering between the ideas of international development and the ideas of publicly-funded science. The relationship between these two policy domains varies: at times it is symbiotic, and at other times it is conflictive. Synergy is evident when epistemology and ontology align. Such was the case for the Millennium Development Goals, which adopted a focus on welfare and safety nets abroad, reflecting the political discourse at home in donor countries. Such is also the case now for "global challenges" such as addressing the emergence of new zoonotic diseases or adapting public policy to a hotter, drier climate. In such situations, the problems are clearly recognized within the language of foreign policy (used to justify action) and the language of social or natural sciences (used to guide research).

In other cases, the ideas of international development and the ideas of science are at odds. Arguably this was the case at the beginning of this century as a policy focus on new threats to security, governance, and fragile states was held back as social science needed to reformulate these concepts and theories. Similarly, health science is now ahead of policy: whereas decades of development policy sought to control infectious diseases, the burden of disease shifted towards poor diet and sedentary lifestyles as leading causes of poor health.

The shift towards market-inspired governance of public research monies emphasizes the role of R4D funders in allocating scarce resources and demonstrating the performance of their grant portfolios. Yet as intermediaries, R4D funders selectively adopt and connect ideas from both sides: international development and publicly-funded science. That is 
how they maintain credibility with both government and the research community. R4D cannot afford to ignore either and must craft an approach that is compatible with both these separate worldviews. This is the true intellectual task facing R4D management and staff, and requires them to be equal parts policy think tank and research granting council. 


\section{Appendices}

\section{Appendix A Interview Guide}

The following questions represent the general set of questions asked during the semistructured interviews. Some questions were dropped when not applicable to a particular respondent, and further probes were used to elicit further detail or clarification when needed.

1. How does the funder 'fit' within the public research landscape?

2. How does the funder 'fit' within the government's foreign policy?

3. Describe the relationship between [R4D funder] and government stakeholders.

4. Describe what you know of the relationship between the funder and its recipients.

5. Does the funder have particular expectations of the research its funds?

6. To your knowledge, how are recipients of R4D funding identified and selected?

7. Does the funder have methods for determining whether a R4D grant or program is successful?

8. Has domestic policy for public research funding evolved over the past 30 years?

9. Are there incentives for domestic research community to engage in R4D?

10. Is there anyone else that I should contact on these questions? 


\section{References}

ACIAR (2011) Strategic Framework for International Agricultural Research within Australia's aid program. ISBN 9781921962189

_ _ _. (2010) ACIAR Annual Report 2009-2010

_ _ _ (2008) Statement of Expectations received from the Minister for Foreign Affairs in September 2008

_ _ - (2007) Working with ACIAR now and in the future: response to the results of a survey of international stakeholders

_ _ _ . (2006) ACIAR and public funding of R\&D. Submission to productivity commission study on public support for science and innovation. Impact Assessment Series Report No. 41, ACIAR: Canberra

_ _ _. (2003) ACIAR Annual Report 2002-2003

_ _ _ . (1999) Staying ahead: future strategies for ACIAR. Policy statement by the Board of Management following the external review

Argyris, C. and D.A. Schön (1978) Organizational learning: a theory of action perspective. AddisonWesley: Reading, MA.

Arrow, K.J. (1962) Economic welfare and the allocation of resources to invention, in R. Nelson (Ed), The rate and direction of inventive activity: economic and social factors. Princeton University Press.

AusAID (2012a) AgResults: Innovation in Research and Delivery. Draft concept note (http://siteresources.worldbank.org/ accessed 31 March 2013)

_ _ _. (2012b) AusAID Research Strategy 2012-16

_ _ _ (2006) Australian Aid: Promoting growth and stability. A white paper on the Australian government's overseas aid program.

Australia (2011) Independent review of aid effectiveness

_ _ _ (1997) 'Better Aid for a Better Future', the Government's Response to the Committee of Review of Australia's Overseas Aid Program given by Minister Alexander Downer on November 18th

Australian S\&T Council (1990) Setting directions for Australian research: a report to the Prime Minister. Australian Government Publishing Service

Australia Hansard. (1981) Speech by Minister Street on the occasion of the second reading of the ACIAR Act during the $32 \mathrm{nd}$ session of Parliament on October $27^{\text {th }}$

Australia (1982) Australian Centre for International Agricultural Research Act 1982. [Online] http://www.comlaw.gov.au/Details/C2012C00015 (Accessed 12 May 2012)

_ _ _ . (1979) Australia and the Third World: report of the committee on Australia's relations with the Third World. Australia government publishing service: Canberra. 
Barlow, Thomas (2006) The Australian miracle: an innovative nation revisited. Pan Macmillan: Sydney NSW

Barney, J.B. and D.N. Clark (2007) Resource-based theory: creating and sustaining competitive advantage. Oxford University Press.

Baum, J. (1996) Organizational ecology, in Clegg, S.R.; C. Hardy, T.B. Lawrence and W.R. Nord, eds. Handbook of organization studies. Sage Publications: Thousand Oaks, CA.

Beattie, A. (1994) Experience of Commissioning Research and Development, in Hay, R.K.M. (ed) Science in government: rise of the intelligent consumer. Scottish Agricultural Science Agency: Edinburgh, UK

Beemans, P (1999) Re-inventing IDRC in the 1990s. Presentation to SID-Ottawa Luncheon 18 May. (http://hdl.handle.net/10625/23852 accessed 27 April 2013)

Benner, M. (2011) In search of excellence? An international perspective on governance of university research. In B. Göransson and C. Brundenius (eds.) Universities in transition: the changing role and challenges for academic institutions. New York, NY: Springer.

Boden, R., Cox, D. \& Nedeva, M. (2006) The appliance of science: new public management and strategic change. Technology Analysis \& Strategic Management, 18(2), 125-141.

Boden, R.; D. Cox, M. Nedeva and K. Barker (2004) Scrutinising science: the changing UK government of science. Palgrave MacMillan: Hampshire, UK.

Braun, D. (2003) Lasting tensions in research policy-making - a delegation problem. Science and Public Policy 30(5): 309-321

_ _ _ (1993) Who governs intermediary agencies? Principal-agent relations in research policy-making. Journal of Public Policy 13(2):135-162.

Canada (2012) Economic Action Plan 2012, tabled by James Flaherty on March 29th (http://www.budget.gc.ca accessed 8 May 2013)

_ _ — (2010) The Budget Plan 2010, tabled by James Flaherty on March 4th (http://www.budget.gc.ca accessed 31 March 2013)

_ _ _. (2008) Speech from the Throne. November 19 (http://www.sft-ddt.gc.ca accessed 6 May 2013).

_ _ _ (2007) The Budget Plan 2007, tabled by James Flaherty on March 19th (http://www.budget.gc.ca accessed 31 March 2013)

_ _ - (2005) The Budget Plan 2005, tabled by Ralph Goodale on February $23^{\text {rd }}$ (http://fin.gc.ca/budget05/pdf/bp2005e.pdf accessed 27 April 2013)

_ _ _ . (2004) Address by Prime Minister Paul Martin in Reply to the Speech from the Throne. February 2 (http://www.pco-bcp.gc.ca accessed 27 April 2013).

_ _ _ . (2003) The Budget Plan 2003, tabled by John Manley on February 18th (http://www.budget.gc.ca/ accessed 27 April 2013).

_ _ - (1995) The Budget Plan 1995, tabled by Paul Martin on February $27^{\text {th }}$ (http://www.budget.gc.ca/ accessed 27 April 2013). 
_ _ _ (1992) The Budget 1992, tabled by Don Mazankowski on February 25th (http://www.budget.gc.ca accessed Apr 26, 2013)

_ _ _ . (1991) The Budget, tabled by Michael Wilson on February $26^{\text {th }}$ (http://www.budget.gc.ca/ accessed 27 April 2013).

_ _ _ (1987) For whose benefit? Report of the Standing Committee on External Affairs and International Affairs on Canada's Official Development Assistance Policies and Programs

_ _ _ (1968) Memorandum to Cabinet: International Development Centre, October 9 (http://hdl.handle.net/10625/38415 accessed 22 March 2013)

Carden, Fred (2009) Knowledge to policy: making the most of development research. Thousand Oaks, CA: Sage Publications.

Chen, Huey-Tsyh (2005) Practical Program Evaluation: Assessing and Improving Planning, Implementation, and Effectiveness. Thousand Oaks, CA: Sage Publication.

Cd 9230 (1918) Report of Machinery of Government Committee. Ministry of Reconstruction: London, UK.

Cm 7656 (2009) Eliminating world poverty: Building our common future. White Paper on International Development

Cm 6876 (2006) Making Governance work for the Poor. White Paper on International Development

Cm 5000 (2000) Making Globalisation work for the Poor. White Paper on International Development

Cm 4310 (1999) Modernising government. White Paper presented to Parliament by the Prime Minister. TSO: London, UK

Cm 3789 (1997) White Paper on International Development: Eliminating world poverty.

Cm 2250 (1993) Realising our potential: a strategy for science, engineering and technology. HMSO: London, UK

Cmnd 5046 (1972) Framework for government research and development. HMSO: London, UK

Collis, Brad (2002) Fields of discovery: Australia’s CSIRO. Allen \& Unwin, Crows Nest, NSW.

Conway, G. and J. Waage (2010) Science and Innovation for Development. UK Collaborative for Development Sciences: London, UK.

Core, Peter (2009) A retrospective on rural R\&D in Australia. Australian Government Department of Agriculture, Fisheries and Forestry: Canberra, ACT

Crawford Study Committee (1976) A proposal to establish an international research assistance foundation in Australia. : Canberra

Daniels, D. and T. Dottridge (1993) Managing agricultural research: views from a funding agency. Public Administration and Development 13: 205-15

Davies, H.T.O. and S.M. Nutley (2002) Evidence-based policy and practice: rhetoric to reality, Research Unit for Research Utilisation, discussion paper 2, University of St Andrews 
Demeritt, D. (2000) The new social contact for science: accountability, relevance and value in US and UK science and research policy. Antipode 32(3):308-329

DFID (2011) UK aid: Changing lives, delivering results Department for International Development: London, UK

_ _ _. (2009) DFID Research 2009-2010: providing research evidence that enables poverty reduction. Department for International Development: London, UK

_ _ _ (2008) Research Strategy 2008-2013. Department for International Development: London, UK

_ _ _ . (2004) Research Funding Framework 2005-2007. Department for International Development: London, UK

_ _ _ (2000a) DFID Research: 1999/2000 prepared by Knowledge Policy Unit. Department for International Development: London, UK

_ _ _ (2000b) Science and Innovation Strategy 2001-2005. Department for International Development: London, UK

Doern, G.B. and C. Stoney (2009) Research and Innovation Policy: Changing Federal GovernmentUniversity Relations. University of Toronto Press.

Duncan, R.; M. Williams and S. Howes (2005) Core group recommendations report for a white paper on Australia's aid program. AusAID: Canberra, ACT

Economist (2010) First break all the rules: the charms of frugal innovation. The Economist Apr 15

Edgerton, D. (2009) The 'Haldane principle' and other invented traditions in science policy. WilkinsBernal-Medawar Prize Lecture on 20 April at UK Royal Society

Edwards, M. (2010) Know-how, know-what and the politics of knowledge for development. Speech at HIVOS conference 'Knowledge \& change: theory and practice of development dilemmas' September 29 in Hague, Netherlands [online]

Ely, Adrian and Melissa Leach (2010) Innovation, sustainability, development: a new manifesto. STEPS Centre. University of Sussex: Brighton, UK.

Farrer, Keith (2005) To feed a nation: a history of Australian food science and technology. CSIRO Publishing: Collingwood, NSW

Faulker, D.O. and A. Campbell (2003) Oxford handbook of strategy. Oxford University Press

Ferlie, E. and A. Mark (2002) Organizational research and the new public management in McLaughlin, K. et al (Eds) New public management: current trends and future prospects. Routledge: New York, NY.

Fischer, Frank (2003) Reframing public policy: discursive politics and deliberative practices. Oxford University Press.

Fried, R.C. (1976) Performance in American Bureaucracy. Boston, MA: Little, Brown \& Company

Funnel, Sue C. and Patricia J. Rogers (2011) Purposeful Program Theory: Effective Use of Theories of Change and Logic Models. San Francisco, CA: Jossey-Bass, an imprint of John Wiley and Sons, Inc. 
Gibbons, M. et al. (1994) The new production of knowledge: the dynamics of science and research in contemporary societies. Thousand Oaks, CA: Sage Publications.

Gordon, J. King (ed.) (1979) Canada's role in science and technology for development. Proceedings from a symposium held at the Ontario Science Centre. IDRC report 141-e.

Grace, Cheri (2010) Product Development Partnerships (PDPs): Lessons from PDPs established to develop new health technologies for neglected diseases. DFID Human Development Resource Centre

Guston, D.H. (2000) Between politics and science: assuring the integrity and productivity of research. Cambridge University Press: Cambridge, MA.

Habermann, B. and M. Langthale (2010) Changing the world of development research? An insight into theory and practice. Development in Practice 20(7): 771-783.

Hagen-Zanker, J. et al. (2012) Making systematic reviews work for international development research. Briefing paper for Secure Livelihoods Research Consortium. London: Overseas Development Institute.

Helpman, E. (2004) The mystery of economic growth. Harvard University Press

Hirschman, A.O. (1970) Exit, Voice and Loyalty: Responses to Decline in Firms, Organizations, and States. Harvard University Press.

Holmes, J. and B. Harris (2010) Enhancing the contribution of research councils to the generation of evidence to inform policy making. Evidence \& Policy 6(3): 391-409

Hopper, W.D. (1979) “Time is all important” Mazingira: 8:59-64.

_ _ _ . (1973) "Research policy: eleven issues" IDRC report 14-e. [online] http://hdl.handle.net/10625/308 (accessed 23 August 2013)

IDRC (2009) Innovating for Development: Strategic Framework 2010-2015. Ottawa, Canada: IDRC

- - - (2006) Competitive Grant Projects at IDRC. Evaluation highlight 8. Ottawa, Canada: IDRC [online] http://hdl.handle.net/10625/29989 (accessed 23 August 2013)

_ _ _ (2004) Corporate Strategy and Program Framework 2005-2010. Ottawa, Canada: IDRC

_ _ - (2002) "Closing the loop: communication for change at IDRC" (http://hdl.handle.net/10625/21181 accessed 26 April 2013).

_ _ _ (2000) IDRC Annual Report 1999-2000. Ottawa, Canada: IDRC.

__ _ (1996) IDRC Annual Report 1995-1996. Ottawa, Canada: IDRC.

_ _ _ (1995a) IDRC Annual report 1994-1995. Ottawa, Canada: IDRC.

_ _ _ (1995b) "1995-6 Program update", memo from Caroline Pestieau to Board of Governors dated October $11^{\text {th }}$

_ _ _ (1994) IDRC Annual Report 1993-1994. Ottawa, Canada: IDRC.

_ _ _ (1977) "Clarification of the IDRC's role" Memo from Sylvie Plouffe to David Hopper, 19 August 
_ _ _. (1970) "Statement to the inaugural meeting of the Board of Governors", by W. David Hopper. Ottawa, Canada, 26 October. Document IDRC-002e

Industry Commission (1994) Research and development. Report no. 44 May 15 Australian Government Publishing Service: Canberra ACT

Jefferies, C., ed. (1964) A review of colonial research 1940-1960. Overseas Research Publication no. 6, Department of technical cooperation (HMSO: London)

Jansen, D. (2007) New forms of governance in research organizations. Springer

Kerin, John (2010) Speech on 'what policy framework would I now establish for agricultural research, development and extension' given at University of Melbourne, May $5^{\text {th }}$

Khagram, S. et al. (2009) Evidence for development effectiveness. Journal of development effectiveness. 1(3): 247-270.

King, K. and S. McGrath (2004) Knowledge for development? Comparing British, Japanese, Swedish and World Bank aid. HSRC Press and Zed Books: Cape Town, South Africa and London, UK.

KPMG (2008) Holy Grail or achievable goal? International perspectives on public sector performance management.

Lambeck, Kurt; et al. (2006) Australia's Science and Technology Priorities for Global Engagement. Prime Minister's Science, Engineering and Innovation Council (PMSEIC)

Lundvall, B.A. (1988) Innovation as an interactive process, In Dosi, G. et al (Eds) Technology and economic theory. Pinter Publishers: London, UK.

Meier, G.M. (1994) Review of development research in the UK: report to the Development Studies Association. Journal of International Development 6(5): 465-517.

Merton, R.K. (1942) The normative structure of science in (1973) The sociology of science: theoretical and empirical investigations. University of Chicago Press: Chicago, IL.

Meyer, Michael and Matthew Kearnes (2013) Intermediaries between science, policy and the market. Science and Public Policy 40: 423-429

Mintzberg, H. (2007) Tracking strategies: towards a general theory of strategy formation. Oxford University Press.

Molenaar, H.; L. Box, and R. Engelhard (Eds) (2009) Knowledge on the move: emerging agendas for development-oriented research. International Development Publishers: Leiden, Netherlands.

Moore, Mark H. (1995) Creating public value: strategic management in government. Harvard University Press.

Muirhead, B. and R. Harpelle (2010) IDRC: 40 Years of Ideas, Innovation and Impact. Wilfrid Laurier Press: Waterloo, Canada.

Nairn, M.E.; G.T. Castillo and R.B. Dun (1998) Staying ahead: report of a review of the Australian Centre for International Agricultural Research. Canberra, ACIAR 
Nelson, R.R. and S.G. Winter (1982) An evolutionary theory of economic change. Harvard University Press: Cambridge, MA.

_ _ _ (1977) In search of useful theory in innovation. Research Policy 6: 36-76.

Nutley, S.M.; I. Walter and H.T.O. Davies (2007) Using evidence: how research can inform public services. Policy Press: Bristol, UK

OAG (2008) International Development Research Centre special examination report, submitted to the Board of Governors on March 27th (http://www.idrc.ca accessed 31 March 2013)

_ - - (1988) Report of the Auditor General of Canada, Chapter 4 Well-Performing Organizations, tabled November $1^{\text {st }}$ (http://www.oag-bvg.gc.ca accessed 27 April 2013)

ODM $(1978,1977,1974)$ Report on research and development, Ministry of Overseas Development. HMSO: London.

ODA (1994, 1992) Report on research and development. NRI: Chatham, UK

_ _ - (1988) Report on research and development. ODNRI: Chatham, UK

_ _ _ (1979) Report on research and development. Overseas Development Administration: London, UK

OECD (2010) The OECD innovation strategy: getting a head start on tomorrow. OECD: Paris

_ _ _ . (2003) Governance of public research: toward better practice. OECD: Paris

_ _ _ . $(2002,1963)$ Frascati manual: proposed standard practice for surveys on research and experimental development, $6^{\text {th }}$ edition. Organization for Economic Cooperation and Development: Paris, France.

OECD/Eurostat $(2005,1992)$ Oslo manual: guidelines for collecting and interpreting innovation data, $3^{\text {rd }}$ edition. Organization for Economic Cooperation and Development: Paris, France.

Ostrom, E. (2005) Understanding Institutional Diversity. Princeton, NJ: Princeton University Press

Paarlberg, L.E. and W. Bielfeld (2009) Complexity science - an alternative framework for understanding strategic management in public serving organizations. International Public Management Journal 12(2):236-260

Patton, M.Q. (2002) Qualitative research and evaluation methods, $3^{\text {rd }}$ edition. Sage Publications: thousand Oaks, CA.

Pearson et al. (1969) Partners in development: report of the commission on international development. New York, Washington and London: Praeger.

Pfeffer, J. and G.R. Salanick (1978) The external control of organizations: a resource-dependence perspective. New York, NY: Harper \& Row

Plumptre, A.F.W. (1968) Memorandum to Maurice Strong, subject Proposed International Development Research Institution, 24 January (http://hdl.handle.net/10625/39635 accessed 22 March 2013) 
Poister, T.H.; D.W. Pitts and L.H. Edwards (2010) Strategic management research in the public sector: a review, synthesis and future directions. American Review of Public Administration 40(5): 522-545.

Polanyi, M. (1962) The republic of science. Minerva 1: 54-73.

Polster, C. (2003) Canadian university research policy at the turn of the century: continuity and change in the social relations of academic research. Studies in political economy 71/72: 177-199.

Ravallion, M. and A. Gelb (2010) Research for development: a World Bank perspective on future directions for research. Policy Research Working Paper 5437. World Bank: Washington, DC

Reid, W.V. et al (2010) Earth system science for global sustainability: grand challenges. Science 330 (6006): 916-917.

Rip, A. (2003) Societal challenges for R\&D evaluation. In P. Shapira and S. Kuhlmann (Eds) Learning from Science and Technology Policy Evaluation. Edward Elgar: Cheltenham, UK.

_ _ _. (1994) The Republic of Science in the 1990s. Higher Education 28(1): 3-23.

Rogers, P. (2000) Program theory evaluation: practice, promise and problems. New Directions for Evaluation 87: 5-13.

Rousseau, D. (2006) Is there such a thing as "evidence based management"? Academy of Management Review 31(2): 256-269

Sandland, R. and G. Thompson (2012) Icon in crisis: the reinvention of CSIRO. UNSW Press: Sydney, NSW

Schubert, T. (2009) Empirical observations on New Public Management to increase efficiency in public reseach - boon or bane? Research Policy 38:1225-34.

Scoones, I. and M. Leach (2006). The slow race: making technology work for the poor, Demos: London, UK.

Shove, E. (2003) Principals, agents and research programmes. Science and public policy 30(5):371-381.

Shove, E. and M. Redclift (2001) "Steering research toward policy: the case of social science and environmental change" Policy Studies Annual Review.

Singer et al. (1970) The Sussex manifesto: science and technology to developing countries during the second development decade. Institute of Development Studies, University of Sussex: Brighton, UK.

Sivadasan et al. (2003) Review of the DFID's role in the international research effort

Slaughter, S. and G. Rhoades (1996) The emergence of a competitiveness research and development policy coalition and the commercialization of academic science and technology. Science, Technology and Human Values 21:303-339

Slaymaker, Olva et al. (1998) The nature of research at IDRC, report of research ad hoc committee of the Board. BG 98(06)06 (http://hdl.handle.net/10625/29892 accessed 31 March 2013)

Smillie, Ian, (2011) "Learning and development: three essential books", Development in Practice 21(3):441-43. 
Sparrow, Malcom K. (2011) Governing Science. New Perspectives in Policing. Harvard Kennedy School [online] https://www.ncjrs.gov/pdffiles1/nij/232179.pdf (Accessed 29 August 2013)

Steele, J. (2002) "Mode 2 Research: Fad, Fiction, or Future of the Relationship between Science and Society?" Paper prepared for IDRC's Policy and Planning Group.

Stephan, Paula (2012) How economics shapes science. Harvard University Press

Stockdale, Peter (1995) Pearsonian internationalism in practice: the International Development Research Centre. PhD thesis in political science. Montreal, Canada: McGill University.

Talbot, Colin (2010) Theories of performance: organizational and service improvement in the public domain. Oxford University Press

_ _ - (2008) Performance regimes - the institutional context of performance policies. International Journal of Public Administration 31(14): 1569-91.

Tribe, Derek E. (1991) Doing well by doing good: agricultural research feeding and greening the world. Crawford Fund and Pluto Press: Leichhardt, NSW

Uhrig, J. (2003) Review of the corporate governance of statutory authorities and office holders. Commonwealth of Australia: Canberra, ACT

UK House of Commons (2012) Building scientific capacity for development. Science and Technology Committee, 4th Report of Session 2012-13, HC Report 377

_ _ - (2004) The Use of Science in UK International Development Policy, Science and Technology Committee, 13th Report of Session 2003-04, HC Report 133

_ _ _ (1983) Foreign affairs committee: the Overseas Development Administration's scientific and special units. HMSO: London, UK

UK (2011) Science \& Engineering Assurance Review of the Department for International Development. Government Office for Science

_ _ - (2003) Getting the evidence: research in policy making. Report by comptroller and auditor general HC 586 session 2002-03

_ _ — (2002) DFID Performance Management - helping to reduce world poverty. National Audit Office, Report by comptroller and auditor general HC 739

UK House of Lords (2012) House of Lords select committee on science and technology, inquiry on role and function of scientific advisors

_ — - (2010) Setting priorities for publicly funded research. Science and Technology Committee. 3rd Report of Session 2009-10. HL Paper 104.

UN Millennium Project (2005) Innovation: applying knowledge in development. London, UK: Earthscan.

UNESCO (2010) World social science report. UNESCO: Paris, France

Varmus, H. et al. (2003) Grand challenges in global health. Science 302 (5644) 
Wagner, C. (2008) The new invisible college: science for development. Brookings Institute: Washington, DC

Whitley, R. and J. Gläser (2007) The changing governance of the sciences: the advent of research evaluation systems. Springer: Dordrecht, Netherlands.

World Bank (1998) World Development Report 1998-99: Knowledge for Development. World Bank: Washington, DC. 